\title{
A Study on the Hydrodynamics of a Bench-Scale Top-Fed Bubbling Fluidized Bed Gasifier using Biomass and Coal as Feedstocks
}

\author{
Ali Can Sivri \\ West Virginia University, acs0031@mix.wvu.edu
}

Follow this and additional works at: https://researchrepository.wvu.edu/etd

Part of the Complex Fluids Commons, Energy Systems Commons, and the Other Mechanical

Engineering Commons

\section{Recommended Citation}

Sivri, Ali Can, "A Study on the Hydrodynamics of a Bench-Scale Top-Fed Bubbling Fluidized Bed Gasifier using Biomass and Coal as Feedstocks" (2020). Graduate Theses, Dissertations, and Problem Reports. 7907.

https://researchrepository.wvu.edu/etd/7907

This Dissertation is protected by copyright and/or related rights. It has been brought to you by the The Research Repository @WVU with permission from the rights-holder(s). You are free to use this Dissertation in any way that is permitted by the copyright and related rights legislation that applies to your use. For other uses you must obtain permission from the rights-holder(s) directly, unless additional rights are indicated by a Creative Commons license in the record and/ or on the work itself. This Dissertation has been accepted for inclusion in WVU Graduate Theses, Dissertations, and Problem Reports collection by an authorized administrator of The Research Repository @ WVU.

For more information, please contact researchrepository@mail.wvu.edu. 


\title{
A Study on the Hydrodynamics of a Bench-Scale Top-Fed Bubbling Fluidized Bed Gasifier using Biomass and Coal as Feedstocks
}

\author{
Ali Can Sivri \\ Dissertation submitted to the \\ Benjamin M. Statler College of Engineering and Mineral Resources \\ at West Virginia University \\ in partial fulfillment of the requirements for the degree of \\ Doctor of Philosophy \\ in \\ Mechanical Engineering \\ Cosmin E. Dumitrescu, Ph.D., Chair \\ Jianli Hu, Ph.D. \\ Victor Mucino, Ph.D. \\ William Rogers, Ph.D. \\ V'yacheslav Akkerman, Ph.D. \\ Department of Mechanical and Aerospace Engineering
}

Morgantown, West Virginia

2020

Keywords: Bubbling fluidized bed gasifier; Fluidization Hydrodynamics; Biomass and Coal Gasification; Syngas

Copyright 2020 Ali Can Sivri 


\title{
Abstract \\ A Study on the Hydrodynamics of a Bench-Scale Top-Fed Bubbling Fluidized Bed Gasifier using Biomass and Coal as Feedstocks
}

\begin{abstract}
Ali Can Sivri
The production of synthetic gas (syngas) from renewable or carbon-neutral sources can significantly reduce greenhouse and other emissions associated with conventional fuels. One of the most promising technologies to efficiently convert carbonaceous feedstocks such as biomass, coal, or municipal waste into syngas for transportation, power, heat, electricity generation, and or production of added-value chemicals is the bubbling fluidized-bed gasifier (BFBG). However, the gasification process inside a BFBG is a very complex high-temperature multiphase flow phenomena still not well understood, particularly when binary mixtures are investigated. As a result, despite the numerous correlations in the literature developed to predict the hydrodynamics inside a BFBG, the results are inconsistent, particularly for the minimum fluidization velocity, $U_{m f}$. As predicting the fluidization hydrodynamics is paramount for optimum gasification, this investigation observed the effect of some of the most important fluidization parameters such as the particle size and shape, fluidizing gas properties, moisture content, bed aspect ratio etc. This study designed and built two separate experimental platforms: a bench-scale BFBG with automated feeding and a cold flow model with the same geometry and dimensions as the BFBG. The experiments used well-characterized (i.e., known size and shape distribution, density, moisture content, initial mixing condition) inert material (sand, glass beads) and feedstock (biomass (sawdust) and coal). The cold flow investigation results showed that the initial mixing conditions for binary mixtures with biomass had a significant effect on the measured $U_{m f}$. For example, the
\end{abstract}


relative error in predicting $U_{m f}$ using the available correlation in the literature increased for segregated mixtures. Moreover, lower relative errors in $U_{m f}$ suggested that the fluidization quality was better if the mixture was initially well-mixed (premixed). In addition, a larger biomass moisture content decreased $U_{m f}$ of premixed binary mixtures but increased the relative error between the predicted and the experimental Reynolds number, Re. After reaching the minimum fluidization condition, the fluidization behavior and mixing at various flow rates were also recorded with a high-speed camera. The processed images were used to determine the interval for the fluidizing-gas superficial velocity that produced the best mixing for a particular mixture composition and initial conditions. The images showed that while segregated biomass mixtures did not mix if the bed aspect ratio was larger than five, coal mixtures did mix homogeneously along the reactor bed. Finally, experiments performed at temperatures up to $800{ }^{\circ} \mathrm{C}$ showed a large increase in the bed pressure drop at minimum fluidization velocity with the bed temperature due to the large effect on the fluidizing gas density and viscosity. On the contrary, $U_{m f}$ decreased when the process temperature increased. Finally, preliminary biomass and coal gasification experiments in the BFBG setup produced acceptable syngas composition, suggesting that the BFBG developed in this study can be successfully used to further investigate biomass and coal gasification. 


\section{Dedication}

To my family, Father Mehmet Sivri, Mother Fatma Sivri, Sister Eda Sivri, and Brother Yunus Sezgin Sivri, Grandfathers Ali Sivri (Paşa) and Mahmut Kuraç, Grandmothers Fatma Kınalı,

Huriye Kuraç, Nebahat Sivri, Aunts Ayten Adam, Hatice Akbel, Ferdane Tümer, Huriye Tarhan, Sevim Coşkun, Fatma Gökdemir, and Uncles Ahmet Erten, Hasan Tümer, Hüseyin Adam, Yusuf Tarhan, Ayhan Akbel, Hüseyin Kuraç, Ali Kuraç, Bekir Kuraç and Fahrettin Coşkun. 


\section{Acknowledgement}

I want to express my gratitude to Dr. Cosmin Dumitrescu for being my advisor and for his deep support during my Ph.D. education. I would like to thank my committee members, Dr. Hu, Dr. Akkerman, Dr. Rogers, and Dr. Mucino for their long-term guidance and support. Their suggestions and contributions to my research and dissertation preparation were constructive and very valuable. Thanks to other research group members, Mr. Amoolya Lalsare and Dr. John Hu, for their collaboration and help.

I would like to express my special thanks to National Energy and Technology Laboratory Multiphase Flow Science Group members, Dr. Rogers, Dr. Shahnam, Dr. Gao, Dr. Xi, Dr. Li, Mrs. Huda Ashfag, and other team members for helping me building my knowledge in multiphase flow and fluidization theory. Their collaboration was very beneficial during the development of the experimental test stands.

I appreciate WVU and its Mechanical and Aerospace Engineering Department, the United States Department of Energy, National Energy and Technology Laboratory, and Leidos for their support that made it possible to continue my education and fulfill my research ambition.

Thanks to Dr. Celik, Dr. Mucino, and Dr. Prucz, for considering my application and admittance to the MAE department.

I also want to acknowledge the help from former and current Dr. Dumitrescu's research group members, Mr. Chris Ulishney, Dr. Jinlong Liu, Mr. Hemanth Bommisetty, and Mr. Rahul Kooragayala. 


\section{Table of Contents}

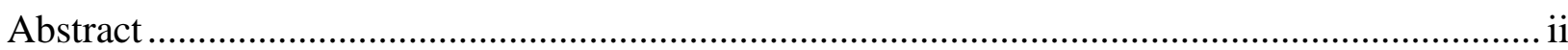

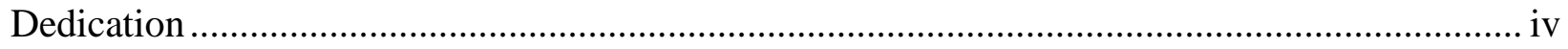

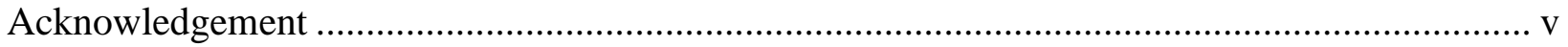

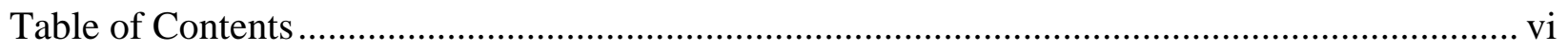

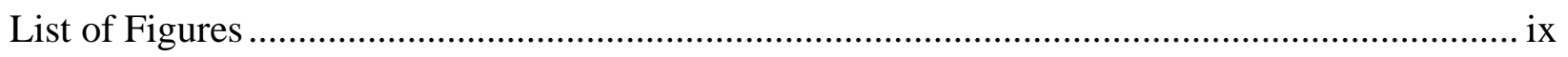

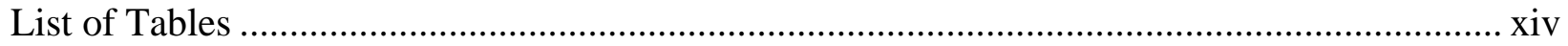

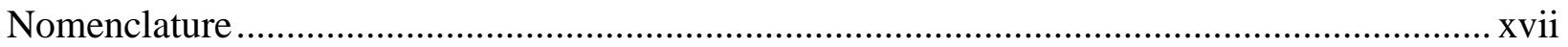

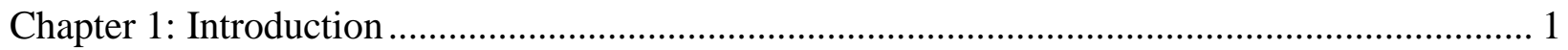

1.1 Background: Problem Statement and Motivation ........................................................... 1

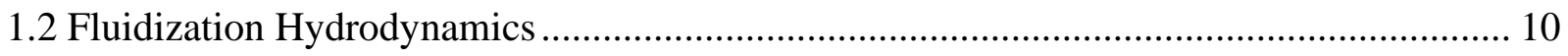

1.2.1 Fluidization Regimes .................................................................................... 10

1.2.2 Geldart's Particle Classification …………………............................................... 12

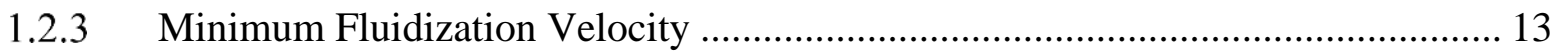

1.2.4 Effects of Particle Characteristics, Bed Aspect Ratio and Temperature on the

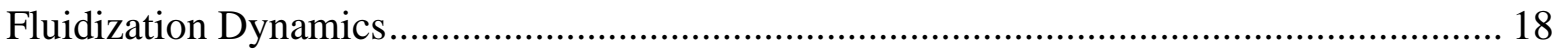

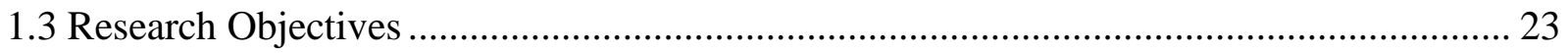

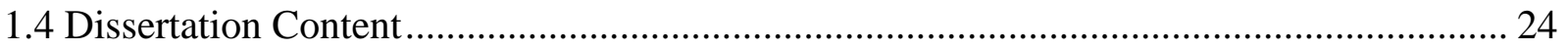


Chapter 2: Experimental Setup and Methodology.....

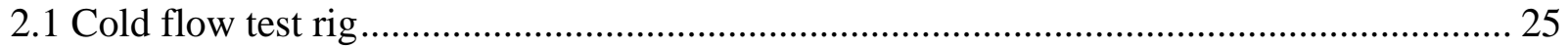

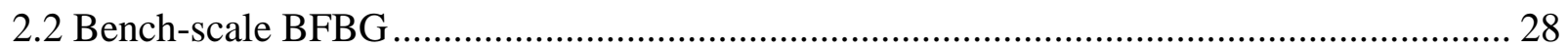

2.2.1 Design Requirements ............................................................................. 28

2.2.2 BFBG Test Stand .............................................................................. 41

2.3 Design and Development of the Various Gasifier Test Stand Components ..................... 44

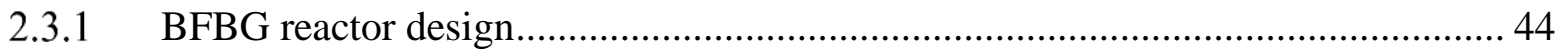

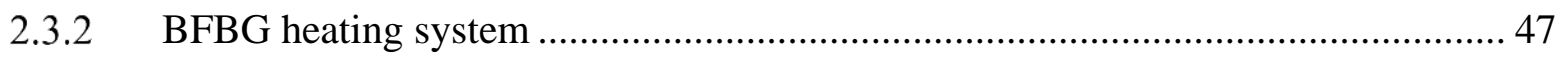

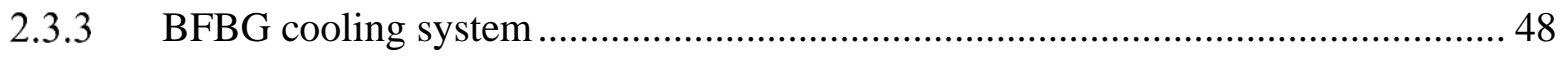

2.3.4 BFBG feedstock feeding system............................................................... 50

2.3.5 Sealing and insulation of main BFBG components ......................................... 51

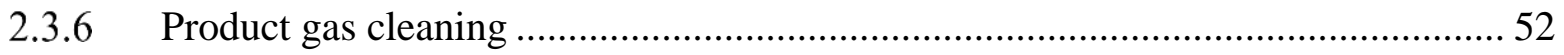

2.4 Fixed-bed Test Stand ....................................................................................... 53

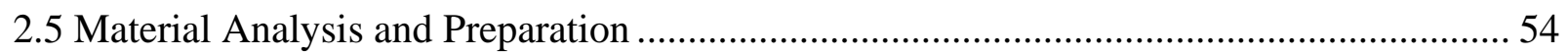

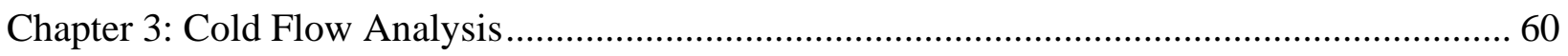

3.1 Effect of Mixture Characteristics on Fluidization Dynamics under Cold Flow Conditions60

3.1.1 Hydrodynamics Inside a Unary Mixture...................................................... 61

3.1.2 Hydrodynamics in Dried Premixed Mixtures of Sawdust and Inert Material ........ 65

3.1.3 Hydrodynamics in Non-Dried Premixed Mixtures of Sawdust and Inert Material 71

3.1.4 Top-Fed Dried and Non-Dried Sawdust and Inert Material Mixtures.................. 75 


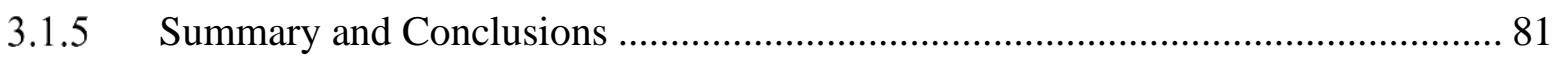

3.2 Mixing and Fluidization Behavior ………………....................................................... 82

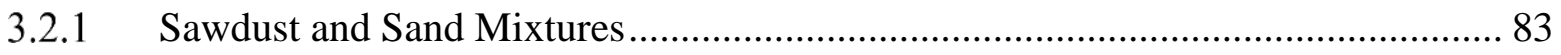

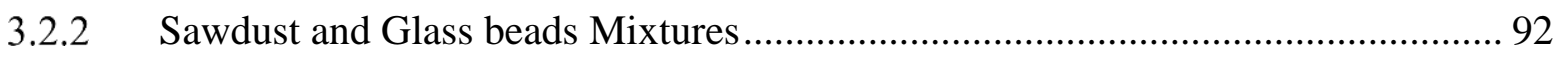

3.2.3 Coal with Sand or Glass beads mixtures........................................................ 101

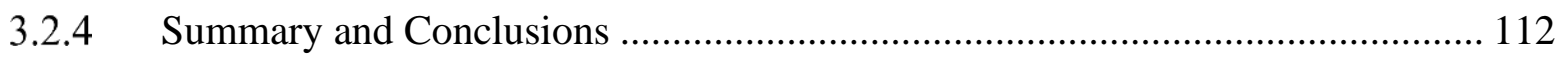

Chapter 4: High Temperature Fluidization and Gasification.................................................... 114

4.1 High-Temperature Hydrodynamical Analysis ........................................................... 114

4.1.1 Effect of Temperature on the Distributor Plate Pressure Drop ............................. 114

4.1.2 Effect of Temperature on the Bed Pressure Drop and Minimum fluidization

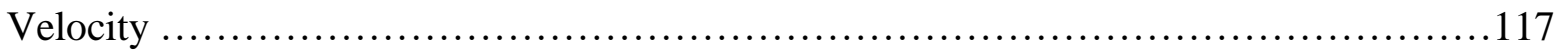

4.1.3 Comparison of the High-Temperature Fluidization Results with Correlations in

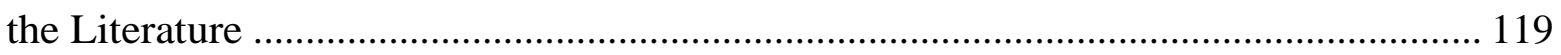

4.2 High-Temperature Gasification Results...................................................................... 122

4.3 Summary and Conclusions ................................................................................... 125

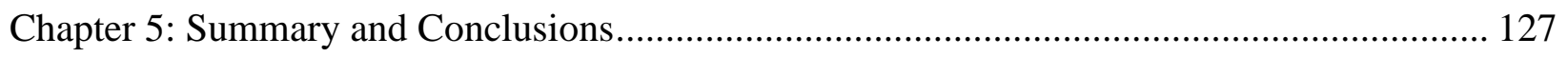

Chapter 6: Future Work and Recommendations............................................................. 131

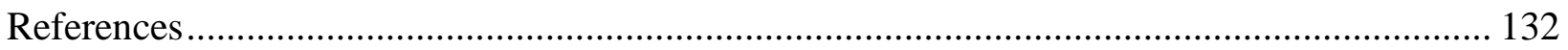




\section{List of Figures}

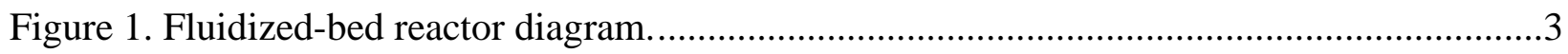

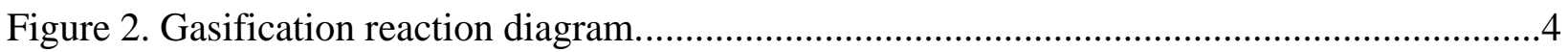

Figure 3. Illustration of the fluidization states with the increase in the fluidizing agent superficial velocity; a) static (fixed) bed, b) suspended bed (minimum fluidization), and c) dynamic bed. ....5

Figure 4. Schematic of a conventional bubbling fluidized bed gasifier. .......................................6

Figure 5. Schematic illustration of the fluidization regimes ......................................................11

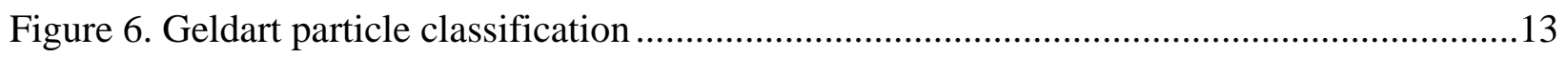

Figure 7. Graphical solution to determine $U_{i f} U_{m f}$, and $U_{c f}$ for increasing superficial gas velocity.

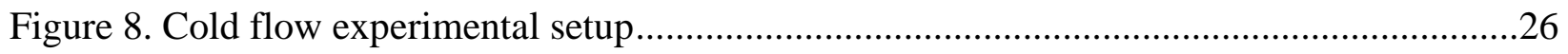

Figure 9. Initial bed conditions for $200 \mathrm{~g}$ of material: a) Inert material only, b) premixed mixture,

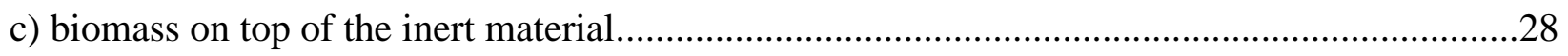

Figure 10. Effect of $\mathrm{H}_{2} / \mathrm{CO}$ ratio on syngas LHV for a) wood and b) coal. ..................................36

Figure 11. Schematic of the 15-cm (or 6-inch) ID BFBG: 1) distributor plate, 2) reactor bed, 3) freeboard, 4) cyclone, 5) ash deposit, 6) hopper, 7) dozer screw, 8) feeder screw, 9) boiler, 10) superheater, 11) bed heaters, $\mathrm{P}$ - pressure sensor, $\mathrm{T}$ - temperature sensor, $\mathrm{R}$ - ash recycling pipe.

Figure 12. Schematics (top) and details (bottom) of the bench-scale BFBG test stand 42 
Figure 13. BFBG reactor. The smaller diameter tubes were used to measure the pressure at various bed heights. .43

Figure 14. Bubbling fluidized-bed reactor (left) and high-temperature furnace (right)

Figure 15. Bubbling fluidized bed test stand (P-pressure transducer, T-thermocouple, 1- nitrogen tank, 2-compressed air tank, 3-expansion tanks, 4-bed reactor, 5-furnace, 6-feeding system gas flow line, 7-inlet feedstock delivery, 8-product gas line, 9-gas sampling valve, 10-reactor cooling line, 11-reactor fluidization gas line)

Figure 16. Prototype feeding system assembly .51

Figure 17. Fixed-bed test stand. .53

Figure 18. a) Glass beads, b) silica sand, c) sawdust, d) coal..... .56

Figure 19. Particle sphericity distribution .57

Figure 20. Particle size distribution . .58

Figure 21. Sphericity change with particle size..... .59

Figure 22. Bed pressure drop versus superficial gas velocity at ambient temperature for a) glass beads and b) silica sand. 62

Figure 23. Bed pressure drop versus superficial gas velocity at ambient temperature for the binary mixtures of dried sawdust with a) glass beads and b) silica sand with the mixture masses ..... 67 Figure 24. Bed pressure drop versus superficial gas velocity at ambient temperature for the binary mixtures of non-dried sawdust with a) glass beads or b) silica sand with the mixture masses of 100 $\mathrm{g}, 200 \mathrm{~g}$ and $300 \mathrm{~g}$, respectively. .72 Figure 25. Bed pressure drop versus superficial gas velocity at ambient temperature for the binary mixtures of sawdust (on top) with a) glass beads or b) silica sand with the mixture masses of 100 $\mathrm{g}, 200 \mathrm{~g}$, and $300 \mathrm{~g}$, respectively. . .76 
Figure 26. Bed pressure drop and fluidization behaviors with increasing superficial gas velocity for the mixtures of sand and dried sawdust with the total mixture mass of $100 \mathrm{~g}$ .84

Figure 27. Bed pressure drop and fluidization behaviors with increasing superficial gas velocity for the mixtures of sand and non-dried sawdust with the total mixture mass of $100 \mathrm{~g}$ .85

Figure 28. Bed pressure drop and fluidization behaviors with increasing superficial gas velocity for the mixtures of sand and dried sawdust with the total mixture mass of $200 \mathrm{~g}$. .87

Figure 29. Bed pressure drop and fluidization behaviors with increasing superficial gas velocity for the mixtures of sand and non-dried sawdust with the total mixture mass of $200 \mathrm{~g}$. .88 Figure 30. Bed pressure drop and fluidization behaviors with increasing superficial gas velocity for the mixtures of sand and dried sawdust with the total mixture mass of $300 \mathrm{~g}$. .90 Figure 31. Bed pressure drop and fluidization behaviors with increasing superficial gas velocity for the mixtures of sand and non-dried sawdust with the total mixture mass of $300 \mathrm{~g}$. .91 Figure 32. Bed pressure drop and fluidization behaviors with increasing superficial gas velocity for the mixtures of glass beads and dried sawdust with the total mixture mass of $100 \mathrm{~g}$. .94 Figure 33. Bed pressure drop and fluidization behaviors with increasing superficial gas velocity for the mixtures of glass beads and non-dried sawdust with the total mixture mass of $100 \mathrm{~g}$......95 Figure 34. Bed pressure drop and fluidization behaviors with increasing superficial gas velocity for the mixtures of glass beads and dried sawdust with the total mixture mass of $200 \mathrm{~g}$. .97 Figure 35. Bed pressure drop and fluidization behaviors with increasing superficial gas velocity for the mixtures of glass beads and non-dried sawdust with the total mixture mass of $200 \mathrm{~g} \mathrm{......98}$ Figure 36. Bed pressure drop and fluidization behaviors with increasing superficial gas velocity for the mixtures of glass beads and dried sawdust with the total mixture mass of $300 \mathrm{~g}$. .99 
Figure 37. Bed pressure drop and fluidization behaviors with increasing superficial gas velocity for the mixtures of glass beads and non-dried sawdust with the total mixture mass of $300 \mathrm{~g} . . .100$ Figure 38. Bed pressure drop and fluidization behaviors with increasing superficial gas velocity for the mixtures of coal and glass beads with the total mixture mass of $100 \mathrm{~g}$. .104

Figure 39. Bed pressure drop and fluidization behaviors with increasing superficial gas velocity for the mixtures of coal and sand with the total mixture mass of $100 \mathrm{~g}$. .105

Figure 40. Bed pressure drop and fluidization behaviors with increasing superficial gas velocity for the mixtures of coal and glass beads with the total mixture mass of $200 \mathrm{~g}$. .106 Figure 41. Bed pressure drop and fluidization behaviors with increasing superficial gas velocity for the mixtures of coal and sand with the total mixture mass of $200 \mathrm{~g}$. . .107 Figure 42. Bed pressure drop and fluidization behaviors with increasing superficial gas velocity for the mixtures of coal and glass beads with the total mixture mass of $300 \mathrm{~g}$. 109 Figure 43. Bed pressure drop and fluidization behaviors with increasing superficial gas velocity for the mixtures of coal and sand with the total mixture mass of $300 \mathrm{~g}$. .110 Figure 44. Distributor plate (DP) pressure drop versus a) air flowrate and b) superficial gas velocity at different average temperatures .115 Figure 45. Temperature effect on the ratio of the pressure drop across the distributor plate to the bed pressure drop $\left(R_{m f}\right)$, at minimum fluidization conditions. 116 Figure 46. Bed pressure drop versus $U_{g}$ at different temperatures. Horizontal lines show the theoretical bed pressure drop calculated with Eq. 3. Figure 47. Comparison of $R e_{m f}$ versus $A r$ results vs. literature for silica sand with the total masses of a) $200 \mathrm{~g}$, and b) $300 \mathrm{~g}$ .121 
Figure 48. Comparison of the effect of temperature on minimum fluidization velocity $U_{m f}$ versus literature .

Figure 49. Syngas compositions obtained during the gasification reaction at different reactor types and feedstocks at $900^{\circ} \mathrm{C}$ .124 


\section{List of Tables}

Table 1. Selected correlations to predict $R e$ for Geldart Group B particles ...............................17

Table 2. Selected correlations to predict $U_{m f}$ for binary mixtures ….....................................18

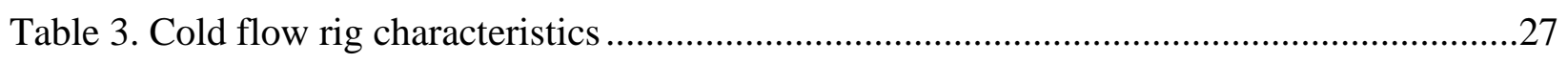

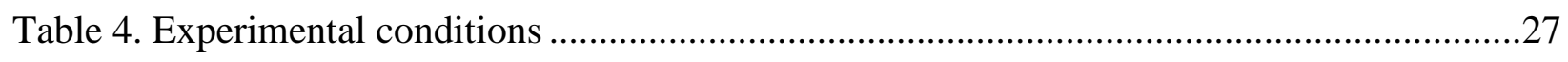

Table 5. Proteus (Ricardo/Cussons) engine specifications................................................29

Table 6. Elemental and proximate analysis (by mass) of biomass and bituminous coal...............30

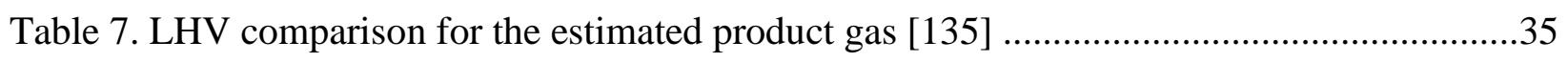

Table 8. Summary of the required feedstock rate calculations for wood and coal.....................35

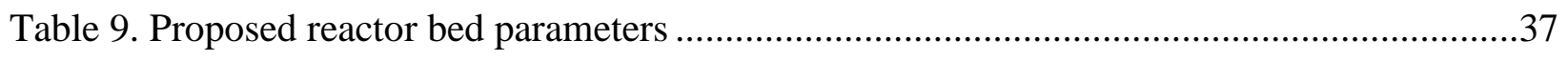

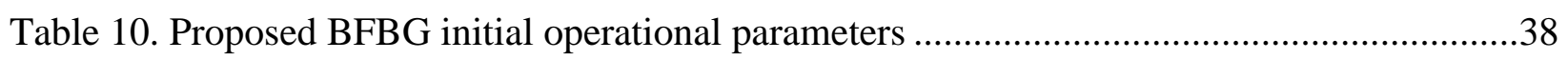

Table 11. Theoretical predictions of $U_{m f}, U_{t}, \varepsilon m f$ based on Kunii-Levenspiel Model................39

Table 12. Experimental conditions for hydrodynamical studies under temperature effect ...........44

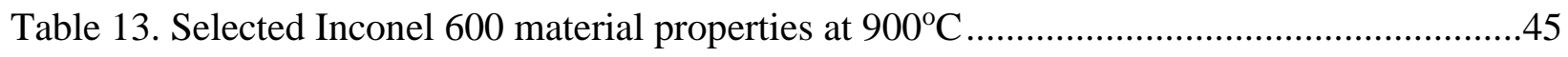

Table 14. Lucifer Furnaces, MODEL P3AC-27-642-X specifications .......................................48

Table 15. Experimental conditions for biomass gasification in fixed bed and BFBG, and coal -

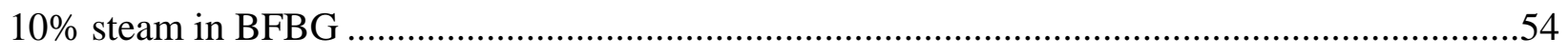

Table 16. Material size, density, sphericity, and Geldart's Group analysis..............................58

Table 17. Experimental values of $\Delta P_{m f}, A r, R e, U_{m f}$ and $H_{p} / D_{b}$ for unary mixtures of silica sand and

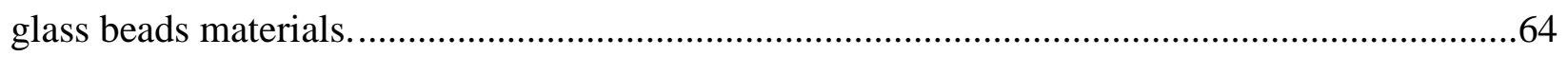

Table 18. Theoretical predictions of $R e$ for unary mixtures of silica sand and glass beads materials. 
Table 19. Error in predicting the $R e$ for unary mixtures of silica sand and glass beads materials.

Table 20. Experimental values of $\Delta P_{m f}, A r, R e, U_{m f}$ and $H_{p} / D_{b}$ for the binary mixtures of dried sawdust with glass beads or silica sand.

Table 21. Theoretical predictions of $R e$ for the binary mixtures of dried sawdust with glass beads or silica sand.

Table 22. Error in predicting the $R e$ for the binary mixtures of dried sawdust with glass beads or silica sand.

Table 23. Experimental values of $\Delta P_{m f}, A r, R e, U_{m f}$ and $H_{p} / D_{b}$ for the binary mixtures of non-dried sawdust with glass beads or silica sand with the mixture masses of $100 \mathrm{~g}, 200 \mathrm{~g}$, and $300 \mathrm{~g}$, respectively. .73

Table 24. Theoretical predictions of $R e$ for the binary mixtures of non-dried sawdust with glass beads or silica sand. .74

Table 25. Error in predicting the theoretical $R e$ for the binary mixtures of non-dried sawdust with glass beads or silica sand.

Table 26. Experimental values of $\Delta P_{m f}, A r, R e, U_{m f}$ and $H_{p} / D_{b}$ for the binary mixtures of dried sawdust (on top) with glass beads or silica sand.

Table 27. Theoretical predictions of $R e$ for the binary mixtures of dried sawdust (on top) with glass beads or silica sand. .78

Table 28. Error in predicting the theoretical $R e$ for the binary mixtures of dried sawdust (on top) with glass beads or silica sand. .78

Table 29. Experimental values of $\Delta P_{m f}, A r, R e, U_{m f}$ and $H_{p} / D_{b}$ for the binary mixtures of non-dried sawdust (on top) with glass beads or silica sand.... .79 
Table 30. Theoretical predictions of $R e$ for the binary mixtures of non-dried sawdust (on top) with glass beads or silica sand.

Table 31. Error in predicting the theoretical $R e$ for the binary mixtures of non-dried sawdust (on top) with glass beads or silica sand.......

Table 32. $\Delta P_{m f}, A r, R e_{m f}$ and $U_{m f}$ for $200 \mathrm{~g}$, and $300 \mathrm{~g}$ of sand as a function of Temperature.....119 Table 33. The theoretical predictions of $R e$ and experimentally-determined Re for each test cases.

Table 34. Error in predicting the theoretical $R e$ for the unary mixtures of silica sand with the masses of $200 \mathrm{~g}$ and $300 \mathrm{~g}$, respectively.

Table 35. Low heating values (LHV) of $\mathrm{CO}, \mathrm{H}_{2}, \mathrm{CH}_{4}[135]$ and syngas compositions obtained during biomass and coal gasification experiments. 


\section{Nomenclature}

$\alpha \quad$ thermal expansion coefficient

$\varepsilon \quad$ bed voidage

$\varepsilon_{m f} \quad$ bed voidage at minimum fluidization

$\eta_{f} \quad$ fuel conversion efficiency

$\mu_{g} \quad$ fluidizing gas viscosity

$\rho_{b} \quad$ bulk density

$\rho_{s} \quad$ skeletal density

$\rho_{e} \quad$ average effective density

$\rho_{g} \quad$ fluidizing gas density

$\phi \quad$ sphericity

A area of the cylinder cross-section

$A_{b} \quad$ cross-sectional area of the bed

$A_{p} \quad$ characteristic area of the particle

Ar Archimedes number

BFBG bubbling fluidized bed gasifier

BFBR bubbling fluidized bed reactor

$C_{D} \quad$ drag coefficient

CFB circulating fluidized bed

$d_{d p} \quad$ diameter of the distributor plate

$d_{o} \quad$ orifice diameter

$d_{p} \quad$ particle diameter

$d_{p e} \quad$ effective mean particle diameter 


$$
\begin{array}{ll}
\mathcal{D} & \text { total drag force } \\
D_{b} & \text { bed diameter } \\
D_{p} & \text { drag force exerted on the particle }
\end{array}
$$

DFBG downdraft-fixed bed gasifier

FBG fluidized bed gasifier

FBR fluidized bed reactor

$g \quad$ acceleration of gravity

$H_{p} \quad$ static bed height

$H_{m f} \quad$ bed height at minimum fluidization

$H_{o} \quad$ orifice distance below the distributor plate

ICE internal combustion engine

IGCC integrated gasification combined cycle

$K_{1} \quad$ constant

$K_{2} \quad$ constant

L column length

$L_{e} \quad$ engine stroke

$\dot{m}_{g} \quad$ fluidizing fluid mass flow rate

$\dot{m}_{f} \quad$ fuel mass flow rate

$N \quad$ engine crankshaft speed

$P \quad$ power

$P_{i} \quad$ indicated power

$P_{m} \quad$ mean effective pressure

$\Delta P_{b} \quad$ bed pressure drop 
$\Delta P_{m f}$ bed pressure drop at minimum fluidization condition

$Q_{L H V}$ lower heating value of the fuel

Re Reynolds number

$R e_{m f} \quad$ Reynolds number at minimum fluidization

$U_{g} \quad$ fluidizing gas superficial velocity

$U_{m f} \quad$ minimum fluidization velocity

$U_{\text {if }} \quad$ initial fluidization velocity

$U_{c f} \quad$ complete fluidization velocity 


\section{Chapter 1: Introduction}

Chapter 1 discusses the use of fluidized bed gasifiers (FBGs) in power and electricity generation applications, including the challenges related to their optimum operation in terms of product composition and process efficiency. Current state-of-the-art and issues of interest for further research are reviewed. Finally, the objectives of this investigation are presented.

\subsection{Background: Problem Statement and Motivation}

The need and demand for clean, sustainable, and feasible energy sources have been growing due to depleting fossil energy supplies and environmental effects, including the large increase in greenhouse gases [1]. Twenty years into the $21^{\text {st }}$ century and fossil fuels are still the primary sources for power generation [2]. However, there is an increasing interest in biomass or bioenergy as a renewable, efficient, and environmentally-friendly energy supply [3]. According to the U.S. Energy Information Administration (EIA), just 5\% of the 2019's total primary energy usage in the USA came from biomass feedstocks, with $20 \%$ of this biomass consisting of wood. The low usage rate of biomass is mainly due to the current state-of-the-art biomass conversion technologies, which have not been marketable and feasible enough compared to other power generation technologies [3]. When converting biomass to value-added products, thermochemical and biochemical processes are the primary technologies used to convert biomass into energy [4]. Among these processes, gasification is a clean and efficient type of thermochemical reaction, which converts carbonaceous feedstock (biomass, coal, municipal waste, etc.) into syngas (also known as producer gas; consisting mainly of $\mathrm{H}_{2}$ and $\mathrm{CO}$ ). Gasification processes use an oxygen source (pure oxygen, air, or steam) as a gasifying agent and reaction temperatures above $700^{\circ} \mathrm{C}[5$, 
6]. There is a consensus that the development of alternative fuels such as syngas from carbonaceous feedstock gasification can help decrease greenhouse gas emissions [7] as syngas is currently used for electricity and heat generation, as a transportation fuel, or as feedstock in the production of various chemicals [2]. With respect to the transportation sector, syngas was used as a direct and or dual fuel in internal combustion engines (ICE) [8-10], gas turbines [11-14], and fuel cells [15-17]. Also, integrated gasification combined cycle (IGCC) applications are quite popular due to their more economical operation $[18,19]$. Irrespective of the syngas use, a continuous fuel supply with a uniform or consistent composition is essential for the successful operation of ICE, gas turbines, and fuel cells because a variable and uncontrolled syngas composition negatively affects the equipment operation and safety. However, biomass gasification usually produces a variable syngas composition, therefore understanding the gasification fundamentals for more accurate control of the syngas production is vital for its large-scale implementation in power or electricity generation or transportation. For further information on the use of syngas in ICEs, the reader is to the reviews done by Hagos et al. [9] and Bates and Dölle [8].

Fluidized-bed reactors (FBRs) produce syngas via gasification, a multiphase process in which chemical reactions between the solid feedstock particles and the reactive fluidizing gas are taking place. It is called a "fluidized-bed reactor" because solid feedstock particles and the fluidizing gas together behave like fluid inside the reactor under specific operating conditions such as specific gas flow rates and particle characteristics (i.e., particle size, density, sphericity, etc.). Figure 1 shows the simplified diagram of a fluidized-bed reactor. 


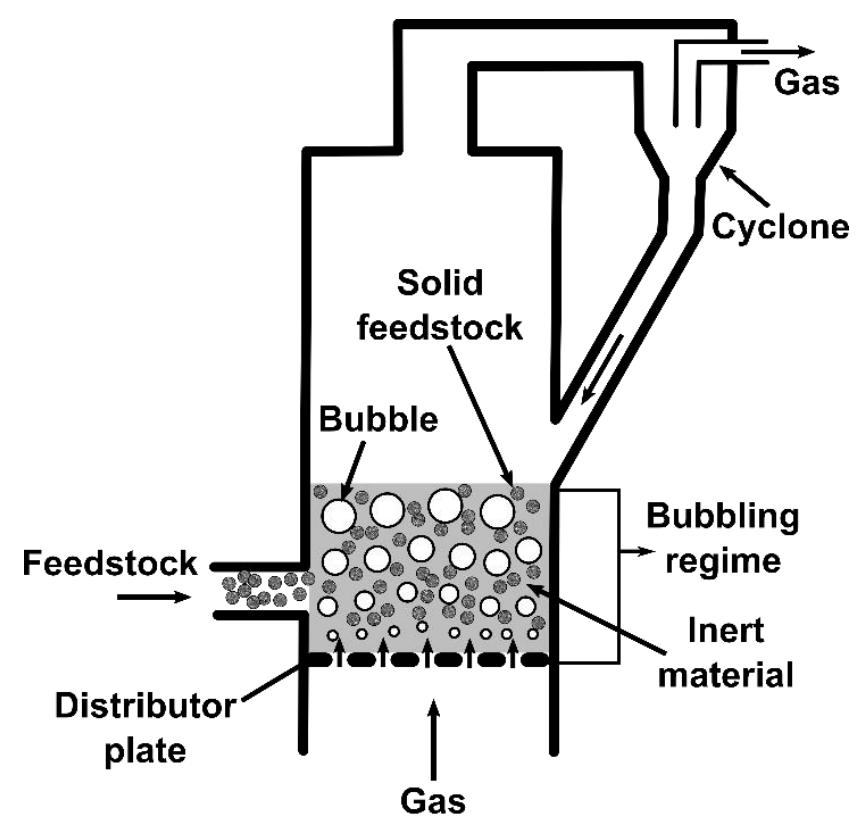

Figure 1. Fluidized-bed reactor diagram.

Compared to fixed-bed reactors, FBRs add mixing and hence higher heat transfer rates between feedstock particles, hence better process efficiency [20, 21]. The "bed" is defined as the total mixture (feedstock and inert material) inside the reactor bed. The gasification process usually starts with providing the heat needed to elevate the temperature of the bed to values generally higher than $700^{\circ} \mathrm{C}$. Therefore, a reliable and controllable heat source is required. In addition, the heat transfer must be fast; therefore, inert material is needed inside the reactor to maintain and transfer the provided heat to the feedstock particles while also promoting the breaking and mixing of the feedstock and fluidizing gas. For a carbonaceous feedstock, the fluidizing agent is also the oxygen source (pure oxygen, air or steam) for the gasification process and, if required, an additional nonreacting fluidizing agent (such as nitrogen) can be introduced into the reactor bed at essential flow rates to sustain efficient mixing and fluidization. Finally, syngas is produced with some remnants 
of heavy carbonaceous materials such as tar and char, and ash. A simplified diagram of the gasification process of a carbonaceous feedstock is shown in Figure 2.

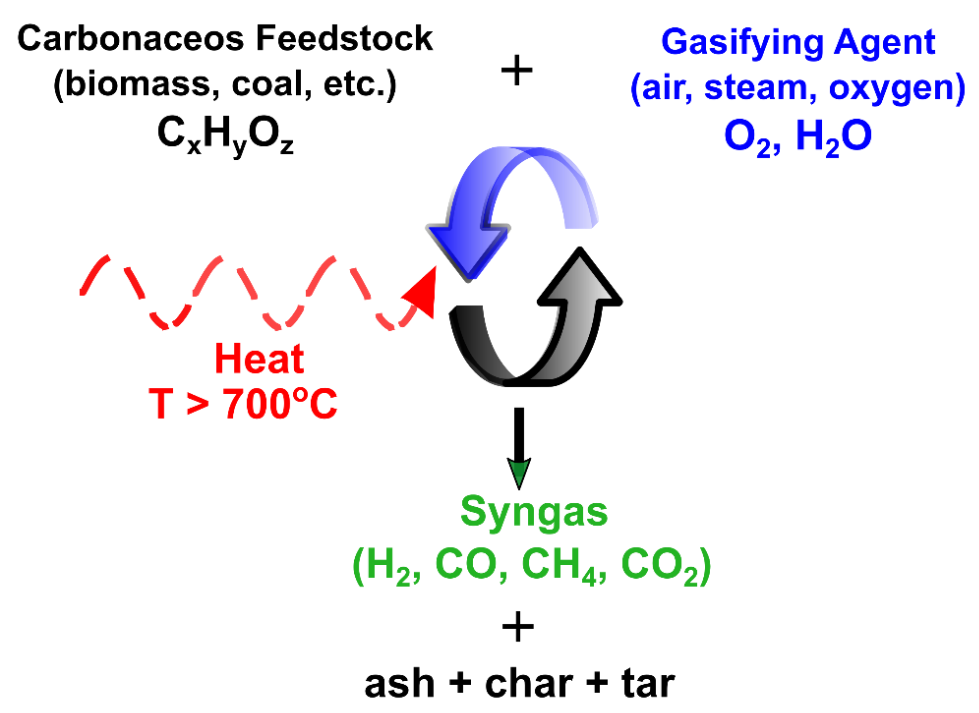

Figure 2. Gasification reaction diagram.

It is important to characterize the fluidization inside the reactor. "Fluidization" is used to describe the state of solid particles. Initially static, as shown in Figure 3a, a steady increase in the fluidizing agent flow rate results in the particles reaching a suspended state (also called "minimum fluidization," see Figure 3b), in which the drag force exerted on the particles by the incoming fluidizing agent is equal to the weight of the material inside the reactor. Further increase in the fluidizing agent (gas or liquid) flow rate moves the particle from the suspended to the dynamic state (see Figure 3c) [22-25].

Feedstock particles are usually delivered to the reactor bed from side, bottom, or top via a screw feeder mechanism. Once the carbonaceous particles are introduced into the oxygen-rich environment, the gasification reaction takes place. However, despite the high carbon conversion efficiency (90-95\%), ash, char, etc. remain inside the FBG after the gasification process is 
complete. Heavy ash particles generally accumulate at the bottom of the reactor bed. However, light char particles leave the reactor and must be collected in a cyclone; in circulating fluidized bed (CFB) applications, the light char particles are returned to the bed for further decomposition, resulting in a higher carbon conversion efficiency. The produced syngas is cooled down and filtered before its consumption in the various applications mentioned before.

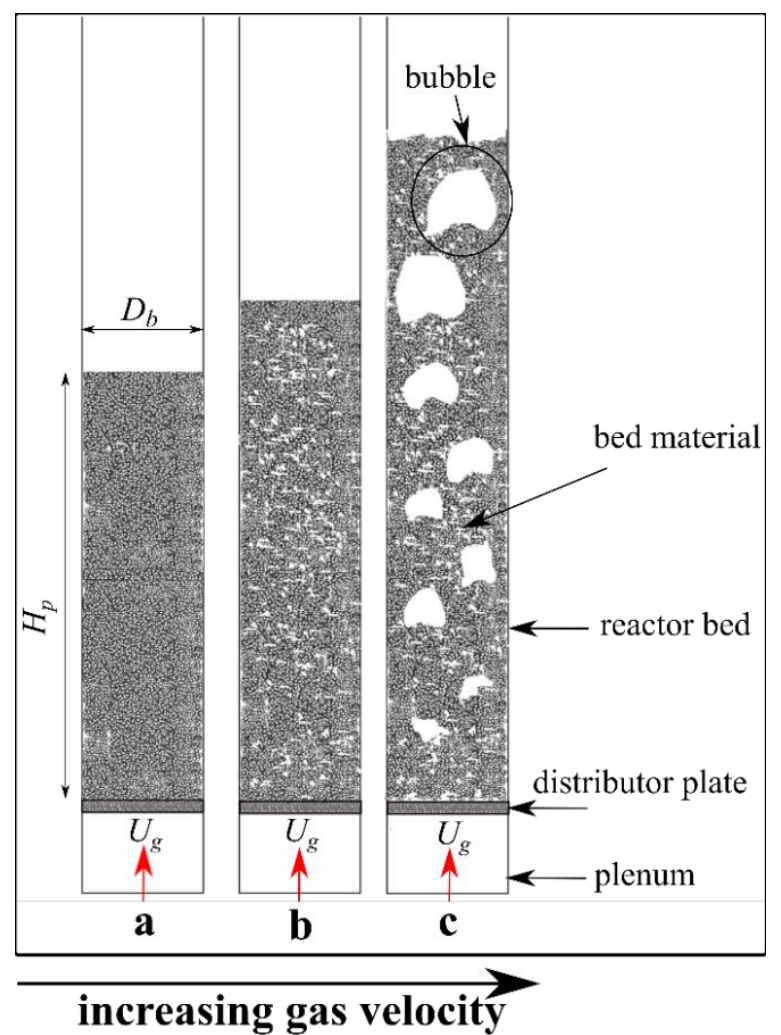

Figure 3. Illustration of the fluidization states with the increase in the fluidizing agent superficial velocity; a) static (fixed) bed, b) suspended bed (minimum fluidization), and c) dynamic bed.

The bubbling fluidized bed gasifier (BFBG) shown in Figure 4 is a particular type of fluidizedbed reactor in which the bed and fuel particles are suspended and mixed by bubbles inside the bed material that are caused by the momentum flux of the fluidizing gas [22]. Besides being more economical to operate and maintain, BFBG can also use a wider range of feedstock [26]. 


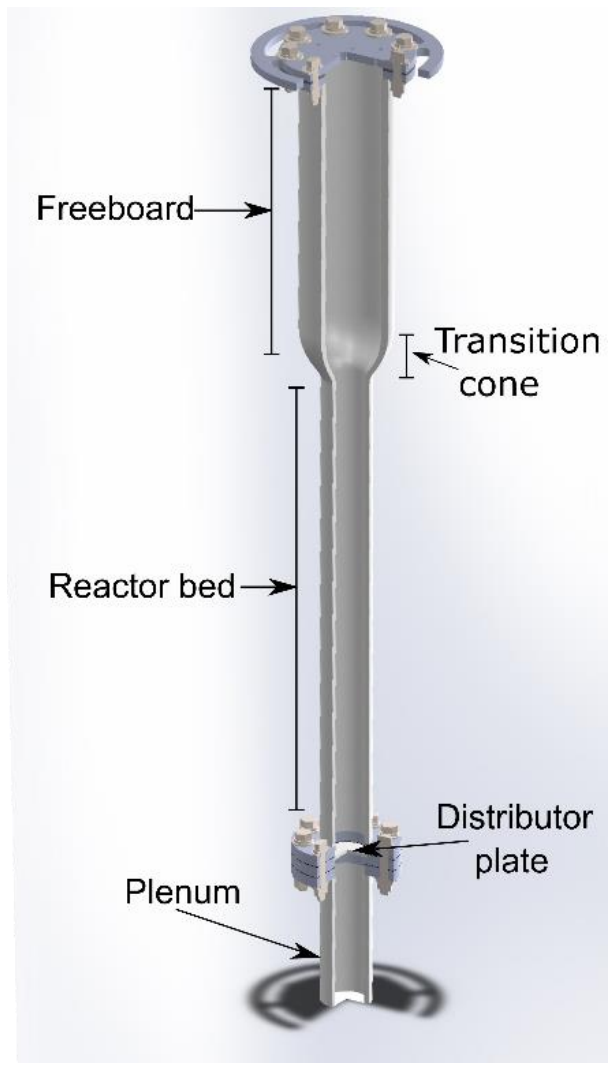

Figure 4. Schematic of a conventional bubbling fluidized bed gasifier.

Figure 4 shows a schematic of a conventional BFBG, which consists of a plenum, distributor plate, reactor bed, transition cone and freeboard. The plenum acts as a reservoir for the fluidizing fluid (usually gas and or steam). The distributor plate separates the plenum from the reactor bed, where bed material and feedstock particles interact and produce the gaseous products. The distributor plate (usually a perforated plate or a sintered metal plate) is one of the most critical BFBG components. Its role is to provide the uniform gas flow distribution and the necessary pressure drop above its surface towards the reactor bed to increase the velocity of the fluidizing fluid to jet levels, which will subsequently influence the hydrodynamics of flow inside the reactor bed, bubble size, and behavior, etc. [27, 28]. Higher fluidizing fluid velocity can result in particle entrainment, a phenomenon in which feedstock and bed particles are carried outside the reactor. 
As a result, a freeboard section is added to decrease the fluidizing fluid velocity to values that will allow feedstock particles that may have been carried away from the reactor to fall back.

For efficient gasification reaction inside a BFBG, operational parameters should be tuned to obtain the optimum fluidization quality. Thus, fluidization hydrodynamics is crucial for BFBGs gasification operations and its efficiency to sustain the optimum intraparticle and/or interparticle heat, energy, and mass transport at microscale [26, 29]. Therefore, the syngas quality (composition), is significantly affected by the operational and hydrodynamical parameters of gasification in BFBG. However, the resulting multiphase-flow phenomenon is a challenging process, particularly for biomass particles, due to their irregular size and shape distributions [26, 30], density [31], moisture content [32], bed aspect ratio, $H_{p} / D_{b}$ (where $H_{p}$ is the static bed height and $D_{b}$ is the bed diameter) [33], surface chemical property, etc. These affect interparticle forces, including inter-locking, cohesion, and liaison between biomass particles [34, 35]. A solution to promote better mixing and higher heat transfer rates from the heat source to the feedstock particles is to add an inert material (alumina, glass beads, sand, etc.) to the reactor (usually called as the "bed material") $[26,33,34,36]$. However, the addition of the inert material increases the hydrodynamics complexity due to the differences between the various particle characteristics (e.g., different density, weight, etc.) [37-40]. Also, the biomass feeding location (bottom, top, side, etc.) [41-44] strongly influences the gasification process through its influence on the biomass distribution inside the inert material, the static electricity created in the process [45], particle agglomeration [46], and particle segregation [47].

The minimum fluidization velocity $U_{m f}$ is one of the most important parameters used to characterize the fluidization process $[30,48]$ because, in addition to identifying the minimum fluidization condition (see Section 1.2.3), it can be used to control the fluidization behavior inside 
the BFBR $[49,50]$. While the literature contains numerous correlations developed to predict the $U_{m f}$ of unary and binary biomass mixtures, there is no general agreement on the most appropriate way to predict $U_{m f}$ due to the large number of process variables that affect the fluidization hydrodynamics in real applications [49]. Also, as the vast majority of these correlations were developed in small-scale applications (i.e., laboratory or bench-scale), the results may differ when applied to large-scale applications [51]. Hence, the accuracy of the experimental measurements and theoretical predictions of the dimensionless numbers such as Reynolds, $R e$, and Archimedes, Ar have critical importance in correlation studies, scaling [51-54], design [52, 55-60], verification [61], validation [62] and optimization [63] of the fluidization process for both experimental and numerical research studies [64]. In addition, a large number of these correlations were based on results from experiments performed at ambient conditions, even if process temperature affects the density and viscosity of the fluidizing agent [65], interparticle forces [66], and heat transfer rates [20, 65] (i.e., process temperature affects both the fluidization and chemistry). Moreover, correlations should consider the inherent temperature fluctuations experienced during the gasification process, as their effect is not negligible $[55,65,67,68]$. However, it is not easy to perform hydrodynamic studies at elevated temperatures, which can be well above $1000^{\circ} \mathrm{C}$, due to the temperature effect of measurement probes and visualization tools.

The bed aspect ratio, $H_{p} / D_{b}$, is another significant hydrodynamical parameter. To provide rapid and homogenous mixing of mixture particles is a challenging problem. For example, the bed aspect ratio affects the temperature gradient and fluidizing fluid and reactant gas residence time inside the bed reactor, particle mixing and contact time, and chemical reaction time [50, 69-72]. In addition, particle mixing becomes more challenging for the deep beds (i.e., beds with a high aspect ratio) with feedstock top-feeding (i.e., on the bed), due to the lightweight and density of the 
feedstock particles coupled with the slug formations (bubble formations with the diameter close or equal to the fluidized bed (column) diameter, see Section 1.2.1 Fluidization Regimes) [73]. Inadequate mixing yields to lower syngas quality with excessive tar formation [42, 44]. For binary mixture applications in fluidized bed reactors, the rapid mixing of the feedstock and inert particles is paramount for high thermal and reaction efficiency. For example, wood biomass particles are highly reactive. Thus, they need to be put in contact with inert material immediately while also providing an adequate fluidizing gas velocity [74, 75], biomass mass ratio [33, 38, 76, 77], moisture content [78] feeding point (in-bed or on-bed) [41, 79], and bed aspect ratio [50, 69, 71] for homogenous and immediate mixing. Moreover, bubble formations (see Section 1.2.1 Fluidization Regimes) along the fluidized bed column have a significant effect on the circulation of particles [80]. Furthermore, significant differences between the inert and biomass particles in terms of particle size, sphericity, density, and weight can lead to poor mixing and segregation [81].

A literature review showed that the theory behind the fluidization process inside a BFBG lacks all the information needed for optimizing the gasification process, especially with respect to the fluidization of binary or ternary mixtures. For example, it is rare to find in the literature a comprehensive study that investigated the hydrodynamics of binary mixtures of sawdust and inert material in top-fed deep-bed applications while also accounting for all primary parameters that affect the fluidization, including mixing and temperature effects. This is impeding the development of accurate multiphase models of the gasification process in fluidized beds, which delays the largescale implementation of this promising technology. This is why the work described here was part of a larger project at WVU designed to support the multiphase flow science research efforts at the National Energy Technology Laboratory in Morgantown, WV. The project also included the development of a cold flow rig and a high-temperature BFBG with similar geometries. The reason 
for the cold flow rig development was to visualize the fluidization behavior (including mixing) at various operating conditions, which is very difficult to do in a high-temperature BFBG.

All the above point to the fact that there is still a significant need of fundamental research on the fluidization hydrodynamics. The objective of this dissertation was to provide a deeper insight into the fluidization hydrodynamics of biomass and/or coal binary mixtures when considering the effects of particle characteristics (i.e., particle size and sphericity distributions, density, and moisture), bed aspect ratio, initial mixing conditions, temperature, fluidization behavior, and mixing due to fluidization. Hence, this comprehensive research study will be a niche in the field of fluidization hydrodynamics of biomass or coal binary mixtures used in top-fed deep-bed BFBG applications. The experimental data obtained in this study can be used to validate, verify, and optimize multiphase gasification models.

\subsection{Fluidization Hydrodynamics}

This section discusses in detail the basics of the fluidization theory, including the fluidization regimes, the Geldart's particle classification, and the minimum fluidization.

\subsubsection{Fluidization Regimes}

Figure 5 shows the possible fluidization regimes inside a fluidized bed with increased superficial gas velocity, $U_{g}$ [26]. Figure 5a shows a fixed or packed bed, in which $U_{g}$ (defined as $U_{g}=\dot{m}_{g} / \rho_{g} A_{b}$, where $\dot{m}_{g}$ and $\rho_{g}$ are the fluidizing fluid mass flow and density, respectively, and $A_{b}$ is the cross-sectional area of the reactor bed) is smaller than the minimum fluidization velocity, $U_{m f}$ (defined later in this paragraph). The increase in fluidizing gas superficial velocity creates a momentum flux and yields motion inside the bed. The state in which the bed material and feedstock 
are simply suspended by the upcoming flow through the distributor plate, as seen in Figure $5 b$, is considered the onset of fluidization inside the BFBG. $U_{g}$ at this condition is defined as the minimum fluidization velocity, $U_{m f}$. Further increase in $U_{g}$ results in bubble formations, as shown in Figure 5c (Note: while the bubble size increases as the bubble moves upwards, the shape and size of the bubbles in Figure 5c are for illustrations purposes only).This is the desired operating regime for a BFBG because it promotes mixing and heat transfer between the bed particles and feedstock, followed by the gasification reactions. Therefore, a bubbling regime with a homogenous bubble distribution is preferred for better mixing and heat transfer rates.

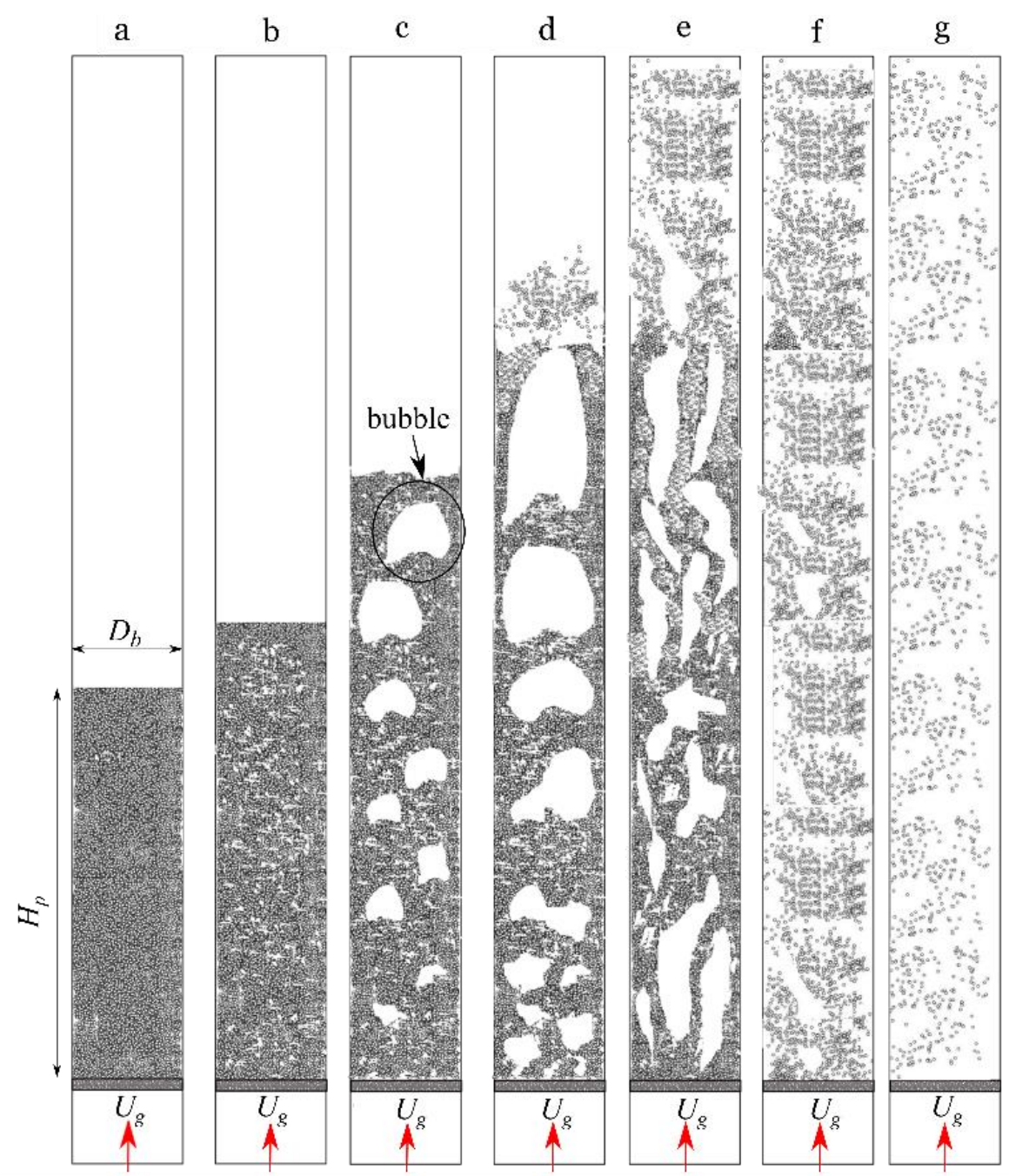

Figure 5. Schematic illustration of the fluidization regimes 
A further increase in $U_{g}$ creates slugging, a process in which bubbles coalesce to form slugs (or bubbles with almost the same diameter as the gasifier column diameter), as shown in Figure 5 d. For even further $U_{g}$ increase, slugging turns into a turbulent regime, where there is only rapid mixing and no more bubble formations, as seen in Figure 5e. Figure 5f and Figure 5g show the regime of fast fluidization and pneumatic transport when $U_{g}$ is increased to even higher values than those corresponding to the turbulent regime. It is important to mention that the bed aspect ratio, $H_{p} / D_{b}$, changes from static (i.e., packed) to minimum fluidization condition, as seen from a comparison of Figure 5a and Figure 5b. This phenomenon is called "bed expansion."

\subsubsection{Geldart's Particle Classification}

Particle size, density, and sphericity have effects on the hydrodynamical behavior in multiphase flow applications, i.e., the fluidization process. A seminal study with respect to characterizing the fluidization behavior of particle groups of different mean sizes and densities was the study done by Geldart in 1973 [82]. Geldart categorized particle groups by comparing the differences between the solid and gas phase densities at a particular mean particle diameter.

As seen in Figure 6, particles were categorized into four groups: A, B, C, and D. Group A represents the particles with small diameter (20 $\mu \mathrm{m}$ to $100 \mu \mathrm{m})$ and or low density, such as cracking catalysts. Beds with this group of particles show dense phase expansion after the minimum fluidization condition. Hence, they require higher gas velocities compared to Group B particles to allow bubble formations. Group B particles have ranges of mean diameter and density of $40 \mu \mathrm{m}$ to $500 \mu \mathrm{m}$ and $1.4 \mathrm{~g} / \mathrm{cm}^{3}$ to $4 \mathrm{~g} / \mathrm{cm}^{3}$, respectively. Sand can be a good example of this group of particles. Bubbles are observable just after the minimum fluidization velocity with a small bed expansion. Particles with high cohesiveness and small mean diameter $(10 \mu \mathrm{m}$ to $80 \mu \mathrm{m})$ fall 
in the classification of Group C. Their high cohesive behavior results in higher interparticle forces, which returns poor mixing and fluidization quality. Group D particles have the highest density and the biggest size. With respect to the mixing characteristics, Group B particles show the highest quality of mixing, while Group C particles can be fluidized only with high effort due to their cohesiveness. Also, Group D particles exhibit a lower quality of mixing and fluidization compared to Group B and A due to their bigger size and higher density.

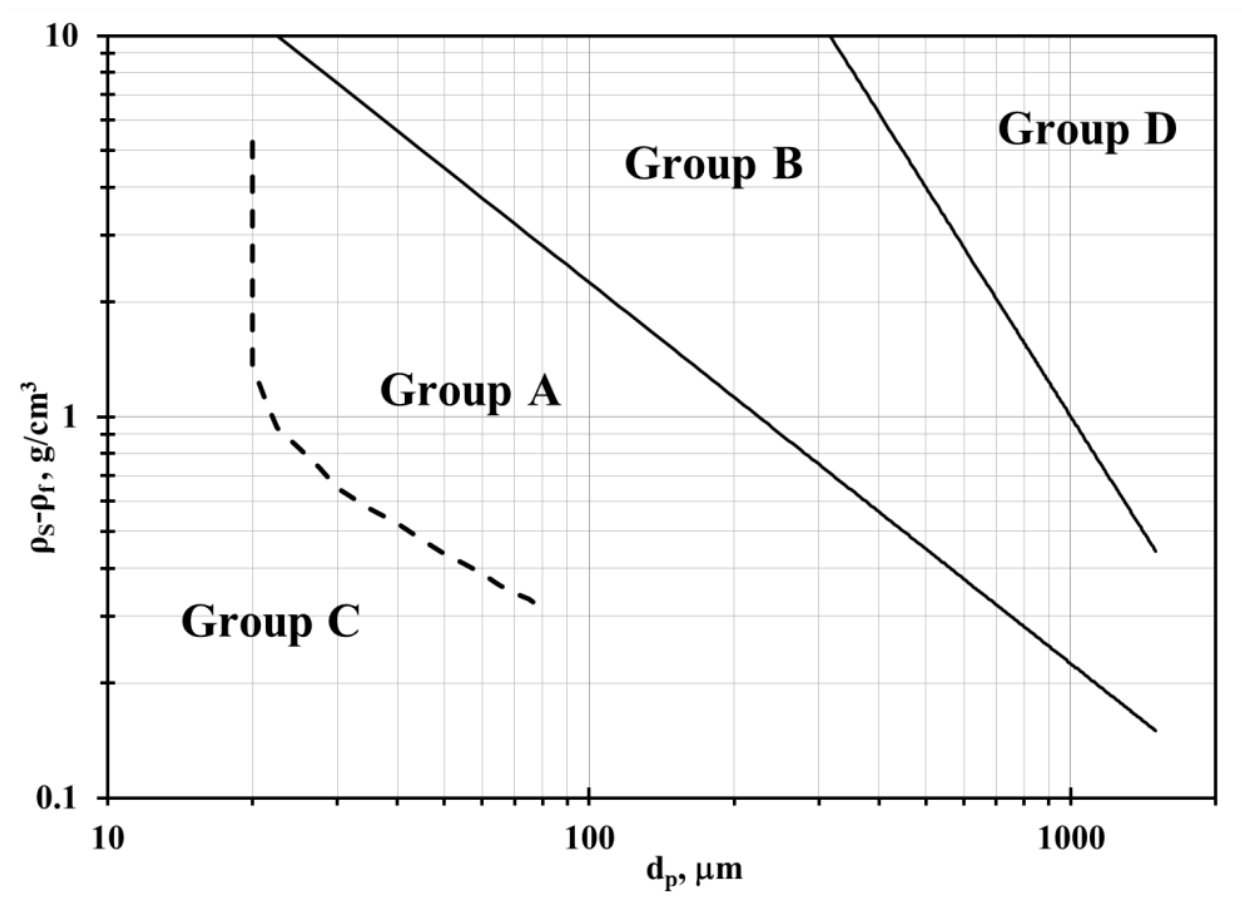

Figure 6. Geldart particle classification

\subsubsection{Minimum Fluidization Velocity}

As previously mentioned, $U_{m f}$ is used to identify the minimum fluidization condition and then facilitates the control and the identification of the fluidization behavior inside the bubbling fluidized bed reactor (BFBR) $[49,50]$. Most correlations that predict $U_{m f}$ use the mean particle size and sphericity of the unary mixture material [49]. For example, Ergun equation [83] correlates the 
pressure drop across a packed bed of non-spherical particles with the fluidizing gas and bed particle parameters:

$$
\frac{\rho_{f}\left(\rho_{p}-\rho_{f}\right)\left(g d_{p}^{3}\right)}{\mu_{f}^{2}}=\frac{150\left(1-\varepsilon_{m f}^{2}\right)}{\phi^{2} \varepsilon_{m f}^{3}} \frac{\rho_{f} U_{m f} d_{p}}{\mu_{f}}+\frac{1.75}{\phi \varepsilon_{m f}^{3}} \frac{\rho_{f}^{2} U_{m f}^{2} d_{p}^{2}}{\mu_{f}^{2}}
$$

where $\Delta P_{b}$ is the pressure drop along the bed length, $H$ is the bed height, $\varepsilon_{m f}$ is the bed voidage, $\mu_{g}$ is the fluidizing gas viscosity, $d_{p}$ is the mean bed particle diameter, $\rho_{f}$ is the gas density, and $\phi$ is the average bed particle sphericity. The bed voidage, $\varepsilon$, is defined as the ratio of the total volume occupied by the voids between bed particles to the total bulk bed volume:

$$
\varepsilon=1-\frac{\rho_{b}}{\rho_{s}}
$$

where $\rho_{b}=m_{b} / V_{b}$ is the bulk density $\left(m_{b}\right.$ and $V_{b}$ are the mass and volume of the bulk material, respectively), and $\rho_{s}$ is the bed skeletal density, defined as the bed's density without porosity.

If $U_{g}=U_{m f}$, then $\Delta P_{b}=\Delta P_{m f}$, where the " $m f$ " index corresponds to the variable value at the minimum fluidization condition. Using a control volume analysis, the assumption is that the bed material weight $W$ is equal to the product of the pressure drop across the bed and the bed crosssectional area at the minimum fluidization condition, and that the bed fluidization is created by the summation of all the drag forces on individual bed particles (hence total drag $\mathcal{D}$ equals the bed weight $W$ ) [84]:

$$
\begin{gathered}
\mathcal{D}=\Delta P_{m f} A_{b}=W, \text { where } W=m g=A_{b} H_{m f}\left(1-\varepsilon_{m f}\right)\left(\rho_{p}-\rho_{f}\right) g \\
\mathcal{D}=\sum \mathcal{D}_{p, i}=\sum \frac{1}{2} C_{D, i} \rho_{f} U_{g, i}^{2} A_{p, i}
\end{gathered}
$$


where $\mathcal{D}$ is the total drag force on the bed particles, $\Delta P_{m f}$ is the pressure drop across the bed, $A_{b}$ is the cross-sectional area of the bed, $m$ is the mass of the bed material, $g$ is the acceleration of gravity, $H_{m f}$ is the height of the bed, $\varepsilon_{m f}$ is the bed voidage at minimum fluidization conditions, $\rho_{p}$ is the particle density, $\rho_{f}$ is the fluidizing gas density, and $\mathcal{D}_{p, i}, C_{D, i}, U_{g, i}$, and $A_{p, i}$ are the drag force exerted, the drag coefficient, the local velocity of the fluidizing gas, and the characteristic area of particle $i$, respectively.

If measurements of bed pressure and flow rate are possible, a more practical way to determine the minimum fluidization velocity is the "graphical" solution, which is based on plotting the measured $\Delta P_{b}$ as a function of $U_{g}$, as shown in Figure 7. Then $U_{m f}$ is the superficial gas velocity $U_{\mathrm{g}}$ found at the intersection between the slope of the increasing bed pressure drop under fixed-bed conditions and the constant bed pressure drop corresponding to a complete fluidization state. The initial fluidization velocity $\left(U_{i f}\right)$ and the complete fluidization velocity $\left(U_{c f}\right)$ correspond to the points where fluidization starts and reaches a fully developed state, respectively, as shown in Figure 7. Measurements are usually taken by increasing the fluidizing gas velocity (i.e., during fluidization) and by considering the initial bed voidage and material packing patterns.

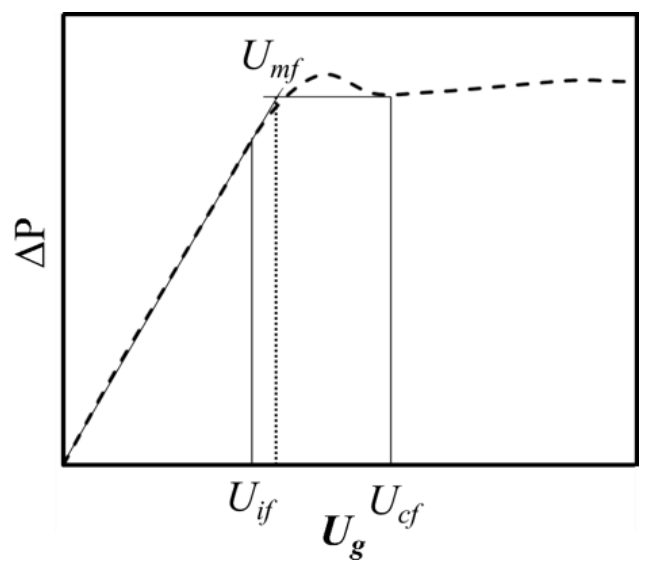

Figure 7. Graphical solution to determine $U_{i f}, U_{m f}$, and $U_{c f}$ for increasing superficial gas velocity. 
Eq.1 can be rewritten with variables that correspond to the minimum fluidization condition:

$$
\frac{\rho_{f}\left(\rho_{p}-\rho_{f}\right)\left(g d_{p}^{3}\right)}{\mu_{f}^{2}}=\frac{150\left(1-\varepsilon_{m f}^{2}\right)}{\phi^{2} \varepsilon_{m f}^{3}} \frac{\rho_{f} U_{m f} d_{p}}{\mu_{f}}+\frac{1.75}{\phi \varepsilon_{m f}^{3}} \frac{\rho_{f}^{2} U_{m f}^{2} d_{p}^{2}}{\mu_{f}^{2}}
$$

In addition to the correlations between $\Delta P_{b}$ and $U_{g}$, several studies [49]correlated $U_{m f}$ with the dimensionless Archimedes (Ar) and Reynolds (Re) numbers [49], defined as:

$$
\begin{gathered}
A r=\frac{\rho_{f}\left(\rho_{p}-\rho_{f}\right)\left(g d_{p}^{3}\right)}{\mu_{f}^{2}} \\
R e_{m f}=\frac{\rho_{f} U_{m f} d_{p}}{\mu_{f}}
\end{gathered}
$$

Then Eq. 1 can be written as a relationship between $A r$ and $R e$ :

$$
A r=\frac{150\left(1-\varepsilon_{m f}\right)}{\phi^{2} \varepsilon_{m f}^{3}} R e_{m f}+\frac{1.75}{\phi^{2} \varepsilon_{m f}^{3}} R e_{m f}^{2}
$$

While there are numerous correlations based on Eq. 8 in the literature that can be used to predict the minimum fluidization velocity in a single-component bed, not so many can predict $U_{m f}$ of binary mixtures [49]. For example, Rao et al. [85] studied different biomass (rice husk, sawdust, and groundnut shell powder) and sand mixture fluidization hydrodynamics for biomass fractions of $2 \%$ to $15 \%$ of the total mass, and derived one of the most used correlation to predict $U_{m f}$ of biomass and sand mixtures. Their results showed that $U_{m f}$ increased proportionally with the increase in the mixture's biomass weight fraction and sand size and density. They compared their experimental data with theoretical predictions using correlations in the literature. However, none of the existing $U_{m f}$ correlations was in agreement with their results. Therefore, Rao et al. [85] developed another correlation (Eq. 11; widely used today), which is valid for $R e<20$ and uses the effective mean mixture density as defined by Eq. 9 and the effective particle diameter as defined by Eq. 10: 


$$
\begin{gathered}
\rho_{e}=k \frac{w_{1} \rho_{1}+w_{2} \rho_{2}}{w_{1}+w_{2}} \\
d_{p e}^{2}=k\left\{d_{p 1}\left[\left(\frac{\rho_{1}}{\rho_{2}}\right)\left(\frac{d_{p 2}}{d_{p 1}}\right)\right]^{w_{2} / w_{1}}\right\}^{2} \\
U_{m f}=\frac{d_{p e}^{2}\left(\rho_{e}-\rho_{f}\right) g}{1650 \mu_{f}}
\end{gathered}
$$

where $k=20 d_{p 1}+0.36, d_{p 1}$ is the mean diameter of sand particles, $d_{p 2}$ is the mean diameter of the biomass particles, $w_{1}$ is the mass of sand, and $w_{2}$ is the mass of biomass particles. The effective mean density, $\rho_{e}$, and effective mean diameter, $d_{p e}$, are also used in other correlations $[30,34,86]$ used to predict the minimum fluidization velocity for binary mixtures, such as those presented in Table 1 . Wen and $\mathrm{Yu}$ [87] proposed that the Re at minimum fluidization velocity should be calculated as [87] $R e_{m f}=\left(K_{1}^{2}+K_{2} A r\right)^{0.5}-K_{1}$, where $K_{l}$ and $K_{2}$ represent constants acquired empirically. Wen and Yu correlation can be considered as a modified and simplified form of the Ergun's equation that can predict $U_{m f}$ without requiring a detailed knowledge of the particle sphericity and bed voidage. Table 1 and Table 2 present selected correlations in the literature used to predict $U_{m f}$ for unary and binary mixtures.

Table 1. Selected correlations to predict Re for Geldart Group B particles

\begin{tabular}{|l|c|l|}
\hline Correlation author(s) & In text mentioned as & Equation \\
\hline Bourgeis and Grenier [90] & $\mathrm{C} 1$ & $R e=\left(25.46^{2}+0.0382 \mathrm{Ar}\right)^{0.5}-25.46$ \\
\hline Leva [89] & $\mathrm{C} 2$ & $R e=(0.000822 \mathrm{Ar})^{0.94}$ \\
\hline Paudel and Feng [30] & $\mathrm{C} 3$ & $R e=\left(30.28^{2}+0.0464 A r\right)^{0.5}-30.28$ \\
\hline Thonglimp et al. [88] & $\mathrm{C} 4$ & $R e=\left(31.6^{2}+0.0425 \mathrm{Ar}\right)^{0.5}-31.6$ \\
\hline Wu and Bayens [91] & $\mathrm{C} 5$ & $R e=\left(30.85^{2}+0.0379 \mathrm{Ar}\right)^{0.5}-30.85$ \\
\hline Zheng et al. [92] & $\mathrm{C} 6$ & $R e=\left(18.75^{2}+0.03125 \mathrm{Ar}\right)^{0.5}-18.75$ \\
\hline
\end{tabular}


Table 2. Selected correlations to predict $U_{m f}$ for binary mixtures

\begin{tabular}{|l|l|c|}
\hline $\begin{array}{l}\text { Correlation } \\
\text { author(s) }\end{array}$ & $\begin{array}{l}\text { In text } \\
\text { mentioned as }\end{array}$ & Equation \\
\hline $\begin{array}{l}\text { Rao and } \\
\text { Bheemarasetti [85] }\end{array}$ & $\mathrm{C} 7$ & $U_{m f}=\frac{d_{p e}^{2}\left(\rho_{e}-\rho_{f}\right) g}{1650 \mu_{f}}$ \\
\hline Zhong et al. [86] & $\mathrm{C} 8$ & $u_{m f}=1.45 \times 10^{-3} X^{0.363}$ \\
& $=1.45 \times 10^{-3}\left[\frac{d_{p e}^{2}\left(\rho_{p e}-\rho_{f}\right)}{\mu_{g}}\left(\frac{\rho_{p e}}{\rho_{f}}\right)^{1.23}\right]^{0.363}$ \\
\hline
\end{tabular}

\subsubsection{Effects of Particle Characteristics, Bed Aspect Ratio and Temperature on the Fluidization Dynamics}

Most of the studies in the literature that investigated the fluidization hydrodynamics were done in unary (i.e., one component) mixtures. As a result, the use of these studies to predict the behavior of a binary mixture of biomass and inert material inside a real BFBG can result in significant differences. For example, it was shown that the biomass mass ratio and particle characteristics have a significant effect on $U_{m f}[30,33-35,37,76,86,93-96]$, pressure fluctuations inside the bed [97-102], particle segregation [37, 47, 76, 77, 96, 102-107], and particle mixing [74, 75, 78, 81, $102,104]$. To add to the difficulty in understanding the specifics of fluidization in binary mixtures, the initial state of the binary mixture before the fluidization varied. For example, the binary mixture was initially premixed (or well-mixed) [37, 95], or the biomass and inert (bed) material were added layer by layer inside the BFBR [33, 34], or the bed material and biomass layers were initially fluidized to obtain some preliminary mixture [86], or the biomass was placed on top of the bed material in a fully-segregated manner [40]. Moreover, the detailed information about the particle size and shape (sphericity) distributions of the materials used in the fluidization experiments was 
not always published, with most papers mentioning just the mean particle size and sphericity but no actual distribution. Furthermore, the reviews of Cui et al. [26] and Gao et al. [40] mention that just a limited number of studies focused on the mixture hydrodynamics of binary mixtures with a wood-based biomass [35, 36, 40, 47, 86, 108, 109], despite the abundance of wood-based feedstocks.

Also, while the percentage of biomass in the binary mixture is usually limited by the actual mixing and heat transfer rates (e.g., Fotovat el al. [38] mentions that a biomass mass ratio of $1 \%$ $5 \%$ in the binary mixture is preferred for optimum mixing and heat transfer rates), multiple studies showed that $U_{m f}$ increases with increasing the percentage of biomass in the mixture [26, 34, 35, 40, 86]. However, Oliveira et al. [37] found the opposite, which was attributed to the irregular size, shape, and distribution of the biomass inside the bed. Pilar et al. [36] compared the theoretical predictions of $U_{m f}$ for the binary mixtures with different size and density differences. They used wood chips, ground thistle, cereal straw, and sawdust at various sizes in their experiments. However, the use of existing correlations in the literature could not predict $U_{m f}$ effectively and the highest relative errors between predictions and experiments were found for biomass and sand mixtures. Davies and Dawson [108], which investigated the agglomeration effect on $U_{m f}$ by adding a small amount of wood ash into wood waste and iron sand agglomerating systems, observed significant changes in $U_{m f}$ with the addition of wood ash. Abdullah et al. [31] conducted experiments with known size, bulk density, fluidizing velocity, etc. for palm fiber, coconut shell, peanut shell, rice husk, sawdust, coal, and ash that measured bed pressure drop when the fluidizing air velocity increased. Similar to Fotovat et al. [38], Abdullah et al. [31] found that the mixture bulk density and the bed voidage significantly affected $U_{m f}$ and Geldart B-group materials fluidized better in comparison with other groups of materials in Geldart's classification. Si and Guo [35] 
investigated the fluidization behavior of binary mixtures of quartz sand with sawdust or wheat stalk in an acoustic bubbling fluidized bed. Their results showed that the addition of sand improved the fluidization quality of the biomass particles. An increase in the biomass fraction resulted in an increase in the minimum fluidization velocity. In addition, the increase in the sound pressure level decreased the minimum fluidization velocity. Furthermore, as existing correlations could not predict $U_{m}$, the authors developed a new correlation to match their experimental data. Cluet et al. [47] studied binary mixtures with wood as feedstock and olivine particles as inert material. The study found that fine olivine particles decreased the binary mixture's voidage, on the contrary, big or coarse olivine particles did not affect the mixture's voidage. In addition, better mixing was observed for the mixture with higher wood density and lower particle sphericity. Berruti et al. [109] examined the residence time and the trace of the biomass particles injected into the fluidized bed with sand at ambient conditions. PVC particles and Styrofoam beads were used to simulate wood and char, respectively. Their results showed that PVC particles and Styrofoam beads mixed well with the sand at various gas velocities. However, Styrofoam beads entrained out of the reactor rapidly. In addition, larger PVC particles had higher circulation time through the bed.

Olatunde et al. [110] showed that $U_{m f}$ increased as the biomass moisture content increased. Clarke et al. [111], who studied the fluidization behavior of sawdust and glass beads binary mixture, explained this phenomenon. Specifically, they observed inadequate fluidization with channeling when attempting to fluidizing the sawdust alone. However, the fluidization quality improved with the addition of glass beads with two different mean diameters of $0.322 \mathrm{~mm}$ and $0.516 \mathrm{~mm}$, respectively. The sawdust mixtures with glass beads of smaller diameter showed better mixing characteristics. The minimum fluidization velocity increased with the increase in the moisture content of the sawdust. More than $33 \%$ sawdust moisture content led to channeling and 
agglomeration with both glass bead types. The authors attributed this phenomenon to the interparticle liquid bridging forces and one of the reasons why existing correlations cannot predict $U_{m f}$ successfully.

In addition to the biomass percentage in the mixture, Zhang et al. [33] found that a larger bed aspect ratio (i.e., the ratio of the bed height to the bed diameter) increased the interparticle cohesion and bridging forces. Moreover, Oliveira et al. [37] found that the BFBR transitioned from bubbling to a slugging regime if the bed aspect ratio was higher than two. However, Formisani et al. [112] found that the minimum fluidization velocity range inside a biomass binary mixture was not affected when changing the bed aspect ratio from 0.7 to 2.4 , but the transition to a slugging regime occurred faster when the bed aspect ratio was higher than five due to rapid bubble coalescence and growth [113]. Escudero et al. [50] studied material density effects and bed height on fluidized bed hydrodynamics particularly for the $U_{m f}$ and gas holdup. They evaluated Geldart Group B particles, including corncob, walnut shell, and glass beads with densities of 1000,1300 , and $2600 \mathrm{~kg} / \mathrm{m}^{3}$, respectively. During their tests, they changed the bed aspect ratio from 0.5 to 3 with 0.5 increments. Their results showed an agreement with the study made by Formisani et al. [112], and $U_{m f}$ did not change with the change in bed height. However, Ramos et al. [114] found opposite by stating the increase in $U_{m f}$ with static bed height in their 2D fluidized bed. Similarly, refs. [115-117] show no change or negligible change in $U_{m f}$ with the bed height, in accordance with Formisani et al. [112] and Escudero et al. [50].

In industrial-scale fluidized beds applications, the importance of temperature as a process parameter is unavoidable [65]. The gas density decreases, and the gas viscosity increases with the increase in temperature. Thus, fluidization hydrodynamics is significantly affected by temperature in terms of interparticle and gas-solid interaction. Some important research studies mentioned here 
considering the temperature effect on unary mixtures, mainly sand, were noted. However, most of the correlations and fluidization models (including Geldart's particle classification) were developed at ambient conditions. Thus, extrapolating the data obtained from studies at ambient conditions to high-temperatures applications can result in discrepancies in both expected fluidization behavior and predicted hydrodynamical parameters. Furthermore, there are contradictory statements in the literature about the effect of temperature on the fluidization hydrodynamics. For example, refs. [118, 119] mention that a higher process temperature will decrease $U_{m f}$ but refs. $[112,119-121]$ mention that a higher temperature will increase $U_{m f}$. Therefore, there is still the need for further investigations on the temperature effect on the interparticle and hydrodynamical forces. For example, Lettieri et al. [122] reported that particle size strongly influences the effect of temperature on interparticle and gas-particle synergy. Their results showed that the Group A powder behaved like Group C particles at elevated temperatures. This phenomenon explained by the increasing inter particle forces with temperature. Pattipati and Wen [119] compared experimental $U_{m f}$ at different temperatures with theoretical predictions using the correlation developed by Wen and Yu [87] for sand material and found no notable change in the bed voidage with the temperature at minimum fluidization conditions. Their comparison showed that the correlation developed by Wen and Yu predicted $U_{m f}$ well. However, their study only mentions the mean particle diameter $(462 \mu \mathrm{m})$ and particle size range $(240-3376 \mu \mathrm{m})$, but no particle size and sphericity distribution. On the contrary, Botterill et al. [120] observed a variation in bed voidage when temperature increased, for sand material. Specifically, $U_{m f}$ increased for Group D particles and decreased for Group B particles with increased process temperature, and the Wen and Yu prediction was higher than the experimental $U_{m f}$. Also, Goo et al. [123] reported that $U_{m f}$ decreased with increasing temperature for silica sand. Yamazaki et al. [124] investigated 
the effect of process temperature and fluidizing gas humidity on the minimum fluidization voidage, $\varepsilon_{\mathrm{mf}}$, of silica particles in a fluidized bed. Their results showed that $\varepsilon_{m f}$ increased with the increase in temperature and decreased as humidity increased. In agreement with Yamazaki et al. [124], Formisani et al. [125] reported a linear increase in $\varepsilon_{m f}$ with temperature for Geldart's Group A, B, and D particles. Jiliang et al. [126] studied the effects of particle size distribution and temperature on $U_{m f}$ for quartz sand and bottom ash mixture in a bench-scale bubbling fluidized bed. They reported that $U_{m f}$ decreased for both groups of materials irrespective of the particle size distribution (i.e., wider or narrower size distribution). However, the decrease in $U_{m f}$ was higher for the group of material with a narrower particle size distribution at the same temperature range. Such observations underline the complexity in understanding and then predicting temperature effects on the fluidization inside a bubbling fluidized bed gasifier.

\subsection{Research Objectives}

The primary objectives of this research study were:

1. Design and develop a bench-scale BFBG

2. Design a feeding system for the bench-scale BFBG

3. Study the effects of bed and feedstock particle characteristics (size and sphericity distributions, density, moisture content), bed aspect ratio, temperature, and initial mixing condition on fluidization hydrodynamics, via a cold flow rig that simulates the processes taking place inside the BFBG (except the chemistry)

4. Investigate the fluidization results inside the cold flow rig to design the gasification experiments inside the BFBG 
5. Use image processing techniques to observe the time-dependence of the fluidization inside the cold flow rig

6. Perform gasification tests with biomass or coal and investigate syngas production and quality

7. Create an accurate and comprehensive experimental data set that can be used for developing coal and biomass gasification models, for process scaling, and for process optimization.

\subsection{Dissertation Content}

This paragraph details the content of the next chapters. Chapter 2 describes the design and development (including the design requirements and considerations) of the two experimental setups used here: the cold flow rig (for experiments at ambient temperature) and the BFBG setup, used for high-temperature measurements (up to $900^{\circ} \mathrm{C}$ ). In addition, information about the DFBG is shared. Detailed characteristics of the feedstock and bed materials used in this work are presented and the conditions at which experiments were run are discussed. Chapter 3 and Chapter 4 present the results and analysis of cold flow and high temperature experiments, respectively. Chapter 5 summarizes and presents the conclusions of this study. Finally, Chapter 6 presents a perspective on future studies on the topic based on the results and analysis presented here. 


\section{Chapter 2: Experimental Setup and Methodology}

This chapter discusses the development of the two experimental setups (the BFBG and the cold flow test rig) used during in this study. In addition, a detailed material analysis and the experimental conditions investigated are presented.

\subsection{Cold flow test rig}

Figure 8 and Table 3 show the cold flow rig setup and details, respectively. The cold flow rig consists of a plenum, a distributor plate, the bed section, the transition cone, and the freeboard. All components of the test rig (except the distributor plate) are made from acrylic, which allows the process visualization. A mass flow controller (Alicat, Model MCP-100SLPM-D/5M) controlled the flow rate of the fluidizing gas, which was nitrogen and air for biomass and coal studies, respectively. The distributor plate was a $316 \mathrm{~L}$ stainless-steel sintered disc $(0.3175-\mathrm{cm}$ thick x 3.81 cm diameter) with a $10-\mu \mathrm{m}$ pore size and $39 \%$ total porosity.

Figure 8 shows the nine pressure tabs (aligned vertically) used to measure the pressure inside the cold flow rig during experiments, from just below the distributor plate (location 1) to below the transition cone (location 9). Pressure taps 1 and 2 (6.35 $\mathrm{mm}$ below and above the distributor plate, respectively) measured the pressure drop across the distributor plate. The distance between each pressure tap from location 2 to location 8 was $38.1 \mathrm{~mm}$. A pressure transmitter (Rosemount, Model 2024 D 2 A 22B 2S1 H 0016E 5) connected between taps 2 and 9 measured the bed pressure drop. Seven other pressure transducers (Omega, Models 2xPX409-015DDUI, PX429-015A5V, PX409-2.5DDU5V, PX429-030A5V, and 2 x PX409-005GI) measured the pressure drop inside the bed at different bed heights. A data acquisition system (Labjack, Model UE9) and a Pythonbased proprietary software (Scimitar) collected and recorded the analog flow and pressure signals 
with a $10 \mathrm{~Hz}$ sampling rate. Also, images of the initial bed height and fluidization behavior for most of the investigated conditions were recorded with the high-speed camera (Photron, Model SA5). Later, images were processed using an open-source image processing tool, Python scikitimage, improving image quality and increasing the contrast between inert and feedstock particles to illustrate the feedstock particles' distributions better.

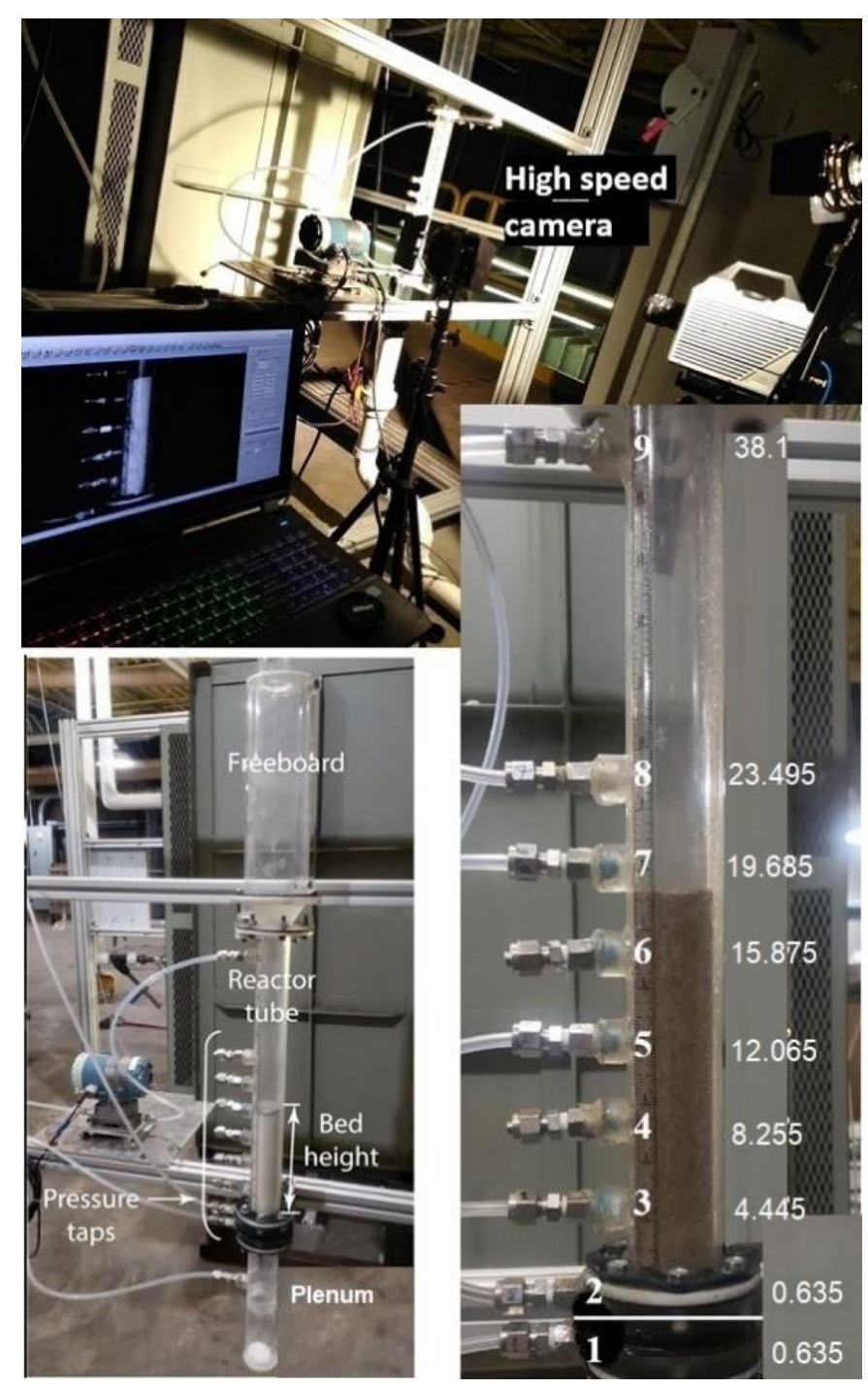

Figure 8. Cold flow experimental setup 
Table 3. Cold flow rig characteristics

\begin{tabular}{|l|c|}
\hline Material & Polymethyl-methacrylate \\
Reactor internal diameter [in] & 1.5 \\
Reactor tube height [in] & 16 \\
Transition cone height [in] & 1 \\
Freeboard internal diameter [in] & 3 \\
Freeboard height [in] & 10 \\
\hline
\end{tabular}

Table 4 shows the experimental conditions for the cold flow rig experimental setup. Pressure measurements were taken at each flow rate for a minimum of 30 seconds after waiting at least 30 seconds after changing the flow rate of the fluidizing fluid (to stabilize the pressure drop). Simultaneously with the pressure drop measurements, fluidization behavior and mixing were recorded for the segregated mixtures to simulate the on-bed (top-fed) feeding process for the BFBG. Three different initial bed conditions were observed: premixed mixture, feedstock on top of the inert material (segregated mixture), and only inert material, as shown in Figure 9. For each condition, measurements were repeated three times, and the average values are shown in the Results section.

Table 4. Experimental conditions

\begin{tabular}{|lcccccc|}
\hline Bed material & $m_{\text {mixture }}(\mathrm{g})$ & $\begin{array}{c}m_{\text {biomass,coal }}(\mathrm{g}) \\
\text { moisture }(\%)\end{array}$ & $\begin{array}{c}\text { Coal } \\
\text { moisture }(\%)\end{array}$ & Premixed & $\begin{array}{c}\text { Biomass } \\
\text { or coal, } \\
\text { on top }\end{array}$ \\
\hline Glass beads & $100 ; 200 ; 300$ & $0 ; 4 ; 8 ; 12$ & 3.7 & $7.6 ; 3.3$ & No/Yes & No/Yes \\
Sand & $100 ; 200 ; 300$ & $0 ; 4 ; 8 ; 12$ & 3.7 & $7.6 ; 3.3$ & No/Yes & No/Yes \\
\hline
\end{tabular}




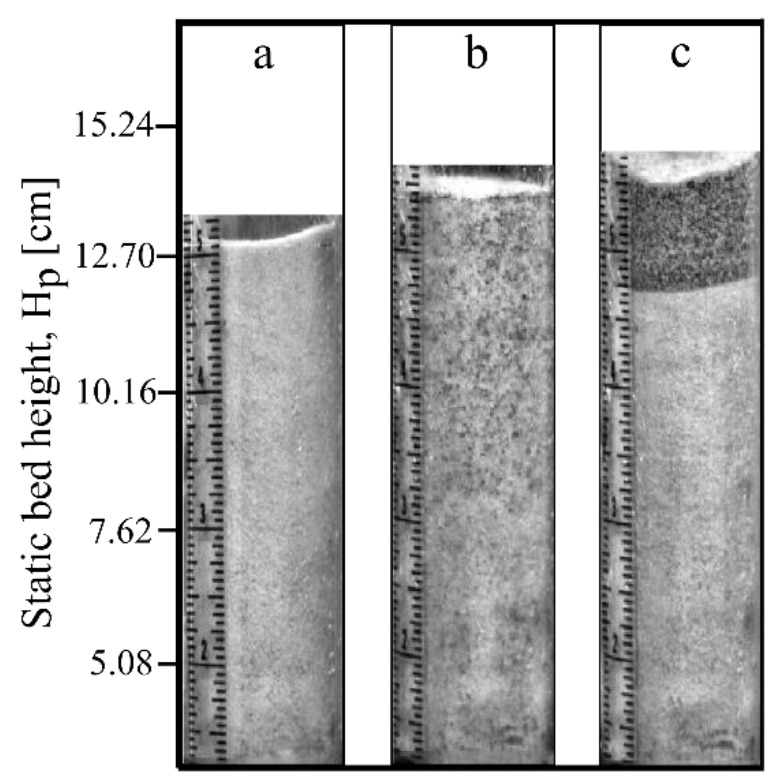

Figure 9. Initial bed conditions for $200 \mathrm{~g}$ of material: a) Inert material only, b) premixed mixture,

c) biomass on top of the inert material

\subsection{Bench-scale BFBG}

\subsubsection{Design Requirements}

\subsubsection{Considerations Based on the Syngas Flow Rate Needed to Operate an IC Engine}

As stated in the Introduction section, syngas can be used as direct or dual fuel in ICE applications. The design of the bench-scale BFBG used in this study was based on producing enough syngas to fuel existing IC engines at WVU. Specifically, one of the engine tests stands in WVU' Advanced Combustion Laboratory is a diesel research engine (Ricardo/Cussons, Model Proteus) converted to natural gas spark ignition. The engine maximum power in its original diesel configuration is $55 \mathrm{~kW}$ at $2200 \mathrm{rpm}$. Experiments conducted by Liu [127] and Bommisetty [128] found that the indicated thermal efficiency of the converted engine in its current natural gas spark 
ignition configuration was $\sim 37 \%$. As the design of this research engine is more tolerant to fuel contaminants than conventional SI engines, it was the first choice when looking for an engine to run on syngas from coal and biomass gasification. Some of the engine specifications are shown in Table 5 .

Table 5. Proteus (Ricardo/Cussons) engine specifications.

\begin{tabular}{|lc|}
\hline Maximum power and rpm & $55 \mathrm{~kW}$ at $2200 \mathrm{rpm}$ \\
Number of Cylinders & 1 \\
Thermal efficiency (\%) & 37 \\
Cycle & 4 -stroke \\
Bore (mm) & 130.2 \\
Stroke (mm) & 150 \\
Displacement (liters) & 1.997 \\
\hline
\end{tabular}

Previous experiments using the converted engine [127] produced an indicated power of $25 \mathrm{~kW}$ at $900 \mathrm{rpm}$. The indicated power, $P_{i}$, of a four-stroke engine can be calculated with the formula [129]:

$$
P_{i}=\frac{P_{m} \cdot L \cdot A \cdot N}{60000 \cdot 2}, \mathrm{~kW}
$$

where $P_{m}$ is the actual mean effective pressure $\left(\mathrm{N} / \mathrm{m}^{2}\right), L$ is the engine stroke $(\mathrm{m}), A$ is the area of the cylinder cross-section $\left(\mathrm{m}^{2}\right)$, and $N$ is the rpm of the engine crankshaft.

If the engine thermal efficiency is known, the required syngas amount needed to produce the power $P$ can be found by using the fuel conversion efficiency $\left(\eta_{f}\right)$ equation [129], 


$$
\eta_{f}=\frac{P}{\dot{m}_{f} Q_{L H V}}
$$

where $\dot{m}_{f}$ is the fuel mass flow rate, $Q_{L H V}$ is the lower heating value of the fuel and $P$ is the power.

Based on the above equations and the engine values mentioned above, the total fuel energy required to operate of the Proteus engine is around $67.5 \mathrm{kWh}$, which can be further assumed as 75 kWh or $270 \mathrm{MJ}$ when accounting for additional losses (e.g., mechanical losses) during engine operation. The next step will calculate the required syngas amount according to its composition and feedstock type.

\subsubsection{Gasification considerations}

After determining the required fuel energy to run the engine, the next step is to calculate the required feedstock rate under selected gasification process parameters that will produce the amount of syngas needed. Considerations were made for the gasification reactions of various wood or coal feedstocks with air as oxidant. Feedstock elemental and compound compositions are vital to estimating the heating values. Ultimate and proximate analyses were used to determine the feedstock compositions, including ash content (see Table 6 for details).

Table 6. Elemental and proximate analysis (by mass) of biomass and bituminous coal

\begin{tabular}{|lcccccc|}
\hline & $\begin{array}{c}\text { Carbon }(\mathrm{C}) \\
(\%)\end{array}$ & $\begin{array}{c}\text { Hydrogen }(\mathrm{H}) \\
(\%)\end{array}$ & $\begin{array}{c}\text { Oxygen }(\mathrm{O}) \\
(\%)\end{array}$ & $\begin{array}{c}\text { Sulfur (S) } \\
(\%)\end{array}$ & $\begin{array}{c}\text { Moisture } \\
(\%)\end{array}$ & $\begin{array}{c}\text { Ash } \\
(\%)\end{array}$ \\
\hline Hardwood & 45.25 & 4.65 & 49.2 & 0.0 & 7.16 & 0.32 \\
biomass & & & & & & \\
\hline Pittsburgh \#8 & 73.62 & 4.38 & 7.83 & 2.59 & 3.69 & 7.89 \\
Coal & & & & & & \\
\hline
\end{tabular}


The literature $[130,131]$ suggests that the use of oxygen and steam as oxidants in the gasification reaction produces higher-quality syngas (i.e., higher heating values). However, operating the BFBG with air (and steam) is usually preferable (as was done in this work, too) due to being more feasible and economical compared to oxygen and steam. References [132, 133] suggested an equivalence ratio of 4 relative to the stoichiometric combustion air requirements, for optimum syngas heating values. Based on the ultimate analysis in Table 6 , the molecular formulas of the feedstocks were:

$$
\text { Biomass (hardwood): } \mathrm{CH}_{1.33} \mathrm{O}_{0.83}
$$

and

\section{Coal: $\mathrm{CH}_{0.71} \mathrm{O}_{0.18}$.}

The stoichiometric air to fuel ratio must be calculated for the complete combustion with air. Complete combustion equations for wood $\mathrm{CH}_{1.33} \mathrm{O}_{0.83}$,

$$
\begin{gathered}
\mathrm{C}+\mathrm{O}_{2} \rightarrow \mathrm{CO}_{2} \\
0.66 \mathrm{H}_{2}+0.33 \mathrm{O}_{2} \rightarrow 0.66 \mathrm{H}_{2} \mathrm{O}
\end{gathered}
$$

As it can be seen in the combustion equations, 1.33 moles of $\mathrm{O}_{2}\left(\chi_{\mathrm{O}_{2}}\right)$ are needed to completely oxidize one mole of $\mathrm{CH}_{1.33} \mathrm{O}_{0.83}$ when the oxygen in the molecule was not considered. Therefore, when considering the oxygen amount in the wood molecule, the net amount of $\mathrm{O}_{2}$ needed is 0.92 moles. Therefore, the complete combustion equation for wood with air can be written as:

$$
\mathrm{CH}_{1.33} \mathrm{O}_{0.83}+4.38\left(0.21 \mathrm{O}_{2}+0.78 \mathrm{~N}_{2}\right) \rightarrow \mathrm{CO}_{2}+0.66 \mathrm{H}_{2} \mathrm{O}+3.15 \mathrm{~N}_{2}
$$


Stoichiometric molar and mass ratios of air to fuel ratio can be calculated using equations 17 and 18. Hence the molar stoichiometric air to fuel ratio can be calculated as 4.38. And, stoichiometric air to fuel mass ratio is 4.7 ,

$$
\begin{aligned}
& \left(\frac{\chi_{\text {air }}}{\chi_{f}}\right)_{\text {st }} \\
& \left(\frac{m_{\text {air }}}{m_{f}}\right)_{s t}
\end{aligned}
$$

where $m$ is the mass and suffixes $f$ and $s t$ stand for fuel and stoichiometric, respectively. The equivalence ratio $(\phi)$ is the ratio of the actual air to fuel ratio to the stoichiometric air to fuel ratio

$$
\phi=\frac{\left(m_{\text {air }} / m_{f}\right)_{s t}}{m_{\text {air }} / m_{f}}=\frac{\left(\chi_{\text {air }} / \chi_{f}\right)_{s t}}{\chi_{\text {air }} / \chi_{f}}
$$

where $\chi$ is the number of moles.

For the gasification reaction with the suggested $\phi=4$, the required moles of air, $\chi_{\text {air }}$ is 1.1 moles. The molar mass of the wood molecule $M W_{\mathrm{CH}_{1.33} \mathrm{O}_{0.83}}$ is $26.6 \mathrm{~g} / \mathrm{mol}$ and the molar mass of the air $M W_{\text {air }}$ is $29 \mathrm{~g} / \mathrm{mol}$. Therefore 26.6 grams of wood requires $32 \mathrm{~g}$ of air for gasification reaction with the equivalence ratio of 4 . Hence, $1000 \mathrm{~g}$ of wood requires $1203 \mathrm{~g}$ of air. And the mass of the total product gas can be calculated as $2203 \mathrm{~g}$ per $1000 \mathrm{~g}$ of wood. Assuming total conversion carbon and hydrogen in wood to $\mathrm{CO}$ and $\mathrm{H}_{2}$, respectively, calculations (not shown here) indicated a maximum theoretical $\mathrm{H}_{2} / \mathrm{CO}$ volumetric ratio of 0.66 for an equivalence ratio of 4, with some elemental carbon remaining in the char and tar residues.

Combustion equations for coal $\mathrm{CH}_{0.71} \mathrm{O}_{0.18}$ can be written as:

$$
\begin{gathered}
\mathrm{C}+\mathrm{O}_{2} \rightarrow \mathrm{CO}_{2} \\
0.35 \mathrm{H}_{2}+0.17 \mathrm{O}_{2} \rightarrow 0.35 \mathrm{H}_{2} \mathrm{O}
\end{gathered}
$$


1.17 moles of $\mathrm{O}_{2}$ are required for the complete coal combustion. By accounting for the oxygen amount in the coal molecule, the net amount of $\mathrm{O}_{2}$ is found as 1.08 moles. The complete combustion for coal with air can be written as,

$$
\mathrm{CH}_{0.71} \mathrm{O}_{0.18}+5.14\left(0.21 \mathrm{O}_{2}+0.78 \mathrm{~N}_{2}\right) \rightarrow \mathrm{CO}_{2}+0.35 \mathrm{H}_{2} \mathrm{O}+4 \mathrm{~N}_{2}
$$

The molar stoichiometric air to fuel ratio is 5.14 and the stoichiometric air to fuel mass ratio is 9.55:

$$
\begin{aligned}
& \left(\frac{\chi_{\text {air }}}{\chi_{f}}\right)_{s t}=5.14 \\
& \left(\frac{m_{\text {air }}}{m_{f}}\right)_{s t}=9.55
\end{aligned}
$$

The molar mass of the coal $M W_{\text {coal }}$ is $15.6 \mathrm{~g} / \mathrm{mol}$ and the molar mass of the air $M W_{\text {air }}$ is $29 \mathrm{~g} / \mathrm{mol}$. For the gasification (partial oxidation) reaction, with the equivalence ratio of 4, 15.6 grams of coal requires $37.7 \mathrm{~g}$ of air. Thus, $1000 \mathrm{~g}$ of coal requires $2417 \mathrm{~g}$ of air. Hence, total product gas is 3417 g. Assuming total conversion of carbon and hydrogen in coal to $\mathrm{CO}$ and $\mathrm{H}_{2}$, respectively, calculations (not shown here) indicated a maximum theoretical $\mathrm{H}_{2} / \mathrm{CO}$ volumetric ratio of 0.5 for an equivalence ratio of 4 , with some elemental carbon remaining in the char and tar residues. It should be noted that the addition of steam to the gasifying agent will change the $\mathrm{H}_{2} / \mathrm{CO}$ volumetric ratio (e.g., promote $\mathrm{H}_{2}$ and $\mathrm{CH}_{4}$ production).

The major 1-step reactions producing syngas during the gasification process are [134]:

\section{Water-gas shift reaction}

$\mathrm{CO}+\mathrm{H}_{2} \mathrm{O} \rightleftharpoons \mathrm{CO}_{2}+\mathrm{H}_{2} \quad \Delta \mathrm{H}^{\circ} 298 \mathrm{~K}=-41 \mathrm{~kJ} \mathrm{~mol}^{-1}$

\section{Steam methane reforming reaction}
$\mathrm{CH}_{4}+\mathrm{H}_{2} \mathrm{O} \rightleftharpoons \mathrm{CO}+3 \mathrm{H}_{2}$
$\Delta \mathrm{H}^{\circ} 298 \mathrm{~K}=206 \mathrm{~kJ} \mathrm{~mol}^{-1}$ 


\section{Boudouard reaction}

$\mathrm{C}+\mathrm{CO}_{2} \rightleftharpoons 2 \mathrm{CO} \quad \Delta \mathrm{H}^{\circ} 298 \mathrm{~K}=172 \mathrm{~kJ} \mathrm{~mol}^{-1}$

Methanation reaction

$\mathrm{C}+2 \mathrm{H}_{2} \rightleftharpoons \mathrm{CH}_{4} \quad \Delta \mathrm{H}^{\circ} 298 \mathrm{~K}=-75 \mathrm{~kJ} \mathrm{~mol}^{-1}$

Water-gas reaction

$\mathrm{C}+\mathrm{H}_{2} \mathrm{O} \rightleftharpoons \mathrm{CO}+\mathrm{H}_{2} \quad \Delta \mathrm{H}^{\circ} 298 \mathrm{~K}=131 \mathrm{~kJ} \mathrm{~mol}^{-1}$

where $\Delta \mathrm{H}^{\circ} 298 \mathrm{~K}$ is the enthalpy increase at $298 \mathrm{~K}$.

For the estimated volumetric product gas composition of $\mathrm{H}_{2}$ of $20 \%, \mathrm{CO}$ of $20 \%$, and $\mathrm{N}_{2}$ of $60 \%$, the volume of the syngas per kg of solid feedstock type can be calculated using the ideal gas law,

$$
P V=n R T
$$

where $P$ is the pressure (Pa), $V$ is the volume $\left(\mathrm{m}^{3}\right), n$ is the mole number, $R$ is the proportionality constant (8.314), and $\mathrm{T}$ is the temperature $(\mathrm{K})$.

The estimated product gas mass is $22.8 \mathrm{~g} / \mathrm{mole}$. The syngas produced with wood has a total mass of $2203 \mathrm{~g}$ per $\mathrm{kg}$ of wood. The total number of the syngas moles $\chi_{\text {syngas }}$ can be calculated by using the formula,

$$
\chi_{\text {syngas }}=\frac{m_{\text {syngas }}}{M W_{\text {syngas }}}
$$

Hence, $\chi_{\text {syngas }}$ is 96.6 , and $V_{\text {syngas }}$ can be calculated as $2.32 \mathrm{~m}^{3}$ per $\mathrm{kg}$ of wood with the given wood composition and estimated product gas composition. And the volume of the syngas produced by the coal with air gasification can be calculated as $3.6 \mathrm{~m}^{3}$. It can be seen that coal produced $55 \%$ more syngas than wood with the same feedstock mass and estimated product gas composition. Per $\mathrm{kg}$ of wood $2.32 \mathrm{~m}^{3}$, and per $\mathrm{kg}$ of coal $3.6 \mathrm{~m}^{3}$ syngas can be produced. In addition, ash is an 
important compound in the feedstock that must be considered. The ash weight percentage, \%wt, for both wood and coal is showed in Table 6 . Wood has a negligible amount of ash, $0.3 \% \mathrm{wt} / \mathrm{wt}$. However, coal has a significant amount of ash with $7.89 \% \mathrm{wt} . / \mathrm{wt}$. After considering the ash amount in the coal, the amount of coal needed to produce $3.6 \mathrm{~m}^{3}$ increases to $\sim 1080 \mathrm{~g}$. The low heating value (LHV) of the estimated syngas is $4.66 \mathrm{MJ} \mathrm{Nm}^{-3}$. Table 7 presents the comparison of the LHVs of the estimated product gas with the pure gases of $\mathrm{CO}, \mathrm{CH}_{4}$, and $\mathrm{H}_{2}$ per $\mathrm{m}^{3}$.

Table 7. LHV comparison for the estimated product gas [135]

\begin{tabular}{|ccccc|}
\hline & $(\mathrm{CO})$ & $\left(\mathrm{CH}_{4}\right)$ & $\left(\mathrm{H}_{2}\right)$ & Syngas \\
\hline $\begin{array}{c}\mathrm{LHV} \\
\left(\mathrm{MJNm}^{-3}\right)\end{array}$ & 12.6 & 35.8 & 10.7 & 4.66 \\
\hline
\end{tabular}

As stated in the engine considerations, $25 \mathrm{kWh}(270 \mathrm{MJ})$ is required for the Proteus engine baseline operation at 900 RPM. Consequently, calculations based on data presented in Table 8 show that $\sim 58 \mathrm{Nm}^{3}$ syngas is needed per hour of engine operation. The total masses of the feedstocks are required to provide $58 \mathrm{Nm}^{3}$ product gas can be sourced from $25 \mathrm{~kg}$ of wood or 17.5 $\mathrm{kg}$ of coal with the rounded calculations.

Table 8. Summary of the required feedstock rate calculations for wood and coal

\begin{tabular}{|c|c|c|}
\hline Estimated Parameters & Wood, per $1000 \mathrm{~g}$ & Coal, per $1000 \mathrm{~g}$ \\
\hline Equivalence ratio, $\phi$ & 4 & 0.25 \\
\hline Required air mass (g) & 1203 & 2238 \\
\hline Syngas production $\left(\mathrm{m}^{3}\right)$ & 2.32 & 3.33 \\
\hline $\begin{array}{l}\text { Required feedstock rate per hour } \\
\text { for } 58 \mathrm{~m}^{3} \text { product gas }(\mathrm{kg} / \mathrm{h})\end{array}$ & 25 & 17.5 \\
\hline
\end{tabular}


Syngas composition can vary significantly due to feedstock composition, operational parameters, and other parameters discussed in this study, such as particle characteristics, bed aspect ratio, feeding location, and BFBG design. A typical syngas composition presented by NETL [136] with the following gas composition, $\mathrm{CO} 30-60 \%, \mathrm{H}_{2} 25-30 \%, \mathrm{CH}_{4} 0-5 \%$, and $\mathrm{CO}_{2} 5-15 \%$. The analysis showed that the syngas obtained by wood and coal contained around $50 \% \mathrm{~N}_{2}$. However, the $\mathrm{CO}$ to $\mathrm{H}_{2}$ ratio is expected to vary from 1 to 2 . The effect of $\mathrm{H}_{2} / \mathrm{CO}$ ratio on the LHV of a syngas containing $5 \mathrm{vol} \% \mathrm{CH}_{4}$ and $10 \mathrm{vol} \% \mathrm{CO}_{2}$, in $\mathrm{MJ}$ per normal $\mathrm{m}^{3}$, is illustrated in Figure 10.
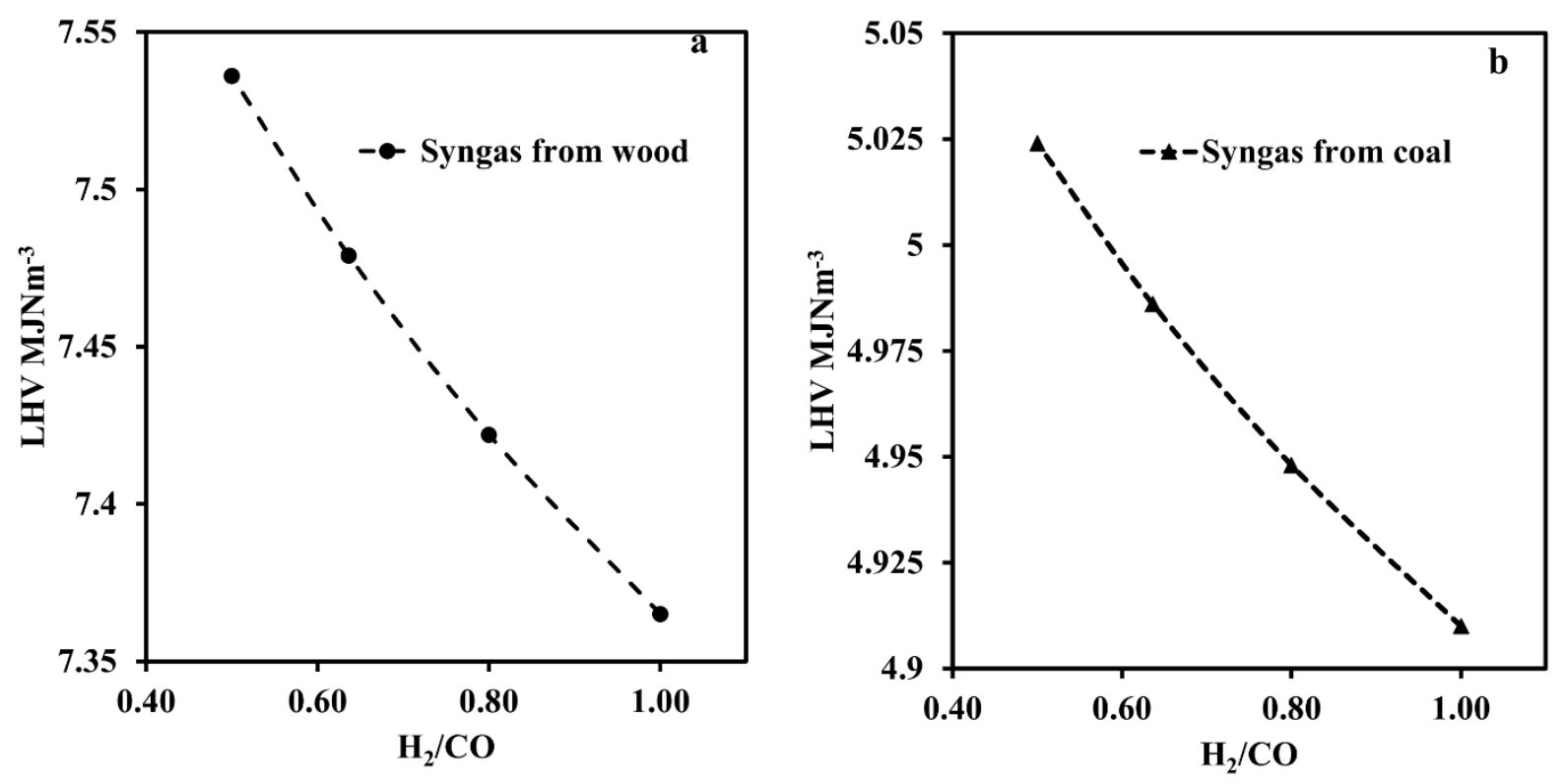

Figure 10. Effect of $\mathrm{H}_{2} / \mathrm{CO}$ ratio on syngas LHV for a) wood and b) coal.

\subsubsection{BFBG sizing}

BFBG dimensions and process conditions were determined based on the feedstock rate needed to produce the syngas for the IC engine. Firstly, the reactor bed must be large enough to contain all the inert and feedstock material for adequate mixing and high heat transfer rates. Hence, the 
reactor diameter and length to diameter ratio $(L / D)$ were the primary parameters use to determine the reactor size. A $L / D$ ratio of ten was chosen to also allow for deep bed applications. Table 9 presents the selected parameters used in dimensioning the BFBG, for two different reactor diameters of $0.15 \mathrm{~m}$ and $0.032 \mathrm{~m}$.

Table 9. Proposed reactor bed parameters

\begin{tabular}{|lll|}
\hline $\mathrm{ID}(\mathrm{m})$ & 0.15 & 0.032 \\
\hline Length $(L)(\mathrm{m})$ & 1.5 & 0.32 \\
Length to diameter ratio $(L / D)$ & 10 & 10 \\
Cross-section Area $(A)\left(\mathrm{m}^{2}\right)$ & 0.0177 & 0.011 \\
Volume of the reactor bed $\left(\mathrm{m}^{3}\right)$ & 0.0265 & 0.0004 \\
Inert material & Sand & Sand \\
Sand bulk density $\left(\mathrm{kg} / \mathrm{m}^{3}\right)$ & 1430 & 1430 \\
Sand skeletal density $\left(\mathrm{kg} / \mathrm{m}^{3}\right)$ & 2640 & 2640 \\
Sand mean diameter $(\mu \mathrm{m})$ & 323 & 323 \\
Mean sphericity of the sand & 0.86 & 0.86 \\
Height of the static bed $\left(H_{p}\right)(\mathrm{m})$ & 0.6 & 0.13 \\
Volume of the sand $\left(\mathrm{m}^{3}\right)$ & 0.0106 & 0.0001 \\
Weight of sand $(\mathrm{kg})$ & 15 & 0.21 \\
Bed voidage & 0.45 & 0.45 \\
\hline
\end{tabular}


Table 10. Proposed BFBG initial operational parameters

\begin{tabular}{|llc|}
\hline ID $(\mathrm{m})$ & 0.15 & 0.032 \\
\hline Feedstock type & \multicolumn{2}{c|}{ coal or wood } \\
Gasifying agent & \multicolumn{2}{c|}{ air } \\
Product gas (syngas) rate $\left(\mathrm{m}^{3} / \mathrm{h}\right)$ & 58 & 1.67 \\
LHV $\left(\mathrm{MJNm}^{-3}\right)$ & 4.66 & 4.66 \\
Wood rate per hour $(\mathrm{kg} / \mathrm{h})$ & 25 & 0.72 \\
Coal rate per hour $(\mathrm{kg} / \mathrm{h})$ & 17.5 & 0.72 \\
Air flow rate, coal $(\mathrm{kg} / \mathrm{h})$ & 38.5 & 1.6 \\
Air flow rate, wood $(\mathrm{kg} / \mathrm{h})$ & 30 & 0.9 \\
\hline
\end{tabular}

The bigger $\mathrm{BFBG}$ diameter $(\mathrm{ID}=15 \mathrm{~cm}$ ) was designed to produce enough syngas for the continuous supply SI engine operation. However, practical experimental requirements (particularly the furnace size needed to create the required heat flux) suggested using a smaller BFBG size. Hence, a smaller diameter $(\mathrm{ID}=3.81 \mathrm{~cm}$ ) BFBG was designed and developed for the current investigation. Table 10 shows the adjusted operational parameters to control the BFBG process.

As stated in the introduction section, $U_{m f}$ is one of the most important hydrodynamical parameters to identify the minimum fluidization condition and predict the later stages of fluidization. In addition to the $U_{m f}$, the terminal velocity, $U_{t}$, is another critical parameter that helps to predict the fluidizing gas velocity that results in particle elutriation out of the reactor bed. Table 
11 summarizes the theoretical predictions of the bed voidage (Eq. 25), $U_{m f}$ (Eq. 26), $\eta$ (Eq. 27), and $U_{t}$ (Eq. 28).

$$
\begin{gathered}
\varepsilon_{m f}=\left(\frac{0.071}{\phi}\right)^{\frac{1}{3}} \\
U_{m f}=\frac{\left(\phi d_{p}\right)^{2}}{150 \mu}\left[g\left(\rho_{p}-\rho_{f}\right)\right] \frac{\varepsilon_{m f}^{3}}{1-\varepsilon_{m f}} \\
\eta=\left[g\left(\rho_{p}-\rho_{f}\right)\right] \\
U_{t}=\left(\frac{1.78 \times 10^{-2} \eta^{2}}{\rho_{g} \mu_{f}}\right)^{1 / 3} d_{p}, \quad 0.4<R e<500
\end{gathered}
$$

Table 11. Theoretical predictions of $U_{m f}, U_{t}, \varepsilon_{m f}$ based on Kunii-Levenspiel Model

\begin{tabular}{|ccc|}
\hline $\mathrm{ID}(\mathrm{m})$ & 0.15 & 0.0318 \\
\hline$\varepsilon_{m f}$ & 0.44 & 0.44 \\
$U_{m f}(\mathrm{~m} / \mathrm{s})$ & 0.10 & 0.10 \\
$U_{t}(\mathrm{~m} / \mathrm{s})$ & 2.6 & 2.6 \\
\hline
\end{tabular}




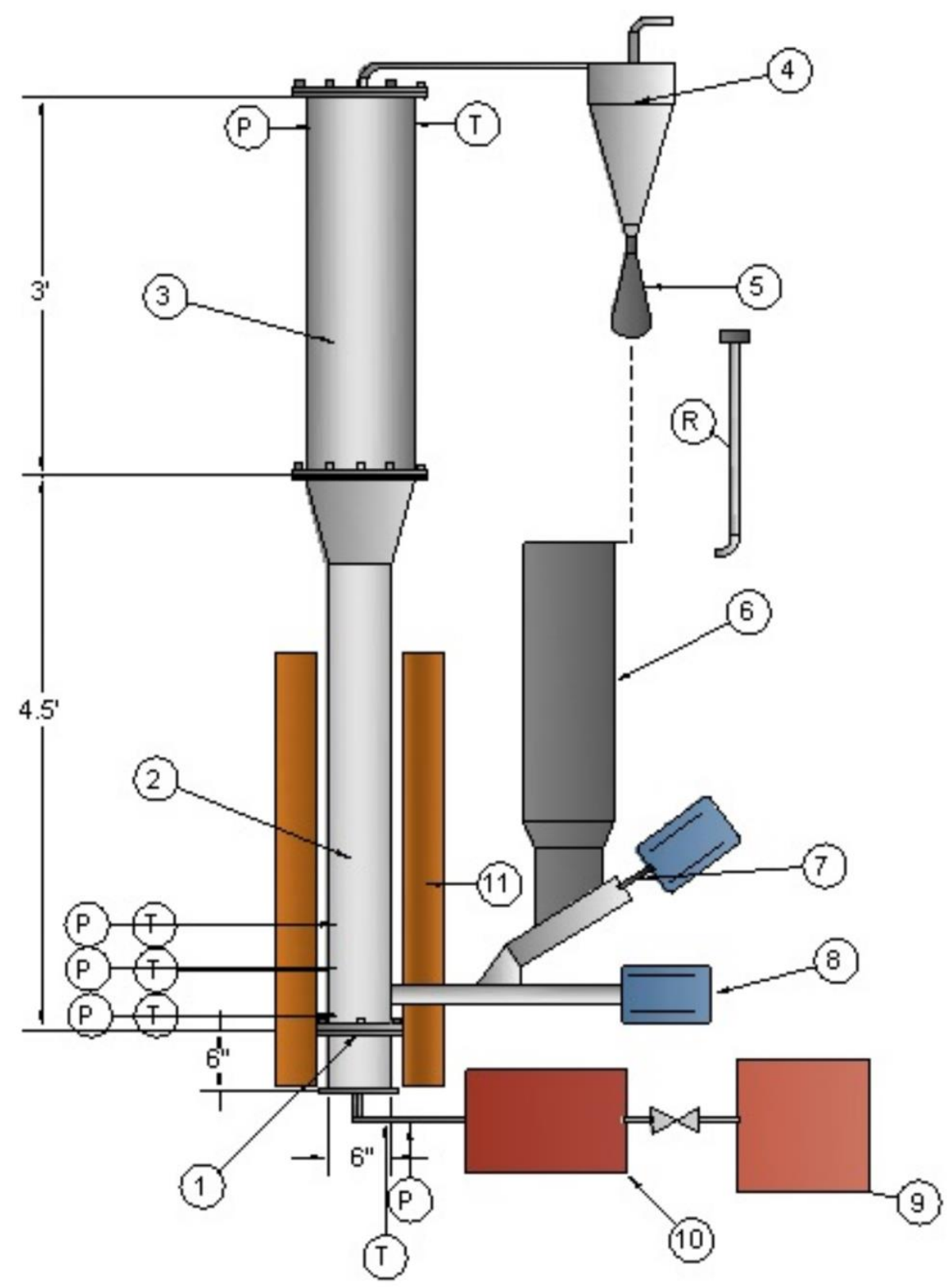

Figure 11. Schematic of the 15-cm (or 6-inch) ID BFBG: 1) distributor plate, 2) reactor bed, 3) freeboard, 4) cyclone, 5) ash deposit, 6) hopper, 7) dozer screw, 8) feeder screw, 9) boiler, 10) superheater, 11) bed heaters, $\mathrm{P}$ - pressure sensor, $\mathrm{T}$ - temperature sensor, $\mathrm{R}$ - ash recycling pipe.

Figure 11 shows the schematic of the 15-cm ID BFBG. This design should be capable of running $25 \mathrm{~kg} / \mathrm{h}$ of wood feedstock with an estimated $58 \mathrm{~m}^{3} / \mathrm{h}$ syngas production, large enough to 
operate an IC engine at high load. Side feeding close to the distributor plate with a deep bed application where $H_{p} / D_{b} \geq 4$ was considered for high efficiency. The cyclone with the attached recycling tube will allow flyover particles to return to the reactor bed. The boiler and super heater will also allow steam generation up to necessary temperatures for higher quality syngas with higher heating values than the gasification process with air as a gasifying agent.

However, the project designed and built the smaller 3.81-cm ID BFBG. In accordance with the experimental requirements, sensors and measurement tools for robust data acquisition at elevated temperatures were considered. The detailed information about the smaller scale BFBG is presented in Section 2.2.2 BFBG Test Stand.

\subsubsection{BFBG Test Stand}

Figure 12 shows the test bench BFBG experimental setup. It consists of a high-temperature furnace, the BFBG reactor (see Figure 13 for details), the double-screw feeder for feedstock delivery, and the micro gas chromatograph (Inficon Fusion) for real-time product composition measurements. The top-loading furnace (Lucifer Furnaces Inc., Model P3AC-27-642-X) has an internal diameter of 6 inches and can operate up to $1500^{\circ} \mathrm{C}$. The BFBG temperature was measured with a K-type thermocouple (OmegaTM) placed just above the bed material. The furnace controller can adjust the set point temperature and ramping rate of three different furnace sections (bottom, middle, and top). The maximum temperature reached at the bottom, middle, and top furnace sections during these experiments were $810^{\circ} \mathrm{C}, 820^{\circ} \mathrm{C}$, and $820^{\circ} \mathrm{C}$, respectively. The BFBG reactor was made of Inconel, an oxidative-corrosion resistant metal alloy. The BFBG, which had similar dimensions to the cold flow rig discussed above, consists of a plenum below the distributor plate, the distributor plate section, the reactor bed, the transition cone, and the disengagement zone 
(freeboard) that also contains the connections for the feeding line, product gas, and various temperature and pressure sensors.

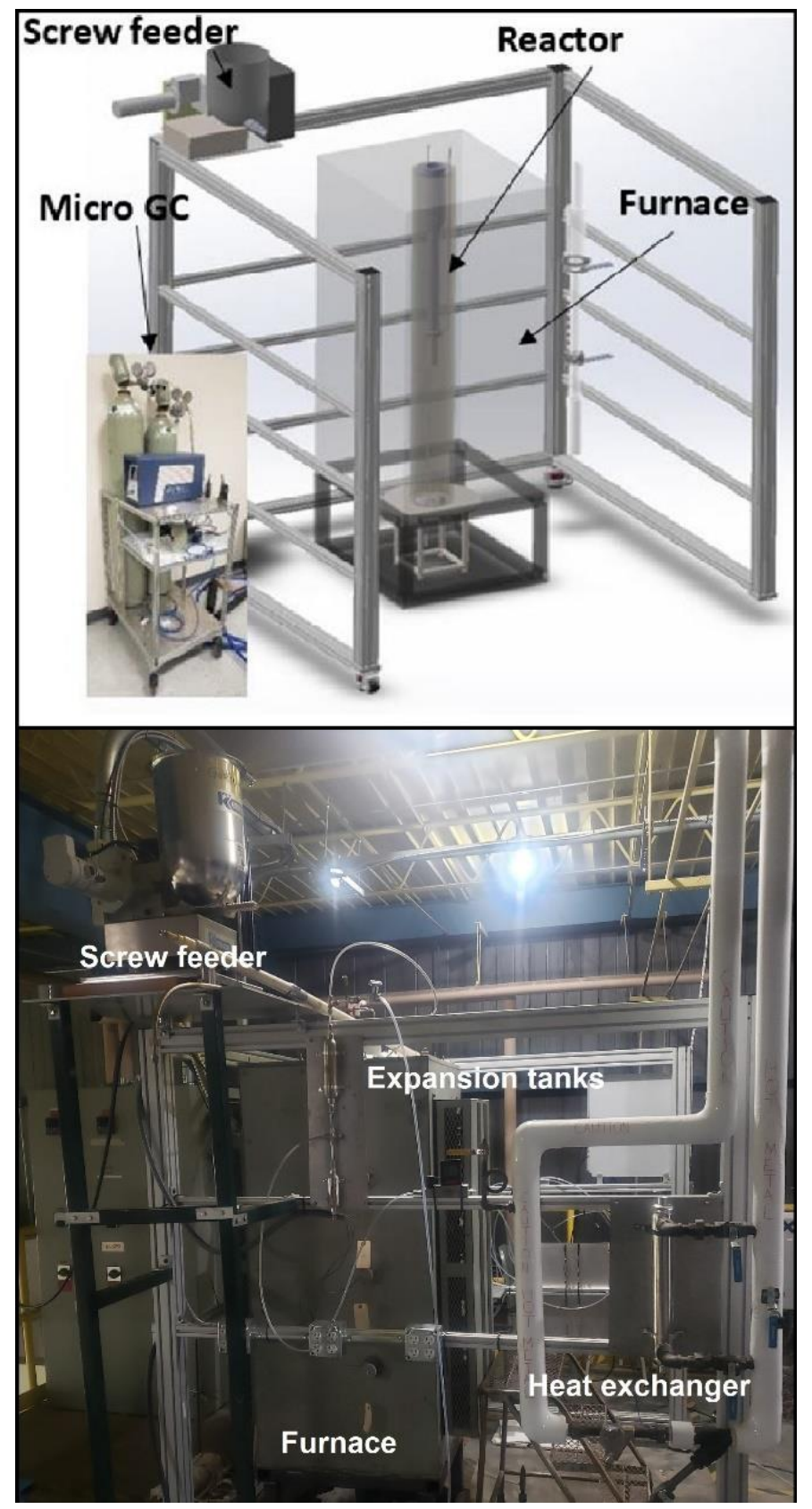

Figure 12. Schematics (top) and details (bottom) of the bench-scale BFBG test stand 
To avoid substantial pressure drop across the distributor plate associated with the decrease in the fluidizing fluid density at higher temperature, the hot flow experiments used a distributor plate with larger pores $(40 \mu \mathrm{m})$ than the cold flow experiments $(10 \mu \mathrm{m})$. Pressure tabs were added at the same positions as those in the cold- flow rig to help compare with the cold-flow data, but, as seen in Fig. Figure 13, placed at different locations on the reactor circumference to allow for the stainless steel pressure tubes to exit the furnace and connect with the outside pressure transmitters. Several 0.5- $\mu \mathrm{m}$ filters (Swagelok, Model SS-4F-05, SS 316) were placed in the product gas and pressure transducer lines to prevent particle entrainment inside the sensitive instruments and sensors used for measurements.

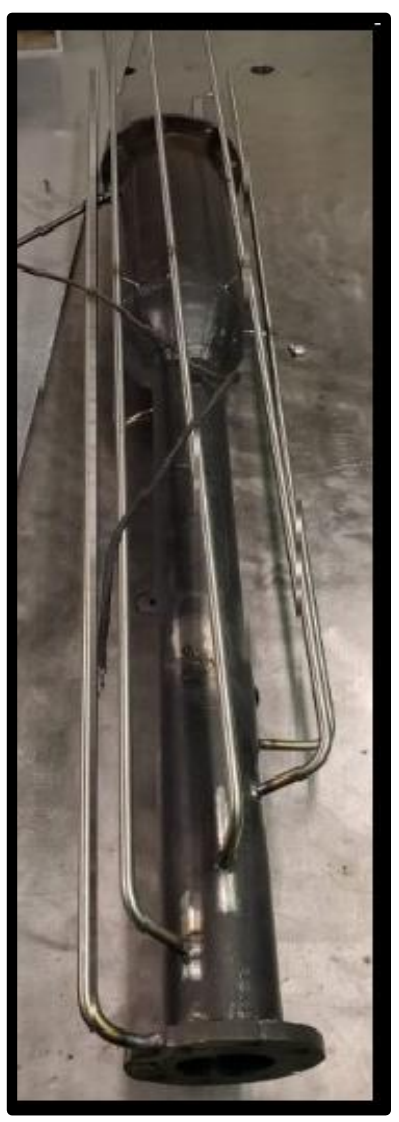

Figure 13. BFBG reactor. The smaller diameter tubes were used to measure the pressure at various bed heights. 
Table 12 shows the experimental conditions. Pressure measurements were taken for a minimum of 30 seconds at each flowrate after waiting at least 30 seconds after changing the fluidizing fluid flow rate to stabilize the pressure drop. Measurements were repeated three times, and the average values are shown in the Results section. BFBG data is from an ongoing multiplehours experiment.

Table 12. Experimental conditions for hydrodynamical studies under temperature effect

\begin{tabular}{|lc|}
\hline \multicolumn{2}{|c|}{ 3.81-cm BFBG } \\
\hline Material & Silica Sand \\
Temperature $\left({ }^{\circ} \mathrm{C}\right)$ & $200-800$ \\
Fluidizing gas & Air \\
Material weight $(\mathrm{g})$ & 200,300 \\
Flowrate $(\mathrm{SLM})$ & $0-14$ \\
\hline
\end{tabular}

\subsection{Design and Development of the Various Gasifier Test Stand Components}

This section describes the design and development of the various BFBG test stand components: the reactor, the heating system, the cooling system, the feedstock feeding system, the component sealing and insulation, and the product gas cleaning.

\subsubsection{BFBG reactor design}

The reactor is the most important BFBG component. Hence, the material selection and dimensioning were considered in detail. The reactor material must withstand temperatures up to 
$1000^{\circ} \mathrm{C}$ and a highly-corrosive environment due to high oxygen existence during the gasification process. Inconel 600 (nickel plus cobalt $72 \%$ wt.), used in various applications at elevated temperature such as turbine seals and exhaust liners, was preferred because of its high resistance to extreme temperatures and corrosion. Besides, Inconel is easy to machine and has a longer lifetime than stainless steel. Table 13 presents the selected material properties of Inconel 600 at $900^{\circ} \mathrm{C}$.

Table 13. Selected Inconel 600 material properties at $900^{\circ} \mathrm{C}$

\begin{tabular}{|cc|}
\hline $\begin{array}{c}\text { Thermal expansion } \\
\text { coefficient, } \alpha\left(\mu \mathrm{m} / \mathrm{m} \cdot{ }^{\circ} \mathrm{C}\right)\end{array}$ & 16.4 \\
Rupture life (hours) & $>10^{4}$ \\
Melting range $\left({ }^{\circ} \mathrm{C}\right)$ & $1354-1413$ \\
\hline
\end{tabular}

The selection of the reactor bed(column) length to diameter ratio, $L / D=10$ was discussed in the section describing the BFBG dimensioning. Also, the dimensions of the other components of the reactor (freeboard section, transition cone, and the plenum, see Figure 4) must be evaluated.

The plenum is the preliminary reservoir for the fluidizing agent before entering the reactor bed through the distributor plate. Fluidizing gas should be distributed uniformly below the distributor plate to be dissipated homogenously above the distributor plate surface. However, the dynamics of the flow of the fluidizing gas below the distributor plate is complicated. Hence, the gas input location and orifice diameter must be considered to provide the gas distribution uniform below the distributor plate. Fluidizing gas can enter the plenum either horizontally from the side or vertically from the bottom. For horizontal flow entry to the plenum, Perry [137] stated that gas expands up 
to 100 times the orifice diameter. Based on his statement, Ajmal [56] derived an equation from calculating the required vertical distance from the distributor plate surface to provide uniform gas distribution for both horizontal and vertical entry of the gas flow. Hence, for horizontal gas entry,

$$
H_{o}=0.2 \times d_{d p}+0.5 \times d_{o} \text { For } d_{o}>\frac{d_{d p}}{100}
$$

and for the vertical gas entry,

$$
H_{o}=18 \times d_{o} \text { For } d_{o}<\frac{d_{d p}}{100}
$$

where $H_{o}$ is the orifice distance below the distributor plate, $d_{d p}$ is the diameter of the distributor plate, and $d_{o}$ is the orifice diameter.

Based on the equations above, $H_{o}$ was calculated as around $1 \mathrm{~cm}$ for an orifice diameter $d_{o}=3.81 \mathrm{~mm}$ and $d_{d p}=38.1 \mathrm{~mm}$. In both the cold flow rig and BFBG reactor, the orifice was placed $12 \mathrm{~cm}$ below the distributor plate for the horizontal gas entry to assure the uniform distribution of the gas inside the plenum.

Another essential part of the reactor is the freeboard section. The length of the freeboard section is important for both phases inside the reactor. It should be long enough to provide enough time to reduce the exiting gas and solid velocity exiting the reactor bed section. However, it should not be longer than the reactor bed, where the reaction takes place. In this study freeboard length was chosen as $25 \mathrm{~cm}$ to keep the reactor size compact enough to sustain workability inside the furnace. The connection between the freeboard and the reactor bed was made by the transition cone. The $2.5 \mathrm{~cm}$ long transition cone was 3D printed, with a smooth curve shape to ease the particle flow back to the reactor bed. 


\subsubsection{BFBG heating system}

The gasification process requires a constant and elevated temperature (above $700{ }^{\circ} \mathrm{C}$ ) inside the reactor. The research team sourced a reliable, robust, and easy-to-control 0.15-m-diameter furnace designed to provide the heating rates/temperature required for successful gasification (see Figure 14).
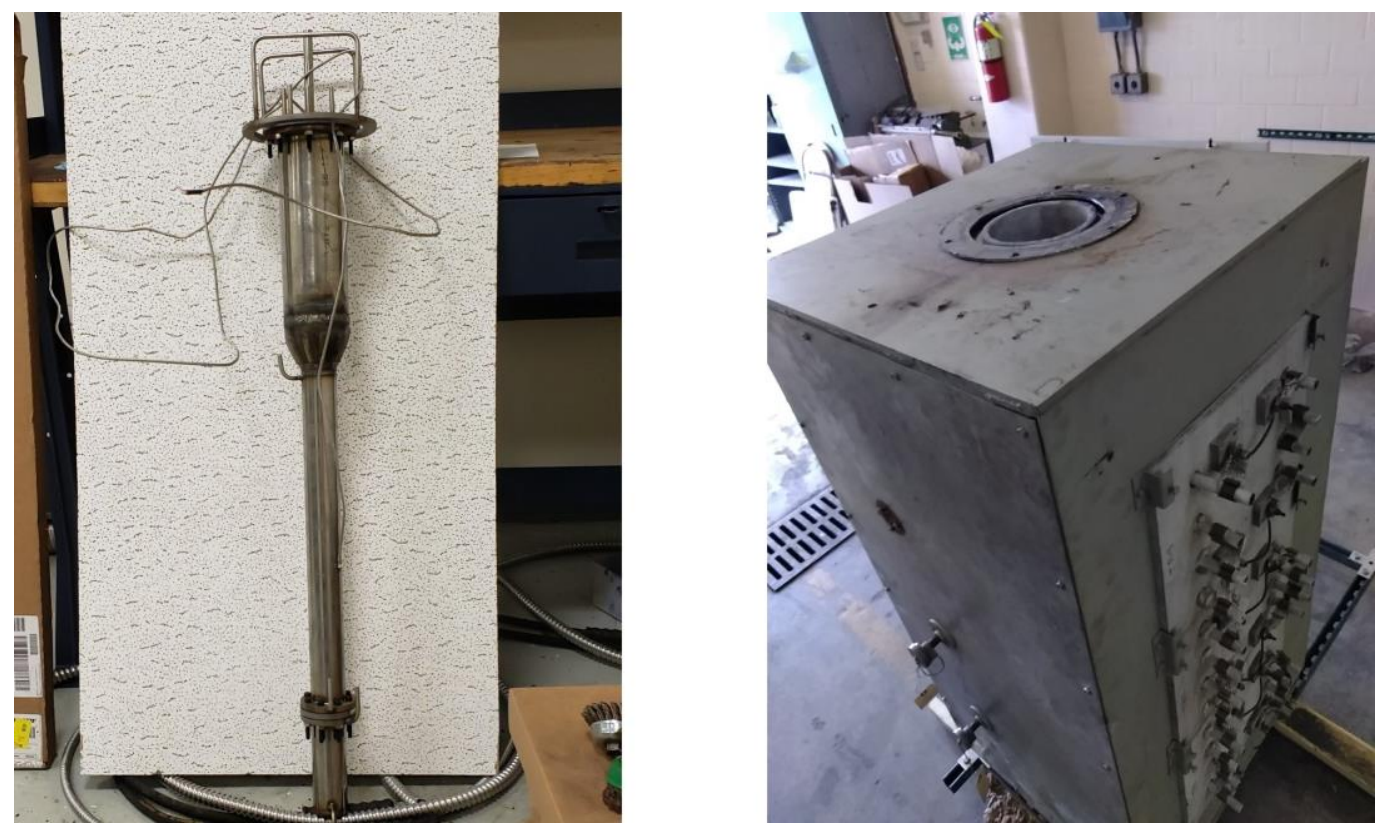

Figure 14. Bubbling fluidized-bed reactor (left) and high-temperature furnace (right)

In addition, to ensure that any heat loss from the furnace will not affect the control and data acquisition equipment installed on the gasifier test setup, the furnace was installed $\sim 6 \mathrm{ft}$ below a building exhaust fan, which, which, in addition to providing the cooling of the area around the furnace, also ensured the safety in case of gas leaks from the gasification process. The furnace uses heating elements made of Silicon Carbide, which can be operated up to furnace temperatures of $1600^{\circ} \mathrm{C}$. $\mathrm{R}$ type thermocouples are used in the furnace to control the temperature. The maximum 
gross heat can be supplied by the furnace is $24 \mathrm{kWh}$ at $61 \mathrm{amps}$. However, the maximum suggested operational amperage range is from 30 to 35 amps for safety purposes. And the corresponding gross heat production in this amperage range is around $12 \mathrm{kWh}$. Table 14 presents the furnace specifications.

Table 14. Lucifer Furnaces, MODEL P3AC-27-642-X specifications

\begin{tabular}{|ll|}
\hline Dimensions (m) & $1.45 \times 0.65 \times 0.75$ \\
Chamber ID (m) & 0.15 \\
Refractory material & Fire bricks \\
Heating element type & Silicon Carbide \\
Voltage & $230 / 3 / 60$ \\
Power (kW) & $24 / 30$ \\
Amps & $62 / 75$ \\
Maximum temperature $\left({ }^{\circ} \mathrm{C}\right)$ & 1510 \\
\hline
\end{tabular}

\subsubsection{BFBG cooling system}

Efficient reactor cooling at the end of gasification is critical for durable, efficient, and economical operation, considering the elevated temperatures (up to $1000^{\circ} \mathrm{C}$ ) at which the reactor material was exposed. For example, the heating temperature reached at the top, at the middle, and the furnace's bottom sections during some of the experiments were up to $1000^{\circ} \mathrm{C}, 1000^{\circ} \mathrm{C}$, and $850^{\circ} \mathrm{C}$, respectively. To reduce the reactor cooling time from $\sim 1.5$ days needed to cool down the reactor inside the furnace by natural convection to temperatures that allowed safe access to it (i.e., 
below $80-90^{\circ} \mathrm{C}$ ), an additional cooling system was conceived to accelerate the reactor cooling after a gasification experiment. The cooling system consisted of an air compressor, a compressed air tank, a valve, and tubing for the air flow. The cooling air was supplied to the reactor using the same input on the plenum for the fluidizing gas. Later, the cooling rate was controlled with a valve attached to the airflow line. In addition to decreasing the reactor wall temperature after experiments, the product gas had to be cooled before its collection inside the plastic sample bags. This was done using longer lines exposed to the environment and the use of gas expansion tanks. The BFBG test stand with its subsystems is illustrated in Figure 15.

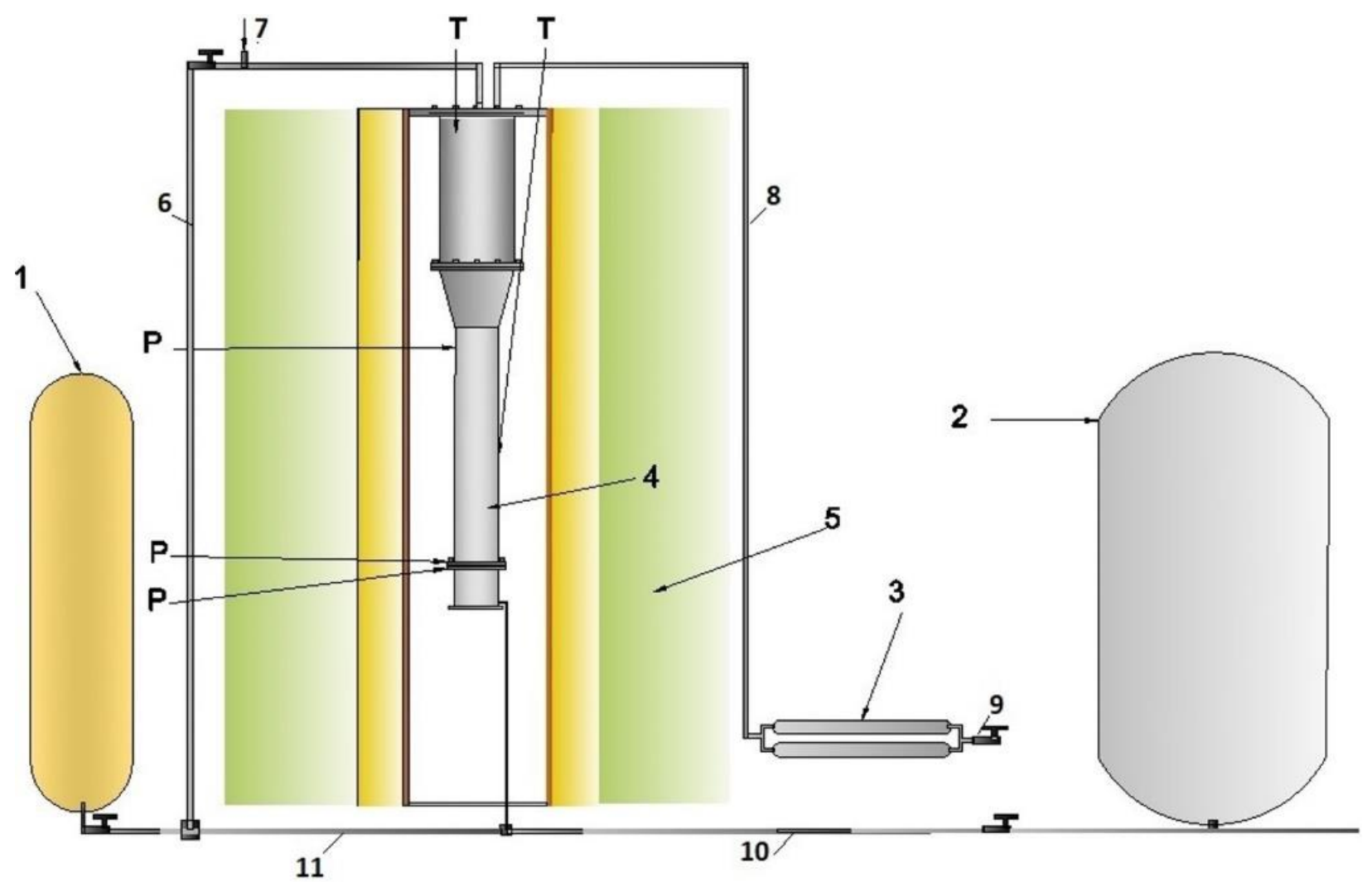

Figure 15. Bubbling fluidized bed test stand (P-pressure transducer, T-thermocouple, 1- nitrogen tank, 2-compressed air tank, 3-expansion tanks, 4-bed reactor, 5-furnace, 6-feeding system gas flow line, 7-inlet feedstock delivery, 8-product gas line, 9-gas sampling valve, 10-reactor cooling line, 11-reactor fluidization gas line) 


\subsubsection{BFBG feedstock feeding system}

The role of the feedstock feeding system is to continuously and robustly deliver the feedstock material at the rate and quality required for optimal gasification. The design of the furnace used in this study limited the feeding to the top-feeding method, which was the major limitation of this study. Specifically, ref. [41] shows that the top feeding (a.k.a. on-bed feeding) reduces the gasification efficiency due to the less-efficient mixing of the inert material and feedstock particles when compared to bottom (i.e., just above the distributor plate) and side-feeding (i.e., in-bed feeding). However, top feeding is still a challenging engineering problem, particularly for biomass particles that have irregular shape and size distributions in addition to their lightweight. This study employed a novel feeding system that used compressed nitrogen as a non-reactive carrier gas to deliver the biomass particles into the bed reactor. The feedstock feeding line was attached to a tube welded under the freeboard cap. Tests performed at ambient conditions showed that this method could deliver small amounts of the coal and dried biomass feedstock effectively on the bed surface, but not continuously. Later two high capacity screw feeders were added to the setup, one for coal and another for biomass. The screw feeders were automatically controlled by a central intelligent control unit, which could precisely adjust the feedstock's mass flow rate into the BFBG. The main problem experienced during the installation of these screw feeders was the screw's connection, which was responsible for delivering the feedstock to the feeding line. It was decided that 3D printing of the twin-screw housing, the adapter to the feeding tube, and the feeding tube connection in a monolithic fashion would minimize the dead volumes inside the setup and provide minimum resistance pneumatic transport of feedstock to the guiding tube to solve this problem. Later tests showed that even non-dried biomass particles could be delivered effectively to the reactor using 
the feeding system's latest improvements. The prototype feeding system assembly used to check the concept is shown in Figure 16.

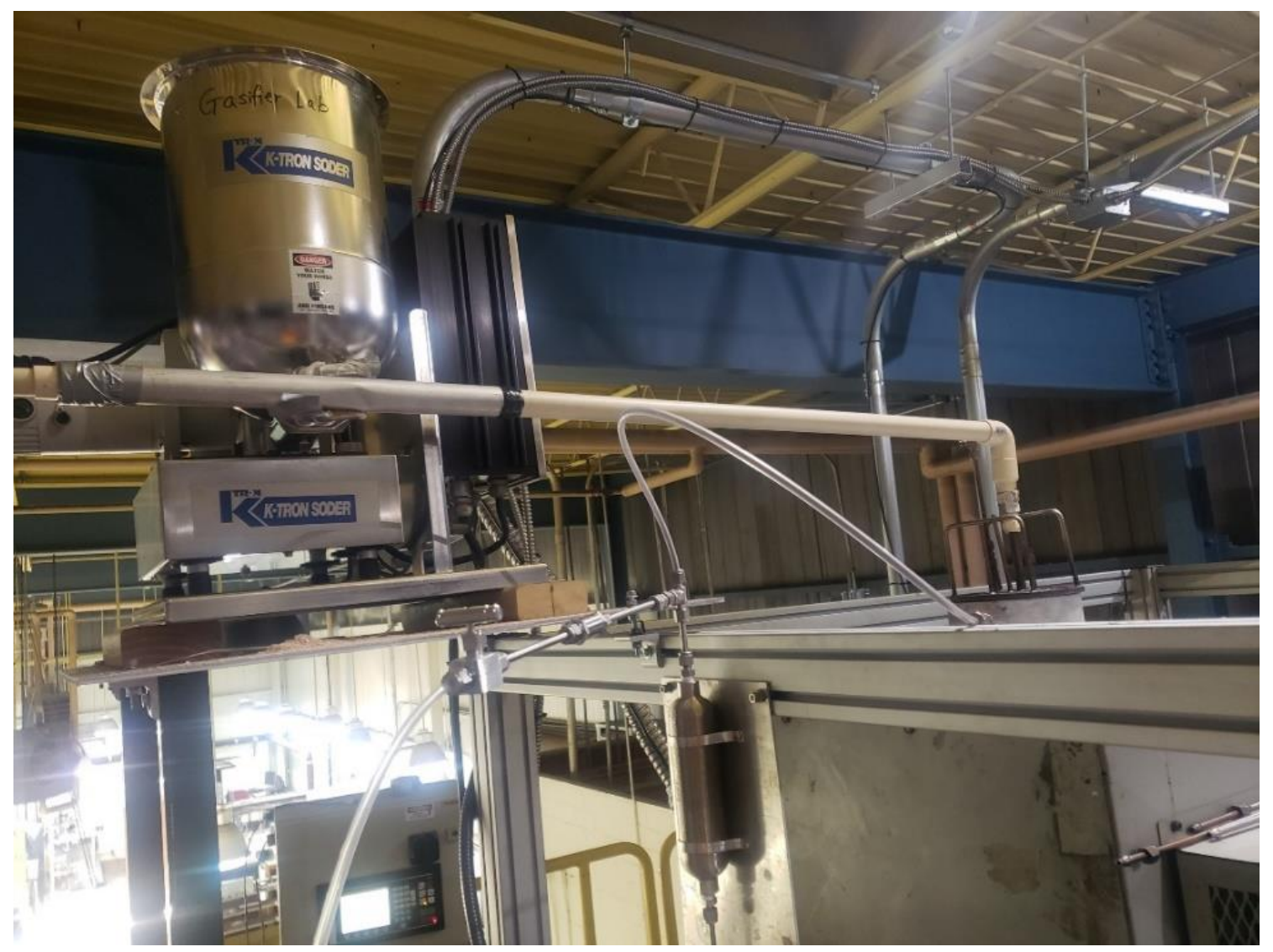

Figure 16. Prototype feeding system assembly.

\subsubsection{Sealing and insulation of main BFBG components}

Effective sealing is essential to prevent leakages from the various flanges used to connect the BFBG components. Various commercial gasket materials (graphite, vermiculite, thermiculite) were assessed to determine the most effective material capable of preventing leakage and resisting the extreme temperature inside the gasification setup. Despite being capable of withstanding temperatures of $\sim 1000^{\circ} \mathrm{C}$ and $\sim 1100^{\circ} \mathrm{C}$, thermiculite and vermiculite are brittle materials, making 
them hard to cut to the desired shape. The experiments also showed that thermiculite and vermiculite became even more brittle and turned into a powder-like compound when exposed for a long time to temperatures up to $800^{\circ} \mathrm{C}$. The result was that thermiculite and vermiculite did not provide effective contact surface sealing. Graphite was evaluated next. Scissors and a punch hole were good enough to prepare the graphite gaskets. The experiments conducted with graphite gaskets demonstrated that sealing could not be achieved due to the graphite's rapid oxidation at temperatures higher than $600^{\circ} \mathrm{C}$. The graphite oxidation was drastically reduced when a Kammprofile® metal ring was used between two graphite gaskets. The Kammprofile $®$-graphite combination successfully blocked the contact between the graphite and the hot gas, allowing the gasket to withstand the high operating temperatures without any recorded leakage or gasket material damage.

The insulation of the furnace and reactor from the ambient conditions is another requirement for efficient operation requirements. Fiberglass woven fabric was used to insulate the furnace cylinder that housed the reactor. Besides, the furnace cylinder's entrance and exit were completely insulated with fiberglass fabric after the reactor was in place ready for an experiment.

\subsubsection{Product gas cleaning}

The product gas must be cleaned before its composition is analyzed. Specifically, tar, fine char, and ash particles must be separated from the gas. A 100-microns mesh was placed at the gas output line entrance to prevent the flying particles from entering it. Two small cylinders (500 ml volume) were introduced as expansion tanks to the gas output line. Their role was to condense the tar and other unwanted species before sampling the gas. Also, a separate fine particle filter $(2 \mu \mathrm{m})$ 
removed the fine particles that escaped the condensing trap. Later, product gas was collected in plastic sample bags and sent for analysis to a gas chromatograph.

\subsection{Fixed-bed Test Stand}

Preliminary biomass non-oxidative gasification was performed at $900^{\circ} \mathrm{C}$ in a downdraft-fixed bed gasifier (DFBG) (12.7 mm diameter, $915 \mathrm{~mm}$ long) stainless steel (316SS) reactor tube (Charleston Valve and Fitting Co.). The DFBG reactor temperature was measured with a K-type thermocouple (OmegaTM) (see Figure 17).

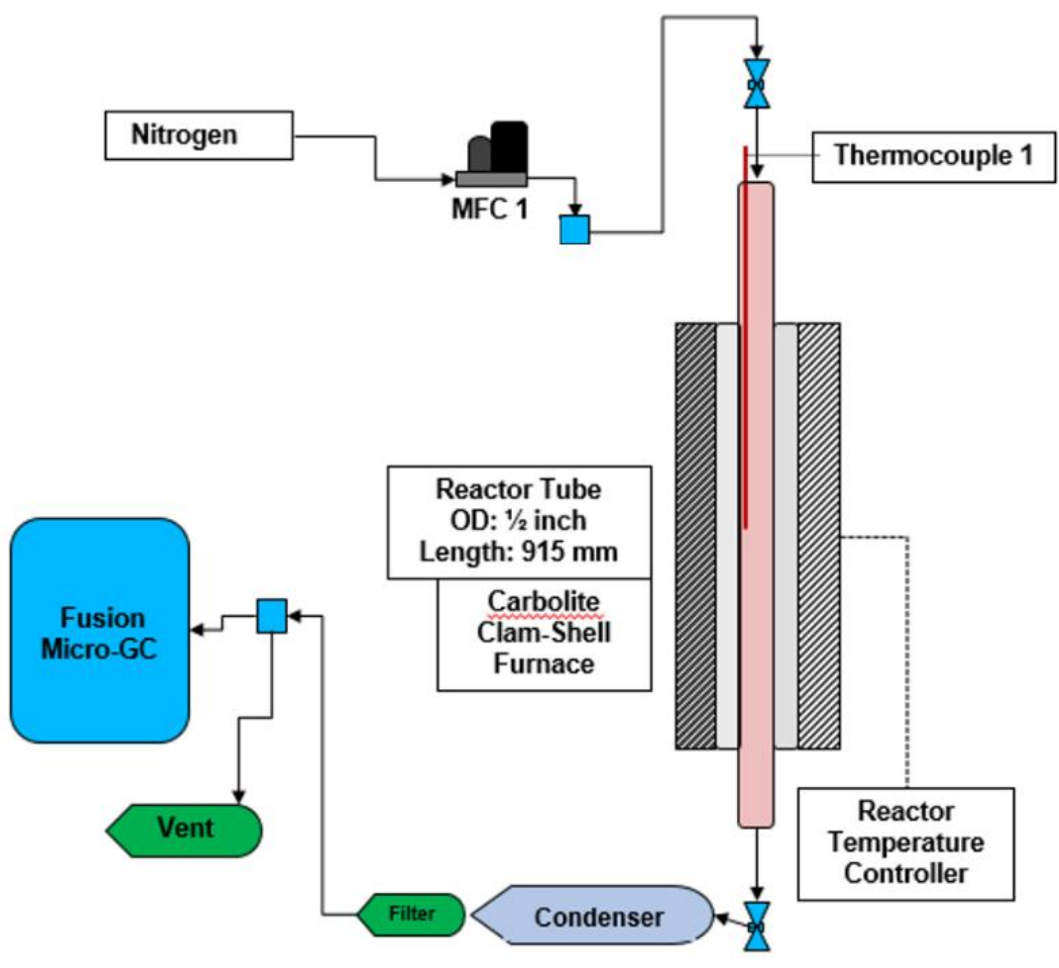

Figure 17. Fixed-bed test stand

Initially, the reactor bed temperature was ramped up at $20^{\circ} \mathrm{C} / \mathrm{min}$ to $100^{\circ} \mathrm{C}$ and held at that temperature. Later, the reactor was purged with $\mathrm{N}_{2}$ to remove air and moisture from the reactor 
tube for gasification reaction. The reactor was completely saturated to a pressure of $50 \mathrm{psig}$, and valves for the gas inlet and outlet were closed. Reactions performed at $900^{\circ} \mathrm{C}$, and the sample product gas was collected with plastic bags. After sampling, a gas chromatograph (Inficon Fusion) analyzed the collected gas samples. Figure 17 shows the schematic of the DFBG test stand. Moreover, Table 15 presents the experimental conditions for gasification studies in both DFBG and BFBG.

Table 15. Experimental conditions for biomass gasification in fixed bed and BFBG, and coal $10 \%$ steam in BFBG

\begin{tabular}{|lll|}
\hline & Fixed bed gasifier & BFBG \\
\hline Femperature $\left({ }^{\circ} \mathrm{C}\right)$ & $900^{\circ} \mathrm{C}$ & $900^{\circ} \mathrm{C}$ \\
Gasifying agent & Biomass & Biomass and coal \\
Bed material weight $(\mathrm{g})$ & 0 & $10 \%$ Steam \\
Fuel processing capacity & 1 to $3 \mathrm{~g}$ per test & 192 \\
Flow rate (SLM) & 0.3 & $2 \mathrm{~g} \mathrm{~min}^{-1}$ \\
Number of repetitions & 5 & $8 \mathrm{SLM}^{-1}$ \\
\hline
\end{tabular}

\subsection{Material Analysis and Preparation}

In this study, sawdust and coal were used during the cold flow and actual BFBG experiments. The biomass (sawdust) used in this study was Appalachian 100\% hardwood pellets (Green Team, Platinum Hardwood Pellet Fuel), and coal was Pittsburgh coal seam \#8. Hardwood is an abundant lignocellulosic raw material and widely used as biofuel for combustion and gasification. However, 
preprocessing biomass material is an arduous process. Table 6 shows the results of biomass and coal moisture, volatile, ash, and elemental analysis. Fine grade commercial silica sand (Quikrete, Commercial Grade Fine Sand) and glass beads (Ballotini) were used as inert materials. Table 16 shows the results of size, density, and sphericity analyses for the feedstock and inert materials. It was observed that sawdust particles had higher porosity and moisture content than silica sand, glass beads, and coal. Sawdust particles, silica sand, glass beads, and coal were sieved with a 300$350 \mu \mathrm{m}$ sieve shaker. Sawdust, sand, and glass beads then left to dry for twenty-four hours in a furnace at $100^{\circ} \mathrm{C}$ to minimize the moisture content. The drying procedure decreased the sawdust mass by $4 \%$ but did not remove all the moisture content. On the other hand, just $0.1 \%$ and $0.2 \%$ of the mass of glass beads and silica sand lost after drying, suggesting a negligible initial moisture content.

Dynamic image analysis (Sympatec GbmH, Model QICPIC) determined the particle size and shape (sphericity) distribution, based on images similar to the ones shown in Figure 18. For example, Figure 18c shows that, after they passed through the sieve shaker, biomass particles had an irregular shape distribution, mostly cylindrical and angular shapes. Figure 19 shows that $90 \%$ of the wood particle sphericity was between 0.37 and 0.74 , with an average value of 0.56 . On the contrary, glass beads and sand particles had more spherical shapes, hence their much narrower sphericity distribution: $90 \%$ of the glass beads and of the sand sphericity was between $0.85 \sim 0.95$, with average sphericity of 0.93 and 0.86 , respectively. Similarly, coal particles had a narrower sphericity distribution compared to sawdust particles with average sphericity of 0.85 , which is less compared to the particles of glass beads and similar to sand particles. Moreover, $90 \%$ of the wood particles had a Sauter diameter between $313 \mu \mathrm{m}$ and $761 \mu \mathrm{m}$, with an average value of $468 \mu \mathrm{m}$. Moreover, coal had a Sauter diameter with $90 \%$ in a range from $315 \mu \mathrm{m}$ to $538 \mu \mathrm{m}$ with an average 
value of $361 \mu \mathrm{m}$. The glass beads and sand had a much narrower size distribution, with $90 \%$ of the glass beads and sand having a Sauter diameter between $235 \mu \mathrm{m}$ and $347 \mu \mathrm{m}$ (average value of $271 \mu \mathrm{m}$ ) and between $309 \mu \mathrm{m}$ and $461 \mu \mathrm{m}$ (average value of $323 \mu \mathrm{m}$ ), respectively.
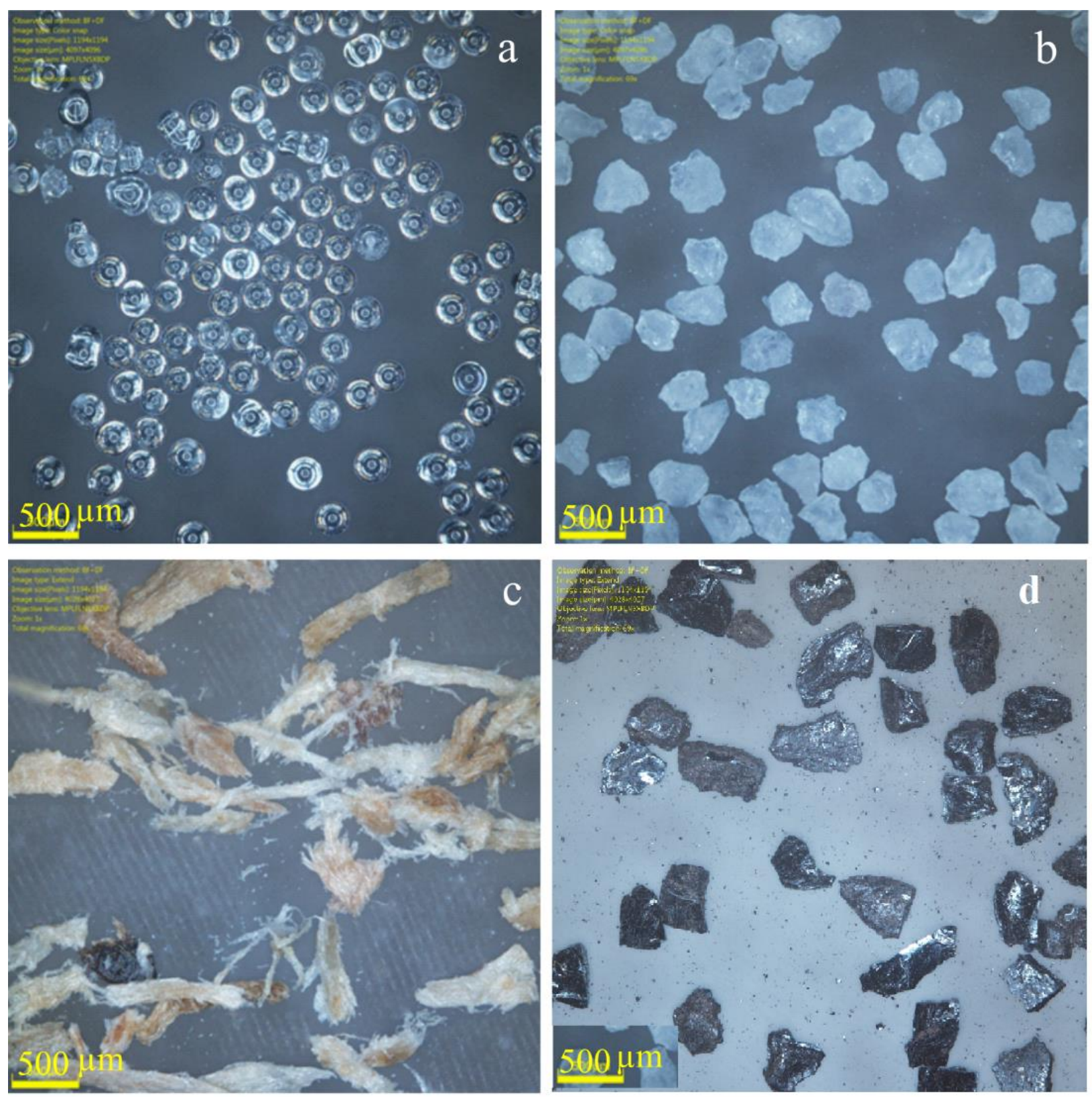

Figure 18. a) Glass beads, b) silica sand, c) sawdust, d) coal 


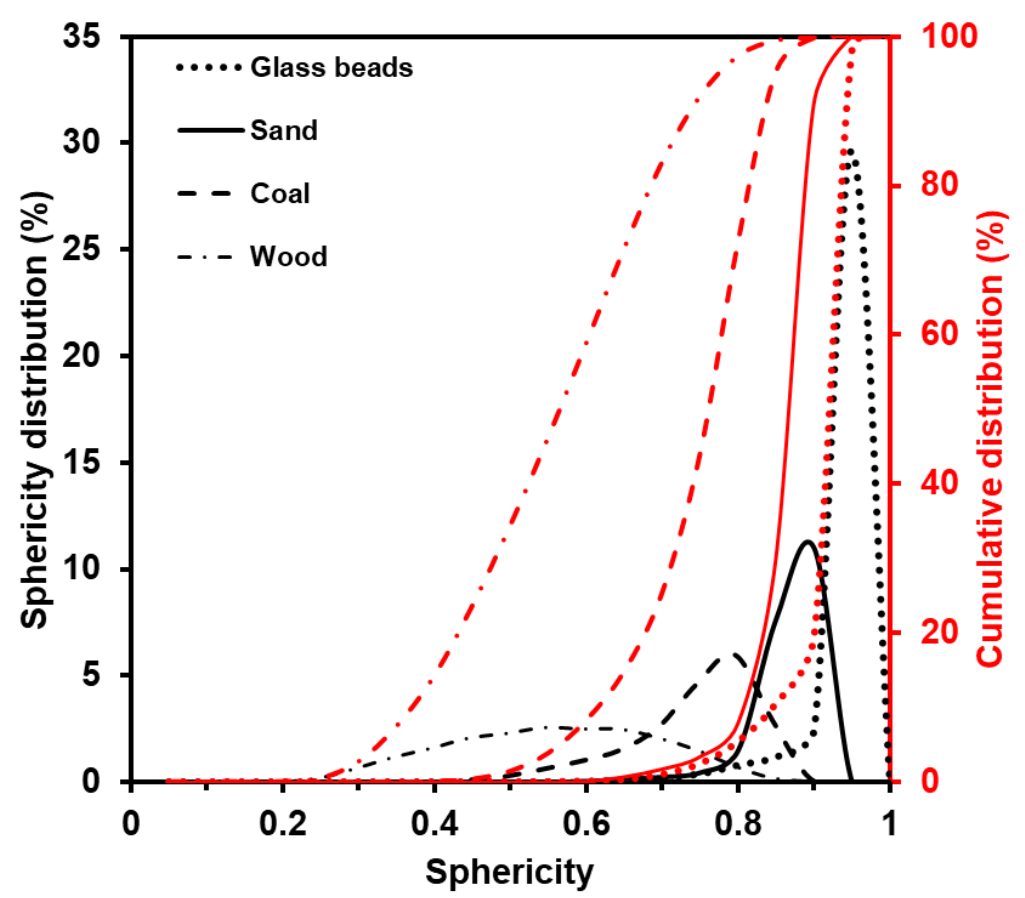

Figure 19. Particle sphericity distribution

Further, a gas pycnometer (AccuPyc, Model 1330 Helium Pycnometer) analyzed each material's particle skeletal density, with the results shown in Table 16. Figure 20 shows that the size distributions for wood, glass beads, sand, and coal are similar to their sphericity distributions. Specifically, $90 \%$ of the wood particles had a Sauter diameter between $317 \mu \mathrm{m}$ and $763 \mu \mathrm{m}$, with an average value of $464 \mu \mathrm{m}$. The glass beads and sand had a much narrower size distribution, with $90 \%$ of the glass beads and sand having a Sauter diameter between $215 \mu \mathrm{m}$ and $331 \mu \mathrm{m}$ (average value of $271 \mu \mathrm{m}$.) and between $239 \mu \mathrm{m}$ and $429 \mu \mathrm{m}$ (average value of $324 \mu \mathrm{m}$ ), respectively. Moreover, coal had a narrower size distribution (mean diameter of $362 \mu \mathrm{m}$ ) compared to wood but had a wider distribution of size than sand and glass beads. Finally, particle sphericity change with the size is presented in Figure 21. Drastic change in sphericity with size was observed for sawdust particles. Furthermore, all particle types showed a tendency to decrease their sphericity at sizes bigger than $500 \mu \mathrm{m}$. 
Table 16. Material size, density, sphericity, and Geldart's Group analysis

\begin{tabular}{|cccccc|}
\hline & $\begin{array}{c}\text { Sauter mean } \\
\text { diameter } \\
(\mu \mathrm{m})\end{array}$ & $\begin{array}{c}\text { Average of } \\
\text { sphericity }\end{array}$ & $\begin{array}{c}\text { Bulk } \\
\text { density } \\
\left(\mathrm{g} / \mathrm{cm}^{3}\right)\end{array}$ & $\begin{array}{c}\text { Skeletal } \\
\text { density } \\
\left(\mathrm{g} / \mathrm{cm}^{3}\right)\end{array}$ & $\begin{array}{c}\text { Geldart's } \\
\text { Group }\end{array}$ \\
\hline Hardwood & 468 & 0.56 & 0.27 & 1.47 & $\mathrm{~B}$ \\
Coal & 361 & 0.85 & 0.7 & 1.36 & $\mathrm{~B}$ \\
Glass beads & 271 & 0.93 & 1.46 & 2.48 & $\mathrm{~B}$ \\
Sand & 323 & 0.86 & 1.43 & 2.64 & $\mathrm{~B}$ \\
\hline $\begin{array}{c}\text { Coal (4\%) } \\
\text { and glass } \\
\text { beads } \\
\text { mixture }\end{array}$ & 282 & 0.93 & 1.61 & 2.44 & $\mathrm{~B}$ \\
\hline $\begin{array}{c}\text { Coal (4\%) } \\
\text { and sand } \\
\text { mixture }\end{array}$ & 368 & 0.86 & 1.56 & 2.59 & $\mathrm{~B}$ \\
\hline $\begin{array}{c}\text { Hardwood } \\
\text { (4\%) and } \\
\text { glass beads } \\
\text { mixture }\end{array}$ & 279 & 0.92 & & & $\mathrm{~B}$ \\
\hline $\begin{array}{c}\text { Hardwood } \\
\text { (4\%) and } \\
\text { sand mixture }\end{array}$ & 329 & 0.85 & 1.26 & 2.44 & $\mathrm{~B}$ \\
\hline
\end{tabular}

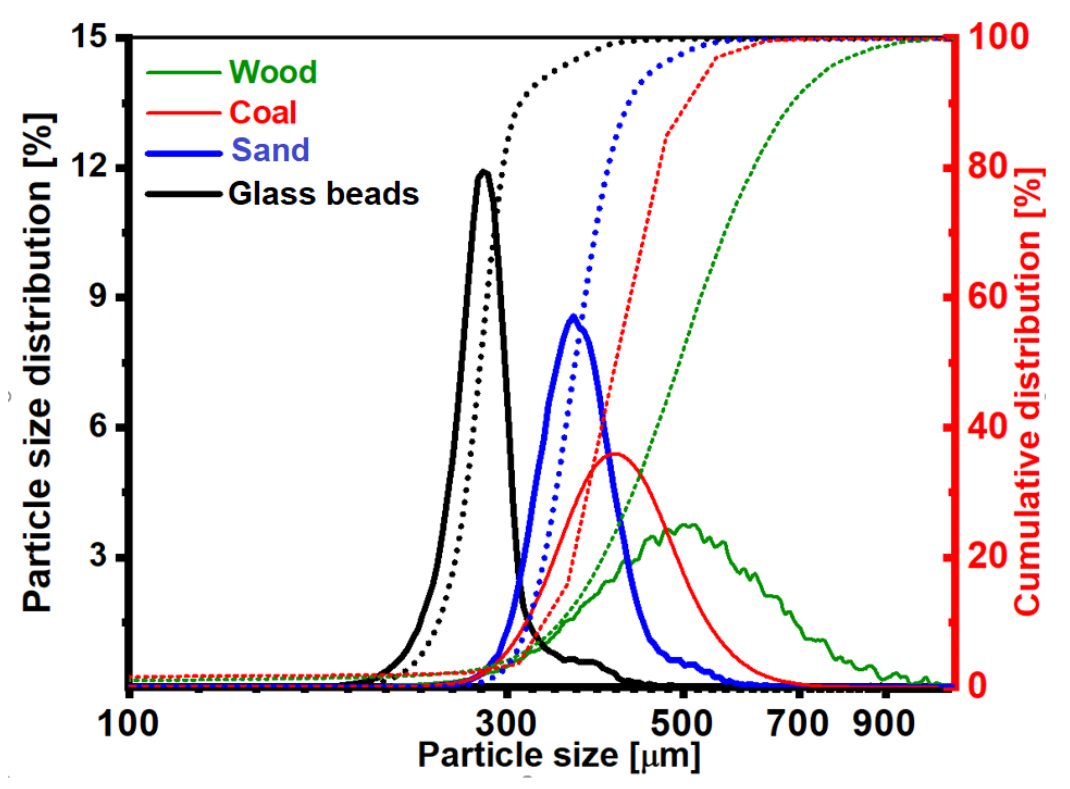

Figure 20. Particle size distribution 


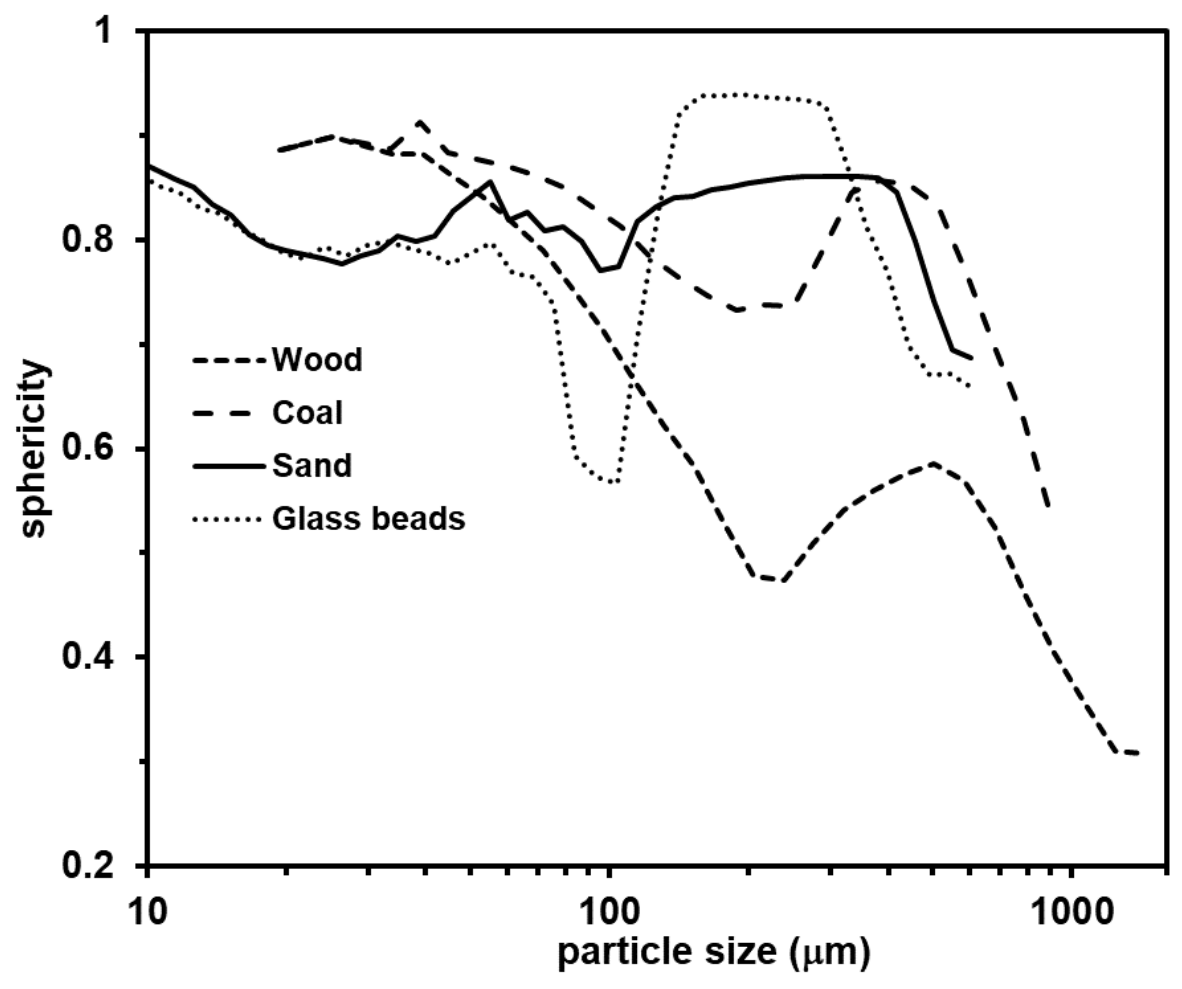

Figure 21. Sphericity change with particle size 


\section{Chapter 3: Cold Flow Analysis}

Chapter 3 investigates the effect of mixture and mixing characteristics on the fluidization dynamics under cold flow conditions, for both unary and binary mixtures.

\subsection{Effect of Mixture Characteristics on Fluidization Dynamics under Cold Flow Conditions}

This section analyzes the effect of mixture properties such as particle characteristics, moisture content, bed aspect ratio, and mixing condition (segregated or premixed) on the fluidized bed hydrodynamics, particularly on the minimum fluidization velocity at ambient conditions. The theoretical prediction of $R e$ using correlations in the literature was compared with the experimentally-determined $R e$ for each test case. The analysis was performed for both unary (i.e., bed material only) and binary mixtures. Images taken during each test case support the discussion on the fluidization behavior and mixing of segregated mixtures and how the findings can be used to predict the actual BFBG operation.

Section 3.1 starts with the analyses of the hydrodynamics inside a unary mixture of sand or glass beads (Section 3.1.1). Unary mixture studies are important to understand the degree of the biomass effect on the binary mixtures' hydrodynamics on measured parameters such as $U_{m f}$ and bed pressure drop. It is well-known that sand and glass beads have narrower size and sphericity distributions compared to biomass. Also, sand and glass beads did not show any significant changes in the moisture content after the drying process (see Section 2.5). Also, it was expected that theoretical predictions of the $U_{m f}$ must not show significant relative errors for inert materials with the very narrow size distributions. Hence, unary mixture studies were fundamentals before conducting the binary mixture studies. Later, in Section 3.1.2 and Section 3.1.3, analyses of the 
hydrodynamics of the dried and the non-dried premixed (well-mixed) binary mixtures of sawdust and inert material are shared, respectively. Studies with the dried and non-dried biomass for the premixed case were analyzed to understand the drying (reduced moisture content) effect. And, finally, analyses of the top-fed (on-bed) dried and non-dried sawdust and inert material mixtures are presented. Studies conducted with various mixing conditions (premixed or on-bed) made possible to analyze the mixing condition effect on the fluidization hydrodynamics.

\subsubsection{Hydrodynamics Inside a Unary Mixture}

Understanding the fluidization behavior in relationship to the minimum fluidization velocity inside a unary mixture (i.e., bed containing sand or glass beads only) is the first step when trying to predict the hydrodynamics of a binary mixture. In this section, the correlation between the bed pressure drop and the superficial gas velocity was plotted, then the graphical method shown in Figure 7 was used to determine the minimum fluidization velocity and analyze the subsequent fluidization behavior.

Figure 22 presents the bed pressure drop change with the increasing superficial gas velocity, for the unary mixtures of glass beads (Figure 22a) and silica sand (Figure 22b). The fluidizing gas was nitrogen. The total mass of the mixture was increased from $100 \mathrm{~g}$ to $200 \mathrm{~g}$ to $300 \mathrm{~g}$, which also resulted in three different bed aspect ratios. Figure 20. and Figure 20 show that both sand and glass particles had narrower size and sphericity distributions compared to the sawdust particles. For both glass beads and silica sand the bed pressure drop increased linearly during the fixed bed state, then the pressure drop curve was almost independent of the superficial gas velocity. However, there was a slight increase in the bed pressure drop for the highest bed aspect ratio (i.e., for the $300-\mathrm{g}$ case), due to higher wall effects. 

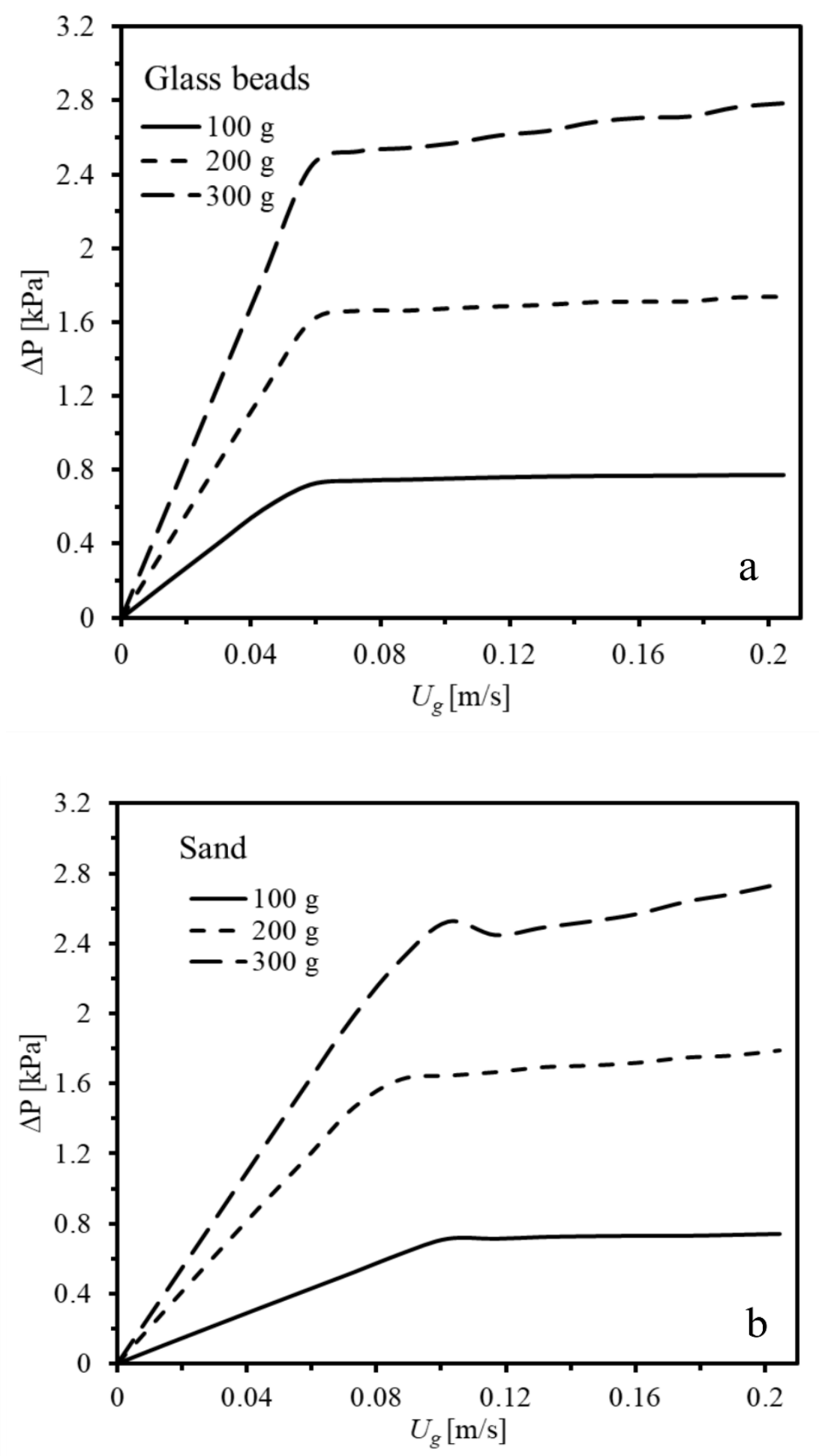

Figure 22. Bed pressure drop versus superficial gas velocity at ambient temperature for a) glass beads and b) silica sand. 
As the transition between fixed to fluidized bed is not instantaneous, a velocity interval should be considered while determining the minimum fluidization velocity. Figure 22 shows that the $U_{g}$ range between the start and complete fluidization was narrower for the glass beads compared with the sand, irrespective of the bed aspect ratios. This was attributed to the higher sphericity and narrower size distribution of the glass beads, which created a better packaging compared with silica sand. The bed pressure drop values corresponding to the minimum fluidization were $0.71 \mathrm{kPa}, 1.65 \mathrm{kPa}$, and $2.50 \mathrm{kPa}$ for silica sand and $0.74 \mathrm{kPa}, 1.65 \mathrm{kPa}$, and $2.50 \mathrm{kPa}$ for glass beads materials with the total mass of $100 \mathrm{~g}, 200 \mathrm{~g}$, and $300 \mathrm{~g}$ respectively. Furthermore, the corresponding bed aspect ratios $\left(H_{p} / D_{b}\right)$ at static bed conditions were 1.6, 3.4 and 5.4 for silica sand and 1.6, 3.6 and 5.0 for glass beads, respectively (total mass of $100 \mathrm{~g}, 200 \mathrm{~g}$, and $300 \mathrm{~g}$ ). The measured $U_{m f}$ for silica sand only were $0.100 \mathrm{~m} / \mathrm{s}, 0.085 \mathrm{~m} / \mathrm{s}$, and $0.096 \mathrm{~m} / \mathrm{s}$, for $100 \mathrm{~g}, 200 \mathrm{~g}$, and $300 \mathrm{~g}$ total mass, respectively. However, $U_{m f}$ of the glass beads only did not change with the bed mass or aspect ratios: the measured value was always $\sim 0.065 \mathrm{~m} / \mathrm{s}$. Again, this was due to the better material packing compared to the silica sand. Next, $A r$ and $R e$ were calculated based on the experimental data. Ar was 3140 and 1698 for silica sand and glass beads, respectively. $R e$ was 2.1, 1.8, and 2.0 for silica sand with total mass of $100 \mathrm{~g}, 200 \mathrm{~g}, 300 \mathrm{~g}$, respectively and 1.0 for glass beads, irrespective of the total mass. Correlations represented by $\mathrm{C} 1: \mathrm{C} 8$ are listed in Table 1 and Table 2. Table 17 shows $\Delta P_{m f}, A r, R e, U_{m f}$, and $H_{p} / D_{b}$ for unary mixtures of silica sand and glass beads materials. 
Table 17. Experimental values of $\Delta P_{m f}, A r, R e, U_{m f}$ and $H_{p} / D_{b}$ for unary mixtures of silica sand and glass beads materials.

\begin{tabular}{|l|c|c|c|c|c|}
\hline \multicolumn{1}{|c|}{ Mixture } & $\Delta P_{m f}[\mathrm{kPa}]$ & $A r$ & $R e$ & $U_{m f}[\mathrm{~m} / \mathrm{s}]$ & $H_{p} / D_{b}$ \\
\hline $100 \mathrm{~g}$, sand & 0.71 & 3140 & 2.1 & 0.100 & 1.6 \\
\hline $200 \mathrm{~g}$, sand & 1.65 & 3140 & 1.8 & 0.085 & 3.4 \\
\hline $300 \mathrm{~g}$, sand & 2.50 & 3140 & 2.0 & 0.096 & 5.4 \\
\hline $100 \mathrm{~g}$, glass beads & 0.74 & 1698 & 1.0 & 0.065 & 1.6 \\
\hline $200 \mathrm{~g}$, glass beads & 1.65 & 1698 & 1.0 & 0.065 & 3.3 \\
\hline $300 \mathrm{~g}$, glass beads & 2.50 & 1698 & 1.0 & 0.065 & 5.0 \\
\hline
\end{tabular}

Table 18. Theoretical predictions of $R e$ for unary mixtures of silica sand and glass beads materials.

\begin{tabular}{|l|l|l|l|l|l|l|l|}
\hline \multicolumn{1}{|c|}{ Mixture } & $R e_{\text {exp }}$ & $\mathrm{C} 1$ & $\mathrm{C} 2$ & $\mathrm{C} 3$ & $\mathrm{C} 4$ & $\mathrm{C} 5$ & $\mathrm{C} 6$ \\
\hline $100 \mathrm{~g}$, sand & 2.06 & 2.26 & 2.44 & 2.32 & 2.05 & 1.87 & 2.46 \\
\hline $200 \mathrm{~g}$, sand & 1.75 & 2.26 & 2.44 & 2.32 & 2.05 & 1.87 & 2.46 \\
\hline $300 \mathrm{~g}$, sand & 1.97 & 2.26 & 2.44 & 2.32 & 2.05 & 1.87 & 2.46 \\
\hline $100 \mathrm{~g}$, glass beads & 1.00 & 1.24 & 1.37 & 1.27 & 1.12 & 1.03 & 1.37 \\
\hline $200 \mathrm{~g}$, glass beads & 1.00 & 1.24 & 1.37 & 1.27 & 1.12 & 1.03 & 1.37 \\
\hline $300 \mathrm{~g}$, glass beads & 1.00 & 1.24 & 1.37 & 1.27 & 1.12 & 1.03 & 1.37 \\
\hline
\end{tabular}

Some of the well-known correlations from the literature (see Table 2 2) were selected to compare against the experimentally-determined Re as a function of Ar, as shown in Table 18. Furthermore, Table 19 presents the relative errors between the correlations in the literature and the experimentally-determined Re for silica sand and glass beads unary mixtures, with total mass of $100 \mathrm{~g}, 200 \mathrm{~g}$, and $300 \mathrm{~g}$, respectively. 
Table 19. Error in predicting the $R e$ for unary mixtures of silica sand and glass beads materials.

\begin{tabular}{|l|c|c|c|c|c|c|c|}
\hline \multicolumn{1}{|c|}{ Mixture } & $R e_{\exp }$ & $\mathrm{C} 1$ & $\mathrm{C} 2$ & $\mathrm{C} 3$ & $\mathrm{C} 4$ & $\mathrm{C} 5$ & $\mathrm{C} 6$ \\
\hline $100 \mathrm{~g}$, sand & 2.06 & $10 \%$ & $19 \%$ & $13 \%$ & $1 \%$ & $9 \%$ & $19 \%$ \\
\hline $200 \mathrm{~g}$, sand & 1.75 & $29 \%$ & $39 \%$ & $33 \%$ & $17 \%$ & $7 \%$ & $40 \%$ \\
\hline $300 \mathrm{~g}$, sand & 1.97 & $14 \%$ & $23 \%$ & $17 \%$ & $4 \%$ & $5 \%$ & $24 \%$ \\
\hline $100 \mathrm{~g}$, glass beads & 1.00 & $24 \%$ & $37 \%$ & $27 \%$ & $12 \%$ & $3 \%$ & $37 \%$ \\
\hline $200 \mathrm{~g}$, glass beads & 1.00 & $24 \%$ & $37 \%$ & $27 \%$ & $12 \%$ & $3 \%$ & $37 \%$ \\
\hline $300 \mathrm{~g}$, glass beads & 1.00 & $24 \%$ & $37 \%$ & $27 \%$ & $12 \%$ & $3 \%$ & $37 \%$ \\
\hline
\end{tabular}

Table 19 shows that the experimentally-determined $R e$ was closest to $\mathrm{Wu}$ and Bayens correlation [91], which is a version of the Ergun equation that includes sphericity effects. The relative error (average) was just 3\% for glass beads and $7 \%$ for silica sand. The next closer was the correlation of Thonglimp et al. [88], with a relative error (average) of $7 \%$ for sand and $12 \%$ for glass beads. Other correlations that produced a relative error less than $30 \%$ for both materials were those of Bourgeis and Grenier [90] and Paudel and Feng [30].

\subsubsection{Hydrodynamics in Dried Premixed Mixtures of Sawdust and Inert Material}

While drying the biomass prior to gasification is both costly and time consuming, a significant moisture content can strongly influence the fluidization hydrodynamics. To check this influence, a drying process was used to reduce the moisture content of sawdust particles from $7.7 \%$ to $3.3 \%$. In this section, the fluidization hydrodynamics of binary mixtures of dried sawdust with silica sand or glass beads at ambient conditions were studied at same total mass as in previous section, to help compare with the behavior of unary mixtures. The mixture was premixed, as shown in Figure 9b. Measurements were taken for the increasing velocity only, considering the initial bed voidage and mixture pattern. It is important to mention here that mixture pattern and the final voidage of the static bed (an approximate fixed bed) for measurements taken for decreasing gas velocity can be 
significantly different from the incipient bed voidage and mixture pattern for the fluidization with increasing gas velocity. As a result, there can be significant discrepancies in the $U_{m f}$ measurement between the measurements taken during fluidization (increasing gas velocity) and defluidization (decreasing gas velocity).

Figure 23 shows the bed pressure drop for premixed binary mixtures of dried sawdust with glass beads (Figure 23a) or silica sand (Figure 23b), with the increasing superficial gas velocity. Sawdust accounted for $4 \%$ of the total mixture mass. The bed pressure drop corresponding to minimum fluidization conditions was $0.75 \mathrm{kPa}, 1.52 \mathrm{kPa}$, and $2.37 \mathrm{kPa}$ for the sawdust - silica sand mixture and $0.75 \mathrm{kPa}, 1.63 \mathrm{kPa}$, and $2.38 \mathrm{kPa}$ for the sawdust - glass beads mixture, respectively (total mass of $100 \mathrm{~g}, 200 \mathrm{~g}$, and $300 \mathrm{~g}$ ). The results show that the bed material had no significant effect on the bed pressure drop corresponding to the minimum fluidization condition at similar total mass. However, the increase in the bed aspect ratio increased in the velocity range for determining the minimum fluidization velocity, created a higher bed pressure drop peak of before the complete fluidization, and, for further increases in the superficial gas velocity, resulted in elutriation and carry out. 

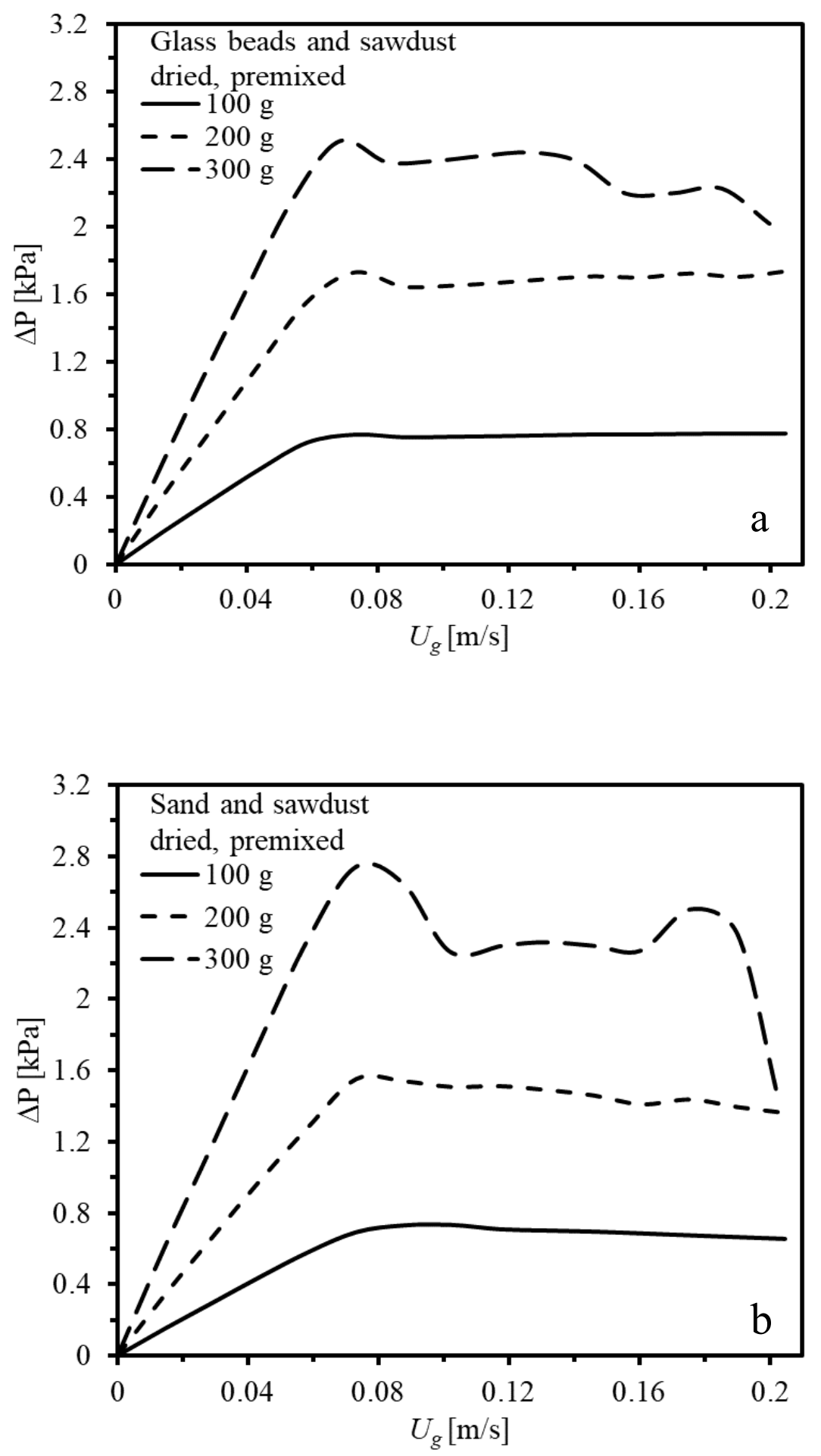

Figure 23. Bed pressure drop versus superficial gas velocity at ambient temperature for the binary mixtures of dried sawdust with a) glass beads and b) silica sand with the mixture masses 
of 100,200 , and $300 \mathrm{~g}$, respectively.

Moreover, the poor fluidization was more evident in the sawdust and silica sand binary mixture due to the higher bed voidage, lower bulk density, and wider sphericity and size distributions compared to the sawdust - glass beads mixture. Measured $H_{p} / D_{b}$ were 1.8, 3.9, and 5.8 for the sawdust and silica sand binary mixture and 1.8, 3.7, and 5.4 for the sawdust and glass beads binary mixture, with total mass of $100 \mathrm{~g}, 200 \mathrm{~g}$, and $300 \mathrm{~g}$, respectively. The difference in the particle characteristics produced the differences in bed aspect ratios, more evident at higher total mass. The measured $U_{m f}$ for sawdust and silica sand, and sawdust and glass beads mixtures (total mass of $100 \mathrm{~g}, 200 \mathrm{~g}$, and $300 \mathrm{~g}$ ) were $0.072 \mathrm{~m} / \mathrm{s}, 0.060 \mathrm{~m} / \mathrm{s}, 0.058 \mathrm{~m} / \mathrm{s}$, and $0.060 \mathrm{~m} / \mathrm{s}, 0.065 \mathrm{~m} / \mathrm{s}$, and $0.062 \mathrm{~m} / \mathrm{s}$, respectively. Formisani et al. [112] mention that the bed aspect ratio does not significantly affect minimum fluidization velocity, which is similar to the $U_{m f}$ presented here. However, interparticle forces and wall effects do not change proportionally when the bed mass increases, which, in addition to the different bed particle characteristics (including a less-packed bed to start with), explains why the bed aspect ratio had a larger effect on the $U_{m f}$ of the sawdust and silica sand mixture. $\Delta P_{m f}, A r, R e, U_{m f}$, and $H_{p} / D_{b}$ for the binary mixtures of dried sawdust with silica sand or glass beads materials are summarized in Table 20. 
Table 20. Experimental values of $\Delta P_{m f}, A r, R e, U_{m f}$ and $H_{p} / D_{b}$ for the binary mixtures of dried sawdust with glass beads or silica sand.

\begin{tabular}{|l|c|c|c|c|c|}
\hline $\begin{array}{c}\text { Mixture mass } \\
\text { and inert material }\end{array}$ & $\Delta P_{m f}[\mathrm{kPa}]$ & $A r$ & $R e$ & $U_{m f}[\mathrm{~m} / \mathrm{s}]$ & $H_{p} / D_{b}$ \\
\hline $100 \mathrm{~g}$, sand & 0.70 & 3226 & 1.50 & 0.072 & 1.8 \\
\hline $200 \mathrm{~g}$, sand & 1.52 & 3226 & 1.25 & 0.060 & 3.9 \\
\hline $300 \mathrm{~g}$, sand & 2.26 & 3226 & 1.21 & 0.058 & 5.8 \\
\hline $100 \mathrm{~g}$, glass beads & 0.75 & 1853 & 1.06 & 0.060 & 1.8 \\
\hline $200 \mathrm{~g}$, glass beads & 1.63 & 1853 & 1.15 & 0.065 & 3.7 \\
\hline $300 \mathrm{~g}$, glass beads & 2.38 & 1853 & 1.10 & 0.062 & 5.4 \\
\hline
\end{tabular}

Table 21. Theoretical predictions of $R e$ for the binary mixtures of dried sawdust with glass beads or silica sand.

\begin{tabular}{|l|c|c|c|c|c|c|c|c|c|}
\hline $\begin{array}{c}\text { Mixture mass } \\
\text { and inert material }\end{array}$ & $R e_{\text {exp }}$ & $\mathrm{C} 1$ & $\mathrm{C} 2$ & $\mathrm{C} 3$ & $\mathrm{C} 4$ & $\mathrm{C} 5$ & $\mathrm{C} 6$ & $\mathrm{C} 7$ & $\mathrm{C} 8$ \\
\hline $100 \mathrm{~g}$, sand & 1.50 & 2.31 & 2.50 & 2.38 & 2.10 & 1.92 & 2.52 & 1.96 & 2.38 \\
\hline $200 \mathrm{~g}$, sand & 1.25 & 2.31 & 2.50 & 2.38 & 2.10 & 1.92 & 2.52 & 1.96 & 2.38 \\
\hline $300 \mathrm{~g}$, sand & 1.21 & 2.31 & 2.50 & 2.38 & 2.10 & 1.92 & 2.52 & 1.96 & 2.38 \\
\hline $100 \mathrm{~g}$, glass beads & 1.06 & 1.35 & 1.49 & 1.39 & 1.22 & 1.12 & 1.49 & 1.14 & 1.41 \\
\hline $200 \mathrm{~g}$, glass beads & 1.15 & 1.35 & 1.49 & 1.39 & 1.22 & 1.12 & 1.49 & 1.14 & 1.41 \\
\hline 300 g, glass beads & 1.10 & 1.35 & 1.49 & 1.39 & 1.22 & 1.12 & 1.49 & 1.14 & 1.41 \\
\hline
\end{tabular}

Table 22. Error in predicting the $R e$ for the binary mixtures of dried sawdust with glass beads or silica sand.

\begin{tabular}{|l|c|c|c|c|c|c|c|c|c|}
\hline $\begin{array}{c}\text { Mixture mass } \\
\text { and inert material }\end{array}$ & $R_{\text {exp }}$ & $\mathrm{C} 1$ & $\mathrm{C} 2$ & $\mathrm{C} 3$ & $\mathrm{C} 4$ & $\mathrm{C} 5$ & $\mathrm{C} 6$ & $\mathrm{C} 7$ & $\mathrm{C} 8$ \\
\hline $100 \mathrm{~g}$, sand & 1.50 & $20 \%$ & $66 \%$ & $58 \%$ & $40 \%$ & $28 \%$ & $68 \%$ & $30 \%$ & $73 \%$ \\
\hline $200 \mathrm{~g}$, sand & 1.25 & $85 \%$ & $100 \%$ & $90 \%$ & $68 \%$ & $53 \%$ & $101 \%$ & $56 \%$ & $108 \%$ \\
\hline $300 \mathrm{~g}$, sand & 1.21 & $91 \%$ & $106 \%$ & $96 \%$ & $73 \%$ & $59 \%$ & $108 \%$ & $61 \%$ & $115 \%$ \\
\hline $100 \mathrm{~g}$, glass beads & 1.06 & $27 \%$ & $40 \%$ & $31 \%$ & $15 \%$ & $5 \%$ & $40 \%$ & $7 \%$ & $76 \%$ \\
\hline $200 \mathrm{~g}$, glass beads & 1.15 & $18 \%$ & $29 \%$ & $21 \%$ & $6 \%$ & $3 \%$ & $29 \%$ & $1 \%$ & $62 \%$ \\
\hline $300 \mathrm{~g}$, glass beads & 1.10 & $23 \%$ & $35 \%$ & $26 \%$ & $11 \%$ & $2 \%$ & $35 \%$ & $4 \%$ & $70 \%$ \\
\hline
\end{tabular}


Table 21 compares the experimentally-determined $R e$ and its theoretical predictions with selected correlations from the literature. Table 22 presents the relative errors between the correlations in the literature and the experimentally-determined $R e$ for the premixed mixtures of dried sawdust with silica sand or glass beads, respectively. Among the selected correlations, $\mathrm{Wu}$ and Bayens [91] and Rao and Bheemarasetti [85] produced the closest results to the experimental Re for the sawdust and glass beads mixture, with relative errors (average) of $3 \%$ and $4 \%$, respectively. However, for the sawdust and silica sand mixtures, Wu and Bayens [91] and Rao and Bheemarasetti [85] produced relative errors (average) of $47 \%$ and $49 \%$, respectively. These significant discrepancies were attributed to the wider particle size and sphericity distribution range of the sawdust and silica sand binary mixtures. As the volume of the void between individual particles is proportional to the particle sphericity, a higher void promotes channeling and poor fluidization. As a result, the increase in the bed's voidage yields an increase in the minimum fluidization velocity. Also, as seen in Figure 23, the minimum fluidization velocity interval significantly increased for the 300 -g sawdust and silica sand binary premixed mixture due to the wide particle size distribution, which is totally different for what is seen for the 300-g sawdust and glass beads binary premixed mixture. In addition, correlations from Bourgeis and Grenier [90], Paudel and Feng [30], and Thonglimp et al. [88] produced relative error (average) lower than 30\% for the sawdust and glass beads binary premixed mixture. However, other selected Re correlations produced very large relative errors (average) irrespective of bed material and total mass. 


\subsubsection{Hydrodynamics in Non-Dried Premixed Mixtures of Sawdust and Inert Material}

In contrast to the previous section, the hydrodynamics of binary mixtures were then studied in this section using non-dried sawdust. Sawdust mass fraction was kept constant at $4 \%$ of the total bed mass and the inert bed materials were the same.

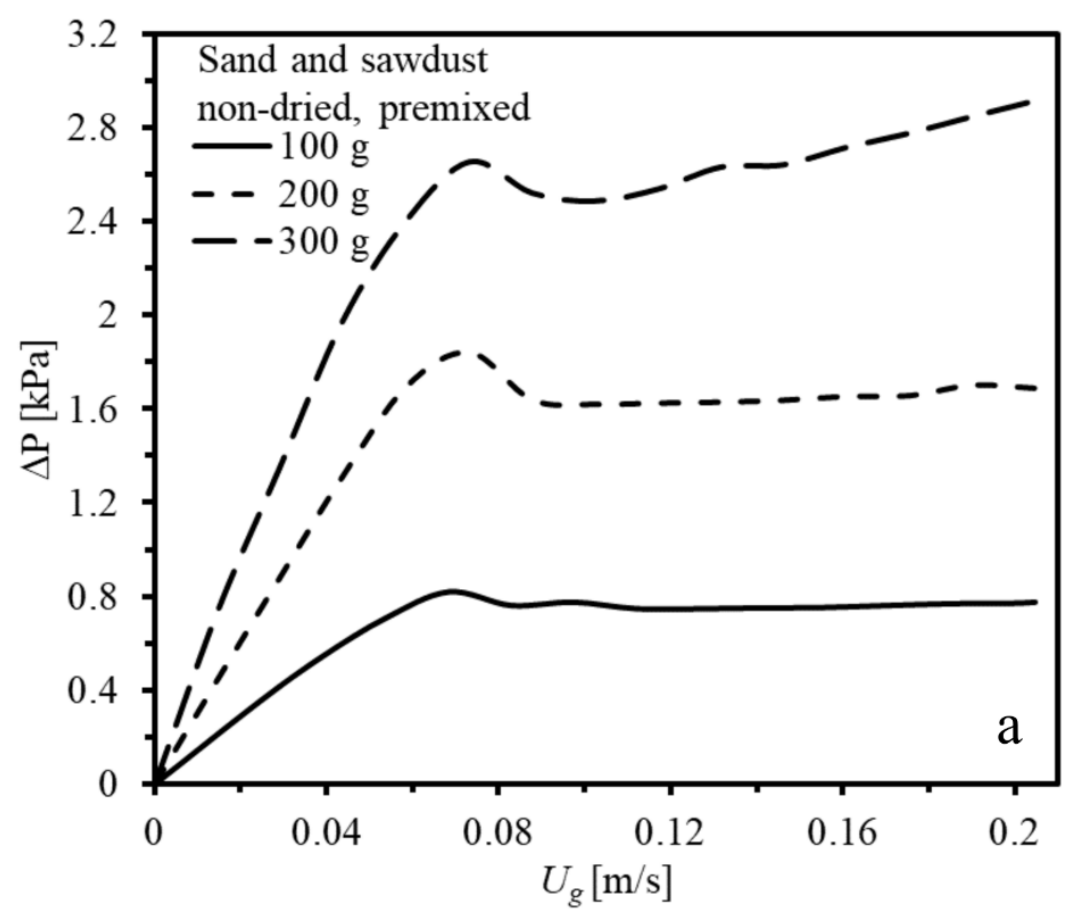




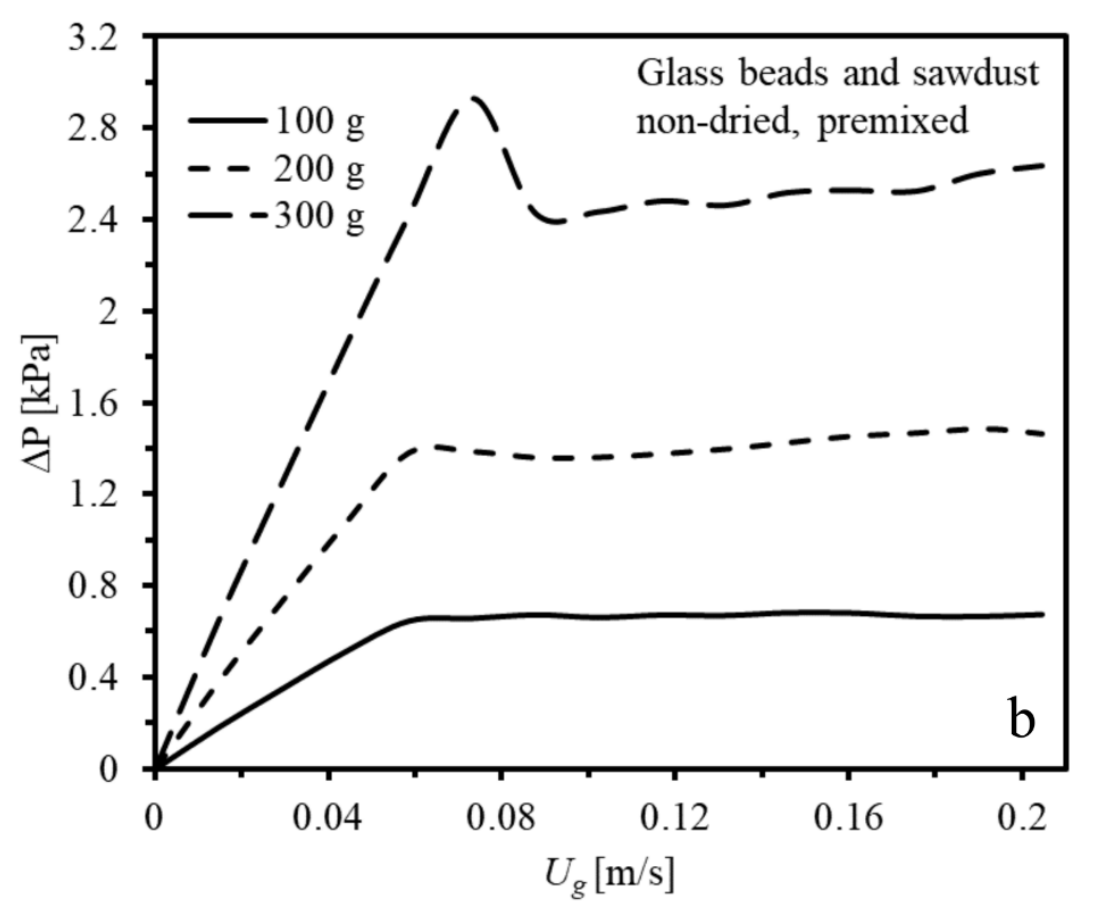

Figure 24. Bed pressure drop versus superficial gas velocity at ambient temperature for the binary mixtures of non-dried sawdust with a) glass beads or b) silica sand with the mixture masses of $100 \mathrm{~g}, 200 \mathrm{~g}$ and $300 \mathrm{~g}$, respectively.

The bed pressure drop of the premixed binary mixtures of non-dried sawdust with glass beads (Figure 24a) or silica sand (Figure 24b) relative to the fluidizing gas superficial velocity at ambient temperature are shown in Figure 24. The bed pressure drop at minimum fluidization conditions was $0.76 \mathrm{kPa}, 1.63 \mathrm{kPa}$, and $2.49 \mathrm{kPa}$ for the mixtures with silica sand and $0.74 \mathrm{kPa}, 1.36 \mathrm{kPa}$, and $2.43 \mathrm{kPa}$ for the mixtures with glass beads materials, respectively (total mass of $100 \mathrm{~g}, 200 \mathrm{~g}$, and $300 \mathrm{~g}$ ). The corresponding $H_{p} / D_{b}$ at static bed condition, for 100,200 , and $300 \mathrm{~g}$ of mixtures with silica sand was $1.8,3.8$, and 5.8 and 1.9, 3.8, and 5.8 for the mixtures with glass beads, respectively (total mass of $100 \mathrm{~g}, 200 \mathrm{~g}$, and $300 \mathrm{~g}$ ). $U_{m f}$ was $0.060 \mathrm{~m} / \mathrm{s}, 0.055 \mathrm{~m} / \mathrm{s}$, and $0.064 \mathrm{~m} / \mathrm{s}$ for the 
mixtures with silica sand and $0.058 \mathrm{~m} / \mathrm{s}, 0.057 \mathrm{~m} / \mathrm{s}$, and $0.059 \mathrm{~m} / \mathrm{s}$ for the mixtures with glass beads, respectively (total mass of $100 \mathrm{~g}, 200 \mathrm{~g}$, and $300 \mathrm{~g}$ ). The results suggest that the bed aspect ratio had negligible effect on the minimum fluidization velocity. On the other hand, compared to the dried sawdust mixtures, the data shows that $U_{m f}$ decreased $\sim 5 \%$. Table 23 summarizes the experimental values of $\Delta P_{m f}, A r, R e, U_{m f}$, and $H_{p} / D_{b}$ for the binary mixtures of non-dried sawdust with silica sand or glass beads, respectively (total mass of $100 \mathrm{~g}, 200 \mathrm{~g}$, and $300 \mathrm{~g}$ ).

Table 23. Experimental values of $\Delta P_{m f}, A r, R e, U_{m f}$ and $H_{p} / D_{b}$ for the binary mixtures of nondried sawdust with glass beads or silica sand with the mixture masses of $100 \mathrm{~g}, 200 \mathrm{~g}$, and $300 \mathrm{~g}$, respectively.

\begin{tabular}{|l|c|c|c|c|c|}
\hline $\begin{array}{c}\text { Mixture mass and } \\
\text { inert material }\end{array}$ & $\begin{array}{c}\Delta P_{m f} \\
{[\mathrm{kPa}]}\end{array}$ & $A r$ & $R e$ & $\begin{array}{c}U_{m f} \\
{[\mathrm{~m} / \mathrm{s}]}\end{array}$ & $H_{p} / D_{b}$ \\
\hline $100 \mathrm{~g}$, sand & 0.76 & 3226 & 1.25 & 0.06 & 1.83 \\
\hline $200 \mathrm{~g}$, sand & 1.63 & 3226 & 1.15 & 0.055 & 3.83 \\
\hline $300 \mathrm{~g}$, sand & 2.49 & 3226 & 1.34 & 0.064 & 5.83 \\
\hline $100 \mathrm{~g}$, glass beads & 0.74 & 1853 & 1.03 & 0.058 & 1.91 \\
\hline $200 \mathrm{~g}$, glass beads & 1.36 & 1853 & 1.01 & 0.057 & 3.83 \\
\hline $300 \mathrm{~g}$, glass beads & 2.43 & 1853 & 1.04 & 0.059 & 5.83 \\
\hline
\end{tabular}

Table 24 compares the experimentally-determined $R e$ and its theoretical predictions with selected correlations from the literature. In addition, Table 25 presents the relative errors between the correlations in the literature and the experimentally-determined $R e$ for the premixed mixtures of non-dried sawdust with silica sand or glass beads, respectively. 
Table 24. Theoretical predictions of $R e$ for the binary mixtures of non-dried sawdust with glass beads or silica sand.

\begin{tabular}{|l|c|c|c|c|c|c|c|c|c|}
\hline $\begin{array}{c}\text { Mixture mass } \\
\text { and inert material }\end{array}$ & $R e_{\text {exp }}$ & $\mathrm{C} 1$ & $\mathrm{C} 2$ & $\mathrm{C} 3$ & $\mathrm{C} 4$ & $\mathrm{C} 5$ & $\mathrm{C} 6$ & $\mathrm{C} 7$ & $\mathrm{C} 8$ \\
\hline $100 \mathrm{~g}$, sand & 1.25 & 2.31 & 2.50 & 2.38 & 2.10 & 1.92 & 2.52 & 1.96 & 2.61 \\
\hline $200 \mathrm{~g}$, sand & 1.15 & 2.31 & 2.50 & 2.38 & 2.10 & 1.92 & 2.52 & 1.96 & 2.61 \\
\hline $300 \mathrm{~g}$, sand & 1.34 & 2.31 & 2.50 & 2.38 & 2.10 & 1.92 & 2.52 & 1.96 & 2.61 \\
\hline $100 \mathrm{~g}$, glass beads & 1.03 & 1.35 & 1.49 & 1.39 & 1.22 & 1.12 & 1.49 & 1.12 & 1.87 \\
\hline $200 \mathrm{~g}$, glass beads & 1.01 & 1.35 & 1.49 & 1.39 & 1.22 & 1.12 & 1.49 & 1.12 & 1.87 \\
\hline $300 \mathrm{~g}$, glass beads & 1.04 & 1.35 & 1.49 & 1.39 & 1.22 & 1.12 & 1.49 & 1.12 & 1.87 \\
\hline
\end{tabular}

Table 25. Error in predicting the theoretical $R e$ for the binary mixtures of non-dried sawdust with glass beads or silica sand.

\begin{tabular}{|l|c|c|c|c|c|c|c|c|c|}
\hline $\begin{array}{c}\text { Mixture mass } \\
\text { and inert material }\end{array}$ & $R e_{\exp }$ & $\mathrm{C} 1$ & $\mathrm{C} 2$ & $\mathrm{C} 3$ & $\mathrm{C} 4$ & $\mathrm{C} 5$ & $\mathrm{C} 6$ & $\mathrm{C} 7$ & $\mathrm{C} 8$ \\
\hline $100 \mathrm{~g}$, sand & 1.25 & $20 \%$ & $100 \%$ & $90 \%$ & $68 \%$ & $53 \%$ & $101 \%$ & $56 \%$ & $108 \%$ \\
\hline $200 \mathrm{~g}$, sand & 1.15 & $102 \%$ & $118 \%$ & $107 \%$ & $83 \%$ & $67 \%$ & $119 \%$ & $70 \%$ & $127 \%$ \\
\hline $300 \mathrm{~g}$, sand & 1.34 & $73 \%$ & $87 \%$ & $78 \%$ & $57 \%$ & $44 \%$ & $88 \%$ & $46 \%$ & $95 \%$ \\
\hline $100 \mathrm{~g}$, glass beads & 1.03 & $32 \%$ & $45 \%$ & $35 \%$ & $19 \%$ & $9 \%$ & $45 \%$ & $9 \%$ & $82 \%$ \\
\hline $200 \mathrm{~g}$, glass beads & 1.01 & $34 \%$ & $47 \%$ & $37 \%$ & $21 \%$ & $11 \%$ & $47 \%$ & $11 \%$ & $85 \%$ \\
\hline $300 \mathrm{~g}$, glass beads & 1.04 & $30 \%$ & $42 \%$ & $33 \%$ & $17 \%$ & $7 \%$ & $42 \%$ & $7 \%$ & $79 \%$ \\
\hline
\end{tabular}

Again, the correlations presente in $\mathrm{Wu}$ and Bayens [91] and Rao and Bheemarasetti [85] predicted the closest $R e_{\text {exp }}$ for the mixture with glass beads (9\% average error). However, the prediction relative error (average) increased to 55\% and 57\%, respectively, for the premixed nondried sawdust mixtures with silica sand. Moreover, the relative errors were higher when compared to the mixtures with dried sawdust. 


\subsubsection{Top-Fed Dried and Non-Dried Sawdust and Inert Material Mixtures}

This section investigates the hydrodynamics of the initially-segregated binary mixtures of topfed dried or non-dried sawdust and silica sand or glass beads. The sawdust mass fraction was kept constant at $4 \%$ of the total bed mass.

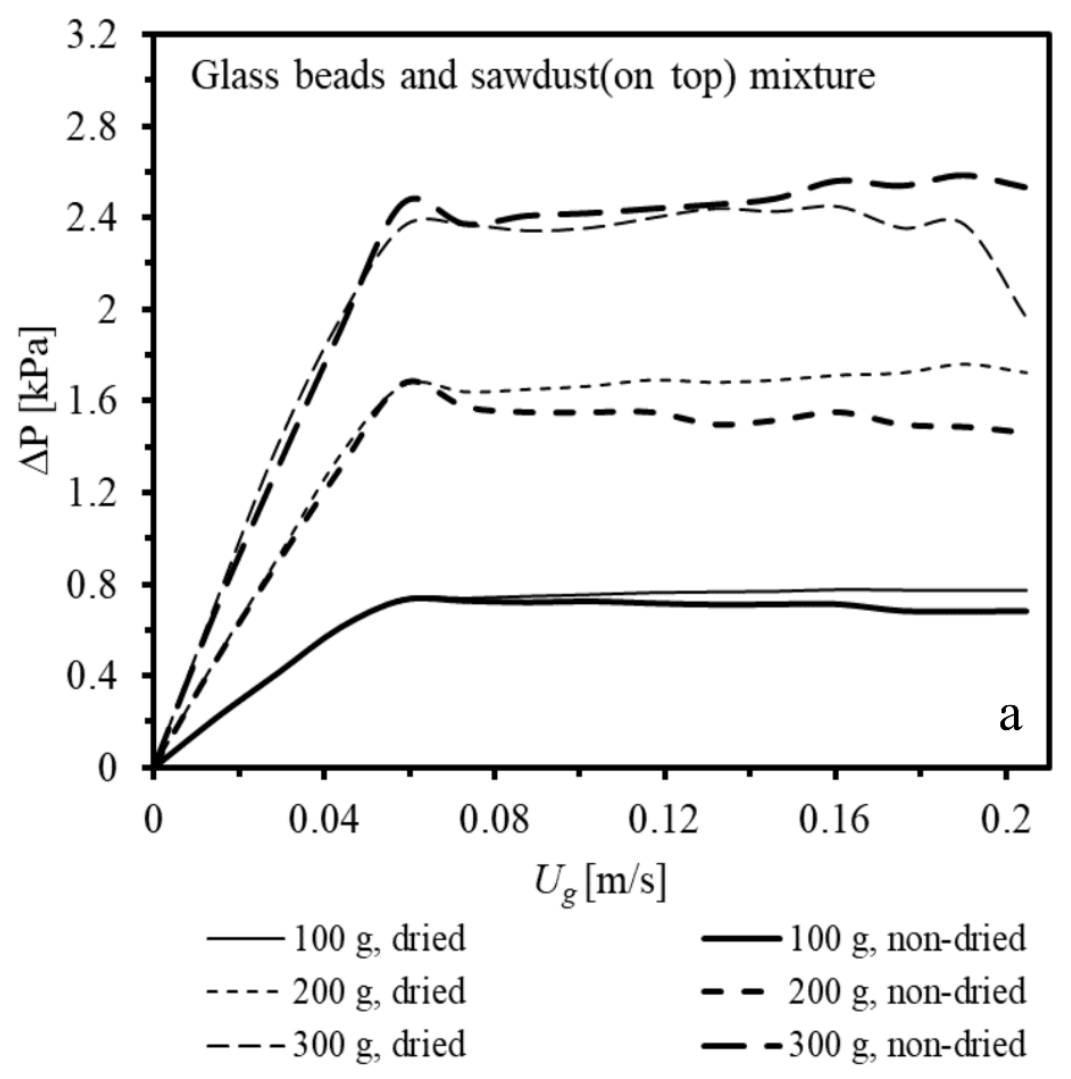




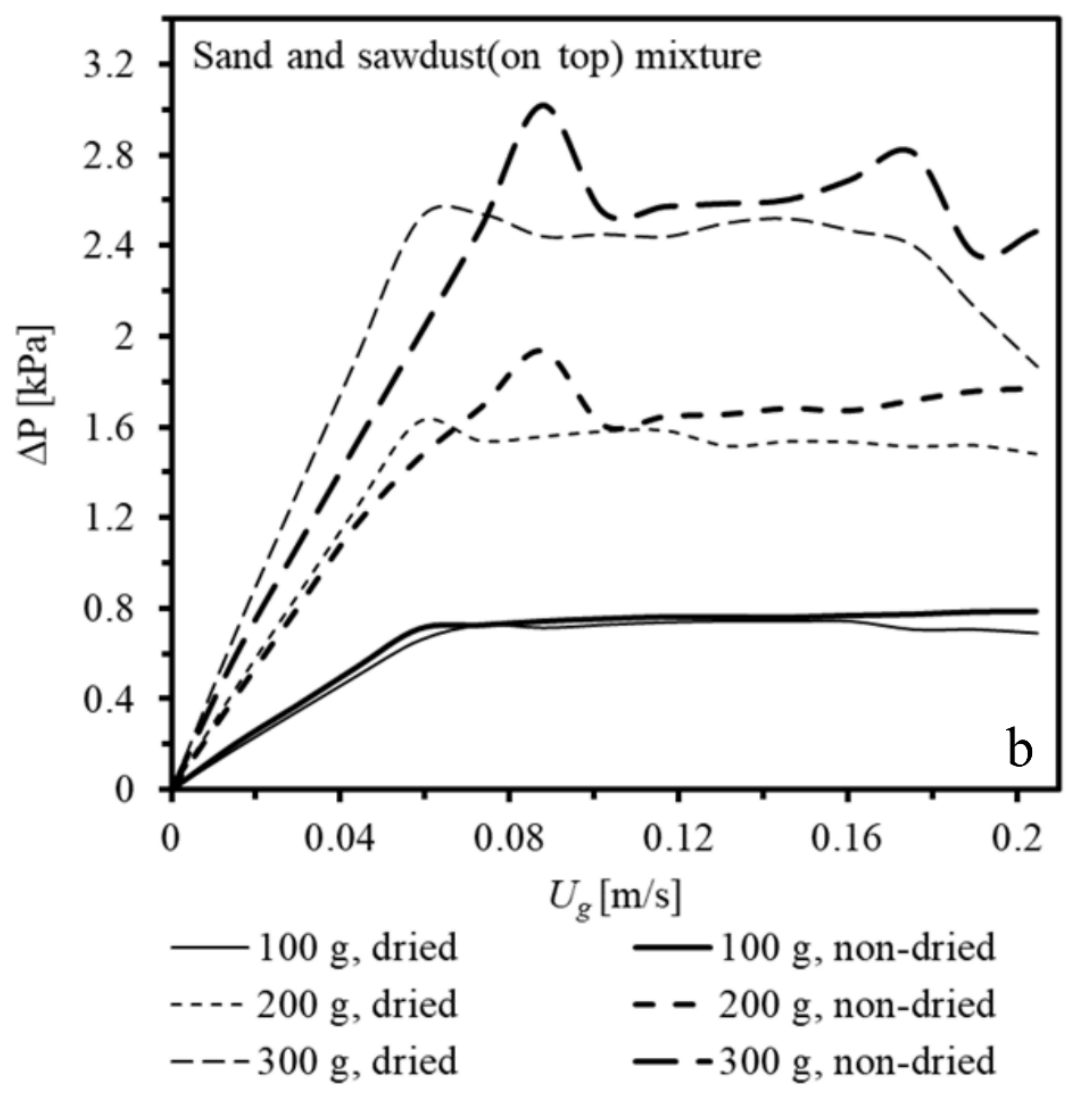

Figure 25. Bed pressure drop versus superficial gas velocity at ambient temperature for the binary mixtures of sawdust (on top) with a) glass beads or b) silica sand with the mixture masses of $100 \mathrm{~g}, 200 \mathrm{~g}$, and $300 \mathrm{~g}$, respectively.

The bed pressure drop inside the segregated binary mixtures of dried or non-dried sawdust (top-fed) with glass beads (Figure 25a) or silica sand (Figure 25b) relative to the fluidizing gas superficial velocity at ambient temperature is shown in Figure 25. The bed pressure drop at the minimum fluidization conditions was $0.73 \mathrm{kPa}, 1.54 \mathrm{kPa}$, and $2.44 \mathrm{kPa}$ for the mixtures dried sawdust with silica sand and $0.74 \mathrm{kPa}, 1.64 \mathrm{kPa}$, and $2.41 \mathrm{kPa}$ for the dried sawdust mixtures with glass beads (total mass of $100 \mathrm{~g}, 200 \mathrm{~g}$, and $300 \mathrm{~g}$, respectively), which suggest a negligible effect of the bed material when the dried sawdust was top fed. The corresponding $H_{p} / D_{b}$ at static bed conditions were 1.9, 4 and 6 for the mixtures with silica sand and were 1.8, 3.8, and 5.7 for the 
mixtures with glass beads (total mass of $100 \mathrm{~g}, 200 \mathrm{~g}$, and $300 \mathrm{~g}$, respectively). The measured $U_{m f}$ were $0.064 \mathrm{~m} / \mathrm{s}, 0.055 \mathrm{~m} / \mathrm{s}$, and $0.056 \mathrm{~m} / \mathrm{s}$ for the mixtures with silica sand and $0.055 \mathrm{~m} / \mathrm{s}, 0.055$ $\mathrm{m} / \mathrm{s}$, and $0.057 \mathrm{~m} / \mathrm{s}$ for the mixtures with glass beads (total mass of $100 \mathrm{~g}, 200 \mathrm{~g}$, and $300 \mathrm{~g}$, respectively), which suggest a negligible effect of the aspect ratio on $U_{m f}$. Table 26 summarizes the experimental values of $\Delta P_{m f}, A r, R e, U_{m f}$, and $H_{p} / D_{b}$ for the mixtures with dried sawdust (top fed) with silica sand or glass beads.

Table 26. Experimental values of $\Delta P_{m f}, A r, R e, U_{m f}$ and $H_{p} / D_{b}$ for the binary mixtures of dried sawdust (on top) with glass beads or silica sand

\begin{tabular}{|l|c|c|c|c|c|}
\hline $\begin{array}{l}\text { Mixture mass } \\
\text { and inert material }\end{array}$ & $\Delta P_{m f}[\mathrm{kPa}]$ & $A r$ & $R e$ & $U_{m f}[\mathrm{~m} / \mathrm{s}]$ & $H_{p} / D_{b}$ \\
\hline $100 \mathrm{~g}$, sand & 0.73 & 3226 & 1.34 & 0.064 & 1.92 \\
\hline $200 \mathrm{~g}$, sand & 1.54 & 3226 & 1.15 & 0.055 & 4 \\
\hline $300 \mathrm{~g}$, sand & 2.44 & 3226 & 1.17 & 0.056 & 6 \\
\hline $100 \mathrm{~g}$, glass beads & 0.74 & 1853 & 0.97 & 0.055 & 1.83 \\
\hline $200 \mathrm{~g}$, glass beads & 1.64 & 1853 & 0.97 & 0.055 & 3.83 \\
\hline $300 \mathrm{~g}$, glass beads & 2.41 & 1853 & 1.01 & 0.057 & 5.66 \\
\hline
\end{tabular}

Table 27 compares the experimentally-determined $\mathrm{Re}$ and its theoretical predictions with selected correlations from the literature. In addition, Table 28 presents the relative errors between the correlations in the literature and the experimentally-determined $R e$ for the initially-segregated mixtures of dried sawdust (top fed) with silica sand or glass beads, respectively. 
Table 27. Theoretical predictions of $R e$ for the binary mixtures of dried sawdust (on top) with glass beads or silica sand.

\begin{tabular}{|l|c|c|c|c|c|c|c|c|c|}
\hline $\begin{array}{l}\text { Mixture mass } \\
\text { and inert material }\end{array}$ & $R e_{\text {exp }}$ & $\mathrm{C} 1$ & $\mathrm{C} 2$ & $\mathrm{C} 3$ & $\mathrm{C} 4$ & $\mathrm{C} 5$ & $\mathrm{C} 6$ & $\mathrm{C} 7$ & $\mathrm{C} 8$ \\
\hline $100 \mathrm{~g}$, sand & 1.34 & 2.31 & 2.50 & 2.38 & 2.10 & 1.92 & 2.52 & 1.96 & 2.61 \\
\hline $200 \mathrm{~g}$, sand & 1.15 & 2.31 & 2.50 & 2.38 & 2.10 & 1.92 & 2.52 & 1.96 & 2.61 \\
\hline $300 \mathrm{~g}$, sand & 1.17 & 2.31 & 2.50 & 2.38 & 2.10 & 1.92 & 2.52 & 1.96 & 2.61 \\
\hline $100 \mathrm{~g}$, glass beads & 0.97 & 1.35 & 1.49 & 1.39 & 1.22 & 1.12 & 1.49 & 1.12 & 1.87 \\
\hline $200 \mathrm{~g}$, glass beads & 0.97 & 1.35 & 1.49 & 1.39 & 1.22 & 1.12 & 1.49 & 1.12 & 1.87 \\
\hline $300 \mathrm{~g}$, glass beads & 1.01 & 1.35 & 1.49 & 1.39 & 1.22 & 1.12 & 1.49 & 1.12 & 1.87 \\
\hline
\end{tabular}

Table 28. Error in predicting the theoretical $R e$ for the binary mixtures of dried sawdust (on top) with glass beads or silica sand.

\begin{tabular}{|l|c|c|c|c|c|c|c|c|c|}
\hline $\begin{array}{l}\text { Mixture mass } \\
\text { and inert material }\end{array}$ & $R e_{\exp }$ & $\mathrm{C} 1$ & $\mathrm{C} 2$ & $\mathrm{C} 3$ & $\mathrm{C} 4$ & $\mathrm{C} 5$ & $\mathrm{C} 6$ & $\mathrm{C} 7$ & $\mathrm{C} 8$ \\
\hline $100 \mathrm{~g}$, sand & 1.34 & $13 \%$ & $87 \%$ & $78 \%$ & $57 \%$ & $44 \%$ & $88 \%$ & $46 \%$ & $95 \%$ \\
\hline $200 \mathrm{~g}$, sand & 1.15 & $102 \%$ & $118 \%$ & $107 \%$ & $83 \%$ & $67 \%$ & $119 \%$ & $70 \%$ & $127 \%$ \\
\hline $300 \mathrm{~g}$, sand & 1.17 & $98 \%$ & $114 \%$ & $103 \%$ & $80 \%$ & $64 \%$ & $115 \%$ & $67 \%$ & $123 \%$ \\
\hline $100 \mathrm{~g}$, glass beads & 0.97 & $39 \%$ & $52 \%$ & $42 \%$ & $25 \%$ & $15 \%$ & $52 \%$ & $15 \%$ & $92 \%$ \\
\hline $200 \mathrm{~g}$, glass beads & 0.97 & $39 \%$ & $52 \%$ & $42 \%$ & $25 \%$ & $15 \%$ & $52 \%$ & $15 \%$ & $92 \%$ \\
\hline $300 \mathrm{~g}$, glass beads & 1.01 & $34 \%$ & $47 \%$ & $37 \%$ & $21 \%$ & $11 \%$ & $47 \%$ & $11 \%$ & $85 \%$ \\
\hline
\end{tabular}

Among the selected correlations, Wu and Bayens [91] and Rao and Bheemarasetti [85] again predicted the closest $R e$ to the experiment using glass beeds, with an average relative error of $14 \%$. However, for the mixtures with silica sand the average relative error were $58 \%$ and $61 \%$ respectively. The next best for the mixtures with glass beads was the correlation in Thonglimp et al. [88], with an average relative error of $24 \%$. Compared to the predictions for the premixed binary mixtures with dried sawdust, the relative error in $R e$ increased $\sim 11 \%$. 
Next, measurements were taken from the fluidization of mixtures with non-dried top-fed sawdust. The bed pressure drop at the minimum fluidization conditions was $0.74 \mathrm{kPa}, 1.61 \mathrm{kPa}$, and $2.55 \mathrm{kPa}$ for the mixtures with silica sand and $0.73 \mathrm{kPa}, 1.57 \mathrm{kPa}$, and $2.37 \mathrm{kPa}$ for the mixtures with glass beads (total mass of $100 \mathrm{~g}, 200 \mathrm{~g}$, and $300 \mathrm{~g}$, respectively). The corresponding $H_{p} / D_{b}$ at static bed condition was1.9, 3.9, and 6 for top-fed non-dried sawdust mixtures with silica sand and 1.9, 3.8, and 5.7 for top-fed non-dried sawdust mixtures with glass beads (total mass of $100 \mathrm{~g}$, $200 \mathrm{~g}$, and $300 \mathrm{~g}$, respectively). The measured $U_{m f}$ were $0.060 \mathrm{~m} / \mathrm{s}, 0.065 \mathrm{~m} / \mathrm{s}$, and $0.071 \mathrm{~m} / \mathrm{s}$ for the mixtures with silica sand and $0.058 \mathrm{~m} / \mathrm{s}, 0.054 \mathrm{~m} / \mathrm{s}$, and $0.055 \mathrm{~m} / \mathrm{s}$ for mixtures with glass beads (total mass of $100 \mathrm{~g}, 200 \mathrm{~g}$, and $300 \mathrm{~g}$, respectively). It is interesting to observe the shift to the right of the minimum fluidization velocity range and the increase in the pressure drop peak value inside the non-dried top-fed sawdust mixtures with silica sand compared with the dried topfed sawdust mixtures. Table 29 summarizes the experimentally-determined $\Delta P_{m f}, A r, R e, U_{m f}$, and $H_{p} / D_{b}$ for the mixtures with non-dried sawdust with silica sand or glass beads.

Table 29. Experimental values of $\Delta P_{m f}, A r, R e, U_{m f}$ and $H_{p} / D_{b}$ for the binary mixtures of nondried sawdust (on top) with glass beads or silica sand

\begin{tabular}{|l|c|c|c|c|c|}
\hline $\begin{array}{c}\text { Mixture mass } \\
\text { and inert material }\end{array}$ & $\Delta P_{m f}[\mathrm{kPa}]$ & $A r$ & $R e$ & $U_{m f}[\mathrm{~m} / \mathrm{s}]$ & $H_{p} / D_{b}$ \\
\hline $100 \mathrm{~g}$, sand & 0.74 & 3226 & 1.25 & 0.060 & 1.92 \\
\hline $200 \mathrm{~g}$, sand & 1.61 & 3226 & 1.36 & 0.065 & 3.92 \\
\hline $300 \mathrm{~g}$, sand & 2.55 & 3226 & 1.48 & 0.071 & 6 \\
\hline $100 \mathrm{~g}$, glass beads & 0.73 & 1853 & 1.03 & 0.058 & 1.92 \\
\hline $200 \mathrm{~g}$, glass beads & 1.57 & 1853 & 0.96 & 0.054 & 3.83 \\
\hline $300 \mathrm{~g}$, glass beads & 2.37 & 1853 & 0.97 & 0.055 & 5.66 \\
\hline
\end{tabular}


Table 30 compares the experimentally-determined $R e$ and its theoretical predictions with selected correlations from the literature.

Table 30. Theoretical predictions of $R e$ for the binary mixtures of non-dried sawdust (on top) with glass beads or silica sand.

\begin{tabular}{|l|c|c|c|c|c|c|c|c|c|}
\hline $\begin{array}{l}\text { Mixture mass } \\
\text { and inert material }\end{array}$ & $R e_{\exp }$ & $\mathrm{C} 1$ & $\mathrm{C} 2$ & $\mathrm{C} 3$ & $\mathrm{C} 4$ & $\mathrm{C} 5$ & $\mathrm{C} 6$ & $\mathrm{C} 7$ & $\mathrm{C} 8$ \\
\hline $100 \mathrm{~g}$, sand & 1.25 & 2.31 & 2.50 & 2.38 & 2.10 & 1.92 & 2.52 & 1.96 & 2.61 \\
\hline $200 \mathrm{~g}$, sand & 1.36 & 2.31 & 2.50 & 2.38 & 2.10 & 1.92 & 2.52 & 1.96 & 2.61 \\
\hline $300 \mathrm{~g}$, sand & 1.48 & 2.31 & 2.50 & 2.38 & 2.10 & 1.92 & 2.52 & 1.96 & 2.61 \\
\hline $100 \mathrm{~g}$, glass beads & 1.03 & 1.35 & 1.49 & 1.39 & 1.22 & 1.12 & 1.49 & 1.12 & 1.87 \\
\hline $200 \mathrm{~g}$, glass beads & 0.96 & 1.35 & 1.49 & 1.39 & 1.22 & 1.12 & 1.49 & 1.12 & 1.87 \\
\hline $300 \mathrm{~g}$, glass beads & 0.97 & 1.35 & 1.49 & 1.39 & 1.22 & 1.12 & 1.49 & 1.12 & 1.87 \\
\hline
\end{tabular}

Table 31. Error in predicting the theoretical $R e$ for the binary mixtures of non-dried sawdust (on top) with glass beads or silica sand.

\begin{tabular}{|l|l|l|l|l|l|l|l|l|l|}
\hline $\begin{array}{l}\text { Mixture mass } \\
\text { and inert material }\end{array}$ & $R e_{\exp }$ & $\mathrm{C} 1$ & $\mathrm{C} 2$ & $\mathrm{C} 3$ & $\mathrm{C} 4$ & $\mathrm{C} 5$ & $\mathrm{C} 6$ & $\mathrm{C} 7$ & $\mathrm{C} 8$ \\
\hline $100 \mathrm{~g}$, sand & 1.25 & $13 \%$ & $100 \%$ & $90 \%$ & $68 \%$ & $53 \%$ & $101 \%$ & $56 \%$ & $108 \%$ \\
\hline $200 \mathrm{~g}$, sand & 1.36 & $71 \%$ & $84 \%$ & $75 \%$ & $55 \%$ & $42 \%$ & $86 \%$ & $44 \%$ & $92 \%$ \\
\hline $300 \mathrm{~g}$, sand & 1.48 & $56 \%$ & $69 \%$ & $60 \%$ & $42 \%$ & $30 \%$ & $70 \%$ & $32 \%$ & $76 \%$ \\
\hline $100 \mathrm{~g}$, glass beads & 1.03 & $32 \%$ & $45 \%$ & $35 \%$ & $19 \%$ & $9 \%$ & $45 \%$ & $9 \%$ & $82 \%$ \\
\hline $200 \mathrm{~g}$, glass beads & 0.96 & $42 \%$ & $55 \%$ & $45 \%$ & $28 \%$ & $17 \%$ & $55 \%$ & $17 \%$ & $95 \%$ \\
\hline $300 \mathrm{~g}$, glass beads & 0.97 & $39 \%$ & $52 \%$ & $42 \%$ & $25 \%$ & $15 \%$ & $52 \%$ & $15 \%$ & $92 \%$ \\
\hline
\end{tabular}

Furthermore, Table 31 presents the relative errors between the correlations in the literature and the experimentally-determined $R e$ for the initially-segregated mixtures of non-dried sawdust (top fed) with silica sand or glass beads, respectively. Among the selected correlations, $\mathrm{Wu}$ and Bayens [91] and Rao and Bheemarasetti [85] predict better Re for the mixture with glass beads, with an average error of $14 \%$. However, for the mixtures with silica sand, the average relative error increased to $42 \%$ and $44 \%$, respectively. The other predictions produced large relative errors. In 
addition, the drying of sawdust particles decreased the relative error for the mixtures with silica sand by $\sim 14 \%$.

\subsubsection{Summary and Conclusions}

This study investigated the fluidization inside a cold flow model of a real-application bench-

scale bubbling fluidized bed reactor (BFBR). The experiment used well-characterized binary mixtures of biomass and sand or glass beads (i.e., known size and shape distribution, density, moisture content, initial mixing condition (premixed or biomass-on-top segregated), bed aspect ratio, etc.). In addition to measuring the minimum fluidization velocity, $U_{m f}$, this study compared the experimental Reynolds number $(R e)$ with selected correlations from the literature for each test case. The main conclusions were:

- The binary mixture created by the addition of $4 \mathrm{wt} . \%$ biomass to sand or glass beads had a worse fluidization behavior compared to the fluidization inside the unary mixture of sand or glass beads. This was also reflected in larger relative errors between the predicted and the experimental $R e$.

- $\quad$ The bed aspect ratio, $H_{p} / D_{b}$, had a negligible effect on $U_{m f}$ of unary mixtures.

- Fluidization behavior of biomass binary mixtures improved when the biomass and sand or glass beads were premixed, supported by the narrower range of measured $U_{m f}$. This was due to the more homogenous distribution of particles inside the mixture and better packing compared to biomass-on-top segregated mixtures.

- Premixed binary mixtures produced lower relative errors between the predicted and the experimental $R e$ compared to segregated binary mixtures. 
- A larger biomass humidity decreased $U_{m f}$ of premixed binary mixtures but increased the relative error between the predicted and the experimental $R e$.

- Wu and Bayens [91] and Rao and Bheemarasetti [85] correlations produced the lowest relative errors between the predicted and the experimental $R e$, among the selected correlations used to predict $R e$ in this study.

\subsection{Mixing and Fluidization Behavior}

The visualization of the fluidization process under cold flow conditions helps to understand the complex hydrodynamics of biomass top-fed deep-bed $\left(H_{p} / D_{b}>2\right)$ binary mixtures. Deep-bed applications are preferred due to better heat transfer rates and higher gas residence time, hence a higher gasification efficiency. This section studied the mixing and fluidization behavior of binary mixtures of sawdust or coal with two different inert materials (glass beads and silica sand). The mixture total mass increased from $100 \mathrm{~g}$ to $300 \mathrm{~g}$ in 100-g increments (i.e., $100 \mathrm{~g}, 200 \mathrm{~g}$, and 300 g). Sawdust or coal (4\% of the total mixture mass) was placed on top of the bed (i.e., segregated state) to simulate the biomass or coal top-fed system of the actual bench-scale BFBG. To investigate the mixture humidity effect on the hydrodynamics, the sawdust was either dried or nondried before being placed atop the bed material. The experiment observed the pressure drop across the bed, $\Delta P_{b}$, as a function of the superficial gas velocity, $U_{g}$. Specifically, the fluidizing gas flowrate was increased in 1-SLM increments, which corresponded to a $0.0146-\mathrm{m} / \mathrm{s}$ in the superficial gas velocity. After reaching the minimum fluidization condition, the bed fluidization and mixing behavior were also recorded with the high-speed camera at each flow rate. These images helped to determine the optimum fluidizing-gas superficial velocity interval for each mixture composition (i.e., the velocity interval that produced the optimum fluidization and 
mixing). This velocity interval was then considered in designing the stable and efficient operation of the BFBG.

\subsubsection{Sawdust and Sand Mixtures}

Figure 26 and Figure 27 show the bed pressure drop and fluidization behavior with increasing the superficial gas velocity for the dried sawdust (Figure 26a, b; Case I) or non-dried sawdust (Figure 27a, b; Case II) and sand mixture with a total mixture mass of $100 \mathrm{~g}\left(H_{p} / D_{b} \approx 2 ; 4 \%\right.$ sawdust of the total mixture mass). During the fixed bed state, defined as the gas velocity interval where the bed pressure drop increases linear, the particles were stationary. However, with the further increase in the gas velocity, small sand particles percolated into the sawdust layer. Also, preference channel formations were observed close to the top of the sand layer. Peak pressure drop for the non-dried sawdust mixture was higher $\left(\Delta P_{b}=0.83 \mathrm{kPa}\right)$ compared to the mixture with dried sawdust $\left(\Delta P_{b}=0.72 \mathrm{kPa}\right)$. The increase was attributed to the higher interparticle forces at higher moisture content, including stronger bridging and inter-locking forces. 


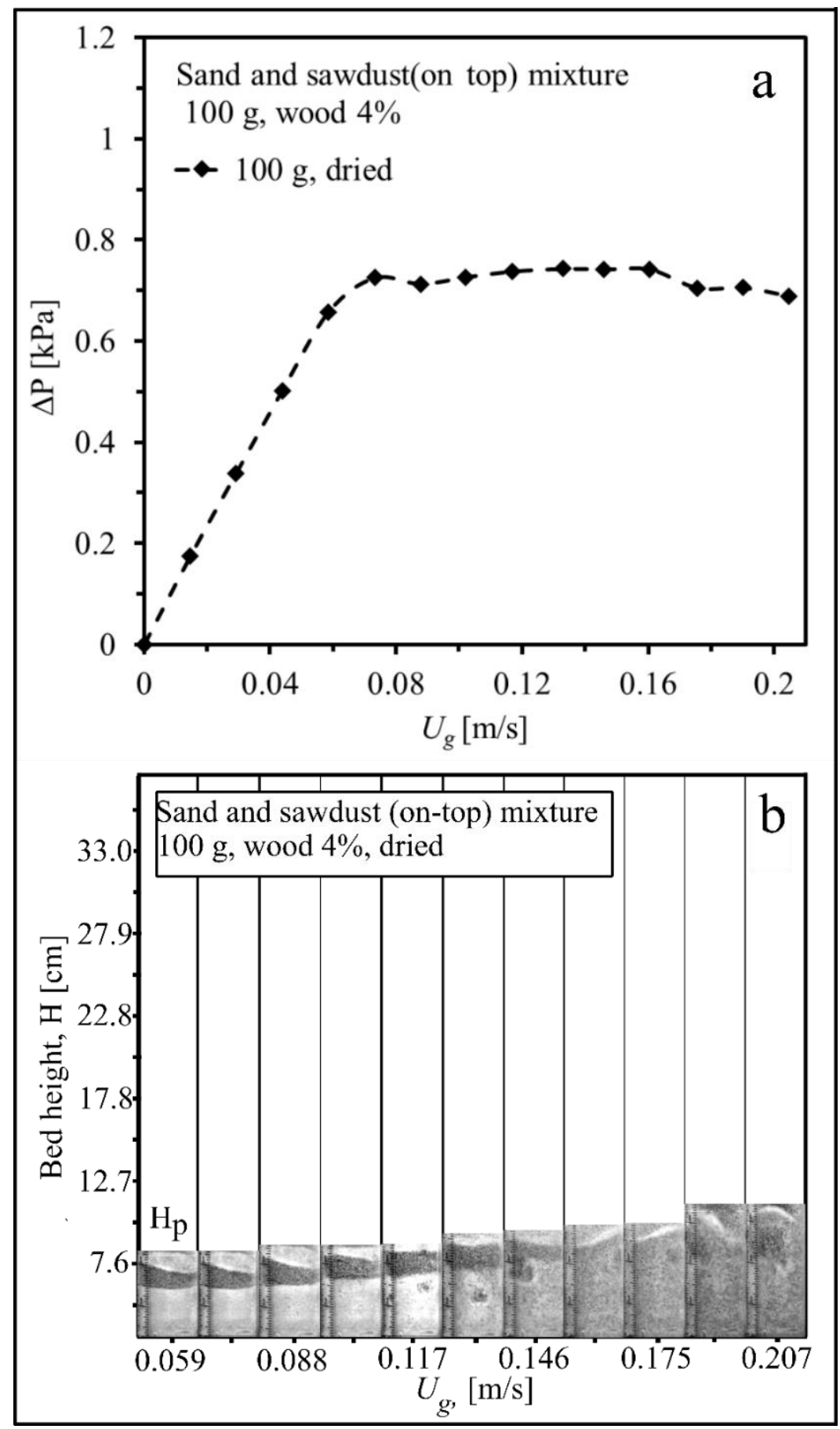

Figure 26. Bed pressure drop and fluidization behaviors with increasing superficial gas velocity for the mixtures of sand and dried sawdust with the total mixture mass of $100 \mathrm{~g}$. 


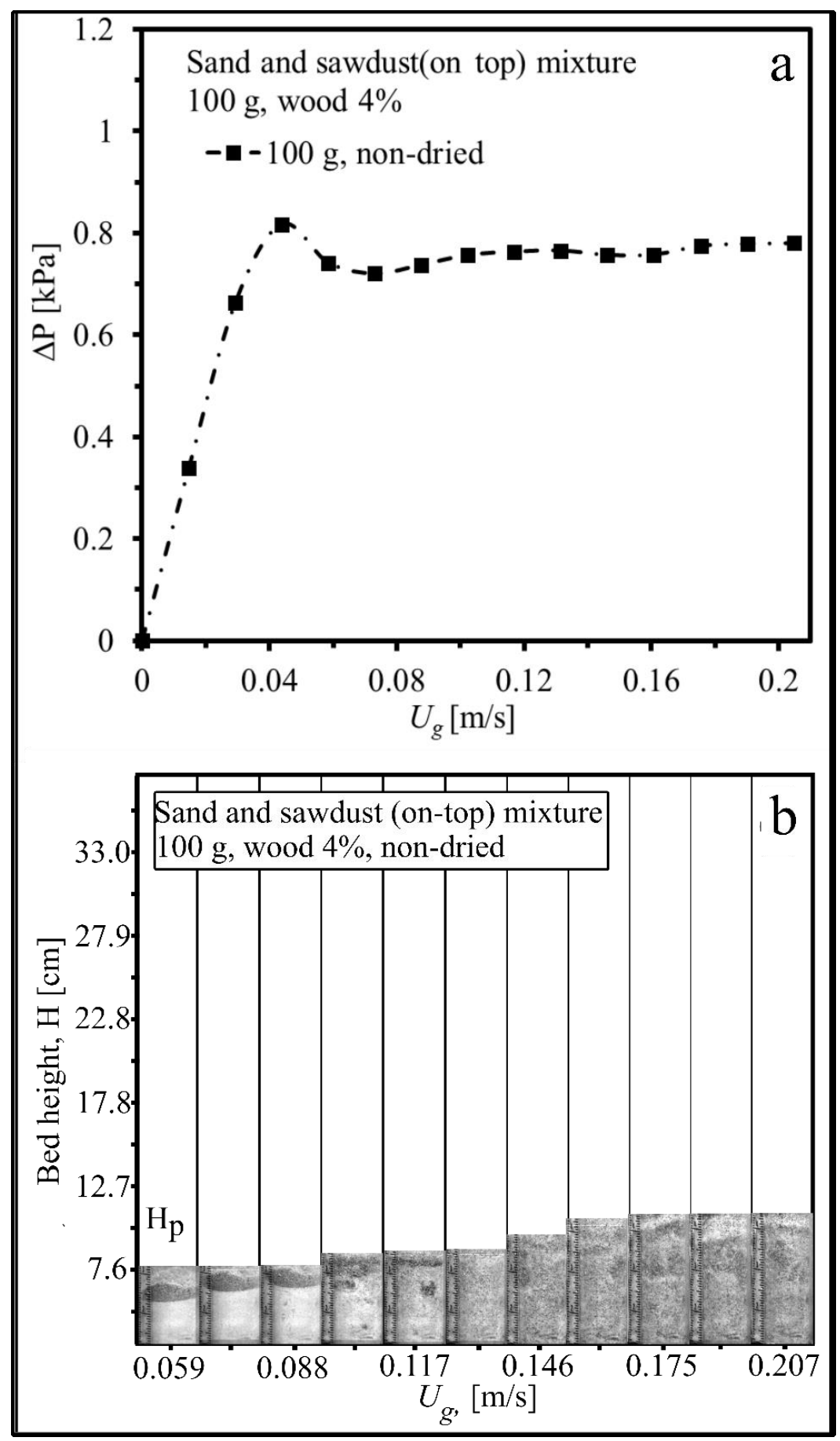

Figure 27. Bed pressure drop and fluidization behaviors with increasing superficial gas velocity for the mixtures of sand and non-dried sawdust with the total mixture mass of $100 \mathrm{~g}$. 
A further increase in the gas velocity during complete fluidization led to visible small bubble formations. While, complete mixing (well-mixed) could be achieved for Case II at $U_{g}=0.13 \mathrm{~m} / \mathrm{s}$, relatively few sawdust particles mixed close to the sand layer surface for Case I at the same gas velocity. This phenomenon can be explained by the more robust interparticle forces formed between the non-dried sawdust particles and sand particles. Also, while dried sawdust particles were entrained by the flow, the non-dried particles resisted the entrainment due to the higher interparticle forces, as mentioned above. As a result, Case I achieved complete mixing $U_{g}=0.16$ $\mathrm{m} / \mathrm{s}$ (i.e., $\sim 20 \%$ increase). After reaching the complete fluidization, the pressure drop curve was almost independent of the superficial gas velocity in both cases. The small fluctuations in the bed pressure drop curve after the complete fluidization velocity were caused by the change in the mixing pattern and bubble size with increased gas velocity. Superficial gas velocities higher than $0.16 \mathrm{~m} / \mathrm{s}$ yielded axial slug formations, but these slugs did not develop into flat slugs due to the relatively low bed aspect ratios. Moreover, recorded images showed that complete mixing was achieved in both cases for the bed aspect ratio of two (i.e., total mass of $100 \mathrm{~g}$ ) and $4 \%$ sawdust of the total mixture mass.

Fluidization and pressure drop behaviors with the increasing superficial gas velocity for Cases I and II (total mixture mass of $200 \mathrm{~g}, H_{p} / D_{b} \approx 4,4 \%$ sawdust of the total mixture mass) are shown in Figure 28 and Figure 29, respectively. The bed pressure drop increased linearly in both cases before the fluidization. In Case II, a small decrease in the slope of the pressure drop just before the peak was observed at $U_{g}=0.10 \mathrm{~m} / \mathrm{s}$. A narrow gap between the sawdust and the sand layer is visible in the image corresponding to that velocity in Figure 29b. 


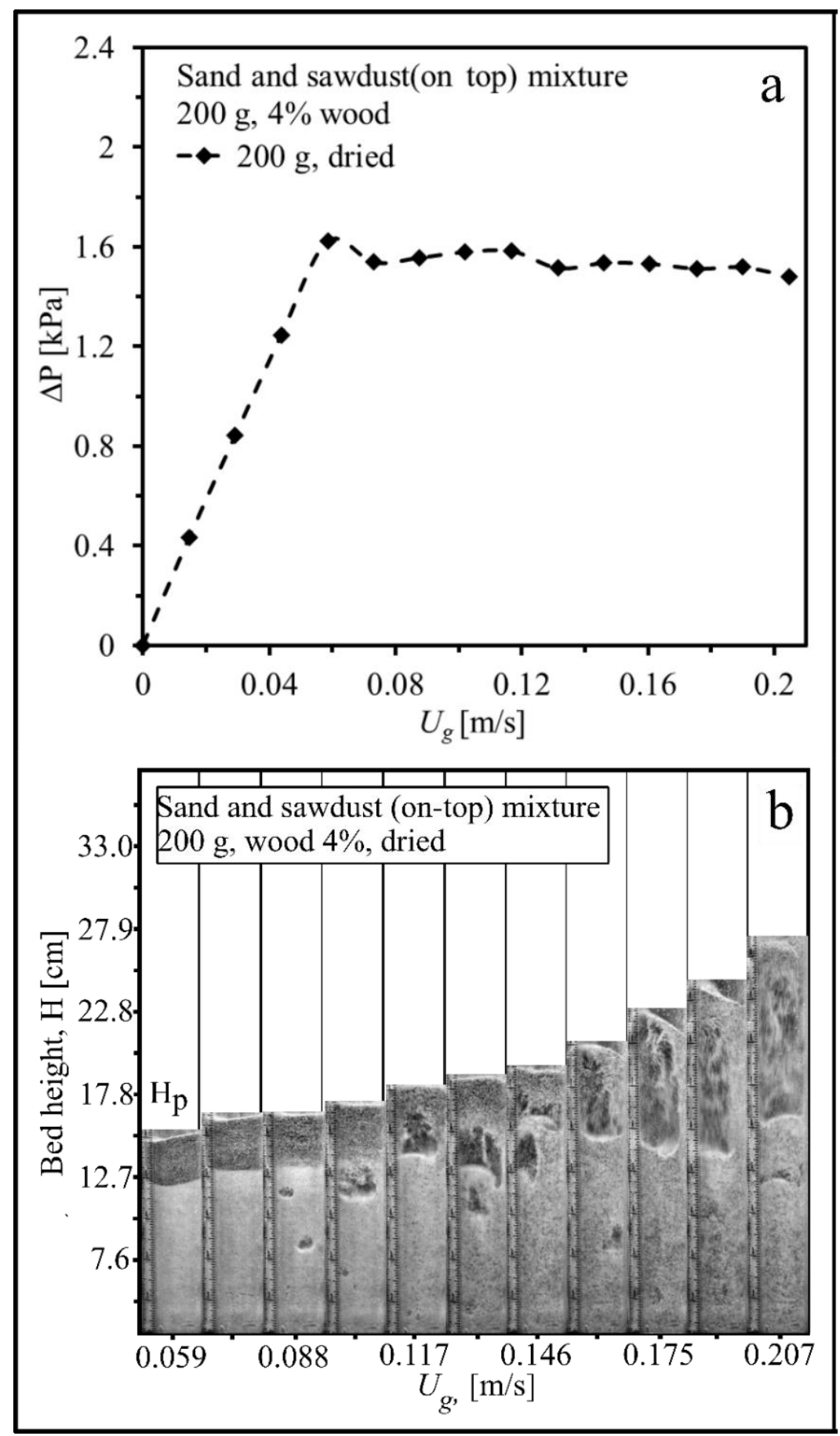

Figure 28. Bed pressure drop and fluidization behaviors with increasing superficial gas velocity for the mixtures of sand and dried sawdust with the total mixture mass of $200 \mathrm{~g}$. 


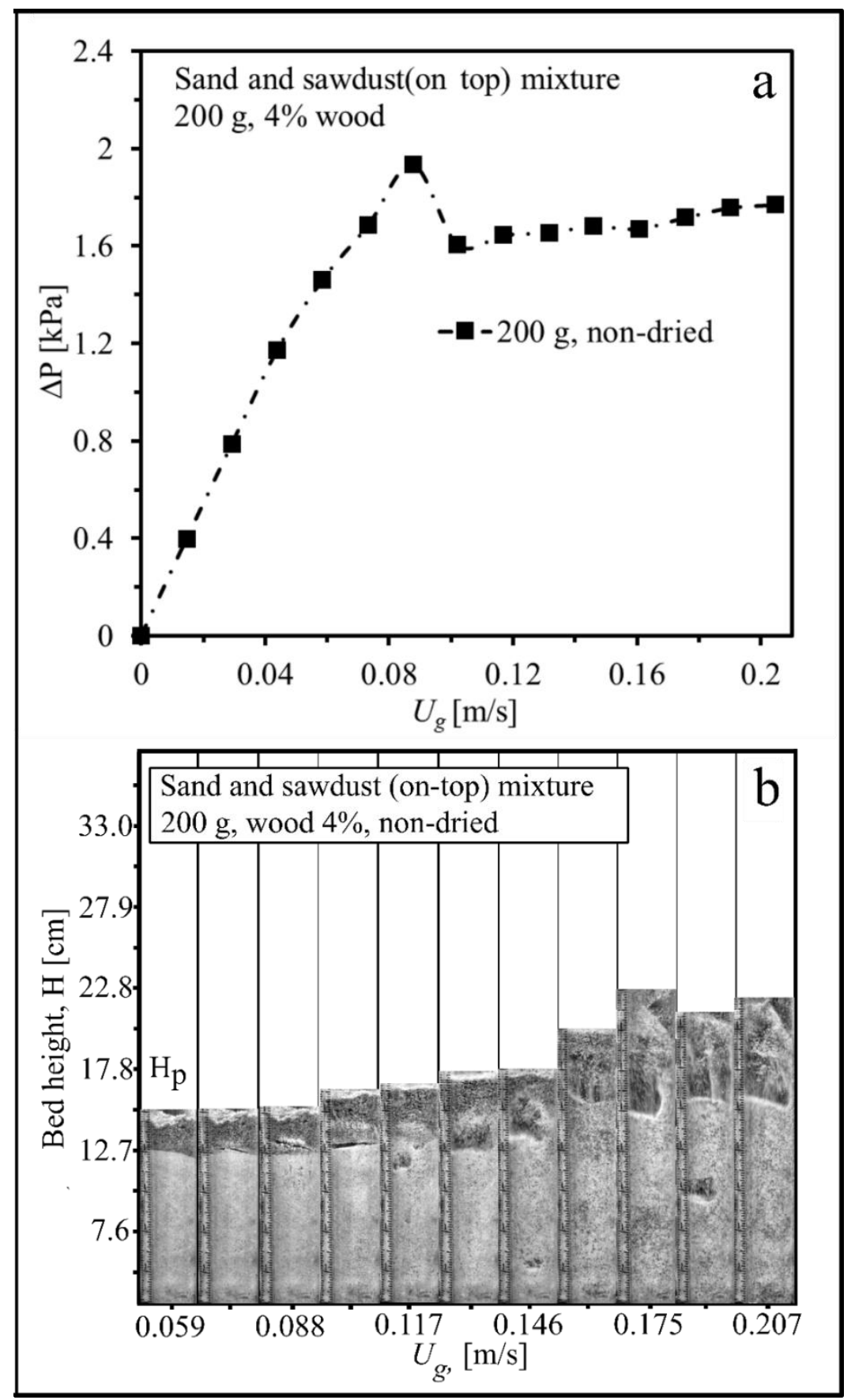

Figure 29. Bed pressure drop and fluidization behaviors with increasing superficial gas velocity for the mixtures of sand and non-dried sawdust with the total mixture mass of $200 \mathrm{~g}$.

The segregated layer of sawdust particles shifted upward in the flow direction, keeping its formation in the agglomerated state. On the surface of the sand layer, the fluidization of relatively 
small particles can be seen. Next, the transition from a fixed bed state into fluidization was smooth for Case I. For Case II, the higher bed pressure drop peak was again due to the humidity effects on the inter-particle forces. Case I reached complete fluidization earlier at $U_{g}=0.09 \mathrm{~m} / \mathrm{s}$, whereas Case II could reach complete fluidization at $U_{g}=0.12 \mathrm{~m} / \mathrm{s}$ (i.e., $\sim 30 \%$ increase). Smooth bubble formations were observed in both cases after reaching the complete fluidization. Slug formations were visible at $U_{g}=0.15 \mathrm{~m} / \mathrm{s}$ for both cases. Also, at $U_{g}=0.15 \mathrm{~m} / \mathrm{s}$, the sawdust layer preserved the most of its agglomerated state in both cases, which means that the drag force and the momentum of already-fluidized particles were not enough to break the strong interparticle forces between the sawdust particles. This is confirmed by the relatively small amount of sawdust particles mixed with the sand near the surface separation of the segregated layers. Later, at $U_{g}=$ $0.16 \mathrm{~m} / \mathrm{s}$, complete mixing was achieved for Case I: the dried sawdust particle layer broke apart and rapidly mixed with the sand particles. Moreover, the sawdust particles showed a homogenous distribution along the bed. On the other hand, at the same gas velocity, the Case-II segregated layer of sawdust particles could not break up completely. However, sand particles spread into the sawdust bulk and filled the gaps. Moreover, strong interparticle forces, including intertwining and bridging of the moist sawdust particles, did not allow the bulk to fluidize and mix with the sand particles thoroughly.

A further increase in the gas velocity yielded flat slug formations in both cases. Ultimately, dried sawdust particles migrated to the top of the bed for Case I. For Case II, the sawdust layer still could not be broken apart completely at the same ultimate velocity, and complete mixing could not be achieved. According to these observations, a $U_{g}$ interval of $0.15-0.18 \mathrm{~m} / \mathrm{s}$ is suggested for the dried sawdust and sand mixtures to achieve complete mixing. 


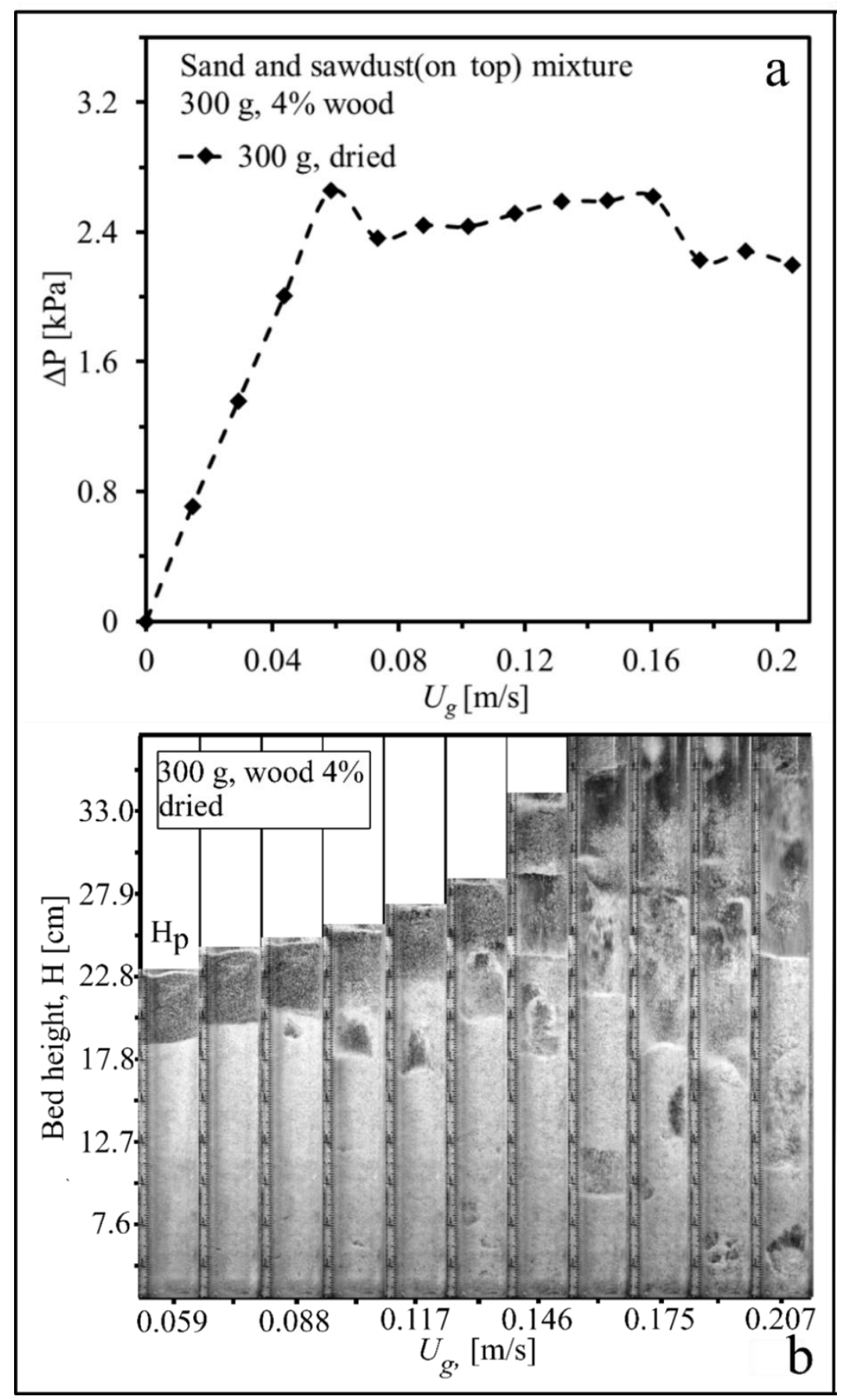

Figure 30. Bed pressure drop and fluidization behaviors with increasing superficial gas velocity for the mixtures of sand and dried sawdust with the total mixture mass of $300 \mathrm{~g}$. 


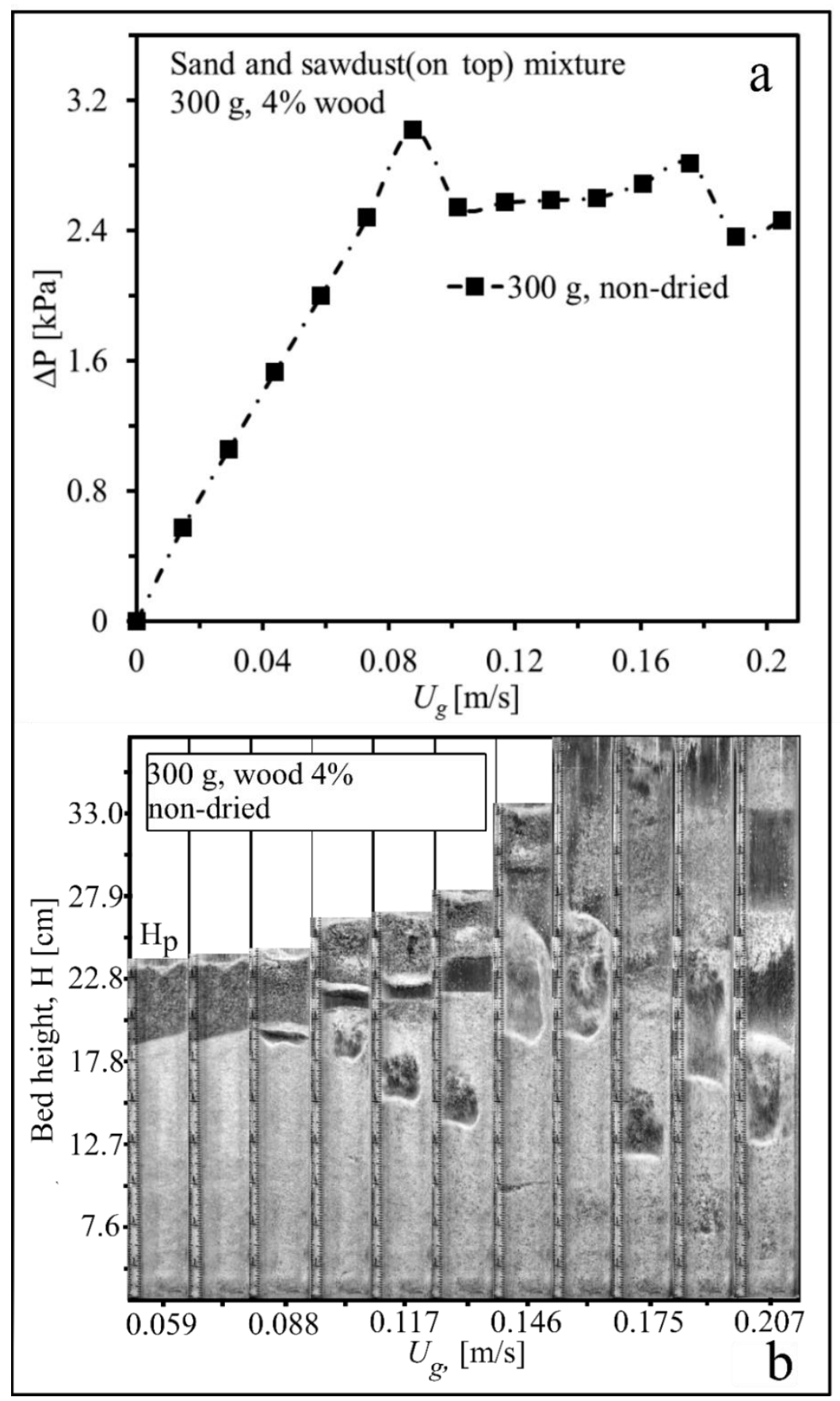

Figure 31. Bed pressure drop and fluidization behaviors with increasing superficial gas velocity for the mixtures of sand and non-dried sawdust with the total mixture mass of $300 \mathrm{~g}$. 
Figure 30 and Figure 31 present the pressure drop and fluidization behaviors for increasing gas velocity for the Cases I and II (total mixture mass of $300 \mathrm{~g}, H_{p} / D_{b} \approx 6,4 \%$ sawdust of the total mixture mass). The bed pressure drop increased linearly during the fixed bed state for both cases. After reaching the peak pressure drop at the end of the fixed bed state, there was a sudden drop in the pressure due to both layers' complete fluidization. The higher peak of pressure drop was again achieved for Case II as it was in the previous tests. The high bed aspect ratio produced axial and wall slugs just after reaching complete fluidization. For Case I, mixing was observed at the contact surface of the segregated layers of sand and sawdust for $U_{g}$ between 0.10 and $0.13 \mathrm{~m} / \mathrm{s}$. For the same $U_{g}$ range, the sawdust layer gradually shifted apart from the sand layer for Case II. In the bed images shown in Figure $31 \mathrm{a} \&$ b, corresponding to $U_{g}=0.15 \mathrm{~m} / \mathrm{s}$, an elevated layer of sawdust particles can be seen in both cases. Strong interparticle forces, including bridging, kept the sawdust layer as a bulk. With the further increase in $U_{g}$, bubbles transformed to flat slugs close to the sand layer surface, and the sawdust layer was carried out by the incoming gas flow while keeping the form. While some of the sawdust particles fell on to the sand surface and mixed with sand, the mixing was not adequate as just a low amount of sawdust particles was retained in a well-mixed state. It can be concluded that in both Cases I and II, the larger total mass (300 g) and aspect ratio (6) impeded the effective fluidization and mixing due to the elutriation of the sawdust layer. This suggested that the bench-scale BFBG should not be operated with a bed aspect ratio of six or total mixture mass of $300 \mathrm{~g}$.

\subsubsection{Sawdust and Glass beads Mixtures}

This section studied the fluidization and mixing behavior for the top-fed mixtures of dried (Case I) or non-dried (Case II) sawdust particles with glass beads (total mixture mass of $100 \mathrm{~g}$, 
$H_{p} / D_{b} \approx 2,4 \%$ sawdust of the total mixture mass). The experimental setup and data acquisition were similar to those presented for the experiments using the sawdust-sand mixtures. 


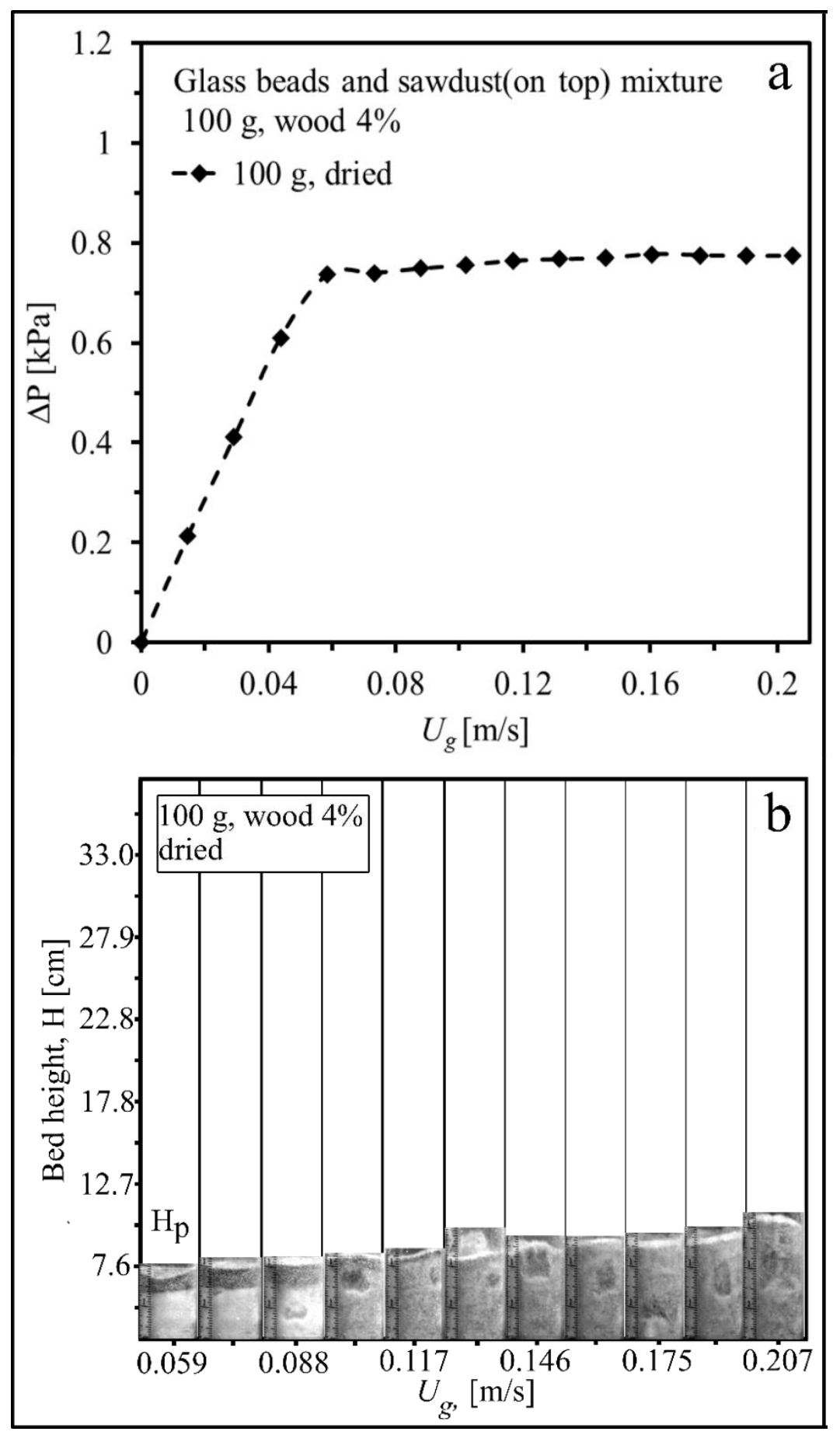

Figure 32. Bed pressure drop and fluidization behaviors with increasing superficial gas velocity for the mixtures of glass beads and dried sawdust with the total mixture mass of $100 \mathrm{~g}$. 


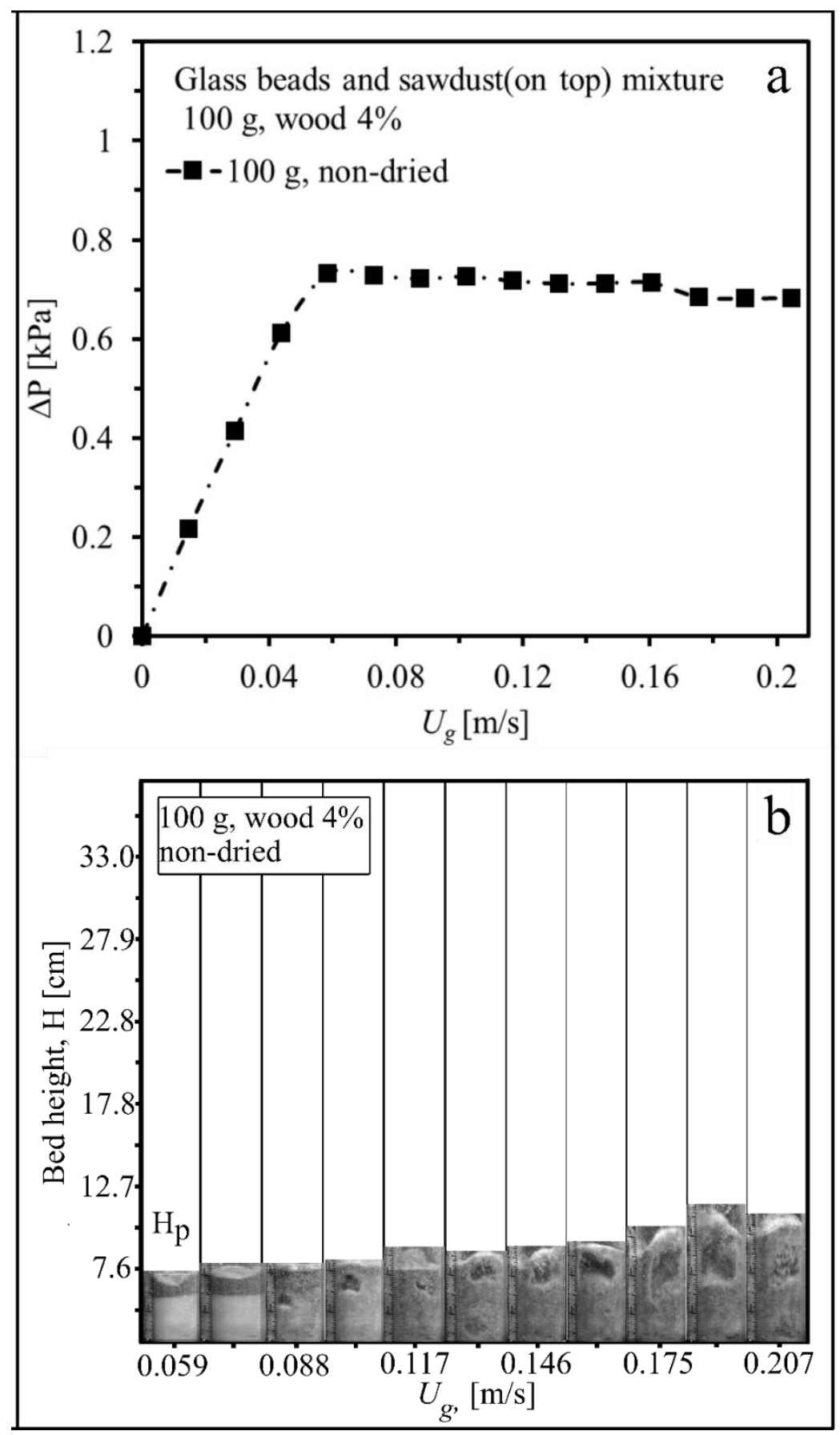

Figure 33. Bed pressure drop and fluidization behaviors with increasing superficial gas velocity for the mixtures of glass beads and non-dried sawdust with the total mixture mass of $100 \mathrm{~g}$. 
Figure 32 and Figure 33 show the bed pressure drop and fluidization behavior with increasing superficial gas velocity for the Case I and Case II mixtures, respectively (total mixture mass of $100 \mathrm{~g}, H_{p} / D_{b}=2,4 \%$ sawdust of the total mixture mass). After the linear increase in the pressure drop during the fixed bed state, a smooth transition to fluidization was observed in both cases. At $U_{g}=0.12 \mathrm{~m} / \mathrm{s}$, sawdust particles were wholly mixed with the sand particles for Case II. However, a thin layer of sawdust particles was observed on top of the sand layer at the same gas velocity for Case I. A further increase in the gas velocity yielded axial slugs and bed expansion but the bed aspect ratio was not enough to develop flat slugs.

Figure 34 and Figure 35 show the bed pressure drop and fluidization behavior with increasing superficial gas velocity for the Case I and Case II mixtures, respectively (total mixture mass of $200 \mathrm{~g}, H_{p} / D_{b}=3.83,4 \%$ sawdust of the total mixture mass). The pressure drop increased linearly during the fixed bed state with the increase in gas velocity. The transition from fixed bed state to fluidization was again smooth. A peak was observed for Case II because of the stronger interparticle bonds associated to the higher sawdust moisture content. Smooth bubble formations were observed after reaching the complete fluidization. Complete mixing was achieved in both cases at $U_{g}=0.13 \mathrm{~m} / \mathrm{s}$. By further increasing the gas velocity, flat slug formations were observed. Even further increase in the gas velocity led to flat slugs that would not mix sawdust material with the glass beads. The results suggest that a $U_{g}$ interval of $0.13-0.15 \mathrm{~m} / \mathrm{s}$ will achieve rapid and complete mixing. 


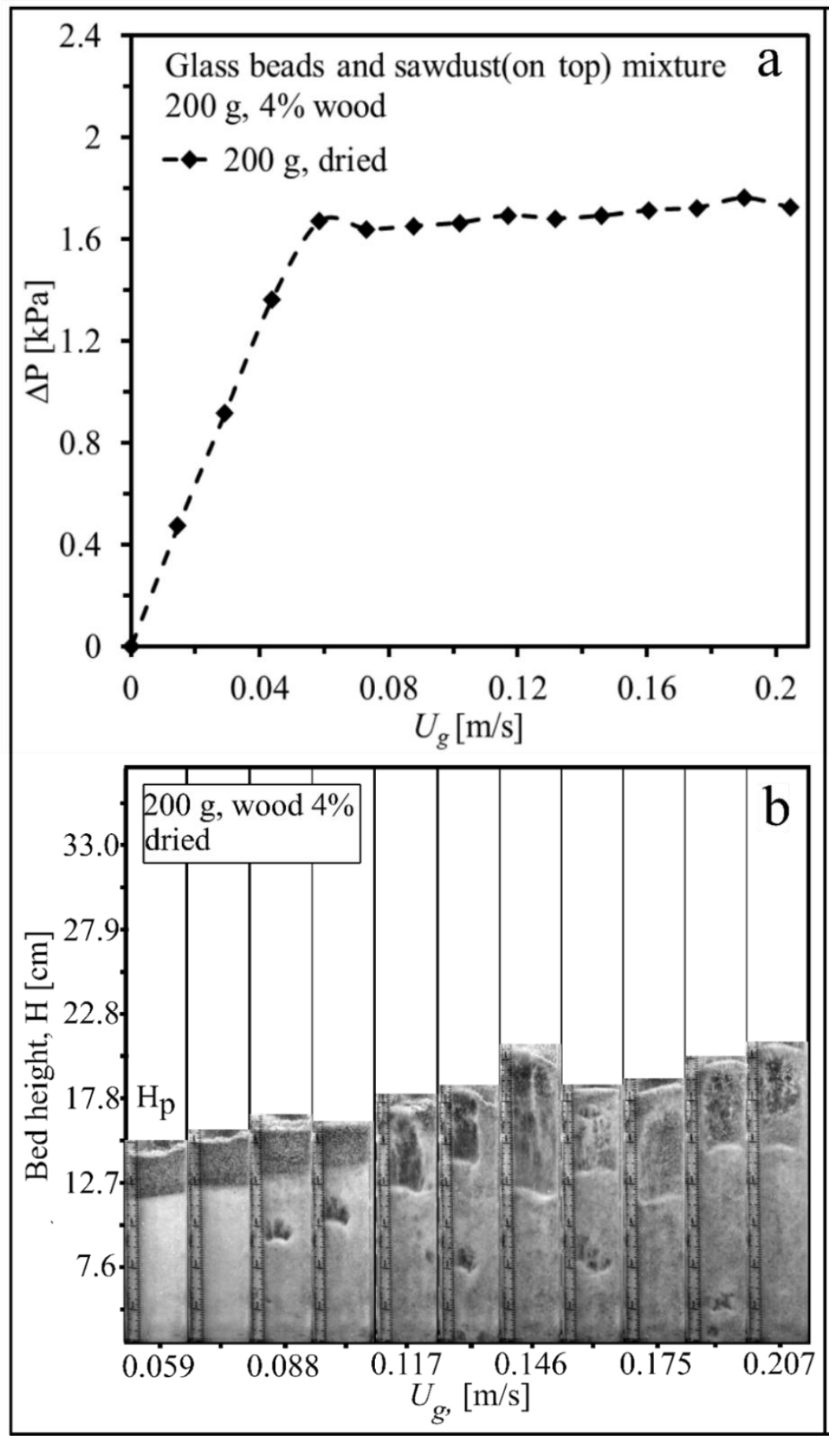

Figure 34. Bed pressure drop and fluidization behaviors with increasing superficial gas velocity for the mixtures of glass beads and dried sawdust with the total mixture mass of $200 \mathrm{~g}$. 


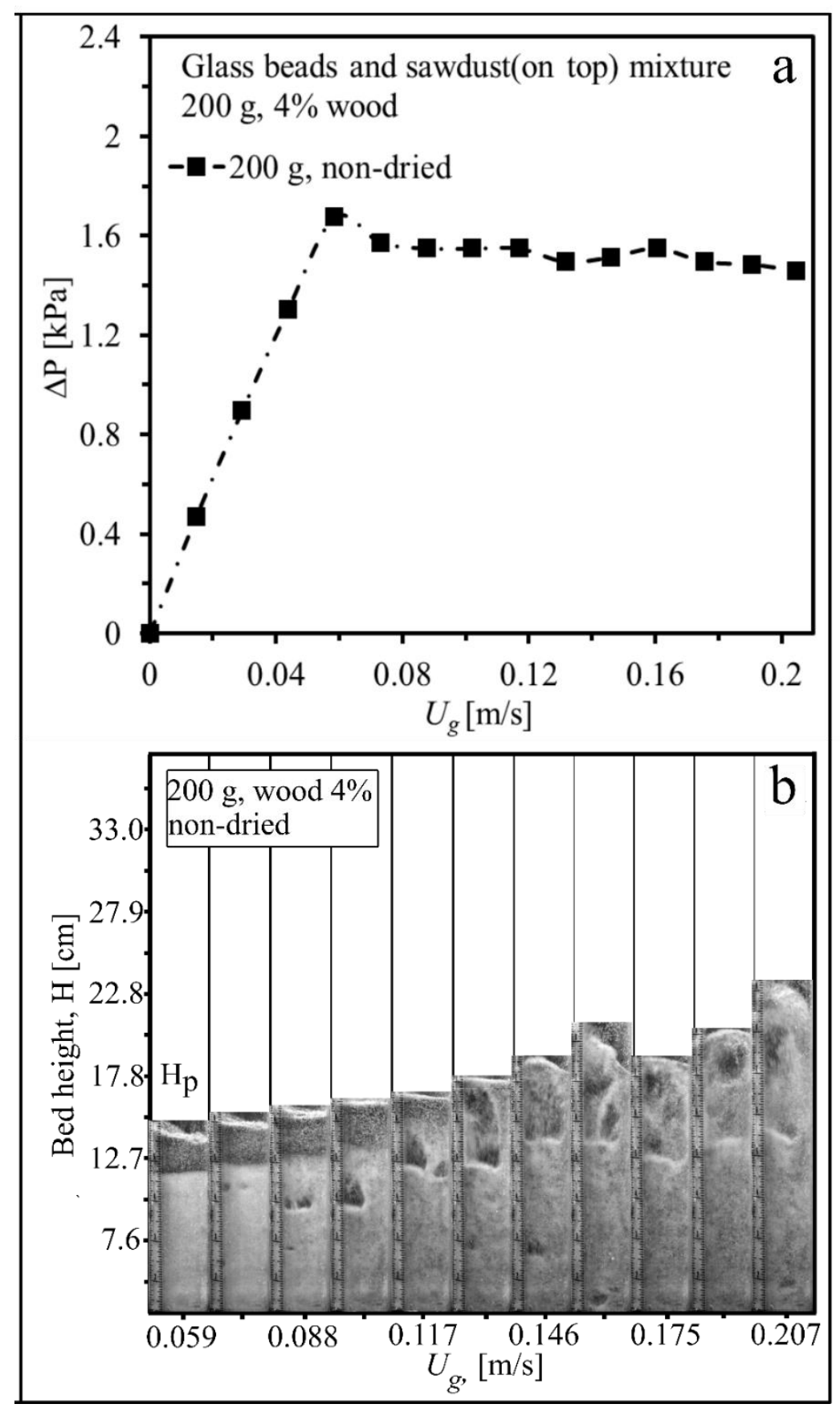

Figure 35. Bed pressure drop and fluidization behaviors with increasing superficial gas velocity for the mixtures of glass beads and non-dried sawdust with the total mixture mass of $200 \mathrm{~g}$ 


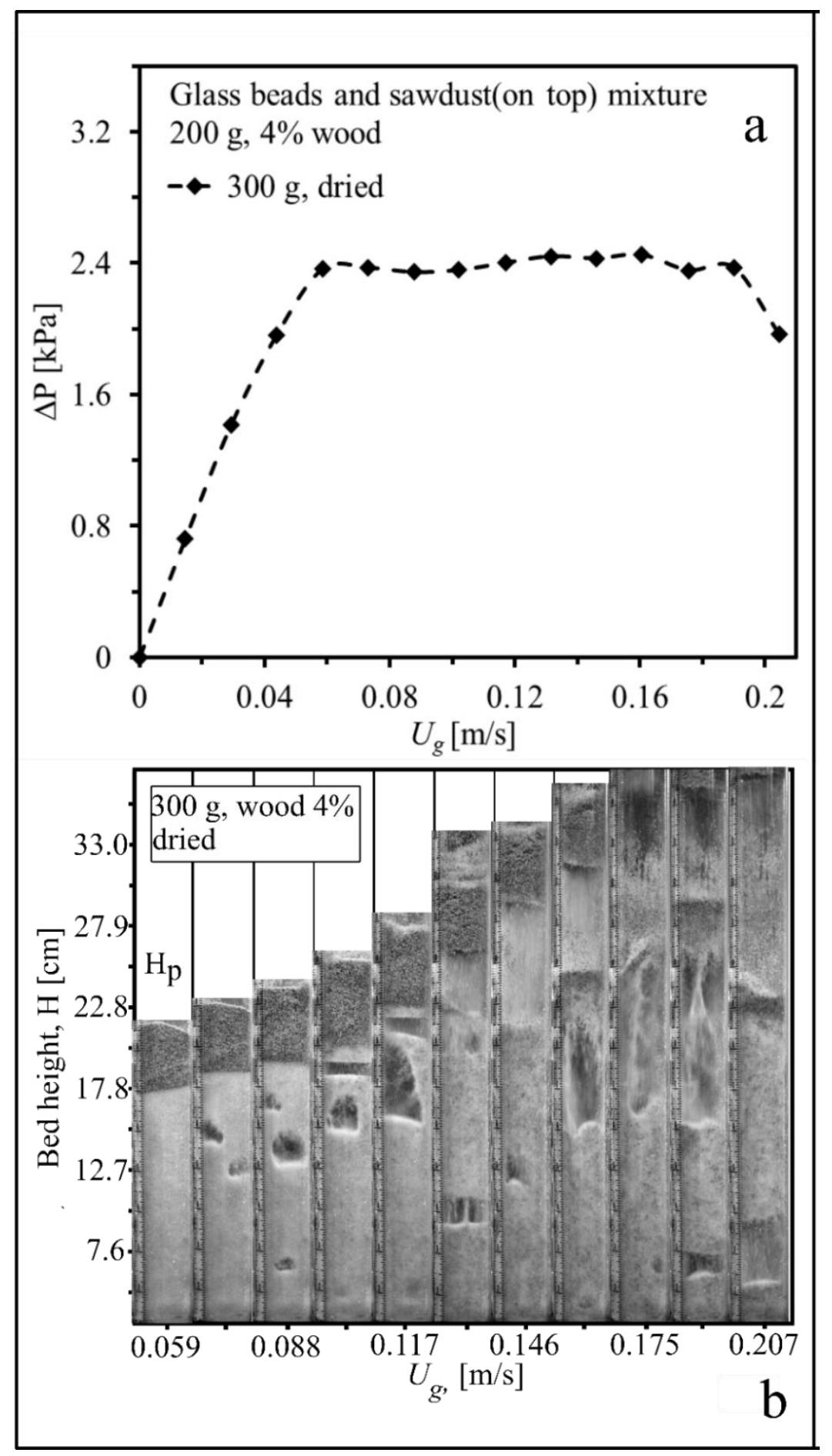

Figure 36. Bed pressure drop and fluidization behaviors with increasing superficial gas velocity for the mixtures of glass beads and dried sawdust with the total mixture mass of $300 \mathrm{~g}$. 


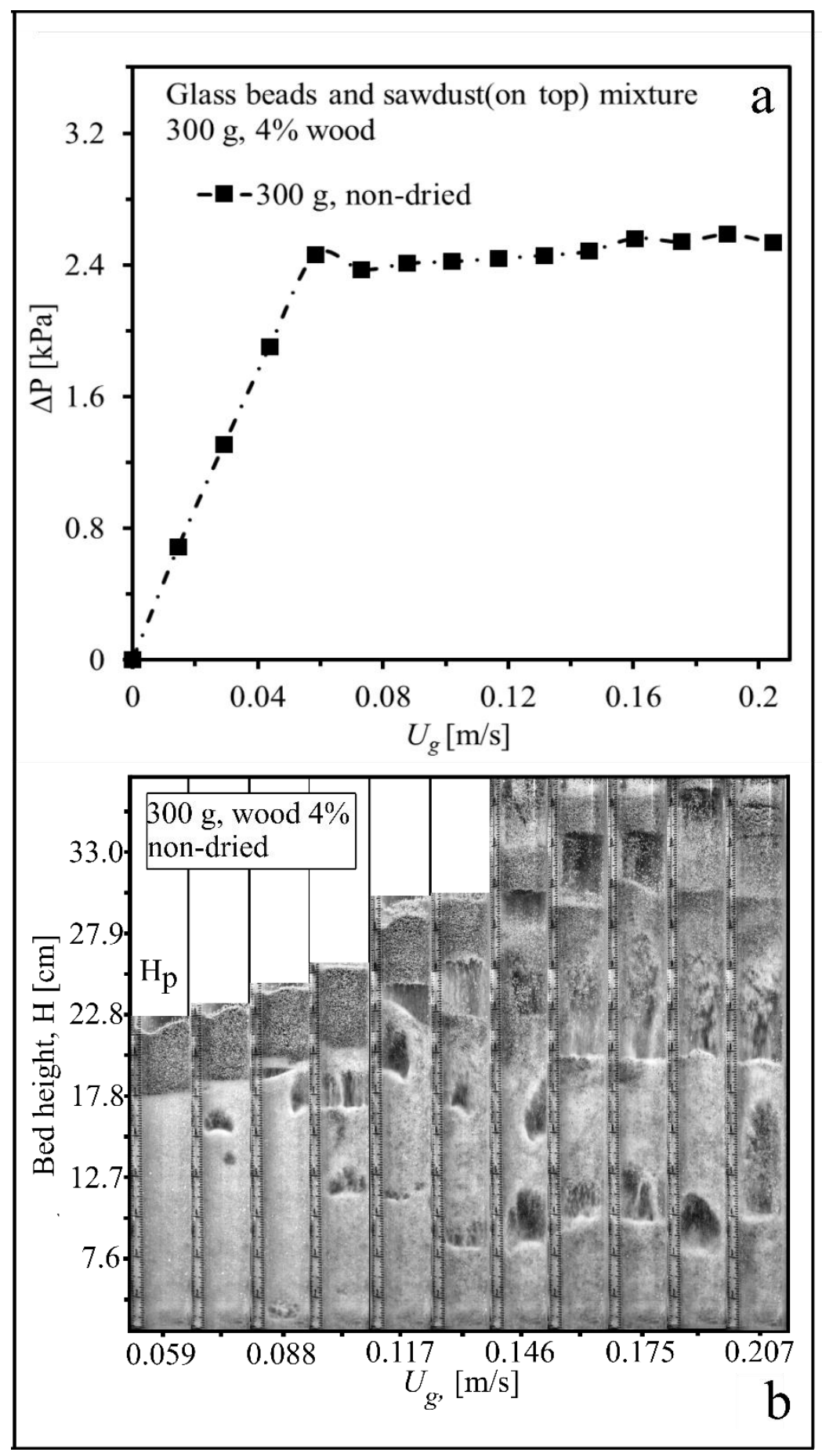

Figure 37. Bed pressure drop and fluidization behaviors with increasing superficial gas velocity for the mixtures of glass beads and non-dried sawdust with the total mixture mass of $300 \mathrm{~g}$. 
Figure 36 and Figure 37 show the bed pressure drop and fluidization behavior with increasing superficial gas velocity for the Case I and Case II mixtures, respectively (total mixture mass of $300 \mathrm{~g}, H_{p} / D_{b}=5.66,4 \%$ sawdust of the total mixture mass). Smooth bubble formations were developed just after reaching fluidization. The high bed aspect ratio promoted rapid bubble growth along the bed. At $U_{g}=0.12 \mathrm{~m} / \mathrm{s}$, wall slugs and the elevation of the sawdust layer were observed. Later, with the further increase in gas velocity, bubbles developed into flat slugs and the sawdust layer shifted upwards while keeping its bulk form. Partial mixing was observed only between the particles that fell from the elevated sawdust layer to the top of the sand layer in both cases. Eventually, $U_{g}>0.15 \mathrm{~m} / \mathrm{s}$ resulted in the sawdust layer being flown out of the mixture. As in the previous experiments with the mixtures of sawdust and sand at the same static bed aspect ratio of six, no adequate mixing was achieved.

\subsubsection{Coal with Sand or Glass beads mixtures}

Mixtures of coal and sand or coal and glass beads have a narrower particle size and sphericity distribution compared to mixtures of sawdust and same inert materials. Combined with the higher bulk density, it suggests that binary coal mixtures should have better fluidization characteristics than binary sawdust mixtures. To investigate this hypothesis, binary coal mixture fluidization experiments where performed for the mixture total mass increasing from $100 \mathrm{~g}$ to $300 \mathrm{~g}$ in $100 \mathrm{~g}$ increments (i.e., $100 \mathrm{~g}, 200 \mathrm{~g}$, and $300 \mathrm{~g}$ ). Coal (4\% of the total mixture mass) was placed on top of the bed (i.e., segregated state) to simulate the coal top-fed system of the actual bench-scale BFBG. The experiment observed the pressure drop across the bed, $\Delta P_{b}$, as a function of the superficial gas velocity, $U_{g}$. Specifically, the fluidizing gas flowrate was increased in 1-SLM increments. Case I and II are used in this section to mention the binary coal mixture with glass 
beads or with sand, respectively. After reaching the minimum fluidization condition, the bed fluidization and mixing behavior were also recorded with the high-speed camera at each flow rate. These images helped to determine the optimum fluidizing-gas superficial velocity interval for each mixture composition (i.e., the velocity interval that produced the optimum fluidization and mixing). This velocity interval was then considered in designing the stable and efficient operation of the BFBG.

Figure 38 and Figure 39 show the bed pressure drop and fluidization behavior with increasing the superficial gas velocity for the coal and glass beads mixture (Figure 38; Case I) or coal and sand mixture (Figure 39; Case II) - total mixture mass of $100 \mathrm{~g}, H_{p} / D_{b} \approx 1.83$ and 2, respectively, $4 \mathrm{wt} \%$ coal of the total mixture mass). For Case I, the pressure curve increased linearly until the initial fluidization, followed by a smooth transition to complete fluidization. For Case II, after reaching a peak in the bed pressure drop, a sudden decrease was next observed when $U_{g}$ increased; $\Delta \mathrm{P}_{\mathrm{b}}$ continued to increase until all particles fluidized due to the larger particle size distribution for the coal-sand mixture. Case I achieved minimum fluidization condition at $U_{g}=0.07 \mathrm{~m} / \mathrm{s}$ (see Figure 38b) and relatively small amounts of particles were mixed at the contact between the two layers of the segregated bed. On the contrary, tiny bubble formations were observed close to the coal and sand layers' surfaces at $U_{g}$ of 0.08 and $0.10 \mathrm{~m} / \mathrm{s}$ in Case II due to channeling. Complete fluidization for Case II was reached relatively late at $U_{g}=0.15 \mathrm{~m} / \mathrm{s}$ due to the late fluidization of the relatively larger particles (i.e., larger interparticle forces and cohesion) and the higher relative humidity of the fluidizing air during this particular experiment. For Case I, the bed was close to a complete mixing state for $U_{g}$ between 0.09 and $0.10 \mathrm{~m} / \mathrm{s}$ (see Figure 38b) except for a thin layer of coal on top of the sand layer. A well-mixed bed was observed with smooth bubbles when $U_{g}=$ $0.12 \mathrm{~m} / \mathrm{s}$. For Case II, $U_{g}=0.16 \mathrm{~m} / \mathrm{s}$ was high enough to overcome the interparticle and cohesive 
forces, including wall effects, hence a thoroughly mixed bed. A further increase in $U_{g}$ caused the elutriation of light coal dust particles. Some of these particles were stuck on the bed wall (see Figure 39b) due to the high cohesiveness caused by the higher relative humidity of fluidizing air. Flat slug formations did not develop for $H_{p} / D_{b} \approx 2$, in both Cases I and II. 


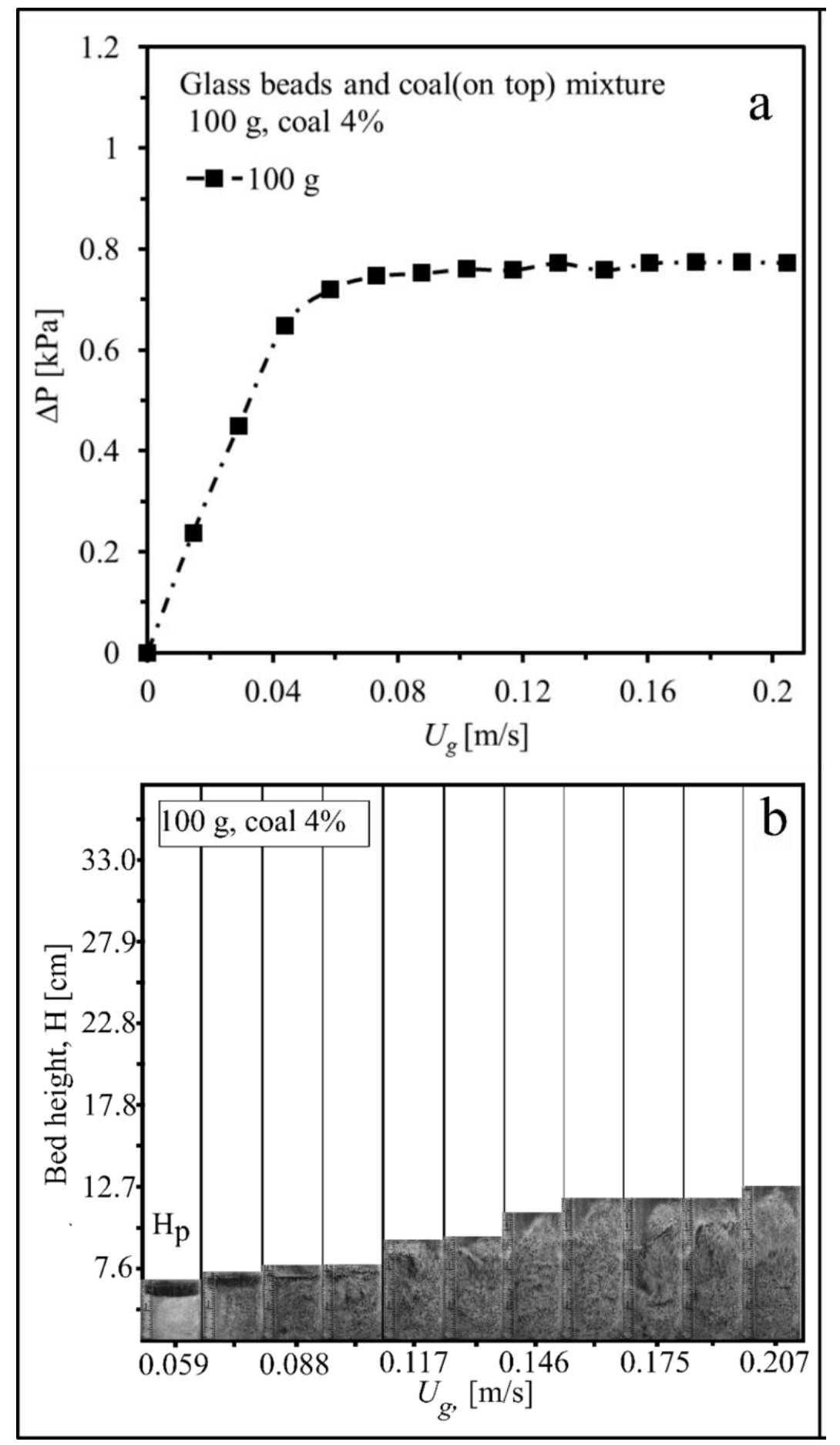

Figure 38. Bed pressure drop and fluidization behaviors with increasing superficial gas velocity for the mixtures of coal and glass beads with the total mixture mass of $100 \mathrm{~g}$. 


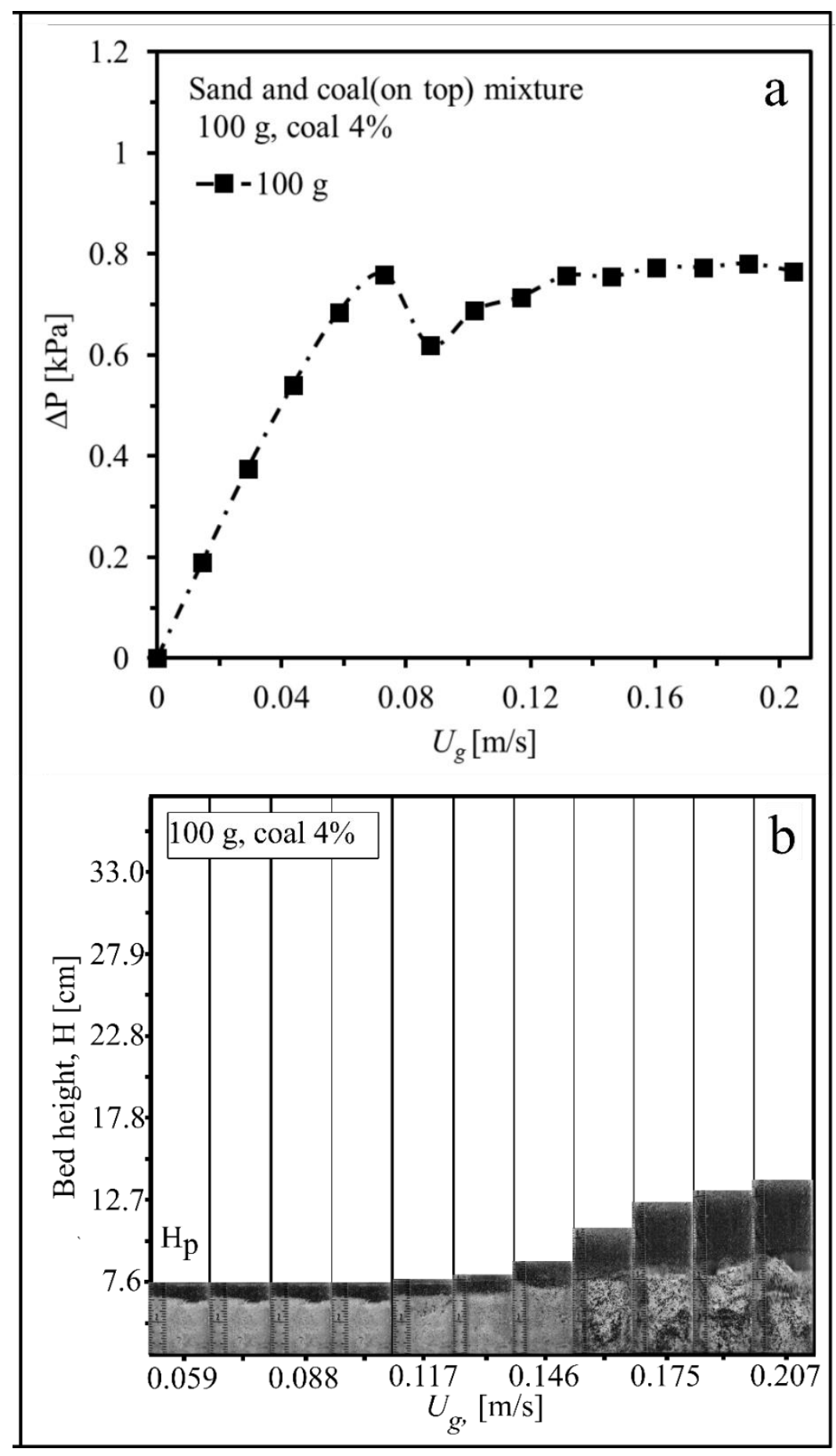

Figure 39. Bed pressure drop and fluidization behaviors with increasing superficial gas velocity for the mixtures of coal and sand with the total mixture mass of $100 \mathrm{~g}$. 


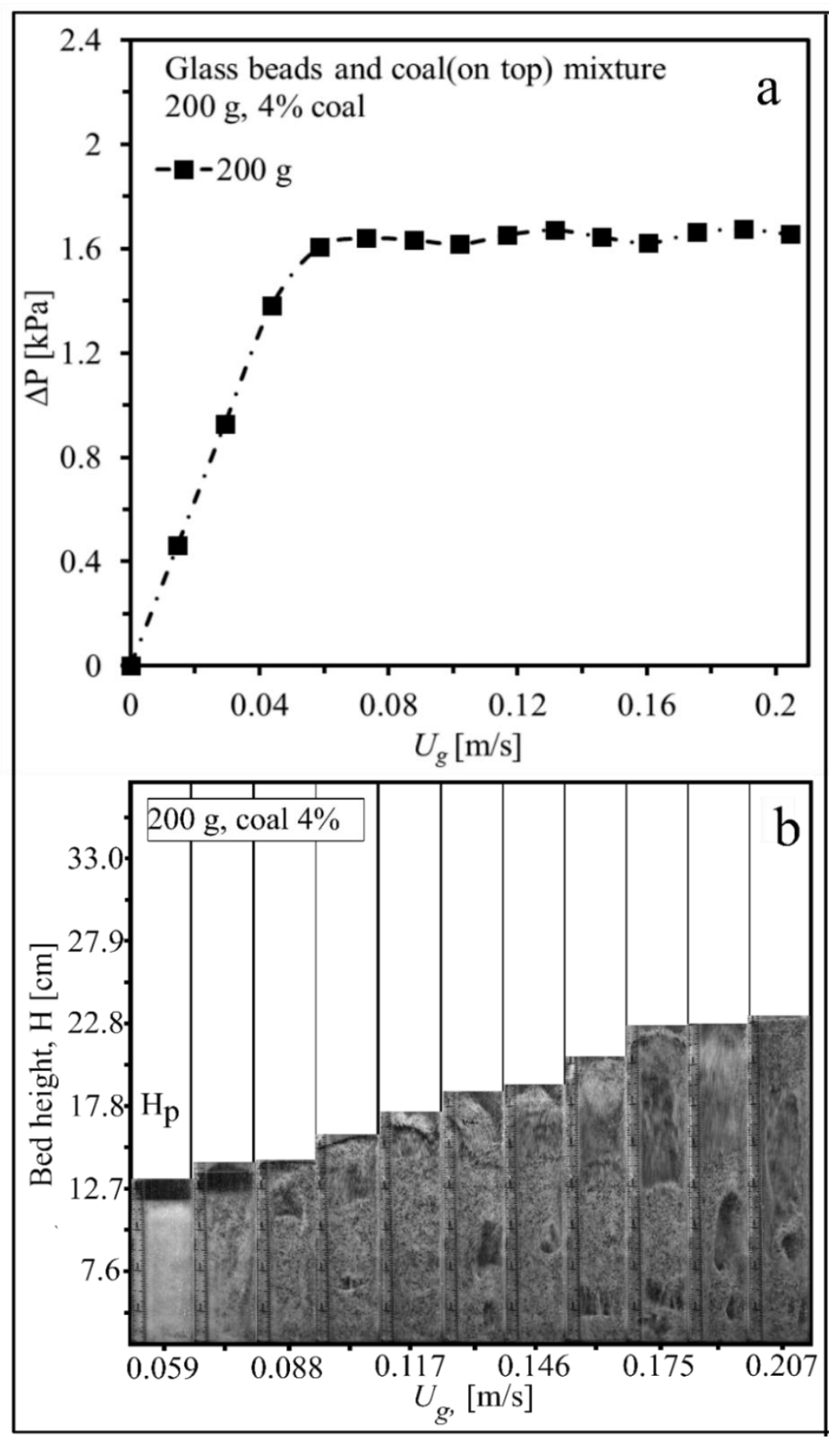

Figure 40. Bed pressure drop and fluidization behaviors with increasing superficial gas velocity for the mixtures of coal and glass beads with the total mixture mass of $200 \mathrm{~g}$. 


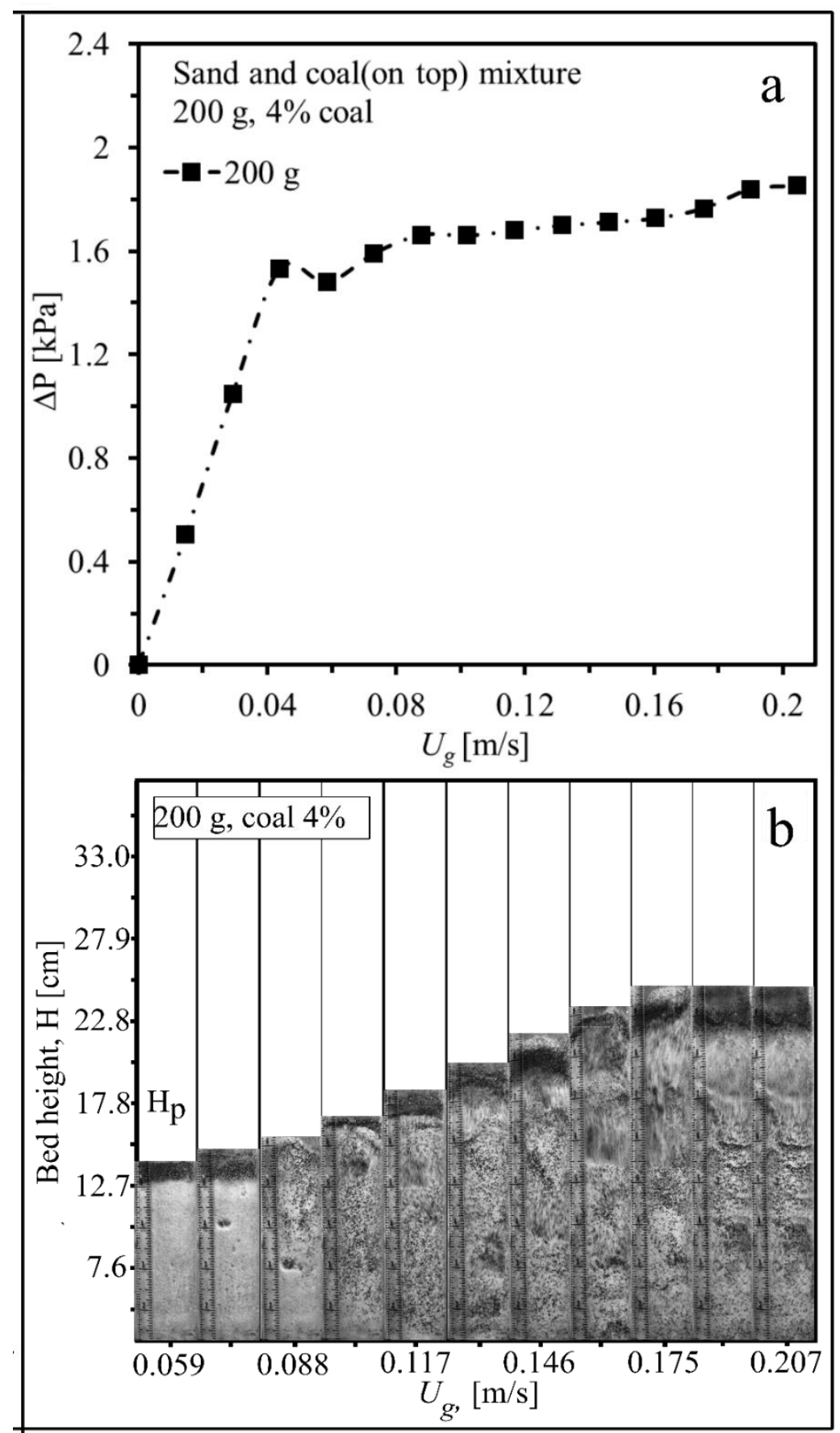

Figure 41. Bed pressure drop and fluidization behaviors with increasing superficial gas velocity for the mixtures of coal and sand with the total mixture mass of $200 \mathrm{~g}$. 
Figure 40 and Figure 41 show the bed pressure drop and fluidization behavior with increasing the superficial gas velocity for the coal and glass beads mixture (Figure 40a\&b; Case I) or coal and sand mixture (Figure 41a\&b; Case II) - total mixture mass of $200 \mathrm{~g},\left(H_{p} / D_{b} \approx 3.5\right.$ and 3.66, respectively, $4 \mathrm{wt} \%$ coal of the total mixture mass). The bed pressure drop increased linearly during the fixed bed state for both cases. Case I had a smoother transition to the fluidization state due to narrower particle size distribution. As in the previous tests with 100-g total mass, the bed pressure drop decreased slightly after reaching the peak before the complete fluidization for the reasons explained previously. In Case I, mixing started immediately once the bed reached complete fluidization: glass beads percolated the coal layer easier than the sand. However, in Case II, when the bed was in a complete fluidization state, mixing did not start despite the apparition of small bubble formations. In addition to the lower sphericity and bigger diameter of the sand particles, the higher relative humidity of the fluidizing air was another reason for the strong bonds between particles. The result was that mixing started later at $U_{g}=0.09 \mathrm{~m} / \mathrm{s}$ (see Figure $41 \mathrm{~b}$ ) for Case II, while the bed was completely mixed at that velocity for Case I. For Case II, a well-mixed state observed at $U_{g}=0.10 \mathrm{~m} / \mathrm{s}$. Wall slugs and later flat slugs were observed in both cases with the further increase in $U_{g}$. Again, some of the coal dust particles stuck on the bed wall due to the air's higher relative humidity. The results show that complete mixing was achieved at lower $U_{g}$ for both coal mixtures compared to the sawdust mixtures. Also, the mixing was homogenous throughout the bed for the $4 \mathrm{wt} \%$ coal in the total mixture mass, while sawdust behaved as a bulk and did not mix at the same static bed aspect ratio and total mass. 


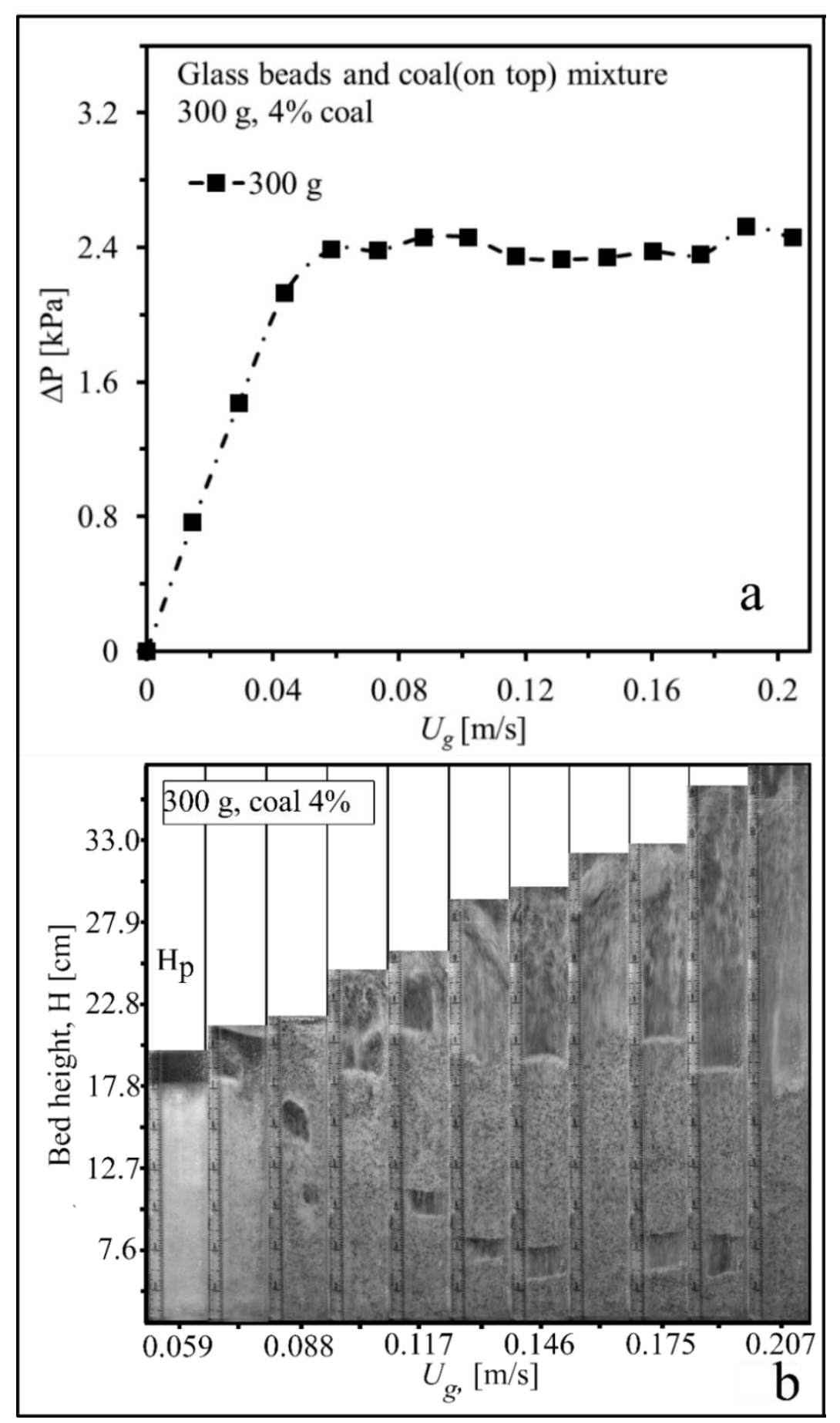

Figure 42. Bed pressure drop and fluidization behaviors with increasing superficial gas velocity for the mixtures of coal and glass beads with the total mixture mass of $300 \mathrm{~g}$. 


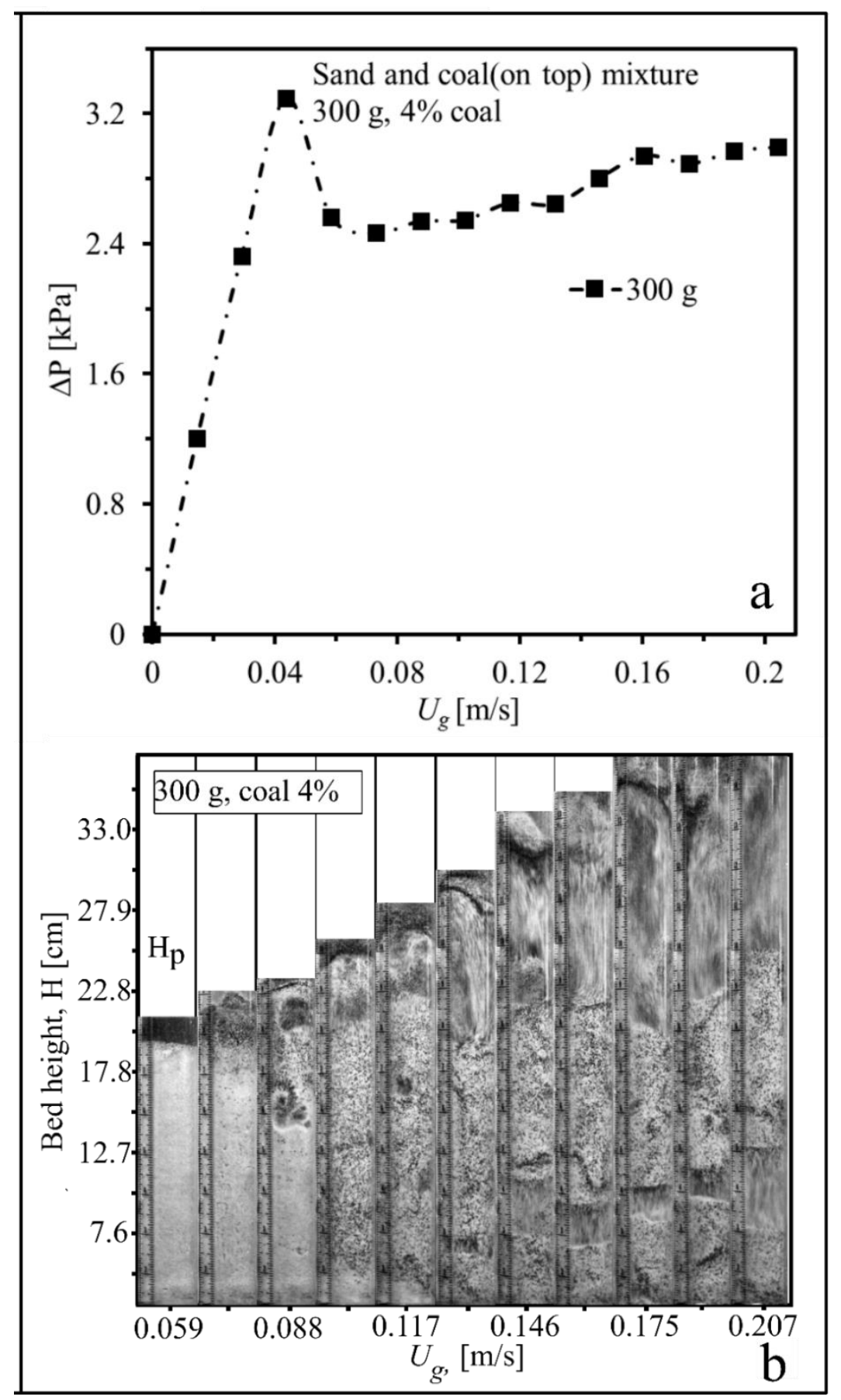

Figure 43. Bed pressure drop and fluidization behaviors with increasing superficial gas velocity for the mixtures of coal and sand with the total mixture mass of $300 \mathrm{~g}$. 
Figure 42 and Figure 43 show the bed pressure drop and fluidization behavior with increasing the superficial gas velocity for the coal and glass beads mixture (Figure 42; Case I) or coal and sand mixture (Figure 43; Case II) - (total mixture mass of $100 \mathrm{~g}, H_{p} / D_{b} \approx 5.16$ and 5.66, respectively, $4 \mathrm{wt} \%$ coal of the total mixture mass). For Case I, the pressure curve increased linearly until the initial fluidization, followed by a smooth transition to complete fluidization. For Case II, after reaching a peak in the bed pressure drop, a sudden decrease was next observed when $U_{g}$ increased; $\Delta \mathrm{P}_{\mathrm{b}}$ continued to increase until all particles fluidized due to the larger particle size distribution for the coal-sand mixture. Case I achieved minimum fluidization condition at $U_{g}=$ $0.07 \mathrm{~m} / \mathrm{s}$ (see Figure 42b) and relatively small amounts of particles were mixed at the contact between the two layers of the segregated bed. On the contrary, tiny bubble formations were observed close to the coal and sand layers' surfaces at $U_{g}$ of 0.08 and $0.10 \mathrm{~m} / \mathrm{s}$ in Case II due to channeling. Complete fluidization for Case II was reached relatively late at $U_{g}=0.15 \mathrm{~m} / \mathrm{s}$ due to the late fluidization of the relatively larger particles (i.e., larger interparticle forces and cohesion) and the higher relative humidity of the fluidizing air during this particular experiment. For Case I, the bed was close to a complete mixing state for $U_{g}$ between 0.09 and $0.10 \mathrm{~m} / \mathrm{s}$ (see Figure $42 \mathrm{c}$ ) except for a thin layer of coal on top of the sand layer. A well-mixed bed was observed with smooth bubbles when $U_{g}=0.12 \mathrm{~m} / \mathrm{s}$. For Case II, $U_{g}=0.16 \mathrm{~m} / \mathrm{s}$ was high enough to overcome the interparticle and cohesive forces, including wall effects, hence a thoroughly mixed bed. A further increase in $U_{g}$ caused the elutriation of light coal dust particles. Some of these particles were stuck on the bed wall (see Figure 43b) due to the high cohesiveness caused by the higher relative humidity of fluidizing air. 


\subsubsection{Summary and Conclusions}

This study investigated the mixing characteristics and fluidization behavior of unary mixtures (sand or glass beads) and binary mixtures (biomass or coal with sand or glass beads) at different bed aspect ratios, while keeping constant feedstock ratio of $4 \mathrm{wt} \%$. The feedstock was placed on top of the inert material to simulate the fluidization behavior of the top-fed BFBG. The main conclusions were:

- The higher peak bed pressure drop for non-dried versus dried sawdust and sand mixtures and difficulty in separating the particles suggests that mixture humidity increased inter particle forces and wall adhesion for sawdust and sand mixtures. However, the humidity had negligible effect on the peak bed pressure drop for non-dried versus dried sawdust and glass beads mixtures.

- Non-dried sawdust mixtures mixed completely at lower fluidizing gas velocities compared to dried sawdust mixtures.

- A bed aspect ratio higher than two resulted in slug formation. Increased bed aspect ratio decreased fluidization and mixing quality.

- A larger total mass (i.e., a larger aspect ratio) negatively affected the fluidization and mixing due to the elutriation of the sawdust layer.

- A lower fluidizing gas flow rate was needed to achieve wholly-mixed state for mixtures with glass beads compared to mixtures with sand, as the higher mean sphericity and smaller mean size of the glass beads allowed them to percolate better into the feedstock layer compared to the sand particles. 
- Coal mixtures with sand or glass beads showed better fluidization characteristics and mixing and at lower fluidizing gas flow rates compared to sawdust mixtures.

- Sand particles can produce strong interparticle forces, which then lead to higher peaks of bed pressure drop and cohesiveness, especially for cases in which the fluidizing gas is air with a higher relative humidity than normal. 


\section{Chapter 4: High Temperature Fluidization and Gasification}

Chapter 4 presents the results of the high-temperature fluidization (ambient up to $800^{\circ} \mathrm{C}$ ) and gasification studies.

\subsection{High-Temperature Hydrodynamical Analysis}

\subsubsection{Effect of Temperature on the Distributor Plate Pressure Drop}

As mentioned in the Introduction chapter, the momentum flux of the flow exiting the distributor plate affects the pressure drop across the bed and uniformity of the gas flow distribution above the porous disc surface. The thermal expansion of the fluidizing fluid (air in this section) has a strong effect on the momentum flux provided by the fluidizing gas. Gas density decreases, and viscosity increases with the increase in temperature. As a result, monitoring the distributor plate pressure drop is important for understanding the subsequent bed pressure drop and fluidization quality.

Figure 44 shows the effect of temperature on the pressure drop across the distributor plate at different flow rates (Figure 44a) or different fluidizing gas velocity (Figure 44b). While the DP pressure drop increased linearly with the fluidizing gas flow rate, the temperature effect on the pressure drop was substantial, particularly at high flow rates. 

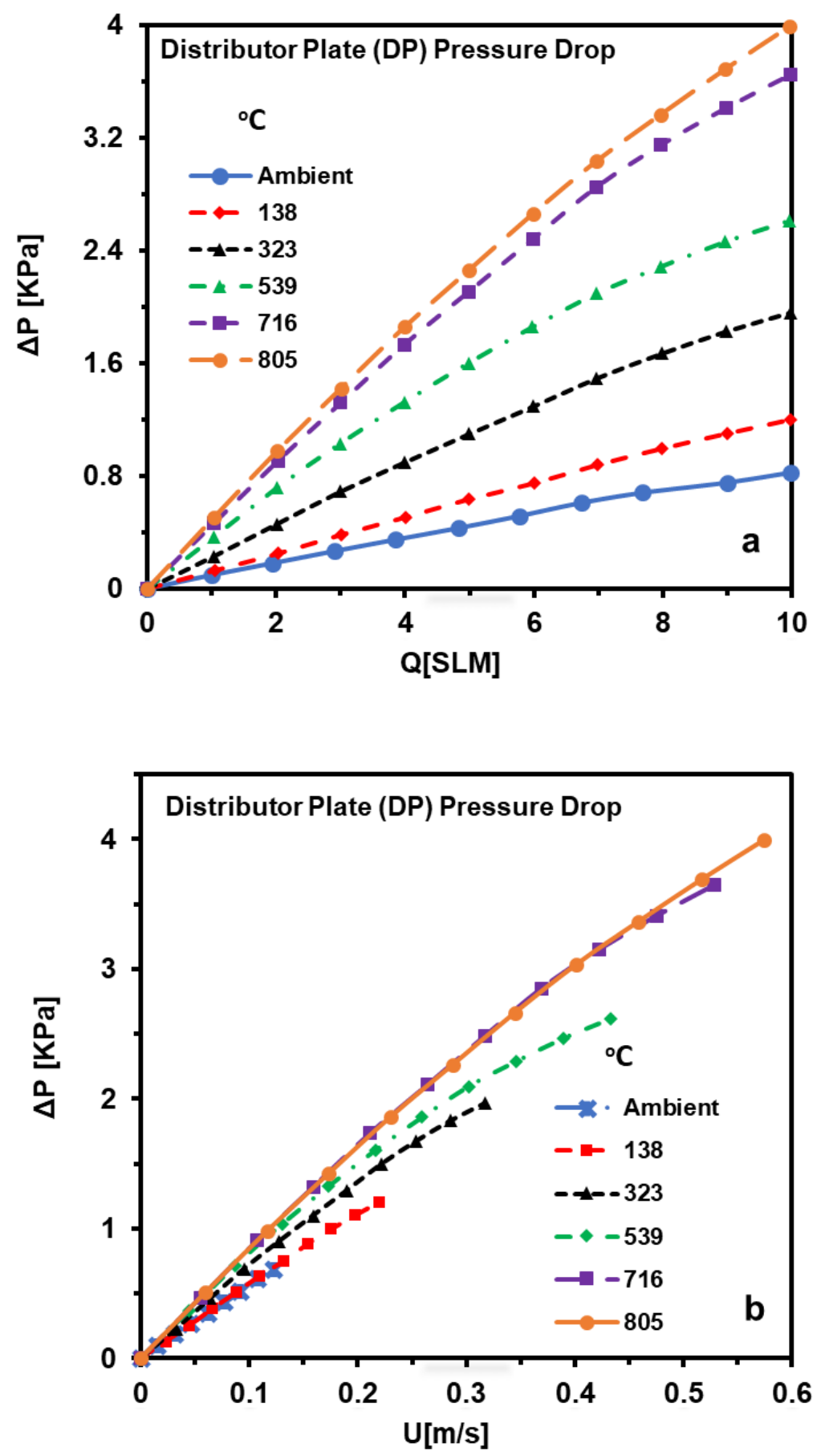

Figure 44. Distributor plate (DP) pressure drop versus a) air flowrate and b) superficial gas velocity at different average temperatures 
Furthermore, in fluidized bed applications, it is essential to provide a uniform distribution of the fluidizing gas above the distributor plate. Figure 45 shows the temperature effect on $R_{m f}$, (defined as the ratio of the pressure drop across the distributor plate, $\Delta P_{d}$, to the pressure drop across the bed, $\left.\Delta P_{b}\right) R_{m f}=\Delta P_{d} / \Delta P_{b}$, at minimum fluidization conditions. $R_{m f}$ changed from 0.34 to 0.37 and from 0.19 to 0.25 , for $200 \mathrm{~g}$ and $300 \mathrm{~g}$ bed material, respectively, when temperature increased from ambient to $\sim 800^{\circ} \mathrm{C}$. The range of the measured $R_{m f}$ values are in agreement with the suggested correlations (see Eqs. 12 and 13) for stable and sufficient operation mentioned by Zuiderweg et al. [138] (Eq. 31) and Siegel et al. [139] (Eq. 32), respectively:

$$
\begin{gathered}
\Delta P_{d}=(0.2-0.4) \Delta P_{b} \\
\frac{\Delta P_{d}}{\Delta P_{b}} \geq 0.14
\end{gathered}
$$

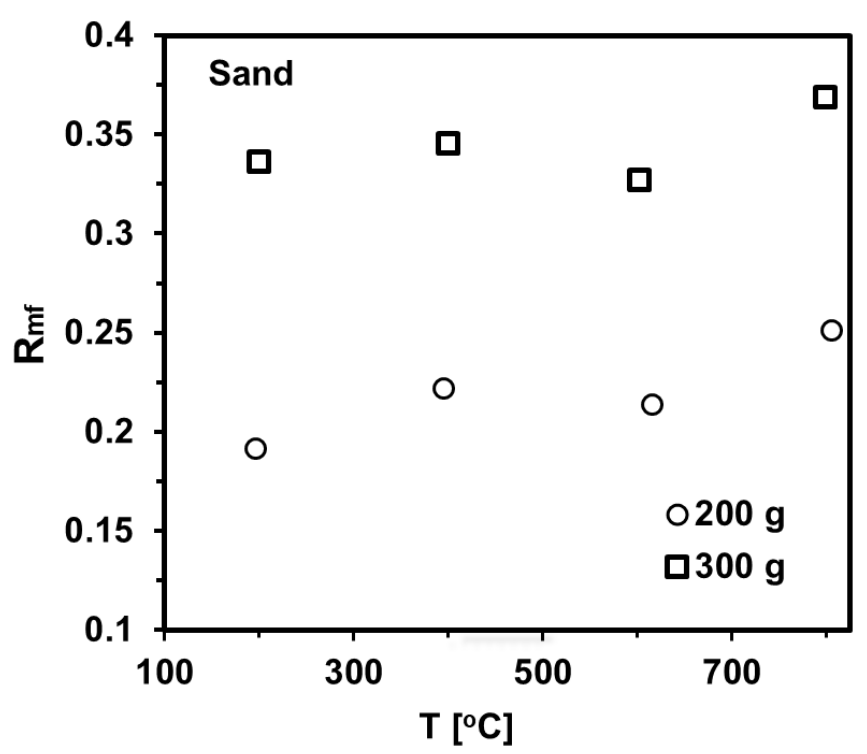

Figure 45. Temperature effect on the ratio of the pressure drop across the distributor plate to the bed pressure drop $\left(R_{m f}\right)$, at minimum fluidization conditions. 


\subsubsection{Effect of Temperature on the Bed Pressure Drop and Minimum fluidization Velocity}

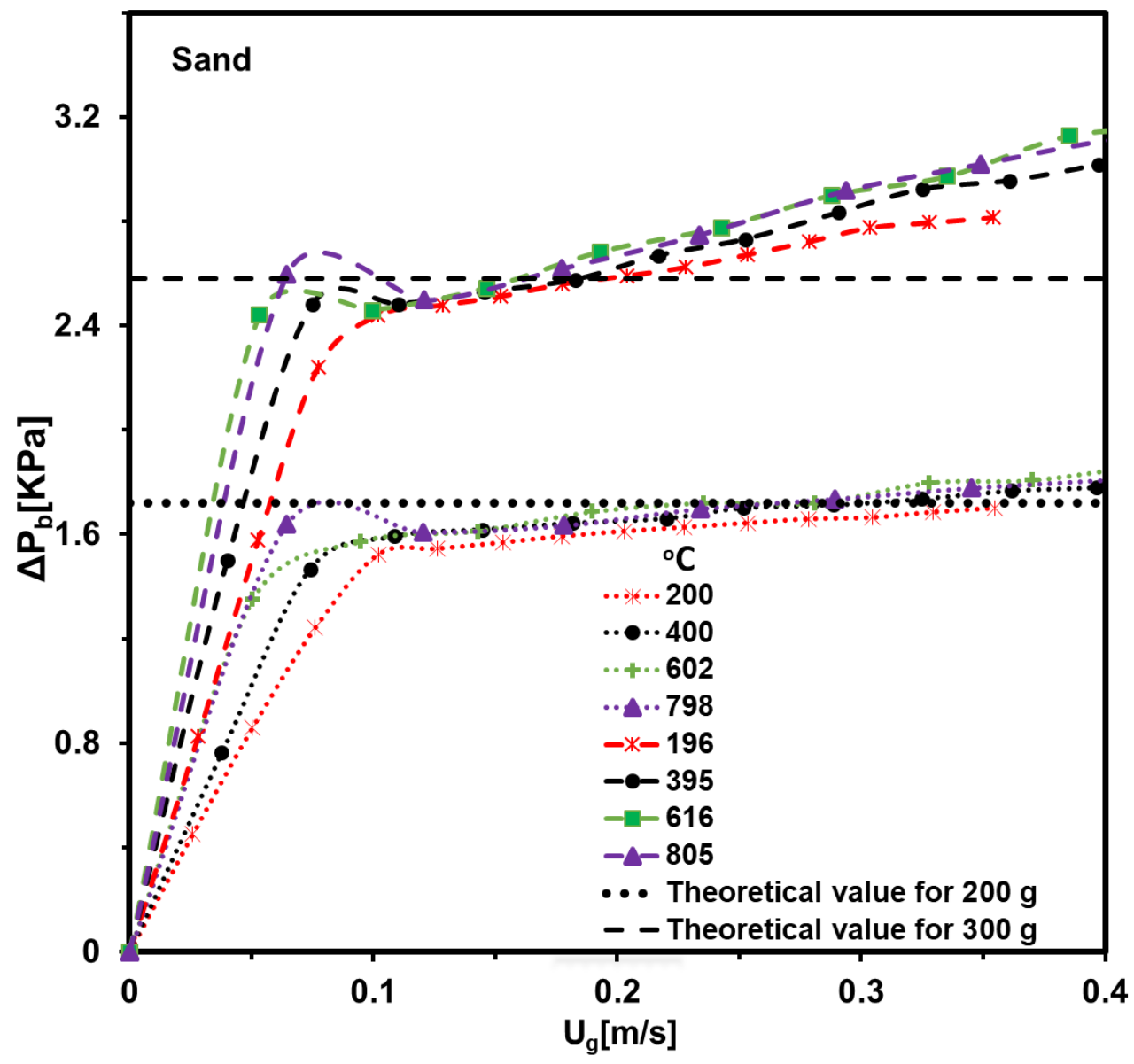

Figure 46. Bed pressure drop versus $U_{g}$ at different temperatures. Horizontal lines show the theoretical bed pressure drop calculated with Eq. 3 .

Figure 46 shows the bed pressure drop inside the BFBG reactor as a function of the superficial velocity of the fluidizing gas (i.e., air velocity), for temperatures up to $805^{\circ} \mathrm{C}$ and $200 \mathrm{~g}$ and $300 \mathrm{~g}$ bed material (i.e., bed aspect ratios of 3.33, Case I and 4.83, Case II respectively). $U_{g}$ in Figure 46 is the $U_{g}$ measured outside of the reactor at ambient conditions then corrected for the actual temperature inside the BFBG reactor. Bed pressure drop increased linearly during the fixed-bed 
state for all test temperatures. Also, a smooth transition was observed from fixed-bed state to fluidization state at each case, which was attributed to the well-packed bed and the narrow size and sphericity distribution of the silica sand. However, the bed pressure drop increased gradually after reaching complete fluidization with the increasing $U_{g}$, due to the strong wall effects associated to the high adhesion between particles and wall, more important when considering the relatively narrow diameter of the BFBG's reactor and deep bed configuration. This is confirmed by the increase in the slope of the pressure drop seen for the higher bed aspect ratio. A similar pressure drop behavior was reported by Olatunde et al. [93] and Srivastava and Sunderasan [140]. On the contrary, Figure 46 shows that the increase in temperature reduced $U_{m f}$ at both bed aspect ratios, due to the higher drag coefficient associated to a lower $R e$ at higher temperature [120]. Besides, the gas velocity range between the initial and the complete fluidization velocities decreased with the increase in the temperature at each total masses of $200 \mathrm{~g}$, and $300 \mathrm{~g}$, respectively. In addition, as the temperature affected the voidage $[124,125,141]$ and interparticle forces [122] of the bed, temperature increased the bed pressure drop. Formisani et al. [125] attributed the increase in the bed voidage to the increased interparticle forces when there was no flow in the bed. The bed pressure drop values corresponding to the minimum fluidization were $1.54 \mathrm{kPa}\left(25^{\circ} \mathrm{C}\right), 1.55 \mathrm{kPa}\left(200^{\circ} \mathrm{C}\right), 1.63 \mathrm{kPa}\left(400^{\circ} \mathrm{C}\right), 1.63 \mathrm{kPa}\left(602^{\circ} \mathrm{C}\right)$, and $1.61 \mathrm{kPa}\left(798^{\circ} \mathrm{C}\right)$ for Case I, and $2.37 \mathrm{kPa}\left(25^{\circ} \mathrm{C}\right), 2.48 \mathrm{kPa}\left(196^{\circ} \mathrm{C}\right), 2.55 \mathrm{kPa}\left(395^{\circ} \mathrm{C}\right), 2.46 \mathrm{kPa}\left(616^{\circ} \mathrm{C}\right)$, and $2.50 \mathrm{kPa}$ $\left(805^{\circ} \mathrm{C}\right)$ for Case II, respectively.

Table 32 shows $\Delta P_{m f}, U_{m f}, A r$, and $R e$ as function of the BFBG temperature. Both $A r$ and $R e$ numbers are affected from the temperature change due to the changes in viscosity and density of the fluidizing gas. $A r$ and $R e$ numbers were determined to compare the experimental $U_{m f}$ with its theoretical predictions. For example, while $\Delta P_{m f}$ increased by $5 \%$ from ambient conditions $\left(25^{\circ} \mathrm{C}\right)$ 
to the maximum temperature $\left(805^{\circ} \mathrm{C}\right), U_{m f}, A r$, and $R e_{m f}$ decreased by $27 \%, 93 \%$, and $90 \%$, respectively, for $200 \mathrm{~g}$ sand. $\Delta P_{m f}$ increased with a similar $5 \%$ from minimum to maximum temperature, but $U_{m f}, A r$, and $R e_{m f}$ decreased by $35 \%, 93 \%$, and $92 \%$, respectively, for $300 \mathrm{~g}$ sand.

Table 32. $\Delta P_{m f}, A r, R e_{m f}$ and $U_{m f}$ for $200 \mathrm{~g}$, and $300 \mathrm{~g}$ of sand as a function of Temperature

\begin{tabular}{|c|c|c|c|c|c|c|c|c|c|}
\hline \multicolumn{9}{|c|}{$200 \mathrm{~g}, H_{p} / D_{b}=3.33$} & \multicolumn{3}{c|}{$300 \mathrm{~g}, H_{p} / D_{b}=4.83$} \\
\hline $\begin{array}{c}\text { Temperature } \\
{\left[{ }^{\circ} \mathrm{C}\right]}\end{array}$ & $\begin{array}{c}\Delta P_{b-m f} \\
{[\mathrm{kPa}]}\end{array}$ & $\begin{array}{c}U_{m f} \\
{[\mathrm{~m} / \mathrm{s}]}\end{array}$ & $A r$ & $\operatorname{Re}_{m f}$ & $\begin{array}{c}\text { Temperature } \\
{\left[{ }^{\circ} \mathrm{C}\right]}\end{array}$ & $\begin{array}{c}\Delta P_{b-m f} \\
{[\mathrm{kPa}]}\end{array}$ & $\begin{array}{c}U_{m f} \\
{[\mathrm{~m} / \mathrm{s}]}\end{array}$ & $A r$ & $R e_{m f}$ \\
\hline 25 & 1.54 & 0.086 & 3065 & 1.80 & 25 & 2.37 & 0.096 & 3065 & 2.00 \\
\hline 200 & 1.55 & 0.100 & 1452 & 1.06 & 196 & 2.48 & 0.085 & 1481 & 0.92 \\
\hline 400 & 1.63 & 0.080 & 639 & 0.47 & 395 & 2.55 & 0.075 & 650 & 0.45 \\
\hline 602 & 1.63 & 0.061 & 355 & 0.24 & 616 & 2.46 & 0.054 & 343 & 0.20 \\
\hline 798 & 1.61 & 0.063 & 225 & 0.18 & 805 & 2.50 & 0.062 & 224 & 0.17 \\
\hline
\end{tabular}

\subsubsection{Comparison of the High-Temperature Fluidization Results with Correlations in}

\section{the Literature}

The Introduction chapter mentions that most $U_{m f}$ correlations in the literature were determined at ambient temperature. Table 33 compares the $A r$ and $R e$ in this work with several correlations for $\mathrm{Ar}$ and $\mathrm{Re}$ in the literature. Also, Table 34 presents the relative errors between the theoretical predictions of $R e$ and experimentally-determined $R e$ for each test cases. 
Table 33. The theoretical predictions of $R e$ and experimentally-determined Re for each test cases.

\begin{tabular}{|l|c|c|c|c|c|c|c|c|c|c|}
\hline & \multicolumn{9}{|c|}{$200 \mathrm{~g}$} & \multicolumn{6}{|c|}{$300 \mathrm{~g}$} \\
\hline$R e_{\exp }$ & 0.18 & 0.24 & 0.47 & 1.06 & 1.8 & 0.17 & 0.2 & 0.45 & 0.92 & 2 \\
\hline$A r$ & 225 & 355 & 639 & 1452 & 3065 & 224 & 343 & 650 & 1481 & 3065 \\
\hline $\mathrm{C} 1$ & 0.17 & 0.26 & 0.47 & 1.07 & 2.20 & 0.17 & 0.26 & 0.48 & 1.09 & 2.20 \\
\hline $\mathrm{C} 2$ & 0.20 & 0.31 & 0.55 & 1.18 & 2.38 & 0.20 & 0.30 & 0.55 & 1.20 & 2.38 \\
\hline $\mathrm{C} 3$ & 0.17 & 0.27 & 0.49 & 1.09 & 2.26 & 0.17 & 0.26 & 0.49 & 1.11 & 2.26 \\
\hline $\mathrm{C} 4$ & 0.15 & 0.24 & 0.43 & 0.96 & 2.00 & 0.15 & 0.23 & 0.43 & 0.98 & 2.00 \\
\hline $\mathrm{C} 5$ & 0.14 & 0.22 & 0.39 & 0.88 & 1.83 & 0.14 & 0.21 & 0.40 & 0.90 & 1.83 \\
\hline $\mathrm{C} 6$ & 0.19 & 0.29 & 0.53 & 1.17 & 2.40 & 0.19 & 0.28 & 0.53 & 1.20 & 2.40 \\
\hline
\end{tabular}

Table 34. Error in predicting the theoretical $R e$ for the unary mixtures of silica sand with the masses of $200 \mathrm{~g}$ and $300 \mathrm{~g}$, respectively.

\begin{tabular}{|l|c|c|c|c|c|c|c|c|c|c|}
\hline & \multicolumn{9}{|c|}{$200 \mathrm{~g}$} & \multicolumn{5}{|c|}{$300 \mathrm{~g}$} \\
\hline$R e_{\exp }$ & 0.18 & 0.24 & 0.47 & 1.06 & 1.8 & 0.17 & 0.2 & 0.45 & 0.92 & 2 \\
\hline C1 & $7 \%$ & $10 \%$ & $1 \%$ & $1 \%$ & $22 \%$ & $1 \%$ & $28 \%$ & $7 \%$ & $18 \%$ & $10 \%$ \\
\hline C2 & $14 \%$ & $31 \%$ & $16 \%$ & $11 \%$ & $32 \%$ & $20 \%$ & $52 \%$ & $23 \%$ & $31 \%$ & $19 \%$ \\
\hline C3 & $4 \%$ & $13 \%$ & $3 \%$ & $3 \%$ & $26 \%$ & $1 \%$ & $31 \%$ & $10 \%$ & $21 \%$ & $13 \%$ \\
\hline C4 & $16 \%$ & $1 \%$ & $9 \%$ & $9 \%$ & $11 \%$ & $12 \%$ & $15 \%$ & $4 \%$ & $7 \%$ & $0 \%$ \\
\hline C5 & $23 \%$ & $9 \%$ & $17 \%$ & $17 \%$ & $2 \%$ & $19 \%$ & $5 \%$ & $12 \%$ & $3 \%$ & $9 \%$ \\
\hline C6 & $4 \%$ & $22 \%$ & $12 \%$ & $11 \%$ & $33 \%$ & $9 \%$ & $42 \%$ & $19 \%$ & $30 \%$ & $20 \%$ \\
\hline
\end{tabular}

Among the selected correlations, the correlation derived by Thonglimp et al. [89] was the closest to the experimentally-determined $R e$, with the average relative errors of $9 \%$ and $7 \%$ for Case I and Case II, respectively. The maximum relative errors for Case I and Case II were 21\% and $29 \%$, respectively, obtained by the correlation derived by Leva [90]. Other good predictions were made by Bourgeis et al. [91] and Wu and Bayens [92] with the relative errors of $8 \%$ for Case I and $9 \%$ for Case II, respectively. The change in theoretical predictions of $R e$ and measured $R e$ 
with Archimedes number (Ar) is shown in Figure 47 for the total masses of $200 \mathrm{~g}$ (Figure 47a) and 300 g (Figure 47b).
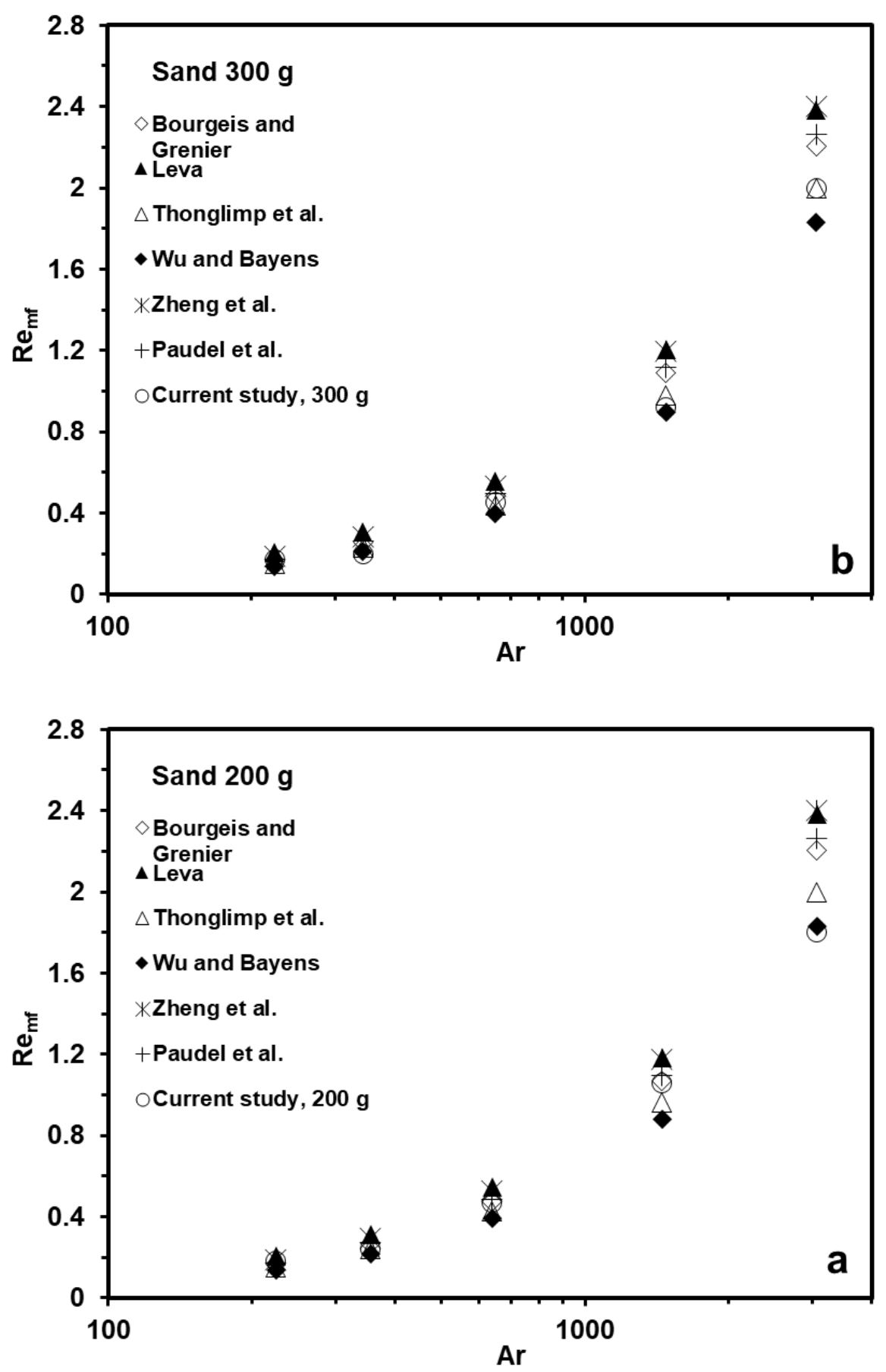

Figure 47. Comparison of $R e_{m f}$ versus $A r$ results vs. literature for silica sand with the total masses of a) $200 \mathrm{~g}$, and b) $300 \mathrm{~g}$ 


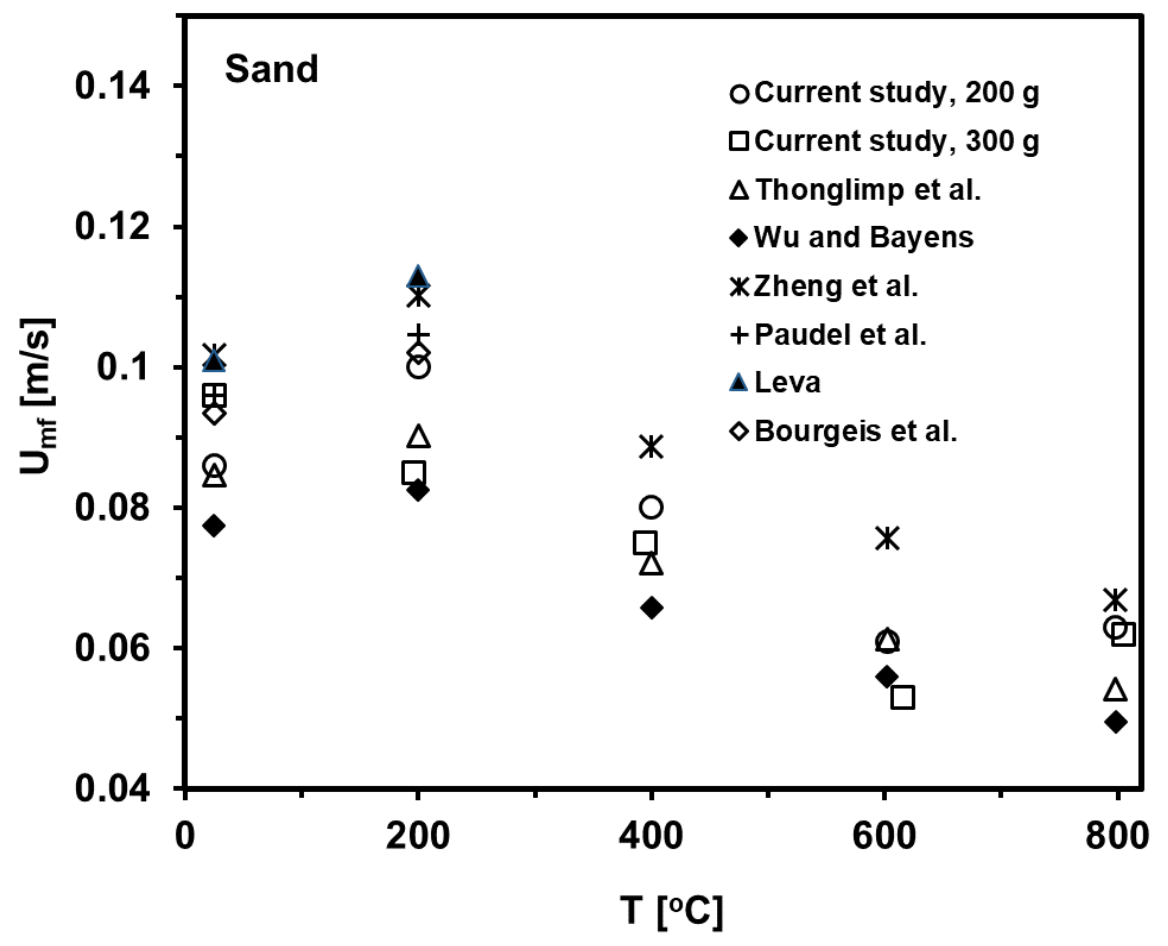

Figure 48. Comparison of the effect of temperature on minimum fluidization velocity $U_{m f}$ versus literature

A comparison of predicted $U_{m f}$ using the $U_{m f}=f(A r, R e)$ correlations in the literature with $U_{m f}$ obtained in this work is shown in Table 33. The error percentages were similar to those shown in Table 34 due to the dependency of $U_{m f}$ on the Re number.

\subsection{High-Temperature Gasification Results}

This subchapter present preliminary results from non-oxidative gasification of biomass in the DFBG and BFBG, and from the gasification of coal with $10 \%$ steam in the BFBG. The elemental composition of coal in Table 6 shows that its oxygen content is low, thus requiring an external gasifying agent to produce the desired syngas composition. With the addition of 10 mole $\%$ steam 
to the coal feed, an average ratio of $\mathrm{H}_{2} / \mathrm{CO}=3.23$ was observed excluding the nitrogen content. Syngas obtained from coal is of higher calorific value and quality than that from biomass gasification [142]. Figure 49 compares the average yield and $\mathrm{H}_{2} / \mathrm{CO}$ of biomass gasification in a fixed bed, bubbling fluidized bed (BFB), and coal - $10 \%$ steam gasification in BFBG. $\mathrm{H}_{2} / \mathrm{CO}$ ratio for non-oxidative biomass gasification in a fixed bed was 0.35 , which improved by nearly 3 times when the same feedstock reacted in the BFBG. It is important to mention that the BFBG was operated in the fast fluidization regime, which improved reaction kinetics. Nitrogen was used as the fluidization gas for non-oxidative biomass gasification and a mixture of nitrogen and steam for the coal gasification. Feeding started when the reactor wall and bed temperatures reached steadystate conditions (i.e., the maximum temperature of the bed and wall achieved for the furnace set points). The biomass/coal mixture was fed to the BFBG using the $1 / 2$ inch OD feeding tube welded on the top flange of the reactor. The same size tube is welded at the bottom of the flange to carry the feedstock to the fluidized bed. The biomass feeding rate was $2 \mathrm{~g}$ per test. Pittsburgh 8 seam coal (which has higher bulk density than biomass) was relatively easier to feed. However, the residence time for coal gasification is generally higher than that for biomass. Therefore, the coal feeding rate was also limited to $2 \mathrm{~g}$ for every test.

The fluidizing gas flow rate was maintained to $0.2 \mathrm{~m} / \mathrm{s}$. It is known from literature that rapid mixing and uniform fluidization achieve higher contact of gas phase and solid phase molecules in a gas-solid multiphase system [143-145]. This was also evident from the significant improvement observed in $\mathrm{H}_{2} / \mathrm{CO}$ ratio obtained from biomass gasification using the BFBG compared to the fixed bed gasifier: 0.91 compared to 0.35 . Since theoretically there is no mixing in the fixed bed downdraft gasifier, it acts as a non-ideal plug flow reactor. With uniform fast fluidization, BFBG could function as a non-ideal Continuously Stirred Tank Reactor (CSTR). Reaction kinetics is 
proportional to the frequency and bubble rise velocity as most of the gasification reactions occur in the bubble cloud and wake [146]. Thus, the development of high-efficiency gasification in the bubbling fluidized bed requires a detailed study of fluidization hydrodynamics, as well as reaction engineering of the feedstock gasification.

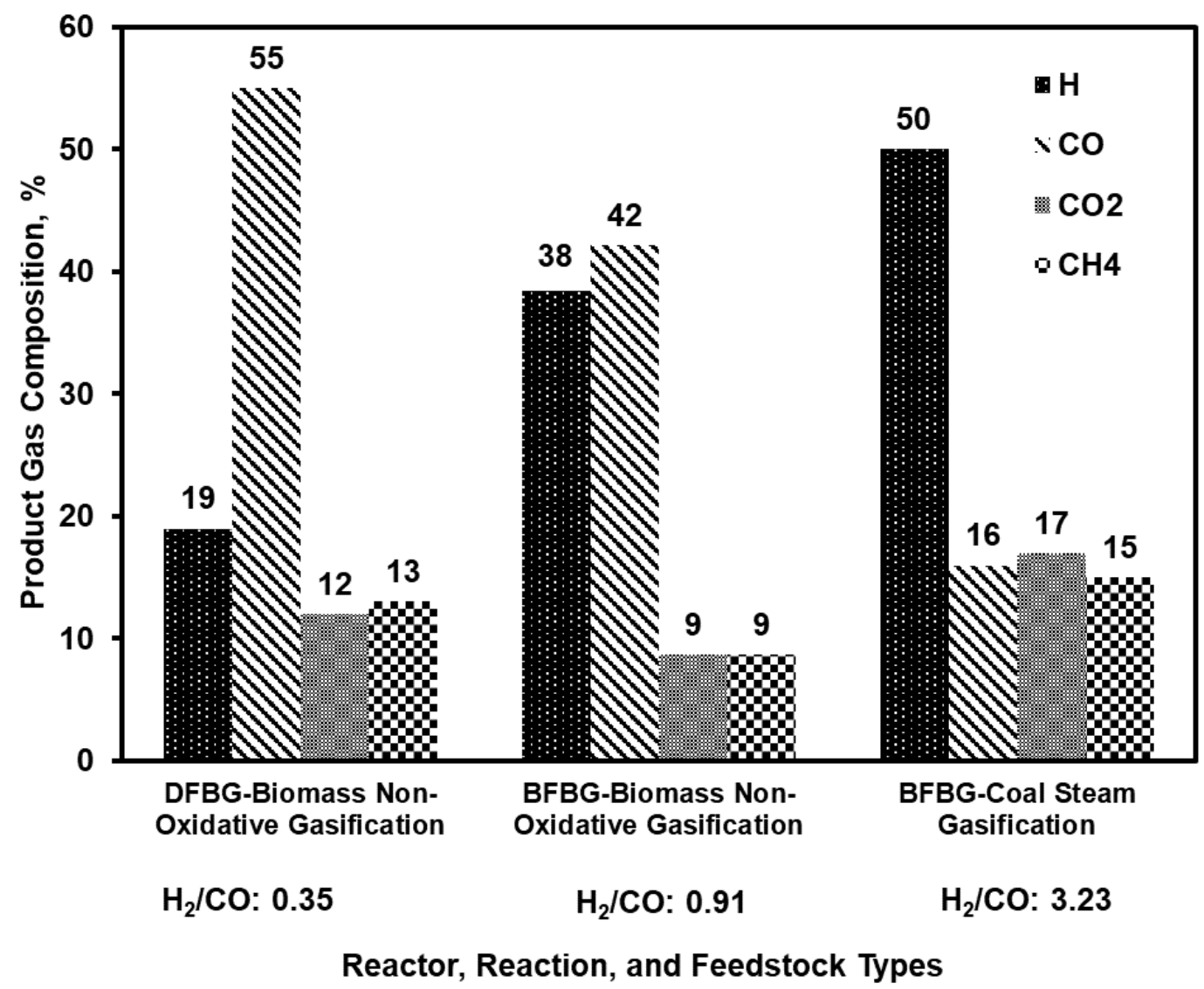

Figure 49. Syngas compositions obtained during the gasification reaction at different reactor types and feedstocks at $900^{\circ} \mathrm{C}$.

Table 35 presents the LHVs for pure gases of $\mathrm{CO}, \mathrm{H}_{2}$ and $\mathrm{CH}_{4}$ compared to LHVs of product syngas from biomass and coal gasification. 
Table 35. Low heating values (LHV) of $\mathrm{CO}, \mathrm{H}_{2}, \mathrm{CH}_{4}[135]$ and syngas compositions obtained during biomass and coal gasification experiments.

\begin{tabular}{|cccccc|}
\hline & $(\mathrm{CO})$ & $\left(\mathrm{H}_{2}\right)$ & $\left(\mathrm{CH}_{4}\right)$ & $\begin{array}{c}\text { Syngas } \\
(\text { biomass })\end{array}$ & $\begin{array}{c}\text { Syngas } \\
(\text { coal })\end{array}$ \\
\hline $\begin{array}{c}\mathrm{LHV} \\
\left(\mathrm{MJNm}^{-3}\right)\end{array}$ & 12.6 & 4.65 & 49.2 & 11.36 & 11.72 \\
\hline
\end{tabular}

\subsection{Summary and Conclusions}

Chapter 4 analyzed the temperature effect on the BFBG hydrodynamics and presented preliminary BFBG gasification results with both coal and biomass as feedstock. the hydrodynamics study was performed with sand, at different total mass and bed aspect ratio. The bed pressure drop was measured at temperatures up to $800^{\circ} \mathrm{C}$ and the corresponding $U_{m f}$ was determined using the graphical method. The experimental Re was compared with selected correlations from the literature. The main conclusions are:

- DP pressure drop increased linearly with the fluidizing gas flow rate. In addition, the temperature effect on the pressure drop was substantial, particularly at higher flow rates.

- Despite the increase in the DP pressure drop with the temperature, the DP choice insured that the ratio of the DP pressure drop to the bed pressure drop was always in the range suggested in the literature.

- Increasing the temperature reduced the minimum fluidization velocity. 
- Experimental $U_{m f}$ was closest to the correlations derived by Thonglimp et al. [89], Bourgeis et al. [91] and $\mathrm{Wu}$ and Bayens [92].

- The decrease in $U_{m f}$ for higher temperatures suggested a decrease in the wall effects at the minimum fluidization condition. However, the gradual increase in the bed pressure drop after the minimum fluidization, especially for the higher bed aspect ratio, suggested that wall effects increased at higher fluidizing gas velocity.

- Preliminary biomass and coal gasification BFBG experiments produced acceptable syngas compositions $\left(\mathrm{H}_{2} / \mathrm{CO}=1: 3\right)$, suggesting that the BFBG setup developed in this study can be successfully used for further investigations of biomass and coal gasification. 


\section{Chapter 5: Summary and Conclusions}

The use of bubbling fluidized bad gasifiers to produce syngas from various feedstocks can reduce greenhouse gas emissions while providing an alternative energy source for various applications. However, a literature review showed that current technology would benefit from additional knowledge on process fundamentals to increase its marketability and feasibility for widespread public use and benefit. Specifically, the number of studies on the fluidization hydrodynamics of binary mixture of biomass and inert materials are limited, more so for woodbased biomass. In addition, the majority of these studies were conducted at ambient conditions, even if the temperature effects are important. As a result, more studies are needed to advance the fluidization theory by comprehensively studying the effects of multiple parameters that affect mixture dynamics such as initial feedstock distribution (mixing condition), material characteristics, and temperature. Besides, it was known that deep-bed gasification applications are more efficient than lower bed aspect ratios, defined as the ratio of the bed to the column diameter. However, most of the studies in the literature were performed at bed aspect ratios from 0.5 to 3 . In this study, the feedstock ratio was kept constant as $4 \mathrm{wt} \%$, and the bed aspect ratio was changed from 2 to 6 . Another important gasification process requirement is adequate feeding and selecting the location where the feedstock and inert materials get in contact. Top-feeding (on-bed) applications are easier to perform but less efficient than side (in-bed) feeding. The novelty of this work is that it addresses a niche in the field of fluidization hydrodynamics of biomass or coal binary mixtures, particularly the fluidization characteristics of top-fed deep-bed BFBG applications. The goal was to obtain a data set that can be used for developing computational models of the multiphase fluidization inside a BFBG, a requirement for scaling up and optimizing the gasification process. To achieve this goal, two separate experimental platforms were designed 
and built: a bench-scale BFBG (ID = 3.81 cm) with a novel on-bed automated feeding system and a cold flow model with the same geometry and dimensions as the BFBG. The preliminary design was based on the syngas mass flow required for the continuous operation of a medium-size sparkignition internal combustion engine. The top-fed deep-bed $\left(H_{p} / D_{b}=2: 6\right)$ was preferred due to experimental limitations. The fluidization behavior and mixing were studied in the cold flow rig to simulate the actual fluidization behavior inside the BFBG under process conditions. The experiments used well-characterized (i.e., known size and shape distributions, density, moisture content, initial mixing condition) inert material (sand, glass beads) and feedstock (biomass (sawdust) and coal). The flow rate of fluidizing gas and pressure at various locations inside the reactor bed were measured and analyzed. High-speed flow visualization was used to investigate the distribution of the feedstock particles (sawdust or coal) inside the reactor bed. The superficial gas velocity interval that assured a rapid and homogenous mixing was determined by different test cases. The cold and hot flow fluidization results were used to design preliminary gasification tests, which were performed with both biomass and coal.

The main conclusions of this study were:

- Fluidization behavior of biomass binary mixtures improved when the biomass and sand or glass beads were premixed, supported by the narrower range of measured $U_{m f}$. This was due to the more homogenous distribution of particles inside the mixture and better packing than biomass-on-top segregated mixtures. In accordance, premixed binary mixtures produced lower relative errors between the predicted and the experimental Re compared to segregated binary mixtures. Hence, the suggested binary mixture definition used in fluidization terminology should represent the premixed (well-mixed) state based on the experiments and analyses. 
- The higher peak bed pressure drop for non-dried versus dried sawdust and sand mixtures and difficulty in separating the particles suggests that mixture humidity increased inter particle forces and wall adhesion for sawdust and sand mixtures. However, the humidity had negligible effect on the peak bed pressure drop for non-dried versus dried sawdust and glass beads mixtures.

- A larger biomass humidity decreased $U_{m f}$ of premixed binary mixtures but increased the relative error between the predicted and the experimental $R e$.

- Non-dried sawdust mixtures mixed completely at lower fluidizing gas velocities compared to dried sawdust mixtures.

- A lower fluidizing gas flow rate was needed to achieve wholly-mixed state for mixtures with glass beads compared to mixtures with sand, as the higher mean sphericity and smaller mean size of the glass beads allowed them to percolate better into the feedstock layer compared to the sand particles.

- Adequate mixing of segregated sawdust (4wt\%) and inert material could be achieved at the bed aspect ratio of $\sim 4$ but could not be achieved at $\sim 6$. Suggested a bed aspect ratio of higher than 4 but less than 6 to be tested for adequate mixing.

- $U_{m f}$ decreased with the increase in temperature for Geldart group B silica sand particles with broad particle size distribution resembling Gaussian (normal) distribution. The decrease in $U_{m f}$ at the higher temperature suggested a decrease in the wall effects at the minimum fluidization condition. However, the gradual increase in the bed pressure drop 
after the minimum fluidization, especially for the higher bed aspect ratio, suggested that wall effects increased at higher fluidizing gas velocity.

- Preliminary biomass and coal gasification BFBG experiments produced acceptable syngas compositions $\left(H_{2} / C O=1: 3\right)$, suggesting that the BFBG setup developed in this study can be successfully used for further investigations of biomass and coal gasification. 


\section{Chapter 6: Future Work and Recommendations}

The results here showed that the top-fed deep-bed BFBGs is feasible for bed aspect ratio up to four, for a biomass ratio of $4 \mathrm{wt} \%$. However, the relatively small diameter (ID $=3.81 \mathrm{~cm}$ ) of the reactor bed created significant wall effects, observed in both cold and high-temperature studies. Thus, a larger reactor bed ID (10 cm or bigger) is recommended to reduce the wall effects and particle bridging forces. A bed aspect ratio of 4 to 6 provided adequate mixing for biomass and coal mixtures. The biomass wt $\%$ can be increased to optimize the biomass amount while keeping the inert material mass constant. Also, results showed that there is still a possibility to obtain mixing for biomass mixtures at 4 to 6 bed aspect ratios. However, for the coal mixtures, adequate mixing was achieved for the bed aspect ratio of six with the mass coal ratio of $4 \mathrm{wt} \%$. This result suggests performing other tests to further increase the coal mass ratio.

In addition to continuing investigating binary mixtures of coal or biomass with inert material, ternary mixtures of coal and biomass with inert material should be studied in both cold and hightemperature studies. The reason is that coal particles are less reactive than biomass particles. In addition, coal's relatively higher mean sphericity and density will improve the feeding and fluidization processes with biomass. Moreover, syngas quality will improve when coal is added to biomass. However, the ternary mixtures of biomass and coal with inert material were not widely studied. 


\section{References}

[1] A. Hussain, S. M. Arif, and M. Aslam, "Emerging renewable and sustainable energy technologies: State of the art," Renewable and Sustainable Energy Reviews, vol. 71, pp. 12-28, 2017.

[2] A. Kumar, D. D. Jones, and M. A. Hanna, "Thermochemical biomass gasification: a review of the current status of the technology," Energies, vol. 2, no. 3, pp. 556-581, 2009.

[3] A. F. Kirkels and G. P. Verbong, "Biomass gasification: Still promising? a 30-year global overview," Renewable and Sustainable Energy Reviews, vol. 15, no. 1, pp. 471-481, 2011.

[4] P. McKendry, "Energy production from biomass (part 2): conversion technologies," Bioresource technology, vol. 83, no. 1, pp. 47-54, 2002.

[5] A. Peres, B. H. Lunelli, and R. Maciel FIlho, "Application of biomass to hydrogen and syngas production," Chemical Engineering Transactions, vol. 32, pp. 589-594, 2013.

[6] L. Cao, K. Iris, X. Xiong, D. C. Tsang, S. Zhang, J. H. Clark, C. Hu, Y. H. Ng, J. Shang, and Y. S. Ok, "Biorenewable hydrogen production through biomass gasification: A review and future prospects," Environmental Research, p. 109547, 2020.

[7] F. Meng, H. Wang, Q. Ma, D. Wang, and J. Lin, "Emission characteristics of vehicles fueled by hydrogen-enriched syngas under no-load condition," International Journal of Hydrogen Energy, vol. 45, no. 6, pp. 3840-3845, 2020. 
[8] R. P. Bates and K. Dölle, "Syngas use in internal combustion engines-a review," Advances in Research, pp. 1-8, 2017.

[9] F. Y. Hagos, A. R. A. Aziz, and S. A. Sulaiman, "Trends of syngas as a fuel in internal combustion engines," Advances in Mechanical Engineering, vol. 6, p. 401587, 2014.

[10] A. S. Bika, "Synthesis gas use in internal combustion engines." 2010.

[11] M. Aneke and M. Wang, "Thermodynamic comparison of alternative biomass gasification techniques for producing syngas for gas turbine application," Energy Procedia, vol. 142, pp. 829-834, 2017.

[12] M. Renzi, F. Patuzzi, and M. Baratieri, "Syngas feed of micro gas turbines with steam injection: Effects on performance, combustion and pollutants formation," Applied Energy, vol. 206, pp. 697-707, 2017.

[13] Y. S. Kim, J. J. Lee, T. S. Kim, J. L. Sohn, and Y. J. Joo, "Performance analysis of a syngas-fed gas turbine considering the operating limitations of its components," Applied Energy, vol. 87, no. 5, pp. 1602-1611, 2010.

[14] Y. S. Kim, J. J. Lee, T. S. Kim, and J. L. Sohn, "Effects of syngas type on the operation and performance of a gas turbine in integrated gasification combined cycle," Energy Conversion and Management, vol. 52, no. 5, pp. 2262-2271, 2011.

[15] M. Minutillo, A. Perna, E. Jannelli, V. Cigolotti, S. W. Nam, S. P. Yoon, and B. W. Kwon, "Coupling of biomass gasification and SOFC-gas turbine hybrid system for small scale cogeneration applications," Energy procedia, vol. 105, pp. 730-737, 2017. 
[16] A. Fernandes, J. Brabandt, O. Posdziech, A. Saadabadi, M. Recalde, L. Fan, E. O. Promes, M. Liu, T. Woudstra, and P. V. Aravind, "Design, construction, and testing of a gasifierspecific solid oxide fuel cell system," Energies, vol. 11, no. 8, p. 1985, 2018.

[17] H. Ghezel-Ayagh, S. Jolly, D. Patel, and D. Stauffer, "Solid oxide fuel cell system utilizing syngas from coal gasifiers," Industrial \& Engineering Chemistry Research, vol. 52, no. 9, pp. 3112-3120, 2013.

[18] U. Ahmed, U. Zahid, and Y. Lee, "Process simulation and integration of IGCC systems for $\mathrm{H}_{2}$ /syngas/electricity generation with control on $\mathrm{CO}_{2}$ emissions," International Journal of Hydrogen Energy, vol. 44, no. 14, pp. 7137-7148, 2019.

[19] D. Cocco, F. Serra, and V. Tola, "Assessment of energy and economic benefits arising from syngas storage in IGCC power plants,” Energy, vol. 58, pp. 635-643, 2013.

[20] M. T. Lim and Z. Alimuddin, "Bubbling fluidized bed biomass gasification-Performance", process findings and energy analysis," Renewable Energy, vol. 33, no. 10, pp. 2339-2343, 2008.

[21] I. Narvaez, A. Orio, M. P. Aznar, and J. Corella, "Biomass gasification with air in an atmospheric bubbling fluidized bed. effect of six operational variables on the quality of the produced raw gas," Industrial \& Engineering Chemistry Research, vol. 35, no. 7, pp. 2110-2120, 1996.

[22] O. L. Daizo Kunni, Fluidization engineering, 2nd ed. Stoneham, MA (United States); Butterworth Publishers, 1991. 
[23] A. Soomro, S. R. Samo, and A. Hussain, "Fluidization in cold flow circulating fluidized bed system," in Energy, Environment and Sustainable Development. Springer, 2012, pp. $161-173$.

[24] R. Cocco, S. R. Karri, T. Knowlton et al., "Introduction to fluidization," Chem. Eng. Prog, vol. 110, no. 11, pp. 21-29, 2014.

[25] J. G. Yates and P. Lettieri, Fluidized-bed reactors: processes and operating conditions, 1st ed. Springer, 2016.

[26] H. Cui and J. R. Grace, "Fluidization of biomass particles: A review of experimental multiphase flow aspects," Chemical Engineering Science, vol. 62, no. 1-2, pp. 45-55, 2007.

[27] Y. Liao, X. Li, W. Zhong, G. Tao, H. Liu, and T. Kagawa, "Experimental study of pressure drop-flow rate characteristics of heated tight porous materials," Journal of Fluids Engineering, vol. 138, no. 7, p. 071102, 2016.

[28] Y. Liao, X. Li, W. Zhong, and G. Tao, "Study of pressure drop-flow rate and flow resistance characteristics of heated porous materials under local thermal non-equilibrium conditions," International Journal of Heat and Mass Transfer, vol. 102, pp. 528-543, 2016.

[29] W. Prins and W. P. M. van Swaaij, "The influence of transport phenomena on the fluidized bed combustion of a single carbon particle," Fuel processing technology, vol. 24, pp. 355$365,1990$. 
[30] B. Paudel and Z.-G. Feng, "Prediction of minimum fluidization velocity for binary mixtures of biomass and inert particles," Powder technology, vol. 237, pp. 134-140, 2013.

[31] M. Abdullah, Z. Husain, and S. Y. Pong, "Analysis of cold flow fluidization test results for various biomass fuels," Biomass and Bioenergy, vol. 24, no. 6, pp. 487-494, 2003.

[32] K. Clarke, T. Pugsley, and G. Hill, "Fluidization of moist sawdust in binary particle systems in a gas-solid fluidized bed," Chemical Engineering Science, vol. 60, no. 24, pp. 6909-6918, 2005.

[33] Y. Zhang, W. Zhong, and B. Jin, "Experimental and theoretical study on fluidization of stalk-shaped biomass particle in a fluidized bed," International Journal of Chemical Reactor Engineering, vol. 9, no. 1, 2011.

[34] N. P. Pérez, D. T. Pedroso, E. B. Machin, J. S. Antunes, R. A. V. Ramos, and J. L. Silveira, "Fluid dynamic study of mixtures of sugarcane bagasse and sand particles: Minimum fluidization velocity," Biomass and bioenergy, vol. 107, pp. 135-149, 2017.

[35] C. Si and Q. Guo, "Fluidization characteristics of binary mixtures of biomass and quartz sand in an acoustic fluidized bed," Industrial \& engineering chemistry research, vol. 47, no. 23, pp. 9773-9782, 2008.

[36] M. P. Aznar, "Minimum and maximum velocities for fluidization for mixtures of agricultural and forest residues with a second fluidized solids. I. Preliminary data and results with sand-sawdust mixtures," Int. Chem Eng., vol. 32, pp. 95-102, 1992. 
[37] T. Oliveira, C. Cardoso, and C. Atade, "Bubbling fluidization of biomass and sand binary mixtures: Minimum fluidization velocity and particle segregation," Chemical Engineering and Processing: Process Intensification, vol. 72, pp. 113-121, 2013.

[38] F. Fotovat, J. Chaouki, and J. Bergthorson, "The effect of biomass particles on the gas distribution and dilute phase characteristics of sand-biomass mixtures fluidized in the bubbling regime," Chemical Engineering Science, vol. 102, pp. 129-138, 2013.

[39] F. Fotovat, R. Ansart, M. Hemati, O. Simonin, and J. Chaouki, "Sand-assisted fluidization of large cylindrical and spherical biomass particles: Experiments and simulation," Chemical Engineering Science, vol. 126, pp. 543-559, 2015.

[40] X. Gao, J. Yu, C. Li, R. Panday, Y. Xu, T. Li, H. Ashfaq, B. Hughes, and W. A. Rogers, “Comprehensive experimental investigation on biomass-glass beads binary fluidization: A data set for CFD model validation," AIChE Journal, 2019.

[41] V. Wilk, J. Schmid, and H. Hofbauer, "Influence of fuel feeding positions on gasification in dual fluidized bed gasifiers," Biomass and bioenergy, vol. 54, pp. 46-58, 2013.

[42] J. Corella, J. Herguido, and F. Alday, "Pyrolysis and steam gasification of biomass in fluidized beds. influence of the type and location of the biomass feeding point on the product distribution," in Research in thermochemical biomass conversion. Springer, 1988, pp. $384-398$.

[43] D. Ross, R. Noda, M. Horio, A. Kosminski, P. Ashman, and P. Mullinger, "Axial gas profiles in a bubbling fluidised bed biomass gasifier," Fuel, vol. 86, no. 10-11, pp. 1417$1429,2007$. 
[44] S. Rapagnà and G. M. Di Celso, "Devolatilization of wood particles in a hot fluidized bed: Product yields and conversion rates," Biomass and Bioenergy, vol. 32, no. 12, pp. 1123$1129,2008$.

[45] H. T. Bi, "Electrostatic phenomena in gas-solids fluidized beds," China Particuology, vol. 3, no. 6, pp. 395-399, 2005.

[46] E. Brus, M. Öhman, and A. Nordin, "Mechanisms of bed agglomeration during fluidizedbed combustion of biomass fuels," Energy \& Fuels, vol. 19, no. 3, pp. 825-832, 2005.

[47] B. Cluet, G. Mauviel, Y. Rogaume, O. Authier, and A. Delebarre, "Segregation of wood particles in a bubbling fluidized bed," Fuel processing technology, vol. 133, pp. 80-88, 2015.

[48] K. Rao and G. Reddy, "Cold flow studies of rice husk, saw dust, and groundnut shell fuels in a fluidized bed," Energy Sources, Part A: Recovery, Utilization, and Environmental Effects, vol. 32, no. 18, pp. 1701-1711, 2010.

[49] A. Anantharaman, R. A. Cocco, and J. W. Chew, "Evaluation of correlations for minimum fluidization velocity $\left(U_{m f}\right)$ in gas-solid fluidization," Powder Technology, vol. 323, pp. 454-485, 2018.

[50] D. Escudero and T. J. Heindel, "Bed height and material density effects on fluidized bed hydrodynamics," Chemical Engineering Science, vol. 66, no. 16, pp. 3648-3655, 2011.

[51] M. Rüdisüli, T. J. Schildhauer, S. M. Biollaz, and J. R. van Ommen, "Scale-up of bubbling fluidized bed reactors: A review," Powder Technology, vol. 217, pp. 21-38, 2012. 
[52] I. Eslami Afrooz, C. M. Sinnathambi, S. Karuppanan, and D. Ling Chuan Ching, "Scaled down design of a cold and hot flow model based on a bubbling fluidized bed pilot plant gasifier," in Applied Mechanics and Materials, vol. 786. Trans Tech Publ, 2015, pp. 232237.

[53] J. Schouten, M. Vander Stappen, and C. Van den Bleek, "Scale-up of chaotic fluidized bed hydrodynamics," Chemical Engineering Science, vol. 51, no. 10, pp. 1991-2000, 1996.

[54] T. Knowlton, S. Karri, and A. Issangya, "Scale-up of fluidized-bed hydrodynamics," Powder Technology, vol. 150, no. 2, pp. 72-77, 2005.

[55] B. Abdelgawad, "Design of a gas-solid fluidized bed reactor at high temperature and high pressure," Ph.D. dissertation, École Polytechnique de Montréal, 2013.

[56] A. Latif, "A study of the design of fluidized bed reactors for biomass gasification," Ph.D. dissertation, University of London, 1999.

[57] A. Johari, B. Nyakuma, A. Ahmad, T. Abdullah, M. Kamaruddin, R. Mat, and A. Ali, "Design of a bubbling fluidized bed gasifier for the thermochemical conversion of oil palm empty fruit bunch briquette," in Applied Mechanics and Materials, vol. 493. Trans Tech Publ, 2014, pp. 3-8.

[58] S. Martnez-Lera, J. Torrico, J. Pallarés, and A. Gil, "Design and first experimental results of a bubbling fluidized bed for air gasification of plastic waste," Journal of Material Cycles and Waste Management, vol. 15, no. 3, pp. 370-380, 2013. 
[59] B. B. Nyakuma, A. A. Anwar Johari, T. A. Abdullah, and M. Mazangi, "Design of a bubbling fluidized bed gasifier for the gasification of palm waste," Science and Engineering, vol. 58, pp. 85-88, 2012.

[60] D. Castiella Franco et al., "Designing a bubbling fluidized bed (BFB) boiler for research purposes," 2013.

[61] R. Garg, J. Galvin, T. Li, and S. Pannala, "Open-source MFIX-DEM software for gassolids flows: Part I-" Verification studies," Powder Technology, vol. 220, pp. 122-137, 2012.

[62] T. Li, R. Garg, J. Galvin, and S. Pannala, "Open-source MFIX-DEM software for gassolids flows: Part II-" Validation studies," Powder Technology, vol. 220, pp. 138-150, 2012.

[63] Z. Zhao, J. Yang, W. Zhang, P. Li, W. Lian, Z. Zhang, Y. Huang, X. Hao, C. Fushimi, and G. Guan, "Hydrodynamic simulation and optimization of the feeding system of a bubbling fluidized-bed gasifier in a triple-bed circulating fluidized bed with high solids flux," Powder technology, vol. 321, pp. 336-346, 2017.

[64] X. Gao, C. Wu, Y.-w. Cheng, L.-j. Wang, and X. Li, "Experimental and numerical investigation of solid behavior in a gas-solid turbulent fluidized bed," Powder technology, vol. 228, pp. 1-13, 2012.

[65] P. Lettieri and D. Macr, "Effect of process conditions on fluidization," KONA Powder and Particle Journal, p. 2016017, 2016. 
[66] R. R. Grim, "Hydrodynamics of fluidized beds under reaction conditions," Master thesis, Eindhoven University of Technology, 2015.

[67] S. Sanaei, N. Mostoufi, R. Radmanesh, R. Sotudeh-Gharebagh, and J. Chaouki, "Effect of temperature on hydrodynamics of fluidized beds," in Proceedings of European Congress of Chemical Engineering (ECCE-6), 2007.

[68] X. Wu, K. Li, F. Song, and X. Zhu, "Fluidization behavior of biomass particles and its improvement in a cold visualized fluidized bed," BioResources, vol. 12, no. 2, pp. 3546$3559,2017$.

[69] L. Liao, "Influence of particle shape and bed height on fluidization," Ph.D. dissertation, University of Florida, 2013.

[70] T. V. Thelen and W. F. Ramirez, "Bed-height dynamics of expanded beds," Chemical engineering science, vol. 52, no. 19, pp. 3333-3344, 1997.

[71] R. Sarker, M. Rahman, N. Love, and A. Choudhuri, "Effect of bed height, bed diameter and particle shape on minimum fluidization in a gas-solid fluidized bed," in 50th AIAA Aerospace Sciences Meeting including the New Horizons Forum and Aerospace Exposition, 2012, p. 644.

[72] Y. Zhang, C. Lu, and M. Shi, "A practical method to estimate the bed height of a fluidized bed of fine particles," Chemical Engineering \& Technology: Industrial Chemistry-Plant Equipment-Process Engineering-Biotechnology, vol. 31, no. 12, pp. 1735-1742, 2008. 
[73] C. E. Agu, A. Ugwu, C. Pfeifer, M. Eikeland, L.-A. Tokheim, and B. M. Moldestad, "Investigation of bubbling behavior in deep fluidized beds at different gas velocities using electrical capacitance tomography," Industrial \& Engineering Chemistry Research, vol. 58, no. 5, pp. 2084-2098, 2019.

[74] I. Julián, J. Herguido, and M. Menéndez, "Experimental and simulated solids mixing and bubbling behavior in a scaled two-section two-zone fluidized bed reactor," Chemical Engineering Science, vol. 143, pp. 240-255, 2016.

[75] G. Hofer, T. Märzinger, C. Eder, F. Pröll, and T. Pröll, "Particle mixing in bubbling fluidized bed reactors with continuous particle exchange," Chemical Engineering Science, vol. 195, pp. 585-597, 2019.

[76] Y. Zhang, B. Jin, W. Zhong, B. Ren, and R. Xiao, "Characterization of fluidization and segregation of biomass particles by combining image processing and pressure fluctuations analysis," International Journal of Chemical Reactor Engineering, vol. 7, no. 1, 2009.

[77] A. Di Renzo, F. P. Di Maio, R. Girimonte, and V. Vivacqua, "Segregation direction reversal of gas-fluidized biomass/inert mixtures-experiments based on particle segregation model predictions," Chemical Engineering Journal, vol. 262, pp. 727-736, 2015.

[78] H. Xu, W. Zhong, Y. Shao, and A. Yu, "Experimental study on mixing behaviors of wet particles in a bubbling fluidized bed," Powder Technology, vol. 340, pp. 26-33, 2018.

[79] B. Bronson, P. E. Gogolek, P. Mehrani, W. Duo et al., "Evaluating the impact of feed location on the bubbling fluidized bed gasification of biomass," 2016. 
[80] C. Y. Wen, N. R. Deole, and L. Chen, "A study of jets in a three-dimensional gas fluidized bed," Powder Technology, vol. 31, no. 2, pp. 175-184, 1982.

[81] M. Wirsum, F. Fett, N. Iwanowa, and G. Lukjanow, "Particle mixing in bubbling fluidized beds of binary particle systems," Powder Technology, vol. 120, no. 1-2, pp. 63-69, 2001.

[82] D. Geldart, “Types of gas fluidization," Powder technology, vol. 7, no. 5, pp. 285-292, 1973.

[83] S. Ergun, "Fluid flow through packed columns," Chem. Eng. Prog., vol. 48, pp. 89-94, 1952.

[84] M. Hartman, O. Trnka, and M. Pohorely, "Minimum and terminal velocities in fluidization of particulate ceramsite at ambient and elevated temperature," Industrial \& Engineering Chemistry Research, vol. 46, no. 22, pp. 7260-7266, 2007.

[85] T. R. Rao and J. R. Bheemarasetti, "Minimum fluidization velocities of mixtures of biomass and sands," Energy, vol. 26, no. 6, pp. 633-644, 2001.

[86] W. Zhong, B. Jin, Y. Zhang, X. Wang, and R. Xiao, "Fluidization of biomass particles in a gas- solid fluidized bed," Energy \& Fuels, vol. 22, no. 6, pp. 4170-4176, 2008.

[87] C. Wen and Y. Yu, "A generalized method for predicting the minimum fluidization velocity," AIChE Journal, vol. 12, no. 3, pp. 610-612, 1966.

[88] V. Thonglimp, N. Hiquily, and C. Laguerie, "Vitesse minimale de fluidisation et expansion des couches fluidisées par un gaz," Powder technology, vol. 38, no. 3, pp. 233-253, 1984. 
[89] F. Leva, Fluidization, McGraw Hill, New York, p. 49, 1959.

[90] P. Bourgeois and P. Grenier, "The ratio of terminal velocity to minimum fluidising velocity for spherical particles," The Canadian Journal of Chemical Engineering, vol. 46, no. 5, pp. 325-328, 1968.

[91] S. Wu and J. Baeyens, "Effect of operating temperature on minimum fluidization velocity," Powder technology, vol. 67, no. 2, pp. 217-220, 1991.

[92] Z. Zhiping, N. Yongjie, and L. Qinggang, "Effect of pressure on minimum fluidization velocity," Journal of Thermal Science, vol. 16, no. 3, pp. 264-269, 2007.

[93] G. Olatunde, O. Fasina, T. McDonald, S. Adhikari, and S. Duke, "Moisture effect on fluidization behavior of loblolly pine wood grinds," Biomass Conversion and Biorefinery, vol. 7, no. 2, pp. 207-220, 2017.

[94] P. Pei, K. Zhang, B. Yu, J. Gao, G. Wu, and D. Wen, "Dynamic characteristics of binary mixtures in a two-jet fluidized bed," Chemical engineering science, vol. 66, no. 8, pp. $1702-1714,2011$.

[95] A. M. Sharma, A. Kumar, K. N. Patil, and R. L. Huhnke, "Fluidization characteristics of a mixture of gasifier solid residues, switchgrass and inert material," Powder technology, vol. 235, pp. 661-668, 2013.

[96] B. Cluet, G. Mauviel, Y. Rogaume, O. Authier, and A. Delebarre, "Segregation of wood particles in a bubbling fluidized bed," Fuel processing technology, vol. 133, pp. 80-88, 2015. 
[97] D. Falkowski and R. C. Brown, "Analysis of pressure fluctuations in fluidized beds," Industrial \& engineering chemistry research, vol. 43, no. 18, pp. 5721-5729, 2004.

[98] E. J. Brue, "Pressure fluctuations as a diagnostic tool for fluidized beds," Ph.D. dissertation, Iowa State University, 1996.

[99] A. Croxford and M. Gilbertson, "Pressure fluctuations in bubbling gas-fluidized beds," Chemical engineering science, vol. 66, no. 16, pp. 3569-3578, 2011.

[100] H. Kage, M. Agari, H. Ogura, and Y. Matsuno, "Frequency analysis of pressure fluctuation in fluidized bed plenum and its confidence limit for detection of various modes of fluidization," Advanced Powder Technology, vol. 11, no. 4, pp. 459-475, 2000.

[101] O. Trnka, V. Vesely, M. Hartman, and Z. Beran, "Identification of the state of a fluidized bed by pressure fluctuations," AIChE Journal, vol. 46, no. 3, pp. 509-514, 2000.

[102] Y. Zhang, B. Jin, and W. Zhong, "Fluidization, mixing and segregation of a biomass-sand mixture in a fluidized bed," International Journal of Chemical Reactor Engineering, vol. 6, no. $1,2008$.

[103] A. Di Renzo, F. P. Di Maio, R. Girimonte, and V. Vivacqua, "Segregation direction reversal of gas-fluidized biomass/inert mixtures-experiments based on particle segregation model predictions," Chemical Engineering Journal, vol. 262, pp. 727-736, 2015.

[104] S. Yang, "Density effect on mixing and segregation processes in a vibrated binary granular mixture," Powder Technology, vol. 164, no. 2, pp. 65-74, 2006. 
[105] L. Huilin, H. Yurong, D. Gidaspow, Y. Lidan, and Q. Yukun, "Size segregation of binary mixture of solids in bubbling fluidized beds," Powder Technology, vol. 134, no. 1-2, pp. 86-97, 2003.

[106] A. Marzocchella, P. Salatino, V. Di Pastena, and L. Lirer, "Transient fluidization and segregation of binary mixtures of particles," AIChE Journal, vol. 46, no. 11, pp. 2175$2182,2000$.

[107] A. Rao, J. S. Curtis, B. C. Hancock, and C. Wassgren, "Classifying the fluidization and segregation behavior of binary mixtures using particle size and density ratios," AIChE Journal, vol. 57, no. 6, pp. 1446-1458, 2011.

[108] C. Davies, S. Dawson, and R. Fieldes, "An investigation of thermal agglomeration in fluidized beds," Fluidization VI, pp. 555-562, 1989.

[109] F. Berruti, A. Liden, and D. Scott, "Measuring and modelling residence time distribution of low density solids in a fluidized bed reactor of sand particles," Chemical engineering science, vol. 43, no. 4, pp. 739-748, 1988.

[110] G. Olatunde, O. Fasina, T. McDonald, S. Adhikari, and S. Duke, "Moisture effect on fluidization behavior of loblolly pine wood grinds," Biomass Conversion and Biorefinery, vol. 7, no. 2, pp. 207-220, 2017.

[111] K. Clarke, T. Pugsley, and G. Hill, "Fluidization of moist sawdust in binary particle systems in a gas-solid fluidized bed," Chemical Engineering Science, vol. 60, no. 24, pp. 6909-6918, 2005. 
[112] B. Formisani, R. Girimonte, and T. Longo, "The fluidization pattern of density-segregating binary mixtures," chemical engineering research and design, vol. 86, no. 4, pp. 344-348, 2008.

[113] D. Kunii, O. Levenspiel, Fluidization engineering, Biittenuorth-Heinemann Series in Chemical Engineering, 2nd Edition, Academic Press, New York, pp. 1-4, 1991.

[114] G. R. Caicedo, M. G. Ruiz, J. J. P. Marqués, and J. G. Soler, "Minimum fluidization velocities for gas-solid 2D beds," Chemical Engineering and Processing: Process Intensification, vol. 41, no. 9, pp. 761-764, 2002.

[115] S. Sánchez-Delgado, J. A. Almendros-Ibáñez, N. Garcá-Hernando, and D. Santana, “On the minimum fluidization velocity in 2D fluidized beds," Powder Technology, vol. 207, no. 1-3, pp. 145-153, 2011.

[116] D. Gunn and N. Hilal, "The expansion of gas-fluidised beds in bubbling fluidisation," Chemical Engineering Science, vol. 52, no. 16, pp. 2811-2822, 1997.

[117] R. Cranfield and D. Geldart, "Large particle fluidisation," Chemical Engineering Science, vol. 29, no. 4, pp. 935-947, 1974.

[118] W. Lin, K. Dam-Johansen, and F. Frandsen, “Agglomeration in bio-fuel fired fluidized bed combustors," Chemical Engineering Journal, vol. 96, no. 1-3, pp. 171-185, 2003.

[119] R. R. Pattipati and C. Wen, "Minimum fluidization velocity at high temperatures," Industrial \& Engineering Chemistry Process Design and Development, vol. 20, no. 4, pp. 705-707, 1981. 
[120] J. Botterill, Y. Teoman, Y. Teoman, and K. YÜREGIR, "The effect of temperature on fluidized bed behaviour," Chemical Engineering Communications, vol. 15, no. 1-4, pp. 227-238, 1982.

[121] J. Yates, "Effects of temperature and pressure on gas-solid fluidization," Chemical engineering science, vol. 51, no. 2, pp. 167-205, 1996.

[122] P. Lettieri, J. Yates, and D. Newton, "The influence of interparticle forces on the fluidization behaviour of some industrial materials at high temperature," Powder Technology, vol. 110, no. 1-2, pp. 117-127, 2000.

[123] J. Goo, M. Seo, S. D. Kim, and B. Song, "Effects of temperature and particle size on minimum fluidization and transport velocities in a dual fluidized bed," in Proceedings of the 20th international conference on fluidized bed combustion. Springer, 2009, pp. 305310.

[124] R. Yamazaki, N.-S. Han, Z.-F. Sun, and G. Jimbo, "Effect of chemisorbed water on bed voidage of high temperature fluidized bed," Powder technology, vol. 84, no. 1, pp. 15-22, 1995.

[125] B. Formisani, R. Girimonte, and L. Mancuso, "Analysis of the fluidization process of particle beds at high temperature," Chemical Engineering Science, vol. 53, no. 5, pp. 951961, 1998.

[126] M. Jiliang, C. Xiaoping, and L. Daoyin, "Minimum fluidization velocity of particles with wide size distribution at high temperatures," Powder technology, vol. 235, pp. 271-278, 2013. 
[127] J. Liu, "Investigation of combustion characteristics of a heavy-duty diesel engine retrofitted to natural gas spark ignition operation," Ph.D. dissertation, West Virginia University (WVU), Graduate Theses, Dissertations, and Problem Reports. 3713., 2018.

[128] H. K. Bommisetty, "Gas composition effects in a CI engine converted to SI natural gas operation," Master's thesis, West Virginia University (WVU), Graduate Theses, Dissertations, and Problem Reports. 5230., 2017.

[129] B. John, Heywood internal combustion engine fundamentals, 1st ed. McGraw-Hill Book Company, pp. 42-62, 1988.

[130] R. Rauch, J. Hrbek, and H. Hofbauer, "Biomass gasification for synthesis gas production and applications of the syngas," Wiley Interdisciplinary Reviews: Energy and Environment, vol. 3, no. 4, pp. 343-362, 2014.

[131] M. J. Prins, K. J. Ptasinski, and F. J. Janssen, "From coal to biomass gasification: Comparison of thermodynamic efficiency," Energy, vol. 32, no. 7, pp. 1248-1259, 2007.

[132] A. Ponzio, S. Kalisz, and W. Blasiak, "Effect of operating conditions on tar and gas composition in high temperature air/steam gasification (HTAG) of plastic containing waste," Fuel processing technology, vol. 87, no. 3, pp. 223-233, 2006.

[133] M. Prins, K. Ptasinski, and F. Janssen, "Thermodynamics of gas-char reactions: first and second law analysis," Chemical Engineering Science, vol. 58, no. 3-6, pp. 1003-1011, 2003. 
[134] P. McKendry, "Energy production from biomass (part 3): gasification technologies," Bioresource technology, vol. 83, no. 1, pp. 55-63, 2002.

[135] F. Y. Hagos, A. R. A. Aziz, and S. A. Sulaiman, "Study of syngas combustion parameters effect on internal combustion engine," Asian Journal of Scientific Research, vol. 6, no. 2, pp. 187-196, 2013.

[136] J. P. Ciferno and J. J. Marano, "Benchmarking biomass gasification technologies for fuels, chemicals and hydrogen production," US Department of Energy. National Energy Technology Laboratory, 2002.

[137] R. H. Perry, D. W. Green, J. O. Maloney, Perry's Chemical Engineers Handbook. New York: McGraw-Hill, 1997.

[138] F. Zuiderweg, "Design report on fluidization," in Proceedings of International Symposium on Fluidization, AAH Drinkenburg, ed, 1967, p. 739.

[139] R. Siegel, "Effect of distributor plate-to-bed resistance ratio on onset of fluidized-bed channeling,” AIChE Journal, vol. 22, no. 3, pp. 590-592, 1976.

[140] A. Srivastava and S. Sundaresan, "Role of wall friction in fluidization and standpipe flow," Powder Technology, vol. 124, no. 1-2, pp. 45-54, 2002.

[141] G. Raso, M. D'Amore, B. Formisani, and P. Lignola, "The influence of temperature on the properties of the particulate phase at incipient fluidization," Powder technology, vol. 72, no. 1, pp. 71-76, 1992. 
[142] M. J. Prins, K. J. Ptasinski, and F. J. Janssen, "From coal to biomass gasification: Comparison of thermodynamic efficiency," Energy, vol. 32, no. 7, pp. 1248-1259, 2007.

[143] H. T. Bi, "Transition from turbulent to fast fluidization," Chemical Engineering Communications, vol. 189, no. 7, pp. 942-958, 2002.

[144] H. Liu, R. J. Cattolica, and R. Seiser, "Operating parameter effects on the solids circulation rate in the CFD simulation of a dual fluidized-bed gasification system," Chemical Engineering Science, vol. 169, pp. 235-245, 2017.

[145] F. Berruti, T. Pugsley, L. Godfroy, J. Chaouki, and G. Patience, "Hydrodynamics of circulating fluidized bed risers: a review," The Canadian Journal of Chemical Engineering, vol. 73, no. 5, pp. 579-602, 1995.

[146] Y. Liu, S. Chen, M. Zhu, A. Soomro, and W. Xiang, "Investigation of a dual cold-flow fluidized bed for calcium looping gasification process," Powder Technology, vol. 353, pp. 10-19, 2019. 